\title{
Exercise and cardiovascular risk reduction
}

Citation for published version (APA):

Wijnen, J. A. G. (1994). Exercise and cardiovascular risk reduction. [Doctoral Thesis, Maastricht University]. Datawyse / Universitaire Pers Maastricht. https://doi.org/10.26481/dis.19941221jw

Document status and date:

Published: 01/01/1994

DOI:

10.26481/dis.19941221jw

Document Version:

Publisher's PDF, also known as Version of record

\section{Please check the document version of this publication:}

- A submitted manuscript is the version of the article upon submission and before peer-review. There can be important differences between the submitted version and the official published version of record.

People interested in the research are advised to contact the author for the final version of the publication, or visit the DOI to the publisher's website.

- The final author version and the galley proof are versions of the publication after peer review.

- The final published version features the final layout of the paper including the volume, issue and page numbers.

Link to publication

\footnotetext{
General rights rights.

- You may freely distribute the URL identifying the publication in the public portal. please follow below link for the End User Agreement:

www.umlib.nl/taverne-license

Take down policy

If you believe that this document breaches copyright please contact us at:

repository@maastrichtuniversity.nl

providing details and we will investigate your claim.
}

Copyright and moral rights for the publications made accessible in the public portal are retained by the authors and/or other copyright owners and it is a condition of accessing publications that users recognise and abide by the legal requirements associated with these

- Users may download and print one copy of any publication from the public portal for the purpose of private study or research.

- You may not further distribute the material or use it for any profit-making activity or commercial gain

If the publication is distributed under the terms of Article $25 \mathrm{fa}$ of the Dutch Copyright Act, indicated by the "Taverne" license above, 


\section{EXERCISE AND CARDIOVASCULAR RISK REDUCTION}


Wijnen, Joseph Anna Guillaume

Exercise and cardiovascular risk reduction / Joseph Anna

Guillaume Wijnen. - Maastricht : Universitaire Pers

Maastricht. - III.

Thesis Maastricht. - With ref. - With summary in Dutch.

ISBN 90-5278-165-6

Subject headings: exercise and cardiovascular diseases /

exercise and hypertension / antihypertensives

This thesis was supported, in part, by Funds from the Dutch Ministry of Welfare, Health and Cultural Affairs and SmithKline Beecham BV

Publicatie van dit proefschrift werd mogelijk gemaakt dankzij een opleidingsgrant van $\mathrm{AOV} / \mathrm{ABP}$ 


\section{EXERCISE AND CARDIOVASCULAR RISK REDUCTION}

\section{PROEFSCHRIFT}

ter verkrijging van de graad van doctor aan de Rijksuniversiteit Limburg te Maastricht, op gezag van de Rector Magnificus, Prof. dr. H. Philipsen, volgens het besluit van het college van Dekanen, in het openbaar te verdedigen op woensdag 21 december 1994 om 14.00 uur

door

Joseph Anna Guillaume Wijnen geboren te Maastricht in 1958

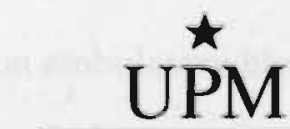

UNIVERSITAIRE PERS MAASTRICHT 
Promotor

Prof. dr. H.A.J. Struijker Boudier

Co-promotores

Dr. M.A. van Baak

Dr. L.M.A.B. Van Bortel

Beoordelingscommissie

Prof. dr. H. Kuipers (voorzitter)

Prof. dr. R.H. Fagard, Katholieke Universiteit Leuven

Prof. dr. J.W. van Ree

Prof. dr. W.H.M. Saris

Dr. J.L.R.M. Smeets 


\section{Contents}

\section{Chapter 1}

General introduction

1.1 Is physical inactivity a risk factor for cardiovascular disease? 9

1.1.1 Direct effect 9

1.1.2 Indirect effect(s) 11

1.2 The effect of chronic exercise on blood pressure 13

1.2.1 The effect of endurance training on blood pressure at rest 13

1.2.2 The effect of endurance training on ambulatory blood pressure $\quad 16$

1.2.3 The effect of endurance training on blood pressure during exercise

1.3 Possible mechanisms for the hypotensive effect of exercise training

1.3.1 Mechanisms for a reduction in cardiac output

1.3.2 Mechanisms for an exercise-related reduction in peripheral resistance

1.4 Effect of chronic exercise on the heart and vessels 25

1.4.1 Heart 25

1.4.2 Vessels 26

1.5 Exercise stress testing in blood pressure evaluation 29

1.5.1 Excessive blood pressure response during exercise as a predictor of future hypertension $\quad 30$

1.5.2 Exercise testing in assessment of hypertension 31

1.6 Antihypertensive medication and exercise 32

1.6.1 Which antihypertensive drug to choose in the physically active patient?

1.6.2 Exercise and beta-blockers with vasodilating activity: a comparison with classical beta-blocker therapy 35

1.7 Aims of this thesis $\quad 40$

1.8 References 41

Chapter 2

Effect of exercise training on ambulatory blood pressure

\section{Chapter 3}

Vessel wall properties of large arteries in trained and sedentary subjects 


\section{Chapter 4}

Vessel wall properties of large arteries and endurance training

Chapter 5.1

Variations in exercise systolic blood pressure in physically active middle-aged men with normal and elevated blood pressure

Chapter 5.2

Exercise systolic blood pressure in middle-aged women with normal and elevated blood pressure

Chapter 6

Beta-blockade and lipolysis during endurance exercise

\section{Chapter 7}

Effect of antihypertensive treatment with carvedilol on submaximal endurance performance in patients with essential hypertension

Chapter 8

General discussion

Samenvatting

List of abbreviations

Dankwoord

Curriculum vitae 
voor Karin

aan mijn ouders 


\section{CHAPTER 1}

\section{General introduction}

\section{GENERAL INTRODUCTION}

Large epidemiologic investigations $(1,2,3)$ have established three major and independent factors that predict the mortality risk of cardiovascular disease, especially of coronary heart disease (CHD). Blood pressure (BP), serum total cholesterol and cigarette smoking have a continuous positive association with major cardiovascular events (4) and a distinct escalation of risk is noted for combinations of these risk factors (2). Other factors have been frequently associated with the pathogenesis of CHD, such as obesity (body mass index), high alcohol consumption, hyperglycemia, hyperinsulinemia, elevated serum levels of uric acid, triglycerides, low-density lipoproteins (LDL) and low serum levels of high-density (HDL) lipoproteins, although their independent predictive ability after allowance for the standard risk factors is doubted by some (5). Nevertheless, there is an increasing body of data to support the independence of a direct relationship of LDL-cholesterol and the inverse relationship of HDL-cholesterol to the risk of developing $\mathrm{CHD}(6,7)$.

\subsection{Is physical inactivity a risk factor for cardiovascular disease?}

Several lines of evidence from epidemiological studies, cross-sectional observations and intervention studies implicate physical inactivity as an important risk factor to develop cardiovascular disease, in different ways.

\subsubsection{Direct effect}

Powell et al (8), reviewing the literature on the role of habitual physical activity in the primary prevention of $\mathrm{CHD}$, concluded that the relative risk for $\mathrm{CHD}$ of physical inactivity appears to be similar in magnitude to that of hypertension, hypercholesterolemia and smoking. In a more positive way, it might be anticipated that regular exercise protects against cardiovascular 
disease. However, one should bear in mind that evidence for this relationship is derived from observational and prospective epidemiological studies. To establish a true cause effect relationship, a large clinical trial is required in which healthy individuals are randomly assigned to different activity patterns ranging from low to high activity levels of different durations, and with and without sufficient intensity to improve cardiovascular fitness (a training status). Those trials have not been performed yet and their feasibility can be questioned, because of high costs, logistic and ethical problems and they would be accompanied by a high attrition rate associated with exercise.

Studies relating physical activity on the job with the incidence of CHD found that workers in physically demanding jobs have a decreased risk of CHD in comparison to their sedentary counterparts (9-13). Paffenbarger and colleagues $(14,15)$ followed longshoremen for 22 years and showed that after adjustments for all major risk factors and post-morbid job transfers men in the highest work activity category had a fatal heart attack rate of only half that of men in the lowest work activity category. In the Framingham study (16), overall mortality and mortality due to cardiovascular and ischemic heart disease were inversely related to the level of physical activity for men but not for women. In a later study of the Framingham cohort (17), improved overall, cardiovascular and coronary mortality was found with increasing levels of 24-hour physical activity in men over a period of 24 years. These mortality benefits applied to both individuals with as well as individuals without intervening overt cardiovascular disease, and was not significantly related to physical demand on the job.

More recent studies have addressed the role of leisure time activity in the prevention of cardiovascular disease. Harvard alumni were followed after graduation (18) and a strong inverse relation was found between habitual exercise and total cardiovascular disease. Sedentary alumni, exercising less than $500 \mathrm{kcal} /$ week, were at $49 \%$ greater adjusted risk for a heart attack compared to the most active men ( $\geq 2000 \mathrm{kcal} /$ week). Other studies $(19,20)$ suggest that especially vigorous aerobic exercise that has to be habitual, and not high totals of physical activity per se, is protective against non-fatal and fatal CHD. Supportive for this suggestion is a study (21) that showed that habitual high intensity leisure time activity $\left(>60 \% \mathrm{VO}_{2 \max }\right.$ ) reduced the risk of primary cardiac arrest by $40 \%$ compared to low and moderate intensity activity. Furthermore, it has been shown that although the risk of cardiac arrest is transiently increased during vigorous exercise, it is much more increased in sedentary individuals (22).

Physical fitness and regular physical activity are related $(23,24)$ although they cannot be regarded as synonymous $(23,25)$. Fitness level depends on genetic endowment, characteristics of the individual and kind, frequency and duration of the activities performed. Initial physical fitness, measured either by maximal treadmill test or maximal cycle ergometry has been found to be predictive for future development of manifestations of cardiovascular disease 
Table 1. Possible direct mechanisms for preventing CHD and CVD by regular physical activity based on ref $8,24,29$

- Decreased myocardial work and oxygen demand

- Enhanced myocardial function

- Improved myocardial oxygen delivery or utilization

- Enhanced myocardial electrical stability

- Modification in structure of the coronary arteries

- Retardation or regression of atherosclerosis

- Reduction of (coronary) vasospasm

- Increased fibrinolytic activity

- Reduction in aggregability of platelets

(26-28). A lower level of physical fitness is associated with a higher risk of death from CHD and cardiovascular disease in healthy men, independent of conventional coronary risk factors, HDL and LDL-cholesterol (24).

A strong and graded association between physical fitness and mortality due to all causes, cardiovascular disease and cancer for both men and women has been found $(24,28)$.

Table 1 summarizes direct mechanisms by which regular physical activity could prevent CHD and cardiovascular disease (CVD), as suggested by the literature $(8,24,29)$.

\subsubsection{Indirect effect(s)}

Cross-sectional studies found a direct inverse relationship between levels of fitness, levels of physical activity and risk factors for cardiovascular disease. In men (30), a consistent, inverse relationship between physical fitness categories and resting heart rate, body mass, percentage body fat, serum levels of cholesterol and triglycerides, glucose and systolic blood pressure (SBP) was observed. In women (31), physical fitness was independently associated with low serum triglycerides, high HDL-cholesterol, low total cholesterol/HDL-ratio, and low blood pressure. Several studies in young, middle-aged and older men reported cross-sectional associations between levels of physical activity and CHD risk factors (32-36). For example, in older Dutch men generally favorable associations were found between total weekly physical activity and specific activities, such as gardening and walking, and serum cholesterol and SBP (36). Even in a physically active, middle-aged population, subjects who were physically more fit and physically more active had better cardiovascular risk profiles based on body fat, blood pressure and smoking habits, than subjects who were less active and less fit (37).

Physical activity is associated with decreases in adiposity among younger and middle-aged populations, independent of caloric intake (38). Regular 
physical activity may prevent the development of non-insulin-dependent diabetes mellitus $(39,40)$.

Further support for the hypothesis that physical activity can favorably alter risk factors can be obtained from numerous training studies. Most studies have demonstrated that chronic exercise is associated with lower resting BP (41). Individuals who participated in training studies have shown increased HDL cholesterol levels (42-45), decreased LDL-cholesterol levels (42) and increases in HDL-cholesterol/total cholesterol ratio (43). Physical exercise has been shown to improve glucose tolerance and insulin sensitivity $(46,47)$.

Is physical inactivity a risk factor for hypertension?

Blood pressure is consistently and quantitatively related to the risk of developing all three major manifestations of cardiovascular disease: coronary heart disease, stroke and transient ischemic attacks, and congestive heart failure (48). In the general population, risks are lowest for adults with an average SBP less than $120 \mathrm{mmHg}$ and an average DBP less than $80 \mathrm{mmHg}$. The higher the SBP, the higher the risk of premature cardiovascular death. The same holds for DBP although SBP is a better predictor (48). Although by convention the term hypertension is used to denote SBP and DBP in adults that exceed 140 and $90 \mathrm{mmHg}$, high normal BP (SBP 130-139 $\mathrm{mmHg}$, DBP $85-89 \mathrm{mmHg}$ ) requires frequent monitoring and lifestyle measures because of the increased risk of developing definite hypertension and non-fatal and fatal cardiovascular events (49).

There are certain risk factors that increase the probability of developing hypertension. About one fourth of normotensive subjects and approximately one half of the hypertensive population can be characterized as sodium-sensitive, meaning that excess sodium in their diets increases their blood pressures $(50)$. Obese persons have a higher likelihood of becoming hypertensive than the non-obese do (51). Excess alcohol ingestion increases blood pressure (52). There is a growing body of evidence that associates a sedentary lifestyle with high blood pressure.

Paffenbarger et al (53) followed nearly 15,000 Harvard male alumni for 6-10 years. Alumni who did not engage in vigorous sports play were at $35 \%$ greater risk of hypertension than those who did, at all ages. Blair and colleagues (54) found that risk of developing hypertension was substantially increased with increasing baseline BP after a follow-up of 1-12 years. After adjusting for sex, age, baseline $\mathrm{BP}$, and body mass index, persons with low levels of physical fitness had a relative risk of 1.52 for the development of hypertension when compared to highly fit persons.

Fifteen endurance exercising adult males and 15 matched non-exercising males were followed for 20 years in a study by Kasch et al (55). Resting BP was found to be considerably higher on follow-up in the non-exercising group. Whereas two men in the exercise group and three in the control group were 
initially hypertensive, after 20 years six of the non-exercisers became hypertensive and none in the exercise group.

A graded, inverse association was shown between total weekly physical activity and mean BP in a large random sample of a Finnish male population (56). Total weekly physical activity and specific activities as gardening and walking were favorably associated with SBP in a representative sample of older Dutch men (36). In the Minnesota Heart Survey (34), greater heavy intensity activity during leisure time was reported to be associated with lower SBP in women, but not in men.

Several studies have shown that the level of physical fitness is independently and inversely related to SBP after adjustments for possible confounders such as age, body mass and body fat $(30-32,57)$. This relationship was found in middle-aged and older populations, for both men and women $(30,31)$ and in children $(32,57)$. Even in a fit and active middle-aged population this association was found (37). In general, DBP is not related to physical fitness $(30,31,57)$.

Most of the exercise intervention studies show a reduction in resting $\mathrm{BP}$ in both normotensive and hypertensive subjects. This will be discussed in more detail, in the next section.

In summary, studies have demonstrated that physical fitness and physical activity, be it occupational or recreational, is associated with decreased risks of coronary heart disease and hypertension.

\subsection{The effect of chronic exercise on blood pressure}

The achievement of long-term blood pressure control in persons prone to hypertension or with mild hypertension is of central strategic concern in the prevention of cardiovascular morbidity and mortality. Chronic aerobic exercise has been suggested as an effective and physiologically desirable nonpharmacological approach that can be used (a) in the strategy of prevention of hypertension, (b) as a definite intervention, and (c) as an adjunct to pharmacological therapy (58). A reduction in BP with regular participation in aerobic exercise could be due to the accumulative effects of single exercise bouts rather than actual long-term adaptations to exercise training. Post-exercise hypotension ranging from $10-25 \mathrm{mmHg}$ for SBP and 5-10 $\mathrm{mmHg}$ for DBP has been observed 1-4 hours after cessation of aerobic exercise (59-61). In a recent study (62), BP was significantly lowered even up to 13 hours in a group of hypertensive men after a single bout of dynamic exercise. Although this is a much noted observation which needs additional research, most attention has been focussed on the effects of endurance exercise training.

\subsubsection{The effect of endurance training on blood pressure at rest}

A definite conclusion on the effect of dynamic isotonic training on BP at rest has been seriously hampered by the lack of well designed, controlled and 
randomized studies $(41,63)$. Extensive variability in design has further complicated the matter. Designs differ with regard to number of subjects studied (range 4-66 subjects), length of training (range 4-52 wk), mode of training (walking, cycling, jogging, combinations), session duration (20-60 min), frequency of training ( 2 days/week to daily), and intensity (low to high)(41). Various conditions for BP recording have been used and some studies in hypertensives failed to ascertain that subjects had persistent elevations in BP before enrollment (64). Most studies have been limited to male subjects (41, 65 ). In recent years, more well controlled studies with fewer design deficiencies have been performed (65).

On average, endurance exercise training has been found to lower $\mathrm{BP}$ at rest in normotensives by $3-4 \mathrm{mmHg}$ for both SBP and DBP $(66,67)$. In a metaanalysis of 25 studies examining the BP lowering effects of endurance exercise training on individuals with essential hypertension, the average reduction in SBP by training, weighted for sample size, was $10.8 \mathrm{mmHg}$ for SBP and 8.2 $\mathrm{mmHg}$ for DBP (65). In a more recent meta-analysis by Fagard (67) only studies with a control group or period were included. The weighted average training-induced change in BP was $-6.2 /-6.8 \mathrm{mmHg}$ in borderline hypertensives, and $-9.9 /-7.6 \mathrm{mmHg}$ in hypertensives. Furthermore, it was noted that controlled studies which followed most rigorous scientific criteria showed the smallest decrease in $\mathrm{BP}$ (Table 2).

The intensity of exercise, the weekly frequency, the time per session and the length of the training program did not contribute significantly to the inter-

Table 2. Training-induced changes in $\mathrm{BP}^{\mathrm{P}}$ in controlled studies according to study design

\begin{tabular}{|c|c|c|c|}
\hline \multirow[t]{2}{*}{ Study design } & & \multicolumn{2}{|c|}{ Change in $\mathrm{BP}$ at rest } \\
\hline & & SBP & DBP \\
\hline $\begin{array}{l}\text { Random allocation to control } \\
\text { or exercise group with regular } \\
\text { contact of subjects during } \\
\text { control period }\end{array}$ & $\begin{array}{l}\mathrm{N} \\
\mathrm{H}\end{array}$ & $\begin{array}{l}-2(-6 \text { to }+3) \\
-7(-13 \text { to }-2)\end{array}$ & $\begin{array}{l}-2(-5 \text { to }+0.6) \\
-5(-9 \text { to }-1)\end{array}$ \\
\hline $\begin{array}{l}\text { Random allocation to control } \\
\text { or exercise group without } \\
\text { regular contact of subjects } \\
\text { during control period }\end{array}$ & $\begin{array}{l}\mathrm{N} \\
\mathrm{H}\end{array}$ & $\begin{array}{l}-4(-10 \text { to }+2) \\
-9(-18 \text { to } 0)\end{array}$ & $\begin{array}{l}-3(-5 \text { to }-0.6) \\
-10(-11 \text { to }-9)\end{array}$ \\
\hline $\begin{array}{l}\text { No random allocation to } \\
\text { control or exercise group }\end{array}$ & $\begin{array}{l}\mathrm{N} \\
\mathrm{H}\end{array}$ & $\begin{array}{l}-4(-7 \text { to }-0.5) \\
-10(-15 \text { to }-5)\end{array}$ & $\begin{array}{l}-5(-8 \text { to }-1) \\
-9(-14 \text { to }-3)\end{array}$ \\
\hline
\end{tabular}

Adapted from Fagard (67). Changes in BP ( $m m \mathrm{mg}$ ) and $95 \%$ confidence limits. Changes after adjustment for control observations and weighted for number of participants. N, normotensive groups; H, hypertensive groups. 
study variance of the BP response in normotensives or hypertensives (67). Some studies $(68-70)$ seem to indicate that low-intensity $\left(50-55 \% \mathrm{VO}_{2 \max }\right)$ endurance training has the same BP lowering effect as training at a moderate intensity level $\left(70-75 \% \mathrm{VO}_{2 \max }\right)$. It is not clear how long it takes for endurance training to elicit lower blood pressures, but most studies suggest that BP lowering will likely occur after 3 weeks and before 12 weeks of training have been completed (41). Jennings and colleagues found that exercising for 4 weeks, three times a week for $40 \mathrm{~min}$ at $60-70 \% \mathrm{~W}_{\max }$, lowered resting BP by $10 / 7 \mathrm{mmHg}$ in sedentary subjects $(71)$ and $11 / 9 \mathrm{mmHg}$ in hypertensive subjects (72). In a later study (73), applying the same protocol in healthy sedentary subjects, they even stated that BP fell $10 / 6 \mathrm{mmHg}$ after the third training bout at the beginning of the second training week and no further reduction occurred beyond the fourth bout of exercise. Urata et al (74) found resting $B P$ to be reduced after 3 weeks of low-intensity training in mildly hypertensive patients and no further reduction in BP was seen after 7 weeks of training.

Less fit and less active subjects may probably show the largest increase in exercise capacity and the largest reduction in BP following training. This is partially suggested by the meta-analysis of training studies by Fagard (67) who found the response of DBP to be significantly related to the increase in exercise capacity. In addition, in a study amongst Antarctic expeditioners (75), 3 weeks of moderate exercise training significantly lowered BP in the winter, when physical activity was limited to indoor activities because of climatic conditions. In the summer, however, climatic conditions are improved and subjects were more active during work and leisure time. BP at rest in the summer was similar to the post-training levels during the winter and additional moderate training for 3 weeks did not further reduce BP.

At present it is not known whether hypertensive subjects are able to maintain lower blood pressure levels with continuation of training for years. In a study by Jennings et al (76) the supine resting BP of 13 untreated hypertensive patients fell $11 / 9 \mathrm{mmHg}$ below sedentary levels after one month of moderate endurance exercise three times a week. After one year of exercise three times a week, these lower levels were maintained in all subjects. However, in the second year several patients had a $\mathrm{BP}$ returning towards hypertensive levels, despite good compliance to regular exercise.

Finally, many studies have considered weight reduction and change in diet as possible confounding factors. These factors are unlikely to bias the observed hypotensive effect by training $(65,67)$. Studies that show a statistically significant lowering of BP by training may be more likely to be published than those that do not. To which extent this obscures a definite conclusion on the effect of training on BP, especially in normotensives where the effect is small, is not known. 
On cessation of endurance training, $\mathrm{BP}$ at rest will return to sedentary levels, usually in several weeks or a few months, depending on training duration (41).

\subsubsection{The effect of endurance training on ambulatory blood pressure}

The majority of training studies suggests that blood pressure at rest is lowered by aerobic exercise in hypertensives and to a lesser extent in normotensives. Most of the evidence is derived from single or repeated indirect measurement of casual BP, or more or less basal BP, in a relatively short span of time. Apart from potential errors and inconsistencies in technique, random variation of $\mathrm{BP}$ is large and fluctuations of $40 \%$ in BP can occur during the day (77). To detect an anticipated fall by training of $8-10 \mathrm{mmHg}(7-10 \%)$ in resting $\mathrm{BP}$ in a hypertensive population or $3 \mathrm{mmHg}(2-3 \%)$ in resting $\mathrm{BP}$ in a normotensive population (67) could present a difficult problem against this background.

Ambulatory monitoring of BP can play an important role in improving the precision of a trial and minimizing the number of subjects required by reducing within-subject variability of BP, by the greater number of observations (77). Furthermore, levels of BP measured under resting conditions in a laboratory often overestimate levels measured throughout the entire day under free-living conditions (78). Ambulatory pressure measurements are fairly reproducible (79), correlate usually better with left ventricular mass (index) than casual pressure (80), and are free of confounding factors, such as the alerting response (77). In longitudinal studies, casually determined pressures can decrease over time without corresponding changes in levels measured by ambulatory monitoring (81). Moreover, it is of interest to study the effect of training on the circadian pattern of BP during the day, whereby $\mathrm{BP}$ reaches its highest level at mid-morning, to fall thereafter throughout the day to its nadir during sleep with a rise again before or at wakening (82).

The technique of ambulatory BP measurement has only recently been introduced in training studies (Table $3 a$ and $3 b$ ). Together, the results of these investigations indicate that low- to moderate-intensity aerobic exercise training has, if any, only a small effect on 24-hour levels of arterial BP in normotensive or mildly hypertensive subjects. All, but one (88), found no effect of training on night-time BP. Some studies $(86,88)$ found ambulatory BP lowered by training without a concomitant decrease in BP at rest.

\subsubsection{The effect of endurance training on blood pressure during exercise}

Relatively few controlled training studies have presented interpretable BP data during steady-state submaximal exercise $(65,67)$. The majority of studies compared exercise BP at the same absolute submaximal workload, whereas four studies $(68,71,83,89)$ compared exercise BP at similar relative workloads before and after training and one study (72) compared exercise SBP at a percentage of predetermined baseline $W_{\max }$ before and after training. A reduction in BP at the same absolute workload following training could be the 
Table 3a. Effects of training on resting and ambulatory blood pressure. Longitudinal controlled studies. Study design

\begin{tabular}{|c|c|c|c|c|c|c|c|c|c|c|}
\hline Investigator & Ref. & Group & $\mathrm{n}$ & Age & Sex & $\begin{array}{l}\text { Duration } \\
\text { of training } \\
\text { (weeks) }\end{array}$ & $\begin{array}{l}\text { Mode of } \\
\text { training }\end{array}$ & $\begin{array}{l}\text { Frequency } \\
\text { (per week) }\end{array}$ & $\begin{array}{l}\text { Session } \\
\text { duration } \\
\text { (min) }\end{array}$ & Intensity \\
\hline Van Hoof (1989) & 83 & $\mathrm{~N}$ & 26 & $39 \pm 10$ & M & 16 & Combin. & 3 & 60 & $?$ \\
\hline Gilders (1989) & 84 & $\begin{array}{l}\mathrm{N} \\
\mathrm{BH} / \mathrm{H}\end{array}$ & $\begin{array}{l}10 \\
7\end{array}$ & $\begin{array}{l}41 \pm 9(\mathrm{SE}) \\
46 \pm 2(\mathrm{SE})\end{array}$ & $\begin{array}{l}M, F \\
M, F\end{array}$ & $\begin{array}{l}16 \\
16\end{array}$ & $\begin{array}{l}\text { bicycle } \\
\text { bicycle }\end{array}$ & $\begin{array}{l}3 \\
3\end{array}$ & $\begin{array}{l}30 \\
30\end{array}$ & $\begin{array}{l}70 \% \mathrm{VO}_{2 \max } \\
70 \% \mathrm{VO}_{2 \max }\end{array}$ \\
\hline Somers (1991) & 85 & $\mathrm{BH}$ & 13 & $35 \pm 9$ & $M, F$ & 24 & jogging & daily & $10-30$ & $?$ \\
\hline $\begin{array}{l}\text { Seals and Realing } \\
\text { (1991) }\end{array}$ & 86 & $\begin{array}{l}\mathrm{H} \\
\mathrm{H}\end{array}$ & $\begin{array}{l}11 \mathrm{C}, 13 \mathrm{E} \\
8 \mathrm{C}, 10 \mathrm{E}\end{array}$ & $\begin{array}{l}61 \pm 2(\mathrm{SE}) \\
62 \pm 3(\mathrm{SE})\end{array}$ & $\begin{array}{l}M, F \\
M, F\end{array}$ & $\begin{array}{l}28 \\
58\end{array}$ & $\begin{array}{l}\text { walking } \\
\text { walking }\end{array}$ & $\begin{array}{l}3-4 \\
3-4\end{array}$ & $\begin{array}{l}30-50 \\
30-60\end{array}$ & $\begin{array}{l}40-50 \% \text { heart rate reserve } \\
40-50 \% \text { heart rate reserve }\end{array}$ \\
\hline Blumenthal (1991) & 87 & $\mathrm{H}$ & $\begin{array}{l}23 \mathrm{C}, 35 \mathrm{~S} \\
41 \mathrm{E}\end{array}$ & $45 \pm 8$ & $\mathrm{M}, \mathrm{F}$ & 24 & $\begin{array}{l}\text { walking/ } \\
\text { jogging }\end{array}$ & 3 & 35 & $\geq 70 \% \mathrm{VO}_{2 \max }$ \\
\hline Marceau (1993) & 88 & $\begin{array}{l}\mathrm{H} \\
\mathrm{H}\end{array}$ & $\begin{array}{l}9 \\
9\end{array}$ & $\begin{array}{l}43 \pm 2(S E) \\
43 \pm 2(S E)\end{array}$ & $\begin{array}{l}\mathrm{M}, \mathrm{F} \\
\mathrm{M}, \mathrm{F}\end{array}$ & $\begin{array}{l}10 \\
10\end{array}$ & $\begin{array}{l}\text { bicycle } \\
\text { bicycle }\end{array}$ & $\begin{array}{l}3 \\
3\end{array}$ & $\begin{array}{l}30-45 \\
30-45\end{array}$ & $\begin{array}{l}50 \% \mathrm{VO}_{2 \max } \\
70 \% \mathrm{VO}_{2 \max }\end{array}$ \\
\hline
\end{tabular}

Table organized according to date of publication. Abbreviations: $N$, normutensive; $B H$. borderline hypertensive; $H$, hypertensive; $C$, control; $E$, exercise trained: S, strength/flexibility trained: $M$, male; F. female: VO2max, maximal oxygen consumption; ?, not available; SE, standart error 
Table 3b. Effects of training on resting and ambulatory blood pressure. Longitudinal controlled studies. Results

\begin{tabular}{|c|c|c|c|c|c|c|c|c|c|c|c|c|}
\hline \multirow[t]{3}{*}{ Investigator } & \multirow[t]{3}{*}{ Ref. } & \multicolumn{2}{|c|}{$\mathrm{BP}$ at rest $(\mathrm{mmHg})$} & \multicolumn{6}{|c|}{ Ambulatory BP (mmHg) } & \multirow{3}{*}{$\begin{array}{l}\Delta \mathrm{VO}_{2 \max } \\
(\%)\end{array}$} & \multirow{3}{*}{$\begin{array}{l}\Delta \text { body mass } \\
(\%)\end{array}$} & \multirow{3}{*}{ Comment } \\
\hline & & \multirow[t]{2}{*}{$\triangle S B P$} & \multirow[t]{2}{*}{$\triangle \mathrm{DBP}$} & \multicolumn{3}{|c|}{$\triangle S B P$} & \multicolumn{3}{|c|}{$\triangle \mathrm{DBP}$} & & & \\
\hline & & & & day & night & $24 \mathrm{~h}$ & day & night & $24 \mathrm{~h}$ & & & \\
\hline Van Hoof (1989) & 83 & -4 & $-5^{*}$ & -2 & +2 & $?$ & $-5^{*}$ & -1 & $?$ & $+14^{*}$ & $-2^{*}$ & $\begin{array}{l}\text { Measurements between } 6 \text { and } \\
8 \mathrm{AM} \text {, and } 8 \text { and } 12 \mathrm{PM} \text { not } \\
\text { used in analysis. }\end{array}$ \\
\hline Gilders (1989) & 84 & $\begin{array}{l}\text { n.c. } \\
\text { n.c. }\end{array}$ & $\begin{array}{l}\text { n.c. } \\
\text { n.c. }\end{array}$ & $\begin{array}{l}-1 \\
-3\end{array}$ & $\begin{array}{r}0 \\
-9\end{array}$ & $\begin{array}{l}-1 \\
-5\end{array}$ & $\begin{array}{l}+2 \\
+1\end{array}$ & $\begin{array}{l}+4 \\
-2\end{array}$ & $\begin{array}{l}+3 \\
-2\end{array}$ & $\begin{array}{l}+10 \\
+14^{*}\end{array}$ & $\begin{array}{l}\downarrow * \\
\text { n.c. }\end{array}$ & $\begin{array}{l}\text { Training period of } 16 \text { wks } \\
\text { compared to control and } 12 \\
\text { wks deconditioning period. } \\
\text { Hypertensive subjects had } \\
\text { DBP } \geq 85 \text { and }<104 \mathrm{mmHg} \text {. }\end{array}$ \\
\hline Somers (1991) & 85 & $-10^{*}$ & $-6^{*}$ & $-5^{*}$ & +6 & $?$ & $-8^{*}$ & +2 & $?$ & $?$ & n.c. & $\begin{array}{l}\text { ABP measured intra-arterially } \\
\text { in } 10 \text { patients. Sleeping values } \\
(n=6) \text {. Six subjects studied } \\
\text { after training and detraining } \\
\text { for } 4 \text { months. }\end{array}$ \\
\hline $\begin{array}{l}\text { Seals and Realing } \\
\text { (1991) }\end{array}$ & 86 & $\begin{array}{l}-1 \\
-2\end{array}$ & $\begin{array}{l}-1 \\
-2\end{array}$ & $\begin{array}{l}-2 \\
-6^{*}\end{array}$ & $\begin{array}{l}-1 \\
-6\end{array}$ & $\begin{array}{l}-2 \\
-6^{*}\end{array}$ & $\begin{array}{r}0 \\
-2\end{array}$ & $\begin{array}{l}+1 \\
-2\end{array}$ & $\begin{array}{l}+1 \\
-1\end{array}$ & $\begin{array}{l}+6^{*} \\
+10^{*}\end{array}$ & $\begin{array}{l}\text { n.c. } \\
-2^{*}\end{array}$ & $\begin{array}{l}\text { Study with non-exercising } \\
\text { controls. Eight subjects conti- } \\
\text { nued exercising after } 6 \text { months } \\
\text { at higher intensity. Control } \\
\text { and trained subjects showed } \\
\text { equal decreases in casual BP. }\end{array}$ \\
\hline
\end{tabular}




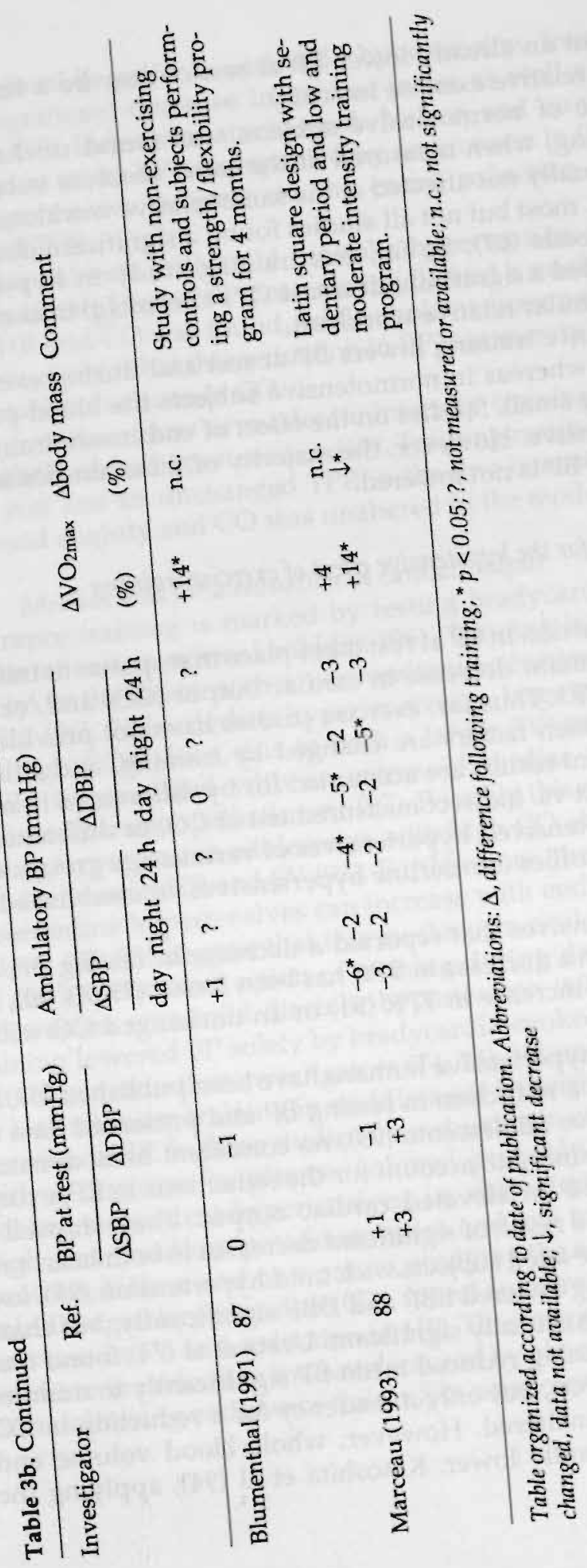


result of starting from an already lower BP at rest or may be a function of exercising at a lower relative exercise intensity.

The blood pressure of normotensive subjects was found unchanged or decreased after training, when measured at the same absolute submaximal workload, but was usually not affected at the same relative workload (67). In hypertensive patients, most but not all studies found a significant decrease in $\mathrm{BP}$ at absolute workloads (67). So far, one training study in hypertensive subjects (68) has reported a significant decrease $(17 / 12 \mathrm{mmHg})$ in exercise BP when measured at a similar relative workload.

In summary, endurance training lowers $\mathrm{BP}$ at rest and during exercise in hypertensive subjects, whereas in normotensive subjects the blood pressure lowering effect is rather small. Studies on the effect of endurance training on 24-hour BP are inconclusive. However, the majority of these studies seem to indicate that night-time $\mathrm{BP}$ is not lowered.

\subsection{Possible mechanisms for the hypotensive effect of exercise training - Hemodynamic effects}

It is obvious that if a reduction in $\mathrm{BP}$ at rest takes place in response to training, there has to be a concomitant decrease in cardiac output (CO) and/or total peripheral resistance (TPR). Thus far, exercise studies have not provided an unanimous picture of which factors are changed by training, and it is not inconceivable that different results are accounted for by differences in measurement techniques (direct vs. indirect measurement of $\mathrm{CO}$ ) or differences in study populations: normotensives, hypertensives of various age groups with different hemodynamic profiles (borderline hypertensives vs. established hypertensives).

In studies with normotensives that reported a decrease in resting BP, not only an increase in CO with a decrease in TPR has been found $(71,73,90)$, but also a drop in $\mathrm{CO}$ with an increase in TPR (91) or an unchanged $\mathrm{CO}$ with a decrease in TPR (92).

To date, seven studies in hypertensive humans have been published $(69,72$, $74,86,93-95)$ that all found a reduction in resting BP and presented data on CO and TPR. In hypertensive adolescents (93), no consistent hemodynamic changes were found with training to account for the reductions in BP, except in subjects who initially had an elevated cardiac output. They showed a significant decrease in CO as a result of significant decreases in both heart rate and stroke volume. In middle-aged subjects with mild hypertension (95), low or moderate intensity training lowered SBP and DBP significantly, but changes in CO or TPR were not statistically significant. Urata et al (74) found that 10 weeks of low intensity training reduced mean BP significantly in middleaged mild hypertensive subjects, but only a tendency for a reduction in $\mathrm{CO}$ was found while TPR was unaltered. However, whole blood volume and plasma volume were significantly lower. Kinoshita et al (94), applying the 
same protocol in patients with mild hypertension, found a reduction in BP with a significant decrease in cardiac index as well as in plasma volume, whereas TPR index was unchanged. Nelson and co-workers (72) found a reduction in mean $\mathrm{BP}$ accompanied by an increase in $\mathrm{CO}$ in trained middleaged hypertensive subjects, so the entire reduction in BP was due to a decreased TPR.

In older subjects with mild diastolic hypertension (86), 6 months of low intensity training lowered mean resting $\mathrm{BP}$ and a small but significant reduction in HR and CO was found, while stroke volume and TPR were unaltered. It was concluded that this reduction in BP was merely mediated by bradycardia-evoked reductions in CO.

Nine months of low or moderate intensity training lowered mean BP significantly in older hypertensives (69). Training resulted in a somewhat lower $\mathrm{CO}$ at rest and an unchanged TPR in the low intensity group, whereas TPR decreased slightly and $\mathrm{CO}$ was unaltered in the moderate intensity group.

\subsubsection{Mechanisms for a reduction in cardiac output}

Endurance training is marked by resting bradycardia and increased stroke volume at rest in normal subjects (96). Training increases parasympathetic activity to the heart with a concomitant reduction in resting sympathetic activity (96). In borderline hypertensives, a large proportion of the subjects have high $\mathrm{CO}$ values, due to both a larger SV and a higher HR (97). This usually is associated with an increased cardiac sympathetic drive and a decreased parasympathetic tone (97). Possibly this can be opposed by training since in hypertensive adolescents with high $\mathrm{CO}$ at rest, exercise reduces $\mathrm{CO}$ by a decrease in HR and SV (93). Furthermore, the low baroreflex sensitivity in borderline hypertensives can increase with endurance training (85). Some authors $(85,88)$ suggest that this mechanism could, at least partially, explain the antihypertensive action of training during daily activities. In older men and women with mild diastolic hypertension $(69,86)$, low-intensity aerobic training lowered BP solely by bradycardia-evoked reductions in cardiac output. However, other investigators $(74,94)$ did not find a heart rate reduction by low-intensity training in middle-aged hypertensives, despite a significant decrease in BP. In these studies the reduction in cardiac output was associated with a decrease in plasma volume, probably because the subjects were volume-dependent hypertensives, i.e. characterized by high cardiac indices, high serum sodium potassium ratios and low total peripheral resistances. In contrast, Nelson and co-workers, studying the effect of endurance training in middle-aged hypertensives (72), found an increase in $\mathrm{CO}$ accompanied by an increase in SV and reduction in HR. They suggested this could be due to an increase in preload to the heart, caused by plasma volume expansion, usually seen following endurance training in normotensive sedentary subjects (98). 


\subsubsection{Mechanisms for an exercise-related reduction in peripheral resistance}

Most training studies in normal and hypertensive subjects have focussed on a reduced peripheral resistance to explain the hypotensive effect of exercise because $\mathrm{CO}$ at rest is usually normal and increased vascular resistance is the hemodynamic characteristic of established hypertension (99).

One of the possible mechanisms underlying the fall in TPR is an increase in cross-sectional area of the vasculature in trained muscles, secondary to an increase in local muscle mass. Increased capillary density (100), capillary to muscle fiber ratio (101) and an increase in maximal muscle blood flow (102) with training have been reported. Physical training increases the capacity for vasodilation in active limbs, probably due to adaptive changes at the arteriolar level $(103,104)$. The extent to which these changes relate to changes in the resistance vasculature and affect resting TPR is at present unknown.

The diameter of the arterioles can change due to vasoconstrictor and dilator influences on vascular tone. The two main mediators of vasoconstriction are the sympathetic nervous system (SNS) and the renin-angiotensin-aldosterone system (RAAS), but other vasoactive hormones may also be involved.

[1] In training studies, plasma catecholamine concentrations have been used by most investigators as an index of SNS activity and a common finding is a decrease in plasma norepinephrine (NE) after training (71-74, 94, 95, 105, 106). In both normotensives and hypertensives, plasma NE fell after training (71-73), although in older hypertensives (69) and adolescents with hypertension (93), it did not. It was reported that the higher the baseline plasma NE, the greater the fall in $\mathrm{BP}$ at rest (105). A good correlation was found between changes in plasma NE and mean blood pressure following training (74). However, in borderline hypertensives, where the higher BP levels are usually associated with an increased sympathetic activity, changes in plasma NE were small and inconsistent (89). Platelet NE was decreased after training which may reflect a decreased long-term activity of SNS (107).

Total resting NE spill-over rate to the plasma provides a measure of whole body average sympathetic neural activity (108). This parameter was found greatly reduced in normal subjects after training (71). The majority $(66 \%)$ of the reduction in spill-over of NE to the plasma was accounted for by a fall in renal NE spill-over whereas no change in cardiac spill-over was found (90).

Because one third of the reduction in total NE spill-over occurred outside the kidney, other regional sympathetic outflows must be involved. Studies in borderline hypertensives (109) have shown that an acute post-exercise hypotension is probably caused by sympatho-inhibition of the muscle nerves as can be measured by microneurographic techniques (109). Furthermore, using the same technique, training markedly reduced sympathetic peroneal nerve activity in normal subjects (110). Although the reduction in NE spill-over is largely seen in the kidneys, the increase in total peripheral conductance seen after training was for only $18 \%$ explained by an increase in renal vascular conductance (90). Probably the fall in TPR can be mediated by modification of 
other regulatory functions of the sympathetic renal nerve through renin release and/or sodium reabsorption. Although studies suggest that a reduction in SNS activity with training is related to a BP reduction, the time course of the effect on $\mathrm{BP}$ appears to be more rapid than the changes in plasma NE (73).

Detraining of subjects showed a gradual increase in BP that was parallelled by a gradual increase in plasma NE, which suggests that the reduction in SNS activity may help to maintain $\mathrm{BP}$ at relatively low levels for some time after training (73).

Whether training can alter the sensitivity of the adrenergic system is still a matter of debate and studies are inconclusive both in humans (111) and animals $(112,113)$. Pressor response to NE infusions was found to be blunted after training (114). In healthy subjects, a variation of responses to endurance training with respect to beta-adrenergic receptor density has been observed. Beta-receptor density has been shown to decrease (115) or not to change (116) in lymphocytes, to increase in leukocytes (117), and to be unchanged in skeletal muscle (118). Probably beta-adrenergic responses to endurance training are tissue-specific (119). Training studies on the possibility of receptor down-regulation in hypertensive subjects have not been reported.

[2] Changes in the renin-angiotensin-aldosterone system could be an important underlying mechanism through their effect on blood volume and through the potent directly acting vasoconstrictor angiotensin II which also potentiates NE release. In young healthy subjects, an inverse relationship was reported between $\mathrm{VO}_{2 \max }$ and plasma renin activity (PRA) at rest (120). Compared to non-trained subjects lower PRA levels were found in well-trained subjects (121). In normotensive subjects, resting supine PRA was unaltered after 4 weeks of training (71) or found to be significantly reduced after 5 months of training (122). Resting plasma angiotensin II was unchanged (123) or increased (124) with training whereas plasma or urinary aldosterone was lower (125), unchanged (122) or higher (124).

In trained subjects, PRA $(122,123)$ and plasma angiotensin II (123) were lower during graded exercise. At a similar relative workload, PRA was unchanged after training (126). In hypertensive subjects, training did not change resting PRA, angiotensin II and plasma aldosterone in a series of studies by the same group $(127)$. Some studies $(69,106)$ seem to indicate that hypertensive subjects with low PRA exhibited a larger reduction in BP than hypertensive subjects with high or normal PRA.

[3] Other hormones have been postulated to explain the BP lowering effect of regular exercise, either through a direct effect or by inhibiting NE release from nerve terminals. Atrial natriuretic peptides (ANP) are released from cardiac atria, predominantly by atrial stretch. ANP has a role in cardiovascular homeostasis by its diuretic, natriuretic and vasodilating effects. ANP has an inhibitory effect on NE stimulated vasoconstriction (128), depresses the release of renin (129) and counteracts the vasoconstrictor activity of angioten- 
$\sin$ II (130). It promotes diuresis and natriuresis, possibly by inhibition of aldosterone or vasopressin (131).

Endurance training is thought to result in expansion of blood and plasma volumes (132) and it is possible that this will result in a higher density of ANP atrial granules and higher plasma ANP levels. To date only few published data are available on the effect of exercise training on ANP in humans. Similar resting ANP values were found when moderately trained young runners were compared to untrained (133) and a training break of 3 weeks in endurance runners did not alter resting ANP (134). During exercise, central blood volume rises and higher ANP levels were found, related to the absolute workload (133). In the normotensive rat model, an increase in resting ANP was observed with training, whereas atrial tissue ANP was not altered (135). However BP was not changed. In mild hypertensive subjects, slightly elevated (136) or unchanged (137) resting ANP levels were found compared to normotensive subjects. Low intensity training in middle-aged hypertensives did not change plasma ANP at rest (138).

Prostaglandin E, originating from the kidney or the skeletal muscle (139), could increase sodium secretion from the kidney and thus reduce plasma volume. Prostaglandin E concentrations at rest were found to be two to three times higher after training in hypertensive subjects (106). This could explain the volume depleting effects of physical training observed by some investigators (74) without alteration in the RAAS. In addition, prostaglandin E may cause local vasodilation in the skeletal muscle (139) or inhibit nerve NE release (140).

An important role for insulin in BP control has been postulated. Hyperinsulinemia could elevate BP by its direct effect on renal sodium retention (141) or by releasing $\mathrm{NE}$, the latter resulting in arterial smooth muscle contraction and renal sodium retention (142). Endurance trained subjects have lower plasma levels of insulin and an increased sensitivity to the peripheral actions of insulin $(62,143)$. Insulin sensitivity rose with endurance training in normal subjects independent of body mass changes (71). Higher levels of insulin have usually been found in sedentary obese hypertensive individuals (144) and Björntorp (145) observed a fall in BP in association with a reduction in plasma insulin in obese patients after training. Whether endurance exercise can lower $\mathrm{BP}$ in association with lower insulin levels in non-obese hypertensives independent of a body mass reduction, warrants further research.

Several other humoral factors may play a role either by inhibiting the release of NE at sympathetic nerve endings or promoting NE uptake (see for review 127).

Finally, endothelium-derived relaxing factor is an endogenous vasodilator released by the vascular endothelium. Recent animal studies $(146,147)$ suggest that chronic exercise enhances endothelium-mediated vasodilation. 
In summary, the mechanisms underlying the hypotensive action of regular exercise are still poorly understood. Studies on hemodynamics are controversial. The antihypertensive mechanism of exercise may be multifactorial and most probably involves suppression of sympathetic activity.

\subsection{Effect of chronic exercise on the heart and vessels}

The majority of ill effects of hypertension and atherosclerosis become manifest in the heart and large vessels. Hypertension is often accompanied with or preceded by changes in cardiac function or structure (148), which considerably increase the risk of morbidity. Furthermore, both components of vascular impedance, i.e. increased resistance and decreased compliance, are affected. So, the potentials of endurance exercise to oppose these changes, beside its effects on blood pressure and other risk factors, are of interest.

\subsubsection{Heart}

Physical conditioning results in a decrease in heart rate at rest and during submaximal workloads, while stroke volume is increased. $\mathrm{VO}_{2 \max }$ and maximal $\mathrm{CO}$ are increased, while peripheral changes result in enhanced maximal arterio-venous oxygen differences $(96,149)$. As a result training reduces cardiac work in proportion to total body work.

When athletes engaged in endurance type of exercise are compared to non-trained subjects, increased left ventricular mass (LVM) is found (150). Athletes have a larger end-diastolic left ventricular internal diameter (150, $151)$ and increased posterior and septal wall thickness $(150,151)$. The ratio of wall thickness to internal radius of the left ventricular cavity is not different from that in untrained persons $(152,153)$ or slightly increased $(150)$. The ratio of septal to posterior wall thickness is not different in athletes and non-athletes $(150,151)$.

Training studies showed a significant increase in LVM and posterior and septal wall thickness after 4-16 weeks without a change in cavity size, when moderate exercise was performed $(154,155)$. In response to vigorous training, the end-diastolic internal diameter of the LV was already increased after one week, whereas changes in wall thickness occurred more gradually (156). Some authors (157) have reported increased end-diastolic dimensions without a change in LVM or wall thickness. Systolic and diastolic function of the left ventricle has usually been found to be in the normal range for athletes (158) or was unchanged after endurance training in sedentary subjects (155-157).

Changes in cardiac structure with endurance training are often referred to as eccentric LVH, because LV internal diameter increases with a proportional increase in wall thickness; this in contrast to the LVH seen in hypertension which is more concentric and marked by excessive wall thickness. In unselected groups of patients with essential hypertension, LVH is found in approximately $12 \%$ of the borderlines (159) and $15-20 \%$ of the mild to 
moderate hypertensives (160). Hypertensives with increased LVM have nearly 3 times as many morbid cardiovascular events than those without (161). The correlation between LVM and casual or clinical BP is rather poor (162) and is usually only slightly better for ambulatory measurements (163). Although not commonly observed (80), some investigators suggest that night time SBP correlates the best with LVM (160); this is of particular interest since endurance training does not appear to lower BP at night $(84,86,87)$. The expected reduction in BP after endurance training in hypertensives (41) could be counteracted by an increase in LVM, due to chronic intermittent overload of the heart by this type of training. A change away from concentric LVH and towards eccentric hypertrophy was found after one year of physical training in hypertensive humans (75). In this study, mean BP was significantly reduced at rest, LV cavity diameter increased significantly, whereas average wall thickness was reduced and LVM was unchanged.

Sixteen months of training in mild hypertensives on a low sodium diet (164) decreased both BP at rest and at maximal exercise, with only a tendency for LVM reduction. When LVM, however, was indexed for body mass (LVMI), no change was seen. No significant correlations between BP changes and changes in LVM or LVMI were found. On the contrary, in hypertensives, a decrease in LVMI was found after 4 months of training, without a decrease in BP at rest or during exercise, nor in 24-hour BP (165). This suggests that a reduction in LVM by training can occur independently of changes in BP, possibly via the involvement of the adrenergic system (166). In hypertension, the diastolic function is often abnormal and usually seen before LVH is obvious (167). It reflects reduced left ventricular compliance (168) or relaxation abnormalities (169). Changes or an improvement of cardiac function in hypertensive humans have not been reported, following endurance training $(75,164)$. In hypertensive rats, training did not change diastolic cardiac function (170) or improved it (171).

In human studies, direct evidence for an increase in the coronary collateral circulation by training is lacking (172). Possibly a decreased propensity towards arrhythmias may be a product of long-term training since an increased threshold for ventricular fibrillation in the isolated trained rat heart was found (173).

\subsubsection{Vessels}

Established hypertension is nearly always characterized by an elevated mean arterial BP and elevated total peripheral vascular resistance. Arterioles and in certain tissues (skeletal muscle, intestines), also muscular arteries contribute to the elevated vascular resistance (174). Proposed mechanisms underlying the overall increased vascular resistance in hypertension are (a) a decrease in the number of arterioles and capillaries, (b) decreased internal diameter of arterioles and small arteries, and (c) increase in arterial and arteriolar wall mass (174). Changes in vascular smooth muscle itself like increased sensitivity 
to vasoconstrictor stimuli and a diminished relaxation process contribute to increased resistance (175).

As discussed above, most training studies have been focussed on factors that influence resistance on a functional basis, i.e. studying predominantly the remote control systems (autonomic nervous system, circulating hormones) in relation to functional vascular diameter regulation. Few studies have addressed the ability of endurance training to remodel the vascular tree. Remodeling could be achieved by chronic change in number of parallel vessels, vascular diameter or wall thickness.

In humans, endurance training can induce capillary growth in active skeletal muscles, if performed for a sufficiently long time (minimum $8 \mathrm{wks}$ ) (100102). This growth is predominantly seen in the vicinity of slow oxidative fibers. As suggested by Hudlicka (176), capillary growth in skeletal muscles is probably initiated by increased blood flow. Increased shear stress in capillaries in skeletal muscle can initiate capillary growth by producing a disturbance of the luminal side of the endothelium. The involvement of growth factors has recently been suggested in endurance-trained rats (177). Whether endurance training induces growth of arterioles in human skeletal muscle is not clear. In rat models, an increase in number of small arterioles in skeletal muscle has been demonstrated, following endurance training (178). Furthermore, an increase in passive diameter of large arteries was shown. In humans, minimal vascular resistance is usually assessed by indirect measurement of limb flow (calf, forearm) by plethysmography at maximal vasodilation. In hypertensive subjects (179), borderline hypertensives (180), and even in normotensive young men with a parental history of hypertension (181), minimal vascular resistance has found to be increased during maximal vasodilation compared to age-matched normotensives. These physiological observations provide indirect evidence for the existence of the afore-mentioned structural abnormalities in hypertension. Physical training increases the capacity for maximal vasodilation in active limbs $(104,182)$ in normal subjects. Whether endurance training can induce regression of structural changes in hypertensive humans in various vascular beds has not been studied. It is known from antihypertensive treatment with different pharmacological agents that structural changes can be reversed in animal models of hypertension and it is evident from these studies that control of BP is not enough to achieve regression (183) and that trophic factors (catecholamines, angiotensin II, insulin) must be favorably altered (184). Reversibility of structural changes depends on the duration of hypertension (183). In man, only prolonged treatment with pindolol, captopril and nitrendipine for at least 6 months has convincingly shown to reduce minimal vascular resistance in the forearm vascular bed (185, 186). 


\section{Large vessels}

Visco-elastic properties of the arterial wall enable large arteries to store to the volume of blood ejected from the heart during cardiac contraction, and to drain this volume during diastole (187). While an increase in vascular resistance causes a proportional elevation of mean BP (and thus SBP and DBP), a reduction in the visco-elastic properties of the arterial wall causes an increase in pulse pressure resulting in an increase in SBP in combination with a decrease in DBP, without a change in mean BP (188).

Several investigations have suggested that increased pulse pressure may be an important risk factor in subjects with hypertension and relates well to increased LVM in hypertensives with similar mean BP $(189,190)$. Furthermore, since cardiovascular morbidity and mortality of hypertensives is mainly related to disease of the large arteries, evaluation of cardiovascular risk could be more suitably done by indexes of arterial disease (191). An adequate quantification of the visco-elastic properties of the large arteries can be made by evaluating compliance and distensibility in a given artery. Arterial compliance is defined as the product of arterial volume by distensibility of the artery. Distensibility is evaluated either from the measurement of pulse wave velocity over a given arterial traject (187) or can be measured locally by the related displacement of the arterial walls per unit of pressure (192). Pulse wave velocity correlates strongly and positively with SBP measured by ambulatory monitoring (191).

Several studies have shown that arterial compliance and distensibility of the large arteries are significantly reduced with age (193) and (borderline) hypertension $(194,195)$. The changes may be due to structural changes, to particular responses of arterial smooth muscle tone or to a combination of both (196, 197).

It has been recognized that different antihypertensive drugs have different effects on large artery compliance, despite of equal reductions in mean BP (198). Calcium antagonists, ACE-inhibitors and some beta-1 selective betablockers improve large artery compliance, while some diuretics and nonselective beta-blockers do not (198). Because these conclusions are based on acute or short-term chronic studies, it is likely that this reflects functional changes rather than structural changes. Whether structural changes resulting in a decrease in compliance can be reversed is not known at present (198).

It has been suggested that an increased distensibility of large arteries will decrease the load on the vessel wall and thus may prevent accelerated aging of the vessels and maybe also atherosclerotic disease (199). Increased compliance might result in a smaller afterload for the heart, and as a consequence, help to prevent cardiac hypertrophy (199).

It would be of particular interest to know whether endurance training can improve compliance and distensibility of large arteries in normotensive and hypertensive subjects and thus reduce pulsatile stress on heart and vessels. 
In a recent study (200), regional aortic compliance was measured by magnetic resonance imaging and endurance athletes were compared to age-matched healthy volunteers. Aortic compliance was found to be negatively related to age and was significantly higher in athletes. A strong negative relation was found between physical working capacity and pulse wave velocity over the carotid-femoral traject in young men (201), which suggests a positive relationship between physical fitness and arterial distensibility. An increased compliance and diameter was found in the radial artery of the dominant arm of hammer throwers compared to sedentary controls (202). The effect of 4 weeks of endurance exercise on regional arterial (aortic) compliance was studied in 7 sedentary males (203). A significant increase in arterial compliance was noticed with a significant fall in SBP. It was suggested that pressure-independent factors could contribute to the improvement (203).

The morphology of systemic arteries following endurance training has been studied in animal models. In trained rats, medial wall thickness was significantly greater in large arteries, whereas number of smooth muscle cells and lumen diameter were unchanged (204). It was suggested that this would lead to a decrease in tangential wall stress at rest. Training in hypertensive rats (205) resulted in a reduction of wall-to-lumen ratio in several large arteries (descending aorta, iliac artery, femoral artery). The trained rats had similar wall thickness values as non-trained hypertensive animals, but larger lumen diameter.

In overview, more studies are needed to establish the remodeling effects of regular exercise on the vascular tree in normotensive and hypertensive populations.

\subsection{Exercise stress testing in blood pressure evaluation}

In clinical practice, routine measurements of $\mathrm{BP}$ during exercise are mainly performed to detect an inadequate BP rise as can be due to aortic valve disease or left ventricular impairment. A decrease of SBP during exercise below the usual resting SBP or a limited $(10 \mathrm{mmHg})$ increase in SBP in patients with suspected or clinically severe cardiovascular disease is a reason to terminate stress testing because of a high likelihood of post-exertional ventricular fibrillation (206).

A limited increase in SBP in normal healthy persons may not be serious in the early stages of stress testing because it may reflect anxiety-induced hypertension (207). Although an excessive rise in SBP (well over $200 \mathrm{mmHg}$ ) is a reason to stop exercise in some centers, complications related to high exercise SBP have never been seen (207).

The so-called double product, or SBP multiplied by heart rate, is often used in clinical and/or pharmacological studies because it provides an excellent index of myocardial oxygen consumption (208). Several investigators (see for review 209) have addressed the question whether exercise (systolic) BP is a 
better predictor of target organ damage or cardiovascular morbidity or mortality than resting BP. Most studies found no significant and independent contribution of exercise BP to the variance of left ventricular mass when adjustments were made for potential confoundens such as resting BP, age, height, weight and aerobic power. The exercise-induced change in SBP from baseline to a work load of $164 \mathrm{~W}$ was found an independent predictor of cardiovascular mortality in a study of healthy male subjects (210). In contrast in hypertensive subjects, Fagard and colleagues (211) found exercise BP not to be an independent predictor of mortality or incidence of cardiovascular events.

\subsubsection{Excessive blood pressure response during exercise as a predictor of future hypertension}

Numerous studies have tried to identify markers for the development of hypertension. In Western society, age, body mass, resting HR and BP have been found to be predictors (212). Laboratory predictors, such as cationic transporters and hormones, especially insulin, have been suggested (212).

In recent years, an excessive rise in BP during exercise has been proposed as a predictor of future hypertension (213-217). Wilson and Meyer (213) retrospectively analyzed the blood pressure profiles of 3395 men and 425 women who attended their clinic two times or more. After an average followup time of 32 months, subjects with a normal resting BP $(<140 / 90 \mathrm{mmHg})$ but with an exaggerated $\mathrm{BP}$ response during exercise $(>225 / 90 \mathrm{mmHg})$ at first visit were compared to subjects with a normal resting and exercise BP. The incidence of subsequent hypertension was for the subjects with exaggerated exercise response 2.38 (relative risk) times greater. Dlin et al (215) examined two matched groups of normotensive young adults. The only differentiating variable was the high BP during exercise $(<$ or $>200 / 100 \mathrm{mmHg}$ ). After 5.8 years of follow-up, the group with the higher BP response had a $11.6 \%$ higher incidence of hypertension. In general, the prevalence of hypertension on follow-up among normotensive subjects with an exaggerated response to exercise testing is 2.1 to 3.4 times higher than among subjects with a normal response (216). Sensitivity of an exaggerated response to exercise for future hypertension varied for studies between 16 and $60 \%$ and specificity between 53 and $95 \%$. However, the predictive value is limited since 38 to $89 \%$ of those with an exaggerated response to exercise did not have hypertension on follow-up (0.5-15 yr) and a normal response only marginally reduced the risk of hypertension. A common point of critic on most of these studies is the absence of standardization of the employed exercise protocols and different definitions of an exaggerated $\mathrm{BP}$ response. Further research should define a cut-off point separating normal from abnormal response according to age, sex and physical fitness (216), and must not only consider the absolute value of BP response but also the magnitude of $\mathrm{BP}$ change at each workload and establish norms that include race, sex, body mass and fitness levels. For testing pur- 
poses, the use of bicycle ergometry should be favored and more studies are needed on the acute BP response to exercise in women (41).

The mechanisms behind an exaggerated $\mathrm{BP}$ response to exercise are poorly understood. Both an impaired capacity for exercise-induced vasodilation and an increased $\mathrm{CO}$ have been suggested. Alternatively, one could speculate that it is related to a low baroreflex sensitivity or a decreased arterial compliance. Wilson et al (218) compared normotensive young men with normal BP responses to exercise with normotensive men with exaggerated $\mathrm{BP}$ responses $(>230 / 110 \mathrm{mmHg}$ ) and a positive parental history of hypertension. A third group of normotensive normal responders with a positive parental history was formed. All three groups had equivalent cardiovascular parameters at rest and $\mathrm{CO}$ increased similarly during exercise. The group of exaggerated responders with a positive parental history showed a blunting in peripheral resistance decline during exercise. Iskandrian and Heo (219) studied normotensive subjects, with and without an exaggerated SBP response to exercise ( $>200 \mathrm{mmHg}$ ) and patients with uncomplicated essential hypertension. Compared to the normal subjects exaggerated responders differed only with regard to a higher cardiac index and SBP during exercise. Compared to the hypertensives, exaggerated responders had a higher exercise HR, SBP, cardiac index, and left ventricular ejection fraction and lower total vascular resistance and end-systolic volume during exercise. Gottdiener and colleagues (220) compared cardiac findings in groups of sedentary normotensive men who did or did not have exaggerated elevation of SBP during treadmill exercise $(<$ or $\geq 210 \mathrm{mmHg}$ ). Men with exaggerated SBP during exercise had significantly elevated left ventricular mass.

\subsubsection{Exercise testing in assessment of hypertension}

Some studies strongly suggest that the assessment of BP during ergometric testing is quite useful in distinguishing between "true" normotensive, borderline hypertensive and hypertensive subjects $(221,222)$. Hypertensive patients were characterized by a rise in diastolic BP during submaximal exercise, whereas diastolic BP remained unchanged or showed only a slight increase in normotensive subjects $(221,222)$. This different hemodynamic pattern can be explained by the inability of hypertensive patients to reduce peripheral resistance to the same extent as normotensive subjects (223). Franz (221) studied a group of male subjects with borderline hypertension at rest (SBP: 140-160 $\mathrm{mmHg}$; DBP: $90-95 \mathrm{mmHg}$ ). Subjects with BP of more than $200 / 100 \mathrm{mmHg}$ at 100 watt and BP of more than $140 / 90 \mathrm{mmHg}$ after $5 \mathrm{~min}$ of recovery were classified as positive responders, i.e. showing a hypertensive response. These subjects did not differ in BP response to exercise from age-matched patients with established hypertension. Subjects with a negative response had the same DBP at 100 watt as normotensive subjects. In a follow-up study of the same investigator (224), 97\% of the borderline hypertensives showing a hy- 
pertensive response during and after exercise testing developed established hypertension under resting conditions within 4 years.

In contrast, other investigators judged that the BP response during exercise was not particularly useful as a modality for diagnosing hypertension, in young females with borderline hypertension (225), and in children with high resting $\mathrm{BP}(226)$. Children with a resting $\mathrm{BP}$ above the 95 th percentile showed a similar rise in exercise SBP as the normal group (226). Although the exercise $\mathrm{BP}$ was significantly higher in young females with borderline hypertension, the mean change between resting and exercise SBP and DBP was not significantly different from the normal group (225). In general, it is believed that in hypertensives changes in $\mathrm{BP}$ during exercise resemble the normal response found in normotensive subjects; this is, hypertensives do not have a greater change in SBP from rest to exercise $(225,227,228)$. Others have pointed to the fact that an excessive rise is mainly seen in hypertensives with advanced stages of disease (229).

More large sample studies are needed to test whether exercise BP is a useful modality for diagnosing hypertension and adjustments should be made for potential confounders as age, sex, weight, body fat, resting BP and physical fitness. Furthermore, both clinical and epidemiological studies $(230,231)$ found substantial variation in the magnitude of $\mathrm{BP}$ response to exercise among healthy men and women and limited data are available at present to explain this variation. Age is independently and positively associated with SBP response to exercise $(231,232)$, whereas obesity (Quetelet index) is positively associated with the SBP response during treadmill testing (230). In smokers SBP during exercise is higher although only for men (232). Whether gender differences exist is not clear at the moment.

\subsection{Antihypertensive medication and exercise}

Lifestyle modifications are frequently advised by physicians as the start of antihypertensive treatment in mildly hypertensive subjects or as an adjunctive therapy to pharmacologic treatment. Lifestyle modification includes weight reduction, moderation of dietary sodium or alcohol intake, and increased physical activity.

Dynamic physical exercise is considered beneficial for many patients with hypertension because its potential benefits include a reduction in BP and favorable effect on other cardiovascular risk factors, increased work capacity and a general sense of well-being (233). However, in many hypertensive patients regular exercise does not lower BP to normotensive levels (65) and pharmacological treatment is necessary.

In the selection of initial drug therapy many factors should be considered and basically two approaches have been suggested $(49,234)$. The first approach (49) emphasizes the fact that although all major classes of antihypertensive drugs are equally effective in lowering $\mathrm{BP}$ at rest, only diuretics and beta- 
blockers have been shown to reduce cardiovascular morbidity and mortality in long-term controlled trials. Consequently, they are recommended as first choice agents, unless they are contra-indicated or unacceptable. In the second approach (234), the selection is based on the hemodynamic profile of the drug, i.e. it should reverse the hemodynamic abnormalities of hypertension by lowering the systemic vascular resistance and preserving cardiac output and perfusion. Furthermore, concomitant diseases should be taken into account, good quality of life maintained and the drugs should have no, or favorable, effects on other CHD risk factors. Consequently in this latter approach, calcium-antagonists, angiotensin-converting enzyme inhibitors and alpha-1 receptor blockers are advocated as first choice drugs.

\subsubsection{Which antihypertensive drug to choose in the physically active patient?}

In addition to the afore-mentioned considerations, the ideal antihypertensive agent for patients who wish to engage in physical exercise should (a) effectively lower BP during exercise, (b) reduce BP by lowering systemic vascular resistance and preserving cardiac output and organ (active muscle) perfusion during exercise, (c) not impair left ventricular function, (d) have no arrhythmogenic potential, and (e) not impair endurance performance and trainability.

Exercise blood pressure. Table 4 compares the antihypertensive effect of several classes of drugs at rest and during exercise. Although all antihypertensive agents effectively lower BP during exercise, beta-blockers reduce exercise SBP more than other classes of antihypertensive agents. This could be an advantage in those patients with very high SBP during exercise. A much more pronounced reduction in exercise HR (20-25\%) is seen with beta-blockade than with other antihypertensive drugs (235). As a consequence, the so-called double product (HRxSBP), and thus myocardial oxygen consumption, is considerably lowered by beta-blockade, which could be an advantage in the treatment of patients with concomitant limited coronary blood supply during exercise.

Exercise hemodynamics. Beta-blockers lower exercise BP by reducing cardiac output (5-20\%), while systemic vascular resistance (SVR) is normal or slightly increased (236). Diuretics lower exercise BP by SVR reduction with preservation of cardiac output (234). Calcium-antagonists and ACE-inhibitors reduce SVR and, during long-term treatment, cardiac output during exercise is usually unaffected (234).

Left ventricular function during exercise. All classes of beta-blockers and the calcium-antagonist verapamil impair left ventricular function, while cardiac contractility is better preserved with nifedipine and diltiazem. Other antihypertensive agents have absent or negligible effects on myocardial contractility (237).

Arrhythmias during exercise. Beta-blockers and non-selective calcium-antagonists like verapamil and diltiazem have mild anti-arrhythmic properties. 
Table 4. Change in resting and exercise blood pressure during chronic treatment ( $>4$ weeks) with antihypertensive agents in patients with essential hypertension

\begin{tabular}{|c|c|c|c|c|c|}
\hline & & Rest & & Exercise & \\
\hline & & SBP & DBP & SBP & DBP \\
\hline Non-selective beta-blockers & $(n=17)$ & $-11 \%(-7$ to -21$)$ & $-12 \%(-5$ to -20$)$ & $-13 \%(-5$ to -20$)$ & $-7 \%(+4$ to -19$)$ \\
\hline Beta-1 selective blockers & $(\mathrm{n}=16)$ & $-10 \%(-5$ to -20$)$ & $-12 \%(-4$ to -20$)$ & $-15 \%(-7$ to -24$)$ & $0 \%(+1$ to -19$)$ \\
\hline ACE-inhibitors & $(n=12)$ & $-13 \%(-6$ to -19$)$ & $-11 \%(-2$ to -19$)$ & $-8 \%(-5$ to -12$)$ & $-8 \%(-3$ to -13$)$ \\
\hline Calcium-antagonists & $(n=24)$ & $-12 \%(-1$ to -26$)$ & $-13 \%(-1$ to -29$)$ & $-8 \%(+4$ to -12$)$ & $-11 \%(-4$ to -20$)$ \\
\hline Diuretics & $(n=10)$ & $-14 \%(-8$ to -24$)$ & $-12 \%(-6$ to -19$)$ & $-8 \%(-5$ to -14$)$ & $-5 \%(-4$ to -14$)$ \\
\hline
\end{tabular}

Adapted from Van Baak (235). SBP, systolic blood pressure; DBP, diastolic blood pressure; $n$, number of studies. Mean percentage changes and range of studies are shown. 
Table 5. Change in maximal oxygen consumption and endurance performance after administration of antihypertensive agents

\begin{tabular}{lllll}
\hline & $\mathrm{VO}_{2 \max }$ & & \multicolumn{2}{l}{ Endurance time } \\
\hline Non-selective beta-blockers & $(\mathrm{n}=19)$ & $-10 \%(-1$ to -19$)$ & $(\mathrm{n}=10)$ & $-41 \%(-25$ to -55$)$ \\
Beta-1 selective blockers & $(\mathrm{n}=21)$ & $-6 \%(-2$ to -17$)$ & $(\mathrm{n}=10)$ & $-24 \%(-11$ to -39$)$ \\
ACE-inhibitors & $(\mathrm{n}=3)$ & $0 \%(+2$ to -2$)$ & $(\mathrm{n}=3)$ & $-8 \%(-3$ and -12$)$ \\
Calcium-antagonists & $(\mathrm{n}=13)$ & $-2 \%(+7$ to -8$)$ & $(\mathrm{n}=2)$ & $-11 \%(-7$ and -16$)$ \\
Diuretics & $(\mathrm{n}=7)$ & $-7 \%(-1$ to -17$)$ & $(\mathrm{n}=1)$ & $-29 \%$
\end{tabular}

Adapted from Van Baak (235). $\mathrm{VO}_{2 m a x}$, maximal oxygen consumption; Endurance time, time until exhaustion at a constant submaximal workload; $n$, number of studies; both studies in hypertensive and normotensive subjects included. Duration of studies with diuretics ranged from single dose to 7 days. Values are percentage changes from control. Mean and range of studies are shown.

Diuretics could induce hypokalemia and thus increase the frequency of premature ventricular contractions at rest and during exercise (238).

Exercise performance. Table 5 summarizes the effects of several classes of antihypertensive drugs on exercise performance. Beta-blockers have a more pronounced negative effect on both maximal aerobic exercise capacity and endurance performance than most other agents. However, in almost all studies a lower endurance exercise capacity with antihypertensive treatment has been reported (235).

Trainability. Very little is known about the influence of antihypertensive medication on trainability. Some studies have shown an attenuated conditioning response with beta-blocker therapy (i.e. a negative influence on the increase of $V_{2} O_{\text {max }}$ ) (239-241), although this is not supported by others (242, 243). Part of this inconsistency is possibly due to the fact that a training effect may become only apparent when the drug is withdrawn (244). A blockade of peripheral adaptations with training during beta-blockade has been reported (239). Beta-1 selective blockade may impair trainability to a lesser degree (245). Trainability is not impaired by calcium-antagonists like nifedipine (246) and diltiazem (247).

\subsubsection{Exercise and beta-blockers with vasodilating activity: a comparison with classical beta-blocker therapy}

Recently, beta-blockers with vasodilating activity have been developed (labetalol, dilevalol, carvedilol, nebivolol). Labetalol is a non-selective betablocker with additional (weak) alpha-1 adrenoceptor antagonist activity (248). Dilevalol, which is the RR-isomer of labetalol, combines non-selective beta-blockade with beta-2 adrenoceptor stimulation (248). Carvedilol can be characterized as a non-selective beta-blocker with an additional vasodilator component, possibly caused by alpha-1 adrenoceptor antagonist activity 
Table 6. Hemodynamic effects of chronic treatment with labetalol, dilevalol and carvedilol in hypertensive patients

\begin{tabular}{llll}
\hline & Labetalol & Dilevalol & Carvedilol \\
\hline Rest & & & \\
BP & $-17 \%$ & $-15 \%$ & $-14 \%$ \\
HR & $-16 \%$ & $-12 \%$ & $-10 \%$ \\
CO & $-3 \%$ & $-13 \%$ & $-12 \%$ \\
SV & $+16 \%$ & $+1 \%$ & $-3 \%$ \\
TPR & $-14 \%$ & $-10 \%$ & $-3 \%$ \\
Exercise & & & \\
BP & $-20 \%$ & $-10 \%$ & $-16 \%$ \\
HR & $-18 \%$ & $-25 \%$ & $-18 \%$ \\
CO & $-10 \%$ & $-11 \%$ & $-9 \%$ \\
SV & $+10 \%$ & $+8 \%$ & $+6 \%$ \\
TPR & $-11 \%$ & $+5 \%$ & $-5 \%$ \\
\hline
\end{tabular}

Based on studies 249-254. BP, mean arterial blood pressure; HR, heart rate; SV, stroke volume, CO, cardiac output; TPR, total peripheral resistance. Mean percentage changes are shown.

(248). Nebivolol is a selective beta-1 antagonist, which has an ancillary vasodilating property of unknown nature (199).

If beta-blockade and vasodilation are properly balanced, these multiple-action drugs could prove to be attractive in the treatment of physically active patients by achieving a similar BP reduction at rest and during exercise as classical beta-blockers, but in a more physiological way. This is by reducing total peripheral resistance with no or only a minor reduction in cardiac output. Possibly this would lead to no or a lesser impairment of exercise tolerance.

Hemodynamics. Table 6 summarizes studies on the hemodynamic effects of labetalol, dilevalol and carvedilol. A marked reduction in BP at rest is found with all agents, caused by a reduction in both cardiac output and total peripheral resistance. Resting heart rate is reduced to a lesser extent than usually seen during chronic treatment with selective and non-selective betablockers without ISA (approximately 20-25\%)(249). Compared to a reduction in cardiac output of $15-20 \%$ during conventional beta-blocker therapy, vasodilating beta-blockers reduce cardiac output less, especially labetalol. All agents reduce total peripheral resistance in contrast to the classical beta-blockers which are found to increase total peripheral resistance by $15-20 \%$ during long-term treatment (234).

During exercise, the beta- 1 blocking activity of the multiple-action drugs seem to become more pronounced, i.e. the reduction in heart rate. Exercise heart rate reduction during conventional beta-blockade is in the order of $20-25 \%$ (236). Exercise stroke volume is increased with labetalol, dilevalol and car- 
vedilol, as usually seen with classical beta-blocker therapy (236). Cardiac output reduction with the vasodilating beta-blockers $(-9$ to $-11 \%)$ is in the range found with classical beta-blockers $(-5$ to $-15 \%)(236)$. During exercise total peripheral resistance is decreased during labetalol treatment, whereas changes during dilevalol and carvedilol treatment are minor. Most studies found total peripheral resistance unchanged during selective or non-selective beta-blockade (246).

At present, no data are available on regional hemodynamics during exercise with vasodilating beta-blockers. When beta-blocker administration also leads to systemic effects, i.e. a reduction of exercise cardiac output, a reduction of skeletal muscle blood flow at submaximal workloads $\left(50-70 \% \mathrm{VO}_{2 \max }\right)$ has been found (255). Although a reduced skeletal muscle blood flow has been suggested to explain the marked impairment of endurance performance during beta-blockade (Table 5), it is probably not the sole mechanism. Oxygen uptake is on the average normal in the exercising muscles during beta-blockade because of an increased oxygen extraction (255).

Metabolism during exercise. Skeletal muscle metabolism during exercise relies on liver and muscle glycogenolysis for provision of energy substrates. Betaoxidation of free fatty acids (FFA) provides an alternative energy source, especially during prolonged submaximal exercise.

Although animal studies have shown that beta- 2 receptors located in the skeletal muscle are involved in the regulation of muscle glycogenolysis during prolonged exercise (256), human studies in general show that the rate of muscle glycogen utilization is unaffected by non-selective as well as beta-1 selective blockade $(257,258)$. Beta- 2 adrenergic stimulation may increase glucose output from the liver (259) and after beta- 2 selective blockade lower blood glucose levels were found at the end of a progressive maximal exercise test (260). Blockade of liver nerve activity, however, had no effect on hepatic glucose output during exercise (261). Whether liver glycogenolysis or gluconeogenesis is impaired by beta-blockers is at the present not known and doubted by some investigators (262). In general, plasma glucose levels during exercise are unaffected by beta-blockade (236).

Lipolysis, i.e. the breakdown of triacylglycerols into glycerol and FFA, in adipose tissue in vivo, is regulated by adrenergic mechanisms at rest and during exercise. Alpha-adrenergic inhibitory effects modulate lipolysis at rest, whereas beta-adrenergic stimulatory effects modulate lipolysis during exercise (263). During exercise, reductions in plasma glycerol and FFA were found ranging from $0-50 \%$ after beta-blockade (236). During recovery from exhaustive exercise, however, levels were consistently found to be lower (264, 265). This decrease tends to be more pronounced after non-selective than after beta- 1 selective blockade (236). Because the uptake of FFA by the active skeletal muscles depends on the plasma concentration, it could be seriously diminished under beta-blockade (255). When lipolysis is attenuated, the reduced availability of FFA during prolonged exercise might cause a shift 
from fat to carbohydrate combustion, leading to a more rapid depletion of the limited carbohydrate stores in the body. This shift is suggested by studies showing a higher respiratory exchange ratio during exercise after beta-blockade $(266,267)$.

On average, a slight reduction of plasma lactate with beta-blockade is found during submaximal and maximal exercise (236). Consistently, increased plasma potassium levels have been found during exercise with beta- 1 selective and non-selective beta-blockade (236), probably due to a reduced reuptake of potassium by inactive skeletal muscles (268).

At present, limited data on the effect of beta-blockers with vasodilating properties on metabolism during exercise are available. During prolonged treatment with labetalol (251), a significant reduction in arterial blood lactate during steady-state submaximal exercise was found. The metabolic effects of treatment with nebivolol, atenolol and placebo have been compared during and after endurance exercise in healthy volunteers (269). During recovery of endurance exercise, plasma FFA and glycerol concentrations were reduced during atenolol and nebivolol treatment as compared to placebo, although these reductions tended to be more pronounced during atenolol than during nebivolol treatment. Lactate and glucose concentrations during exercise did not differ between the three conditions. Plasma potassium concentrations during endurance exercise were significantly higher during atenolol treatment than during nebivolol and placebo treatment.

Exercise performance. One of the most noted side-effects during classical beta-blocker therapy, especially in physically active patients, is exercise-related fatigue. These complaints have been objectivated as a reduced aerobic exercise performance capacity (236). Usually a reduction in maximal aerobic power output and maximal oxygen consumption between 5 and $10 \%$ is found (235) (Table 5). Probably, the hemodynamic effects of beta-blockers play a major role in this reduction since maximal heart rate and maximal cardiac output are reduced and thus oxygen transport capacity. A positive correlation between the reduction of exercise heart rate (and thus dose of the beta-blocker) and the reduction of maximal oxygen consumption has been noted (235). Furthermore, it has been suggested that a maximal heart rate reduction below $15-20 \%$ does not significantly reduce maximal exercise capacity (270). Few studies have investigated maximal work capacity during treatment with vasodilating beta-blockers. $\mathrm{VO}_{2 \max }$ was significantly reduced $(-6 \%)$ during labetalol treatment for 2 weeks (250) with a concomitant decrease in maximal heart rate of $21 \%$ and maximal cardiac output of $9 \%$. Labetalol did not significantly affect $(-6 \%)$ the time to exhaustion on a progressive maximal cycle ergometer test, but $\mathrm{VO}_{2 \max }$ was not measured (271). Treatment with dilevalol significantly reduced $\mathrm{VO}_{2 \max }(-8 \%)(252)$, while maximal heart rate $(-28 \%)$ and maximal cardiac output $(-19 \%)$ were also reduced. Nebivolol had no effect on $\mathrm{VO}_{2 \max }(-1 \%)$, whereas maximal heart rate decreased by $14 \%$ (269). In an uncontrolled study in healthy volunteers (272) the effect of a 
2-week treatment with carvedilol was investigated. Maximal oxygen consumption was unchanged and maximal heart rate declined by $11 \%$.

In a number of studies, the influence of beta-blockade on submaximal endurance performance has been investigated. Endurance exercise is the performance of work at a constant submaximal intensity until exhaustion. It reflects more closely normal daily sporting activity and can thus be of greater importance in clinical practice than maximal work capacity.

Endurance exercise time was found to be greatly reduced in all studies under beta-blockade, ranging from -11 to $-55 \%$ (Table 5) (235). These negative effects on endurance performance tend to be more pronounced during nonselective than during beta- 1 selective blockade. The reduction in submaximal endurance performance is not related to the reduction in exercise heart rate (235). In contrast to classical beta-adrenoceptor drugs, nebivolol did not decrease endurance time significantly $(-6 \%)$ (269). Studies on the effect of other vasodilating beta-blockers on endurance performance have not been reported.

How beta-blockade impairs endurance performance is not clear. Although active skeletal muscle blood flow is probably reduced during submaximal steady-state exercise, oxygen delivery to the muscles is preserved by increased oxygen extraction from the blood (255). During beta-blockade a reduced extramuscular lipolysis is found (236) combined with a blockade of muscle lipolysis (257). Although the significant increase in respiratory exchange ratio in some studies is in line with the expectation that there is a shift from fat to carbohydrate combustion during endurance exercise, muscle glycogenolysis occurs at a comparable rate (257). Some investigators suggest that this apparent inability to increase the rate of glycogenolysis in the muscle is the cause of the reduced exercise capacity (257). Furthermore, a drop in plasma glucose under beta-blockade is not a consistent finding (236). Since plasma lactate is found to be slightly reduced (236), lactate accumulation in the working muscle has to be considered. In hypertensive subjects, slightly higher muscle lactate concentrations have been found after treatment with a non-selective beta-blocker, alprenolol (273). These concentrations are, however, far below those seen after maximal exercise and in healthy subjects muscle lactate accumulation was not seen up to nearly maximal exercise (262). Changes in potassium homeostasis as seen under beta-blockade could potentially decrease endurance performance by a reduction of muscle membrane potential, resulting in impaired excitability and thus contractibility (274). Interestingly, nebivolol, which did not impair endurance performance, showed similar metabolic effects as the classical beta-blockers, except for potassium concentrations which were unchanged (269). 


\subsection{Aims of this thesis}

Physical inactivity and poor fitness can be regarded as important risk factors of hypertension and cardiovascular disease (section 1.1). Sedentary subjects, either normotensive or hypertensive, may benefit from regular exercise by the favorable influence on various risk factors for cardiovascular diseases, such as a lowering of blood pressure (section 1.1 and 1.2). It is recognized that the reduction in resting blood pressure with endurance training is rather small, especially in normotensive subjects. Ambulatory blood pressure monitoring may provide a better estimate of the real pressure load on the heart. To date, few studies have investigated the effect of endurance training on blood pressure during daily activity and at night. In chapter 2 , the effect of a moderate endurance training program on basal, exercise and ambulatory blood pressure was studied in a sedentary male population with normal or slightly elevated resting blood pressure.

It is known that mortality and morbidity from hypertension are better correlated with systolic than with diastolic blood pressure, indicating an important role of pulsatile stress. Because vessel wall properties (compliance and distensibility) of large arteries are important determinants of pulsatile stress it is of interest to know whether regular exercise can improve these determinants. To answer this question, the vessel wall properties of three large arteries (the common carotid, brachial and common femoral artery) of well-trained subjects and sedentary controls were compared, using an original ultrasound echo-tracking system based on Doppler shift (chapter 3 ). The vessel wall properties of these same three arteries were studied after sedentary subjects were trained for 6 weeks. Because we speculated that a potential improvement of the vessel wall properties is probably rather a reflection of functional intrinsic modification than structural change, some neurohumoral parameters were studied as well (chapter 4).

On the one hand, the blood pressure response during acute exercise testing is more frequently used as a diagnostic tool in the detection of true hypertension and in normotensives an exaggerated response is regarded as a predictor of future hypertension (section 1.5). On the other hand, it is noted by some investigators that hypertensives and normotensives show similar blood pressure responses to exercise, that there is considerable interindividual variation in response and that reference values of exercise blood pressure are remarkably scarce, especially in women. Therefore, factors that could explain the variation in blood pressure response to exercise were studied in a large population sample with normal, borderline elevated, and elevated resting casual blood pressure. In chapter 5.1, this was done for men, and in chapter 5.2 for women. Furthermore, reference values were established.

Many patients with hypertension are physically active and need pharmacological treatment to control blood pressure. In the selection of drug therapy, several factors should be considered. It is preferable to choose a medication that does not interfere with exercise performance. Especially beta- 
blockers have been shown to considerably reduce endurance capacity, possibly by a reduction of skeletal muscle flow during exercise and/or by an impairment of lipolysis (section 1.6). During endurance exercise, reductions in plasma glycerol and free fatty acids may or may not be seen. During recovery, reduced levels are a more consistent finding. Because these lower levels could be the consequence of an impaired performance rather than the cause, we tried to differentiate this in chapter 6.

Beta-blockers with vasodilating properties are currently increasingly available and could provide an attractive alternative in the treatment of physically active patients with hypertension because skeletal muscle blood flow during exercise could be unaltered or even enhanced, or because lipolysis is not or less impaired. At present, data on the effect of these drugs on endurance performance are scarce. In chapter 7, carvedilol a new non-selective betablocker with vasodilating properties was studied during exercise in hypertensive subjects. Special interest was given to the effects on endurance performance, metabolic parameters, and neurohumoral factors during exercise.

This thesis contains seven papers which have been originally written as separate manuscripts and are presented in chapter 2 to 7.

\section{REFERENCES}

1. Stokes J III, Kannel WB, Wolf PA, Cupples LA, D'Agostino RB. The relative importance of selected risk factors for various manifestations of cardiovascular disease among men and women from 35-64 years old: 30 years of follow-up in the Framingham study. Circulation 75 (suppl 5): 64-73, 1987.

2. Kannel WB, Neaton JD, Wentworth Det al. Overall and coronary heart disease mortality rates in relation to major risk factors in 325, 348 men screened for the MRFIT. Am Heart J 4: 825-836, 1986.

3. Shaper AG, Pocock SJ, Walker M et al. British regional heart study: cardiovascular risk factors in middle-aged men in 24 towns. Br Med J 282: 179-186, 1981.

4. Shaper AG, Pocock SJ, Walker M et al. Risk factors for ischemic heart disease: the prospective phase of the British Regional Heart Study. J Epidemiol Community Health 39: 197-209, 1985.

5. Shaper AG, Pocock SJ. Risk factors for ischemic heart disease in British men. Br Heart J 57: 11-16, 1987.

6. Gorton T, Castelli WP, Hjortland MC, Kannel WB, Danber TR. High density lipoprotein as a protective factor against coronary heart disease: the Framingham study. Am J Med 62: 707-714, 1977.

7. Zampogna A, Luria MH, Manubens J, Luria MA. Relationship between lipids and occlusive coronary artery disease. Arch Intern Med 140: 1067-1069, 1980.

8. Powell KE, Thompson PD, Caspersen CJ, Kendrick JS. Physical activity and the incidence of coronary heart disease. Ann Rev Public Health 8: 253-287, 1987.

9. Morris JN, Heady JA, Raffle PAB, Roberts CG, Parks JW. Coronary heart disease and physical activity of work. Lancet ii: 1053-1057, 1953.

10. Morris JN, Heady JA, Raffle PAB, Roberts CG, Parks JW. Coronary heart disease and physical activity of work. Lancet ii: 1111-1120. 1953. 
11. Morris JN, Kogan A, Patison DC, Gardner MJ, Raffle PAB. Incidence and prediction of ischemic heart disease in London busmen. Lancet ii: 5535-5539, 1966.

12. Cassel J, Heyden S, Bartel AC et al. Occupation and physical activity and coronary heart disease. Arch Intern Med 128: 920-928, 1971.

13. Brunner D, Manelis G, Modan M, Levin S. Physical activity at work and the incidence of myocardial infarction, angina pectoris and death due to ischemic heart disease: an epidemiological study in Israeli collective settlements (Kibbutzim). J Chron Dis 27: 217-233, 1974.

14. Paffenbarger RS, Hale WE. Work activity and coronary heart mortality. New Engl J Med 292: 545-550, 1975.

15. Brand RJ, Paffenbarger RS, Sholtz RI, Kampert JB. Work activity and fatal heart attack studied by multiple logistic risk analysis. Am J Epidemiol. 110: 52-62, 1979.

16. Kannel WB, Sorlie P. Some health benefits of physical activity. The Framingham study. Arch Intern Med 139: 857-861, 1979.

17. Kannel WB, Belanger A, D'Agostino R, Israel I. Physical activity and physical demand on the job and risk of cardiovascular disease and death: the Framingham study. Am Heart J 112: 820-825, 1986.

18. Paffenbarger RS, Hyde RT, Wing AL, Steinmets $\mathrm{CH}$. A natural history of athleticism and cardiovascular health. JAMA 252: 491-495, 1984.

19. Morris JN, Everitt MG, Pollard R, Chave SPW, Semmence AM. Vigorous exercise in leisure time: protection against coronary heart disease. Lancet ii: 1207-1210, 1980.

20. Morris JN, Clayton DG, Everitt MG, Semmence AM, Burgess EH. Exercise in leisure time: coronary attack and death rates. Br Heart J 63: 325-334, 1990.

21. Siscovick DS, Weiss NS, Hallstrom AP, Inui TS, Peterson DR. Physical activity and primary cardiac arrest. JAMA 248: 3113-3117, 1982.

22. Siscovick DS, Weiss NS, Fletcher RH, Lasky T. The incidence of primary cardiac arrest during vigorous exercise. New Engl J Med 311: 874-877, 1984.

23. Sobolski J, Kornitzer M, De Backer $G$ et al. Protection against ischemic heart disease in the Belgian Physical Fitness Study: physical fitness rather than physical activity? Am J Epidemiol 125: 601-610, 1987.

24. Ekelund L-G, Haskell WL, Johnson JL et al. Physical fitness as a predictor of cardiovascular mortality in asymptomatic North American men: the lipid research clinics mortality follow-up study. New Engl J Med 319: 1379-1384, 1988.

25. Bouchard C. Genetics of aerobic power and capacity. In: Malina RM, Bouchard C, eds. Sport and human genetics. Human Kinetics: Champaign, III, USA, pp 59-88, 1986.

26. Wilhelmsen L, Bjure J, Ekstrom-Jodal B et al. Nine years' follow-up of a maximal exercise test in a random population sample of middle-aged men. Cardiology 68 (suppl 2): 1-8, 1981.

27. De Backer G, Kornitzer M, Sobolski J et al. Primary prevention of coronary heart disease by physical activity. In: Fagard RH, Bekaert IE, eds. Sports cardiology. Martinus Nijhoff Publishers: Dordrecht, The Netherlands, pp 145-150, 1986.

28. Blair SN, Kohl HW, Paffenbarger RS et al. Physical fitness and all-cause mortality: a prospective study of healthy men and women. JAMA 262: 2395-2401, 1989.

29. Oberman A. Exercise and the primary prevention of cardiovascular disease. Am J Cardiol 55: 10D-20D, 1985.

30. Cooper KH, Pollock ML, Martin RPet al. Physical fitness levels vs. selected coronary risk factors. JAMA 236: 166-169, 1976.

31. Gibbons LW, Blair SN, Cooper KH, Smith M. Association between coronary heart disease risk factors and physical fitness in healthy adult women. Circulation 67: 977-983, 1983.

32. Panico S, Celentano E, Krogh V et al. Physical activity and its relationship to blood pressure in school children. J. Chron Dis 40: 925-930, 1987. 
33. Cederholm ], Wibell $\mathrm{L}$. The relationship of blood pressure to blood glucose and physical leisure time activity. Acta Med Scand 219: 37-46, 1986.

34. Folsom AR, Caspersen CI, Taylor HL et al. Leisure time physical activity and its relationship to coronary risk factors in a population-based sample: the Minnesota heart survey. Am J Epidemiol 121: 570-579, 1985.

35. Dannenberg AL, Keller JB, Wilson PWF et al. Leisure time physical activity in the Framingham offspring study: description, seasonal variation, and risk factor correlates. Am J Epidemiol 129: 76-88, 1989.

36. Caspersen CJ, Bloemberg BP, Saris WH, Meritt RK, Kromhout D. The prevalence of selected physical activities and their relation with coronary heart disease risk factors in elderly men: the Zutphen study 1985. Am J Epidemiol 133: 1078-1092, 1991.

37. Bovens AM, Van Baak MA, Vrencken JG et al. Physical activity, fitness, and selected risk factors for CHD in active men and women. Med Sci Sports Exerc 25: 572-576, 1993.

38. Ballor DL, Keesey RE. A meta-analysis of the factors affecting exercise-induced changes in body mass, fat mass and fat-free mass in males and females. Int J Obesity 5: 717-726, 1991.

39. Manson JE, Nathan DM, Krolewski AS et al. A prospective study of exercise and incidence of diabetes among US male physicians. JAMA 268: 63-67, 1992.

40. Kemmer FW, Berger M. Exercise and diabetes mellitus: physical activity as part of daily life and its role in the treatment of diabetic patients. Int J Sports Med 4: 77-88, 1983.

41. Tipton CM. Exercise, training and hypertension: an update. Exerc Sports Sci Revs 19: 447-505, 1991.

42. Stein RA, Michielli DW, Glantz MD et al. Effects of different exercise training intensities on lipoprotein cholesterol fractions in healthy middle-aged men. Am Heart J 119:277-283, 1990.

43. Marti B, Suter E, Riesen WF et al. Effects of long-term, self-monitored exercise on the serum lipoprotein and apolipoprotein profile in middle-aged men. Atherosclerosis 81: 19-31, 1990.

44. Hardman AE, Hudson A, Jones PR, Norgan NG. Brisk walking and plasma high density lipoprotein cholesterol concentration in previously sedentary women. Br Med J 299: 1204-1205, 1989.

45. Sasaki J, Urata $H$, Tanabe $Y$ et al. Mild exercise therapy increases serum high density lipoprotein ${ }_{2}$ cholesterol levels in patients with essential hypertension. Am J Med Sci 297: 220-223, 1989.

46. Heath GW, Gavin JR, Hinderliter JM et al. Effects of exercise and lack of exercise on glucose tolerance and insulin sensitivity. J Appl Physiol 59: 154-159, 1985.

47. Oshida $Y$, Yamanouchi K, Hayamizu S, Sato Y. Long-term mild jogging increases insulin action despite no influence on body mass index or $\mathrm{VO}_{2 \max } \mathrm{J}$ Appl Physiol 66: 2206-2210), 1989.

48. Stokes J, Kannel WB, Wolf PA, D'Agostino RB, Cupples LA. Blood pressure as a risk factor for cardiovascular disease: the Framingham study - 30 years of follow-up. Hypertension 13 (suppl 1): 13-18, 1989.

49. The fifth report of the joint national committee on detection, evaluation and treatment of high blood pressure (JNC V). Arch Intern Med 153: 154-208, 1993.

50. Weinberger MH, Miller JZ, Luft FC et al. Definitions and characteristics of sodium sensitivity and blood pressure resistance. Hypertension 8 (suppl 2): 127-134, 1986.

51. Chiang BN, Perlman LV, Epstein FH. Overweight and hypertension. Circulation 39: 403-415, 1969.

52. Puddely IB, Beilin LJ, Vandongen R et al. Evidence for a direct effect of alcohol consumption on blood pressure in normotensive men. Hypertension 1: 707-713, 1985. 
53. Paffenbarger RS, Wing AL, Hyde RT, Jung DL. Physical activity and incidence of hypertension in college alumni. Am J Epidemiol 117: 245-247, 1983.

54. Blair SN, Goodyear NN, Gibbons LW, Cooper KH. Physical fitness and incidence of hypertension in healthy normotensive men and women. JAMA 252: 487-490, 1984.

55. Kasch FW, Boyer JL, Van Camp SP et al. The effect of physical activity and inactivity on aerobic power in older men (a longitudinal study). Phys Sports Med 18: 73-83, 1990.

56. Tuomilehto J, Marti B, Salonen JT et al. Leisure time physical activity is inversely related to risk factors for coronary heart disease in middle-aged Finnish men. Eur Heart J 8: 1047-1055, 1987.

57. Fraser GE, Phillips RL, Harris R. Physical fitness and blood pressure in children. Circulation 67: 405-412, 1983.

58. Gordon NF, Scott CB, Wilkinson WJ, Duncan JJ, Blair SN. Exercise and mild essential hypertension: recommendations for adults. Sports Med 10: 390-404, 1990.

59. Kaufman FL, Hughson RL, Schaman JP. Effect of exercise on recovery blood pressure in normotensive and hypertensive subjects. Med Sci Sports Exerc 19: 17-20, 1987.

60. Hagberg JM, Montain SJ, Martin WH. Blood pressure and hemodynamic responses after exercise in older hypertensives. J Appl Physiol 63: 270-276, 1987.

61. Paulev P-E, Jordal R, Kristensen O, Ladefoged J. Therapeutic effect of exercise on hypertension. Eur J Appl Physiol 53: 180-185, 1984.

62. Pescatello LS, Fargo AE, Leach CN, Scherzer HH. Short-term effect of dynamic exercise on arterial blood pressure. Circulation 83: 1557-1561, 1991.

63. Fagard R. Habitual physical activity, training, and blood pressure in normo- and hypertension. Int J Sports Med 6: 57-67, 1985.

64. Seals DR, Hagberg JM. The effect of exercise training on human hypertension: a review. Med Sci Sports Exerc 16: 207-215, 1984.

65. Hagberg JM. Exercise, fitness and hypertension. In: Bouchard et al, eds. Exercise, fitness, and health: a consensus of current knowledge. Human Kinetic Books: Campaign, Ill, USA, pp 455-466, 1990.

66. Fagard R. Physical exercise in the management of hypertension: a consensus statement of the World Hypertension League. J Hypertension 9: 283-287, 1991.

67. Fagard RH. Physical fitness and blood pressure. J Hypertens 11 (suppl 5): 47-52, 1993.

68. Román O, Camuzzi AL, Villalón E, Klenner C. Physical training program in arterial hypertension: a long-term prospective follow-up. Cardiology 67: 230-243, 1981.

69. Hagberg JM, Montain SJ, Martin WH, Ehsani AA. Effect of exercise training in 60 to 69 year old persons with essential hypertension. Am J Cardiol 64: 348-353, 1989.

70. Tashiro E, Miura S, Koga M et al. Cross-over comparison between the depressor effects of low and high work-rate exercise in mild hypertension. Clin Exp Pharmacol Phys 20: 689-696, 1993.

71. Jennings $G$, Nelson $L$, Nestel $P$ et al. The effects of changes in physical activity on major cardiovascular risk factors, hemodynamics, sympathetic function, and glucose utilization in man: a controlled study of four levels of activity. Circulation 73: 30-40, 1986.

72. Nelson L, Esler MD, Jennings GL, Korner PI. Effect of changing levels of physical activity on blood pressure and hemodynamics in essential hypertension. Lancet 2: 473-476, 1986.

73. Meredith IT, Jennings GL, Esler MD et al. Time course of the antihypertensive and autonomic effects of regular endurance exercise in human subjects. J Hypertension 8: 859-866, 1990.

74. Urata $H$, Tanabe $Y$, Kiyonaga $A$ et al. Antihypertensive and volume-depleting effects of mild exercise on essential hypertension. Hypertension 9: 245-252, 1987.

75. Jennings GL, Deakin G, Dewar $E$ et al. Exercise, cardiovascular disease and blood pressure. Clin Exp Hypertens A11: 1035-1052, 1989. 
76. Jennnings $G$, Nelson L, Dewar E et al. Antihypertensive and hemodynamic effects of one year's regular exercise. J Hypertension 4 (suppl 6): 659-661, 1986.

77. Conway J, Coats A. Value of ambulatory blood pressure monitoring in clinical pharmacology. J Hypertension 7 (suppl 3): 29-32, 1989.

78. Floras JA, Jones JV, Hassan MO et al. Cuff and ambulatory blood pressure in subjects with essential hypertension. Lancet ii: 107-109, 1981.

79. Conway J, Johnston J, Coods A. The use of ambulatory blood pressure monitoring to improve the accuracy and reduce the numbers of subjects in clinical trials of antihypertensive agents. J Hypertension 6: 111-116, 1988.

80. Pickering TG, Devereux RB. Ambulatory monitoring of blood pressure as a predictor of cardiovascular risk. Am Heart J 114: 925-928, 1987.

81. Marolf AP, Hany S, Battig B, Vetter W. Comparison of casual, ambulatory and self-determined blood pressure measurement. Nephron 47 (suppl 1): 142-145, 1987.

82. Millar-Craig MW, Bishop CN, Raferty EB. Circadian variation of blood pressure. Lancet i: 795-797, 1978.

83. Van Hoof R, Hespel P, Fagard R et al. Effect of endurance exercise training on blood pressure at rest, during exercise and during 24 hours in sedentary men. Am J Cardiol 63: 945-949, 1989.

84. Gilders RM, Voner C, Dudley GA. Endurance training and blood pressure in normotensive and hypertensive adults. Med Sci Sports Exerc 21: 629-636, 1989.

85. Somers VK, Conway J, Johnston J, Sleight P. Effects of endurance training on baroreflex sensitivity and blood pressure in borderline hypertension. Lancet ii: 1363-1368, 1991.

86. Seals DR, Reiling MJ. Effect of regular exercise on 24-hour arterial pressure in older hypertensive humans. Hypertension 18: 583-592, 1991.

87. Blumenthal JA, Siegel WC, Appelbaum M. Failure of exercise to reduce blood pressure in patients with mild hypertension: results of a randomized controlled trial. JAMA 266: 2098-2104, 1991.

88. Marceau M, Kouamé N, Lacourcière $Y$, Cléroux J. Effects of different training intensities on 24-hour blood pressure in hypertensive subjects. Circulation 88: 2803-2811, 1993.

89. Cléroux J, Péronnet F, De Champlain J. Effects of exercise training on plasma catecholamines and blood pressure in labile hypertensive subjects. Eur J Appl Physiol 56: 550-554, 1987.

90. Meredith IT, Friberg P, Jennings GL et al. Exercise training lowers resting renal but not cardiac sympathetic activity in humans. Hypertension 18: 575-582, 1991.

91. Clausen JP, Klausen K, Rasmussen B, Trap-Jensen J. Central and peripheral circulatory changes after training of the arms or legs. Am J Physiol 225: 675-682, 1973.

92. Kilbom A, Hartley LH, Saltin B et al. Physical training in sedentary middle-aged and older men. Scand J Clin Lab Invest 24: 315-322, 1969.

93. Hagberg JM, Goldring D, Ehsani AA et al. Effect of exercise training on the blood pressure and hemodynamic features of hypertensive adolescents. Am J Cardiol 52: 763-768, 1983.

94. Kinoshita A, Urata $H$, Tanabe $Y$ et al. What types of hypertensives respond better to mild exercise therapy. J Hypertension 6 (suppl 4): 631-633, 1988.

95. Nomura G, Kumagai E, Midorikhwa K et al. Physical training in essential hypertension: alone and in combination with dietary salt restriction. J Cardiac Rehab 4: 469-475, 1984.

96. Scheuer J, Tipton CM. Cardiovascular adaptations to physical training. Ann Rev Physiol 39: 221-251, 1977.

97. Julius S. Hemodynamic and neurohumoral evidence of multifaceted pathophysiology in human hypertension. J Cardiovasc Pharmacol 15 (suppl 5): 53-58, 1990.

98. Hartley LH, Mason JW, Hogan RP et al. Multiple hormonal responses to prolonged exercise in relation to physical training. J Appl Physiol 33: 607-610, 1972. 
99. Pickering TG. Pathophysiology of systemic hypertension. Am J Cardiol 58: 12D-15D, 1986.

100. Andersen P, Hendriksson J. Capillary supply of the quadriceps femoris muscle of man: adaptive response to exercise. J Physiol 270: 677-690, 1977.

101. Hermansen L, Wachtlova M. Capillary density of skeletal muscle in well trained and untrained men. J Appl Physiol 30: 860-863, 1971.

102. Brodal P, Ingjer F, Hermansen L. Capillary supply of skeletal muscle fibers in untrained and endurance trained men. Am J Physiol 232: H705-H712, 1977.

103. Martin WH, Montgomery J, Snell PG et al. Maximal vascular conductance and exercise capacity in middle-aged human subjects before and after intense swim training. J Am Coll Cardiol 3: 569-573, 1984.

104. Snell PG, Martin WH, Buckley JC, Blomqvist CG. Maximal vascular leg conductance in trained and untrained men. J Appl Physiol 62: 606-610, 1987.

105. Duncan JJ, Farr JE, Upton SJ et al. The effect of aerobic exercise on plasma catecholamine and blood pressure in patients with mild essential hypertension. JAMA 254: 2609-2614, 1985.

106. Kiyonaga A, Arakawa $\mathrm{K}$, Tanaka $\mathrm{H}$, Shindo $\mathrm{M}$. Blood pressure and humoral response to aerobic exercise. Hypertension 7: 125-131, 1985.

107. Jo $\mathrm{Y}$, Arita $\mathrm{M}, \mathrm{Baba} \mathrm{A}$ et al. Blood pressure and sympathetic activity following responses to aerobic exercise in patients with essential hypertension. Clin Exp Hypertens Theory Pract A11 (suppl 1): 411-417, 1989.

108. Esler M. Assessment of sympathetic nervous function in humans from noradrenaline plasma kinetics. Clin Sci 62: 247-250, 1982.

109. Floras JS, Sinkey CA, Aylward PE et al. Postexercise hypotension and sympathoinhibition in borderline hypertensive men. Hypertension 14: 28-35, 1989.

110. Grassi G, Seravalle G, Calhoun D, Bolla GB, Mancia G. Physical exercise in essential hypertension. Chest 101 (suppl): 312-314, 1992.

111. LeBlanc J, Boulay $M$, Dulac $S$ et al. Metabolic and cardiovascular responses to norepinephrine in trained and non-trained human subjects. J Appl Physiol 42: 166-173, 1977.

112. Edwards JG, Tipton $\mathrm{CH}$, Matthes RD. Influence of exercise training on reactivity and contractility of arterial strips from hypertensive rats. J Appl Physiol 58: 1683-1688, 1985.

113. Rogers PJ, Miller TD, Bauer BA et al. Exercise training and responsiveness of isolated coronary arteries. J Appl Physiol 71: 2346-2351, 1991.

114. Morell EM, Cameron OG, Kandarian SC et al. Aerobic physical training and alterations in pressor response during norepinephrine infusion: a controlled single-subject experiment. Int J Sports Med 11: 53-57, 1990.

115. Ohman EM, Butler J, Kelly J et al. Beta-adrenoceptor adaptation to endurance training. J Cardiovasc Pharmacol 10: 728-731, 1987.

116. Williams RS, Eden RS, Moll ME et al. Autonomic mechanisms of training bradycardia: beta-adrenergic receptors in humans. J Appl Physiol 51: 1232-1237, 1981.

117. Lehmann M, Dickhuth HH, Schmid P et al. Plasma catecholamines, beta-adrenergic receptors, and isoproterenol sensitivity in endurance trained and non-endurance trained volunteers. Eur J Appl Physiol 53: 362-369, 1984.

118. Martin WH, Coggan AR, Spina RJ, Saffitz JE. Effects of fiber type and training on beta-adrenoceptor density in human skeletal muscle. Am J Physiol 257: E736-E742, 1989.

119. Buckenmeyer PJ, Goldfarb AH, Partilla JS et al. Endurance training, not acute exercise, differentially alters beta-receptors and cyclase in skeletal fiber types. Am J Physiol 258: E71-E77, 1990. 
120. M'Buyamba-Kabangu JR, Fagard R, Lijnen P, Amery A. The relationship between resting plasma renin activity and physical fitness in normal subjects. Eur J Appl Physiol 53: 304-307, 1985.

121. Fagard R, Grauwels R, Groeseneken D et al. Plasma levels of renin, angiotensin II and 6-keto-prostaglandin $F_{1 \alpha}$ in endurance athletes. J Appl Physiol 59: 947-952, 1985.

122. Geyssant A, Geelen $G$, Denis $C H$ et al. Plasma vasopressin, renin activity and aldosterone: effect of exercise and training. Eur J Appl Physiol 46: 21-30, 1981.

123. Groeseneken D, Fagard R, Lijnen P et al. Plasma angiotensin II and 6-keto-PGF1 $\alpha$ in runners and non-athletes. Med Sci Sports Exerc 16: 157, 1984.

124. Kosunen $\mathrm{K}$, Pakarinen A, Kuoppasalmi $\mathrm{K}$ et al. Cardiovascular function and the reninangiotensin-aldosterone system in long-distance runners during various training periods. Scand J Clin Lab Invest 40: 429-435, 1980.

125. Melin B, Eclache JP, Geelen G et al. Plasma AVP, neurophysin, renin activity and aldosterone during submaximal exercise performed until exhaustion in trained and untrained men. Eur J Appl Physiol 44: 141-151, 1980.

126. Convertino VA, Keil LC, Greenleaf JE. Plasma volume, renin and vasopressin responses to graded exercise after training. J Appl Physiol 54: 508-514, 1983.

127. Arakawa K. Antihypertensive mechanism of exercise. J Hypertension 11: 223-229, 1993.

128. Nakamura $M$, Inagami $T$. Atrial natriuretic factor inhibits norepinephrine release evoked by sympathetic nerve stimulation in isolated perfused rat mesenteric arteries. Eur J Pharmacol 123: 459-461, 1986.

129. Cuneo RC, Espiner EA, Nicholls MG et al. Renal, hemodynamic and hormonal responses to atrial natriuretic peptide in normal men and effect of sodium intake. J Clin Endocrinol Metab 63: 946-953, 1986.

130. Winquist RJ, Faison EP, Nutt RF. Vasodilator profile of synthetic atrial natriuretic factor. Eur J Pharmacol 102: 169-173, 1984.

131. Leckie B. How the heart rules the kidneys. Nature 326: 644-645, 1987.

132. Convertino VA, Brock PJ, Keil LC et al. Exercise training induced hypervolemia: role of plasma albumin, renin and vasopressin. J Appl Physiol 48: 665-669, 1980.

133. Freund BJ, Claybaugh JR, Dice MS, Hashiro GM. Hormonal and vascular fluid responses to maximal exercise in trained and untrained males. J Appl Physiol 63: 669-675, 1987.

134. Vollmer-Larsen B, Vollmer-Larsen A, Graff Larsen O et al. Atrial natriuretic factor during, exercise in male endurance athletes: effect of training. Clin Physiol 9: 449-465, 1989.

135. Ibanez J, Gauquelin G, Desplanches D et al. Atrial natriuretic peptide response to endurance physical training in the rat. Eur J Appl Physiol 60: 265-270, 1990.

136. Taylor MA, Ragsdale NV, Ayers CR, Gear AR. Atrial natriuretic factor in essential hypertension. Life Sci 44: 603-610, 1989.

137. Hedner T, Hartford M, Caidahl $\mathrm{K}$ et al. Atrial natriuretic peptide (ANP) in relation to blood pressure: a study in middle-aged men with normal and elevated blood pressure. J Intern Med 225: 229-235, 1989.

138. Kinoshita $A$, Koga $M$, Matsusaki $M$ et al. Changes of dopamine and atrial natriuretic factor by mild exercise therapy for hypertensives. Clin Exp Hypertens A13: 1275-1290, 1991.

139. Zambraski EJ, Dunn MJ. Renal prostaglandin E1 and F2 $\alpha$ secretion and excretion in exercising conscious dogs. Prostagland Med 1: 489-497, 1978.

140. Hedqvist P. Studies on the effect of prostaglandins E1 and E2 on the sympathetic neuromuscular transmission in some animal tissues. Acta Physiol Scand suppl 345: 1-40, 1970.

141. De Fronzo RA. The effect of insulin on renal sodium metabolism. Diabetologia 21: 165-171, 1981. 
142. Basarab A, Silva P, Landsberg B. Effect of catecholamines on tubular function in the isolated perfused rat kidney. J Clin Invest 64: 850-857, 1979.

143. Terjung RL. Endocrine system. Straus RH, ed. Sports medicine and physiology. WB Saunders: Philadelphia, USA, pp 147-165, 1979.

144. Fournier AM, Gadia MT, Kubrusly DB et al. Blood pressure, insulin and glycemia in non-diabetic subjects. Am J Med 80: 861-864, 1986.

145. Björntorp P. Effects of physical training on blood pressure in hypertension. Eur Heark J 8 (suppl B): 71-76, 1987.

146. Delp MD, McAllister RM, Laughlin MH. Exercise training alters endothelium-dependent vasoreactivity of rat abdominal aorta. J Appl Physiol 75: 1354-1363, 1993.

147. Wang J, Wolin MS, Hintze TH. Chronic exercise enhances endothelium-mediated dilation of epicardial coronary artery in conscious dogs. Circ Res 73: 829-838, 1993.

148. Devereux RB. Does increased blood pressure cause left ventricular hypertrophy or vice versa? Ann Int Med 112: 1571-159, 1990.

149. Blomqvist CG, Saltin B. Cardiovascular adaptations to physical training. Ann Rev Physiol 45: 169-189, 1983.

150. Shapiro M. Physiological left ventricular hypertrophy. Br Heart J 52: 130-135, 1984.

151. Morganroth J, Maron BJ, Henry WL, Epstein SE. Comparative left ventricular dimensions in trained athletes. Ann Intern Med 82: 521-524, 1975.

152. Fagard R, Aubert A, Staessen J et al. Cardiac structure and function in cyclists and runners. Echocardiographic comparative study. Br Heart J 52: 124-127, 1984.

153. Sugishita $Y$, Koseki $S$, Matsuda $M$ et al. Myocardial mechanics of athletic hearts in comparison with diseased hearts. Am Heart J 105: 273-289, 1983.

154. Shapiro LM, Smith RG. Effect of training on left ventricular structure and function: an echocardiographic study. Br Heart J 50: 534-539, 1983.

155. Vanhees L, Hespel P, Van Hoof Ret al. Effect of physical training on systemic and brachial artery hemodynamics in normal men. Int J Sports Med 13: 145-151, 1992.

156. Ehsani AA, Hagberg JM, Hickson RC. Rapid changes in left ventricular dimensions and mass in response to physical conditioning and deconditioning. Am J Cardiol 42: 52-56, 1978.

157. Wolfe LA, Cunningham DA, Rechnitzer PA, Nichol PM. Effects of endurance training on left ventricular dimensions in healthy men. J Appl Physiol 47: 207-212, 1979.

158. Scheffer MG, McFalls EO, Verdouw FW et al. The utility of echocardiography in the cardiac assessment of athletes. In: Hermans GP, Mosterd WL, eds. Sports, medicine and health. Excerpta Medica: Elsevier Science Publishers, Amsiterdam, The Netherlands, pp 57-66, 1990.

159. Hammond IW, Devereux RB, Alderman $\mathrm{MH}$ et al. The prevalence and correlates of echocardiographic left ventricular hypertrophy among employed patients with uncomplicated hypertension. J Am Coll Cardiol 7: 639-650, 1986.

160. Verdecchia P, Schillaci $G$, Guerrieri $M$ et al. Circadian blood pressure changes and left ventricular hypertrophy in essential hypertension 81: 528-536, 1990.

161. Casale PN, Devereux RB, Milner M et al. Value of echocardiographic measurement of left ventricular mass in predicting cardiovascular morbid events in hypertensive man. Ann Int Med 105: 173-178, 1986.

162. Drayer JI, Gardin GM, Brewer DD. Disparate relationships between blood pressure and left ventricular mass in patients with and without left ventricular hypertrophy. Hypertension 9 (suppl 2): 39-44, 1987.

163. Fagard R, Lijnen P, Staessen J, Thijs L, Amery A. Mechanical and other factors relating to left ventricular hypertrophy. Blood Pressure 3 (suppl 1): 5-10, 1994.

164. Baglivo HP, Fabregrues G, Burrieza $\mathrm{H}$ et al. Effect of moderate physical training on left ventricular mass in mild hypertensive persons. Hypertension 15 (suppl 1): 153-156, 1990. 
165. Gilders RM, Dudley GA. Endurance exercise training and treatment of hypertension: the controversy. Sports Med 13: 71-77, 1992.

166. Sen S, Tarazi RC. Regression of myocardial hypertrophy and influence of adrenergic system. Am J Physiol 244: H97-H101, 1983.

167. Guazzi M, Fiorentini C, Olivari MT. Cardiac load and function in hypertension. Am I Cardiol 44: 1007-1012, 1979.

168. Smith VE, White WB, Karimeddini MK. Echocardiographic assessment of left ventricular diastolic performance in hypertensive subjects. Hypertension 9 (suppl 2): 81-84, 1987.

169. Balogum MO, Dunn FG. Systolic and diastolic function following regression of left ventricualr hypertrophy in hypertension. J Hypertens 9 (suppl 2): 51-55, 1991.

170. Friberg P, Hoffman P, Norlander M, Thorén P. Effects of voluntary physical exercise on cardiac function and energetics in spontaneous hypertensive rats. Acta Physiol Scand 133: 495-500, 1988.

171. Schaible T, Malhotra A, Ciambrone G et al. Combined effects of hypertension and chronic running program on rat heart. J Appl Physiol 63: 322-327, 1987.

172. Franklin BA. Exercise training and coronary collateral circulation. Med Sci Sports Exerc 23: 648-653, 1991.

173. Noakes TD, Higginson L, Opie LH. Physical training increases ventricular fibrillation thresholds of isolated rat hearts during normoxia, hypoxia and regional ischemia. Circulation 67: 24-30, 1983.

174. Struijker Boudier HA, Van Bortel LM, De Mey JG. Remodeling of the vascular tree in hypertension: drug effects. Trends Pharmacol Sci 11: 240-245, 1990.

175. Folkow B. Physiological aspects of primary hypertension. Physiol Rev 62: 347-504, 1982.

176. Hudlicka O. What makes blood vessels grow? J Physiol 444: 1-24, 1991.

177. Yamashita $\mathrm{H}$, Sato $\mathrm{N}$, Yamamoto $\mathrm{M}$ et al. Effect of endurance training on angiogenic activity in skeletal muscles. Pflügers Arch 422: 332-338, 1993.

178. Lash JM, Bohlen HG. Functional adaptations of rat skeletal muscle arterioles to aerobic exercise training. J Appl Physiol 72: 2052-2062, 1992.

179. Conway J. A vascular abnormality in hypertension - a study of blood flow in the forearm. Circulation 27: 520-526, 1963.

180. Takeshita A, Mark AL. Decreased vasodilator capacity of forearm resistance vessels in borderline hypertension. Hypertension 2: 610-616, 1980.

181. Takeshita A, Imaizumi $T$, Ashihara $T$ et al. Limited maximal vasodilation capacity of forearm resistance vessels in normotensive young men with a familial predisposition to hypertension. Circ Res 50: 671-677, 1982.

182. Sinoway LI, Musch TI, Minotti JR, Zelis R. Enhanced maximal metabolic vasodilatation in the dominant forearms of tennis players. J Appl Physiol 61: 673-678, 1986.

183. Dahlöf $B$. Regression of cardiovascular structural changes: a preventive strategy. Clin Exp Hypertens A12: 877-896, 1990.

184. Dahlöf B. Factors involved in the pathogenesis of hypertensive cardiovascular hypertrophy; A review. Drugs 35 (suppl 5): 6-26, 1988.

185. Hansson L, Svensson A, Gudbrandsson T, Sivertsson R. Treatment of hypertension with beta-blockers with and without intrinsic sympathomimetic activity. J Cardiovasc Pharmacol 5 (suppl 1): 26-29, 1983.

186. Agabiti-Rosei E, Muiesan ML. Geri A et al. Long-term antihypertensive treatnnent may induce normalization of left ventricular mass before complete regression of vascular changes: consequences for cardiac function at rest and during stress. J Hypertens 6 (suppl 4): 94-96, 1988.

187. O'Rourke MF, ed. Arterial function in health and disease. Churchill Livingstone: Edinburgh, UK, 1982. 
188. Safar ME. Pulse pressure in essential hypertension: clinical and therapeutical implications. J Hypertens 7: 769-776, 1989.

189. Darne B, Girerd X, Safar M et al. Pulsatile versus steady component of blood pressure: a cross-sectional analysis and a prospective analysis on cardiovascular mortality. Hypertension 13: 392-400, 1989.

190. Safar ME, LaurentS, Safavian AL et al. Pulse pressure in sustained essential hypertension: a hemodynamic study. J Hypertens 5: 213-218, 1987.

191. Asmar RG, Brunel PC, Pannier BM et al. Arterial distensibility and ambulatory blood pressure monitoring in essential hypertension. Am J Cardiol 61: 1066-1070, 1988.

192. Hoeks AP, Brands PJ, Smeets FA, Reneman RS. Assessment of the distensibility of superficial arteries. Ultrasound Med Biol 16: 121-128, 1990.

193. Reneman RS, Van Merode T, Hick P et al. Age-related changes in carotid artery wall properties in men. Ultrasound Med Biol 12: 465-471, 1986.

194. Van Merode T, Hick PJ, Hoeks AP et al. Vessel wall properties of the carotid artery in normotensive and borderline hypertensive young male volunteers. J Hypertens 5 (suppl): 471-473, 1987.

195. Westerhof N, Huisman RM. Arterial hemodynamics of hypertension. Clin Sci 72: 391-398, 1987.

196. Safar ME, Laurent S, Pannier BM, London GM. Structural and functional modifications of peripheral large arteries in hypertensive patients. J Clin Hypertens 3: 360-367, 1987.

197. Laurent S, London GM, Safar ME. Increased response of the brachial artery diameter to norepinephrine in essential hypertension: preliminary report. J Hypertens 4 (suppl 6): 237-239, 1986.

198. Van Bortel LM, Hoeks AP, Kool MJ, Struijker Boudier HA. Introduction to large artery properties as a target for risk reduction by antihypertensive therapy. J Hypertension 10 (suppl 6): 123-126, 1992.

199. Van Bortel LMAB. Beyond the tension of hypertension. Thesis Rijksuniversiteit Limburg, Maastricht, 1993.

200. Mohiaddin RH, Underwood SR, Bogren HG et al. Regional aortic compliance studied by magnetic resonance imaging: the effects of age, training, and coronary artery disease. $\mathrm{Br}$ Heart J 62: 90-96, 1989.

201. Eugene $\mathrm{M}$, Vandewalle $\mathrm{H}$, Bertholon JF, Teillac A. Arterial elasticity and physical working capacity in young men. J Appl Physiol 61: 1720-1723, 1986.

202. Giannattasio $C$, Cattaneo BM, Mangoni AA et al. Changes in arterial compliance induced by physical training in hammer-throwers. J Hypertens 10 (suppl 6): 53-55, 1992.

203. Cameron JD, Dart AM, Topham S. Effects of 4 weeks exercise training on arterial compliance in man. Circulation 86 (suppl 1): 276, 1992.

204. Segal SS, Kurjiaka DT, Caston AL. Endurance training increases arterial wall thickness in rats. J Appl Physiol 74: 722-726, 1993.

205. Oppliger RA, Hodgins T, Tipton CM et al. The influence of training on wall lumen ratio of WKY and SHR populations. Med Sci Sports Exerc 12: 130, 1980.

206. Irving JB, Bruce RA. Exertional hypotension and postexertional ventricular fibrillation in stress testing. Am J Cardiol 39: 849-851, 1977.

207. Ellestad MH. Stress testing: principles and practice. FA Davis: Philadelphia, USA, 1986.

208. Kitamura K, Jorgensen CR, Gobel FL et al. Hemodynamic correlates of myocardial oxygen consumption during upright exercise. J Appl Physiol 32: 516-518, 1972.

209. Fagard R. Exercise blood pressure and cardiovascular morbidity and mortality. Int J Sports Cardiol 3: 9-12, 1994.

210. Filipovsky J, Ducimetière P, Safar ME. Prognostic significance of exercise blood pressure and heart rate in middle-aged men. Hypertension 20: 333-339, 1992. 
211. Fagard R, Staessen ], Thijs L, Amery A. Prognostic significance of exercise versus resting blood pressure in hypertensive men. Hypertension 17: 574-578, 1991.

212. Horan MI, Lenfant C. Epidemiology of blood pressure and predictors of hypertension. Hypertension 15 (suppl 1): 20-24, 1990.

213. Wilson NV, Meyer BM. Early prediction of hypertension using exercise blood pressure. Prev Med 10: 62-68, 1981.

214. Jackson AS, Squires WG, Grimes G, Beard EF. Prediction of future resting hypertension from exercise blood pressure. J Cardiac Rehab 3: 263-268, 1983.

215. Dlin RA, Hanne N, Silverberg DS, Bar-Or O. Follow-up of normotensive men with exaggerated blood pressure response to exercise. Am Heart J 106: 316-320, 1983.

216. Benbassat J, Froom P. Blood pressure response to exercise as a predictor of hypertension. Arch Intern Med 146: 2053-2055, 1986.

217. Chaney RH, Eyman RK. Blood pressure at rest and during maximal dynamic and isometric exercise as predictors of systemic hypertension. Am J Cardiol 62: 1058-1061, 1988.

218. Wilson MF, Sung BH, Pincomb GA, Lovallo WR. Exaggerated pressure response to exercise in men at risk for systemic hypertension. Am J Cardiol 66: 731-736, 1990.

219. Iskandrian AS, Heo J. Exaggerated systolic blood pressure response to exercise: a normal variant or a hyperdynamic phase of essential hypertension. Int J Cardiol 18: 207-217, 1988.

220. Gottdiener JS, Brown J, Zoltick J, Fletcher RD. Left ventricular hypertrophy in men with normal blood pressure: relation to exaggerated blood pressure response to exercise. Ann Intern Med 112: 161-166, 1990.

221. Franz IW. Ergometry in the assessment of arterial hypertension. Cardiology 72: 147-159, 1985.

222. Leibel B, Kobrin J, Ben-Ishay D. Exercise testing in assessment of hypertension. Br Med J 285: 1535-1536, 1982.

223. Lund-Johansen P. Hemodynamics in early essential hypertension. Acta Med Scand suppl 482: 9-101, 1067.

224. Franz IW. Assessment of blood pressure response during ergometric work in normotensive and hypertensive patients. Acta Med Scand suppl 670: 35-50, 1982.

225. Drory X, Pines A, Fisman EZ, Kellermann JJ. Exercise response in young women with of borderline hypertension. Chest 97: 298-301, 1990.

226. Hansen HS, Hyldebrandt N, Nielsen JR, Froberg K. Exercise testing in children as a diagnostic tool of future hypertension: the Odense school child study. J Hypertension 7 (suppl 1): 41-42, 1989.

227. Lund-Larsen P, Helgeland A, Leren P. Systolic blood pressure and heart rate changes during exercise in three groups of 40-49 year old men in Oslo. Acta Med Scand suppl 670: 31-33, 1982.

228. Brorson L, Wasir H, Sannerstedt R. Hemodynamic effects of static and dynamic exercise in males with arterial hypertension of varying severity. Cardiovasc Res 12: 269-275, 1978.

229. Sannerstedt $R$. Hemodynamic response to exercise in patients with arterial hypertension. Acta Med Scand suppl 458, 1966.

230. Bruce RA, Gey Go, Cooper MN et al. Seattle Heart Watch: initial clinical, circulatory and electrocardiographic responses to maximal exercise. Am J Cardiol 33: 45-469, 1974.

231. Wolthuis RA, Froelicher VF, Fischer J, Triebwasser JH. The response of healthy men to treadmill exercise. Circulation 55: 153-157, 1977.

232. Criqui MA, Haskell WL, Heiss G et al. Predictors of systolic blood pressure response to treadmill exercise: the lipid research clinics program prevalence study. Circulation 68 : 225-233, 1983.

233. Kaplan NM. Non-drug treatment of hypertension. Ann Int Med 102: 359-373, 1985. 
234. Houston MC. New insights and new approaches for the treatment of essential hypertension: selection of therapy based on coronary heart disease risk factor analysis, hemodynamic profiles, quality of life, and subsets of hypertension. Am Heart J 117: 911-951, 1989.

235. Van Baak MA. Hypertension, beta-adrenoceptor blocking agents and exercise. Int J Sports Med 15: 112-115, 1994.

236. Van Baak MA. Beta-adrenoceptor blockade and exercise: an update. Sports Med 4: 209-225, 1988.

237. Chick TW, Halperin AK, Gacek EM. The effect of antihypertensive medications on exercise performance: a review. Med Sci Sports Exerc 20: 447-454, 1988.

238. Hollifield JW. Potassium and magnesium abnormalities: diuretics and arrhythmias in hypertension. Am J Med 77: 28-32, 1984.

239. Ades PA, Gunther PG, Meyer WL et al. Cardiac and skeletal muscle adaptations to training in systemic hypertension and effect of beta-blockade (metoprolol or propanolol). Am J Cardiol 66: 591-596, 1990.

240. Sable DL, Brammell HL, Sheenan MW et al. Attenuation of exercise conditioning by beta-adrenergic blockade. Circulation 65: 679-684, 1982.

241. Wolfel EE, Hiat WR, Brammell HL et al. Effects of selective and non-selective betaadrenergic blockade on mechanisms of exercise conditioning. Circulation 74: 664-674, 1986.

242. Madden DJ, Blumenthal JA, Ekelund LG. Effects of beta-blockade and exercise on cardiovascular and cognitive functioning. Hypertension 11: 470-476, 1988.

243. Wilmore JH, Ewy GA, Freund BJ et al. Cardiorespiratory alterations consequent to endurance training during chronic beta-adrenergic blockade with atenolol and propranolol. Am J Cardiol 55: 142D-148D, 1985.

244. Sweeney ME, Fletcher BJ, Fletcher GF. Exercise testing and training with beta-adrenergic blockade: role of the drug wash-out period in "unmasking" a training effect. Am Heart J 118: 941-946, 1989.

245. Gordon NF, Duncan JJ. Effect of beta-blockers on exercise physiology: implications for exercise training. Med Sci Sports Exerc 23: 668-676, 1991.

246. Duffey DJ, Horwitz DL, Brammel HL. Nifedipine and the conditioning response. Am J Cardiol 53: 908-911, 1984.

247. Stewart KJ, Effron MB, Valenti SA, Kelemen MH. Effects of diltiazem or propranolol during exercise training of hypertensive men. Med Sci Sports Exerc 22: 171-177, 1990.

248. Van Zwieten PA. Pharmacology of antihypertensive agents with multiple actions. Eur J Clin Pharmacol 38 (suppl 2): 77-81, 1990.

249. Lund-Johansen $\mathrm{P}$. The role of multiple action agents in hypertension. Eur J Clin Pharmacol 38 (suppl 2): 89-95, 1990.

250. Fagard R, Lijnen P, Amery A. Response of the systemic pulmonary circulation to labetalol at rest and during exercise. Br J Clin Pharmacol 13 (suppl 1): 13-17, 1982.

251. Koch $\mathrm{G}$. Hemodynamic adaptation at rest and during exercise to long-term antihypertensive treatment with combined alpha- and beta-adrenoceptor blockade by labetalol. $\mathrm{Br}$ Heart J 41: 192-198, 1979.

252. Bugni WJ, Ayers CW, Ashby R, Bittle PA. Effects of dilevalol on rest and supine exercise hemodynamics in mild to moderate systemic hypertension. Am J Cardiol 63: 452-456, 1989.

253. Omvik P, Lund-Johansen P. Acute hemodynamic effects of carvedilol in essential hypertension at rest and during exercise. Eur Heart J 12: 736-740, 1991.

254. Lund-Johansen P, Omvik P. Chronic hemodynamic effects of carvedilol in essential hypertension at rest and during exercise. Eur Heart J 13: 281-286, 1992. 
255. Frisk-Holmberg M, Juhlin-Dannfelt A, Aström $\mathrm{H}$. Hemodynamic and metabolic responses to prolonged exercise after chronic beta-1 adrenoceptor blockade in hypertensive man. Clin Physiol 5: 231-242, 1985.

256. Richter EA, Ruderman NB, Galbo H. Alpha- and beta-adrenergic effects on metabolism in contracting, perfused muscle. Acta Physiol Scand 116: 215-222, 1982.

257. Cléroux J, Van Nguyen P, Taylor AW, Leenen FH. Effects of beta-1 versus beta-1 + beta-2 blockade on exercise endurance and muscle metabolism in humans. J Appl Physiol 66: 548-554, 1989.

258. Kaiser P. Physical performance and muscle metabolism during beta-adrenergic blockade in man. Acta Physiol Scand suppl 536: 1-53, 1984.

259. William-Olsson T, Fellenius E, Björntorp S, Smith U. Differences in metabolic response to beta-adrenergic stimulation after propranolol or metoprolol administration. Acta Med Scand 205: 201-206, 1979.

260. Hespel P, Lijnen P, Vanhees L et al. Differentiation of exercise-induced metabolic responses during selective beta-1 and beta-2 antagonism. Med Sci Sports Exerc 18: 186-191, 1986.

261. Kjaer M, Engfred K, Fernandes A et al. Regulation of hepatic glucose reduction during exercise in humans: role of sympathoadrenergic activity. Am J Physiol 265: E275-E283, 1993.

262. Juhlin-Dannfelt A. Beta-adrenoceptor blockade and exercise: effect on endurance and physical training. Acta Med Scand suppl 672: 49-54, 1983.

263. Arner P, Kriegholm E, Engfeldt P, Bolinder J. Adrenergic regulation of lipolysis in situ at rest and during exercise. J Clin Invest 85: 893-898, 1990.

264. Lundborg P, Aström H, Bengtsson C, Fellenius E. Effect of beta-adrenoceptor blockade on exercise performance and metabolism. Clin Sci 61: 299-305, 1981.

265. MacDonald IA, Bennett T, Brown AM et al. The effects of acute or chronic ingestion of propranolol or metoprolol on the metabolic and hormonal response tot prolonged submaximal exercise in hypertensive man. Br J Clin Pharmacol 17: 283-293, 1984.

266. Van Baak MA, Böhm RO, Petri J, Rahn KH. Metabolic effects of verapamil and propranolol during submaximal endurance exercise in patients with essential hypertension. Int J Sports Med 8: 270-274, 1987.

267. Van Baak MA, Böhm RO, Arends BG, Van Hooff ME, Rahn KH. Long-term antihypertensive therapy with beta-blockers: submaximal exercise capacity and metabolic effects during exercise. Int J Sports Med 8: 342-347, 1987.

268. Katz A, Sahlin K, Juhlin-Dannfelt A. Effect of beta-adrenoceptor blockade on $\mathrm{H}+$ and $\mathrm{K}+$ flux in exercising humans. J Appl Physiol 59: 336-341, 1985.

269. Van Bortel LM, Van Baak MA. Exercise tolerance with nebivolol and atenolol. Cardiovasc Drugs Ther 6: 239-247, 1992.

270. Van Baak MA, Verstappen FT, Oosterhuis B. Twenty-four hour effects of oxprenolol oros and atenolol on heart rate, blood pressure, exercise tolerance and perceived exertion. Eur J Clin Pharmacol 30: 399-406, 1986.

271. Schamaun O, Westheim A, Qvigstad EK, Teisberg P. A comparative study on the effect of atenolol and labetalol on exercise capacity and lipid serum levels in essential hypertension. Nephron 47 (suppl 1): 135-137, 1987.

272. Loefsjoegaard-Nilsson E, Atmer B, Gunolf M, Krug-Gourley S. Effect of carvedilol during exercise. J Cardiovasc Pharmacol 19 (suppl 1): 108-113, 1992.

273. Frisk-Holmberg M, Jorfeldt L, Juhlin-Dannfelt A, Karlsson J. Metabolic changes in muscle on long-term alprenolol therapy. Clin Pharmacol Ther 26: 566-571, 1979.

274. Sjøgaard G. Water and electrolyte fluxes during exercise and their relation to muscle fatigue. Acta Physiol Scand suppl 556: 129-136, 1986. 


\section{CHAPTER 2}

\section{Effect of exercise training on ambulatory blood pressure}

JAG Wijnen, MJF Kool, MA van Baak, H Kuipers, CHA de Haan, FTJ Verstappen, HAJ Struijker Boudier, and LMAB Van Bortel

Departments of Pharmacology, Human Biology, and Movement Sciences University of Limburg, Maastricht, The Netherlands

Int J Sports Med 15: 10-15, 1994 


\section{ABSTRACT}

A possible hypotensive action of regular endurance exercise in normotensive sedentary subjects still remains a matter of debate. This is partly caused by the fact that the anticipated fall in resting blood pressure is rather small and fluctuations in blood pressure during the day can be large. The benefits of ambulatory blood pressure monitoring $(A B P)$ originate for a great deal from the fact that the repeatability on different occasions of the ambulatory blood pressure average is improved by the greater number of readings. In this context we evaluated the effect of moderate exercise training in 19 sedentary male subjects, aged 22 to 44 years, with normal or slightly elevated blood pressure. They entered a randomized cross-over study. Measurements were performed before the study, after 6 weeks of sedentary life style (S) and after 6 weeks of training (T) on a cycle ergometer 3 times a week for $45 \mathrm{~min}$ at $75 \%$ VO2max. ABP was measured with a Spacelabs 90207 monitor and cardiac output at rest with echo-Doppler. Training increased $V_{2} \mathrm{O}_{2 m a x}$ from $3.13 \pm 0.09$ to $3.40 \pm 0.08$ $l / \mathrm{min}(p<0.01)$. Resting heart rate decreased from $60 \pm 2$ to $57 \pm 2$ bpm at rest ( $p<$ 0.05). Resting blood pressure was unchanged after training. Resting stroke volume increased from $82 \pm 3$ to $89 \pm 3 \mathrm{ml}(p<0.02)$. Systemic vascular resistance index was significantly decreased due to conditioning $(p<0.05)$. The $24-h$ means of systolic BP (S: $125 \pm 4 ; T: 125 \pm 4 \mathrm{mmHg}$ ), diastolic BP (S: $79 \pm 3 ; T: 78 \pm 3 \mathrm{mmHg}$ ) and HR (S: $73 \pm 3 ; T: 72 \pm 4 \mathrm{bpm})$ did not differ between the two cross-over periods. In conclusion, moderate physical training for six weeks does not lower ambulatory blood pressure, blood pressure at rest and during exercise in normotensive sedentary male subjects; this despite clear cardiac adaptations and a reduction in systemic vascular resistance.

\section{INTRODUCTION}

There is strong evidence from well controlled intervention studies, that regular isotonic exercise can reduce resting casual blood pressure in sedentary untreated hypertensive subjects (10). Reductions in blood pressure are reported with an average of $11 \mathrm{mmHg}$ for systolic blood pressure and 6 $\mathrm{mmHg}$ for diastolic blood pressure (7). Jennings et al demonstrated that a regular exercise program can lower blood pressure to normotensive levels in untreated patients with hypertension, in 4 weeks (21) and over 1 year (13). However, in normotensive sedentary subjects, a possible hypotensive action of regular endurance exercise still remains matter of debate. In a recent consensus statement by the World Hypertension League (8) a small average decline of $4 \mathrm{mmHg}$ for systolic as well for diastolic blood pressure is assumed. But recent controlled studies did not find any blood pressure lowering effect $(14,17,26)$. It is suggested that in the basal state the effect of physical training on blood pressure in normotensives is small, but becomes more important during conditions of stress (26).

The benefits of ambulatory blood pressure monitoring in the assessment of the efficacy of antihypertensive drug treatment are now well established (22). 
Ambulatory blood pressure measurements make it possible to achieve a 24 hour profile of blood pressure during normal daily stress and may demonstrate a blood pressure lowering effect where conventional measurements fail to detect it mainly by reducing within subject variability due to the greater number of observations available (22). Therefore, the purpose of our present study was to evaluate the effect of moderate exercise training on basal blood pressure and on blood pressure during normal daily activities in sedentary men with normal and borderline-elevated blood pressure.

\section{SUBJECTS AND METHODS}

Twenty men aged 22 to 44 years were recruited from the general population by advertising in a local newspaper. Based on 3 consecutive casual blood pressure measurements in the morning on 2 different days 13 subjects had on average blood pressure values lower than $140 / 90 \mathrm{mmHg}, 6$ subjects between $140 / 90 \mathrm{mmHg}$ and $160 / 95 \mathrm{mmHg}$, and one subject had a blood pressure of $160 / 100 \mathrm{mmHg}$. All were free of overt cardiovascular disease or other medical problems as judged by questionnaire, physical examination, routine laboratory examination, resting electrocardiogram and stress testing. They were non-smokers and took no medication. Their life style and jobs were sedentary; none of the subjects was engaged in regular sport activities of more than 1 hour/week for the last two years.

\section{Design}

Each subject gave written informed consent. The protocol of the study was approved by the Ethical Committee of the University of Limburg.

Subjects entered a randomized two-way cross-over study. One group of 10 subjects continued their sedentary lifestyle for 6 weeks, followed by 6 weeks of exercise training. The other group of 10 subjects started with 6 weeks of exercise training followed by normal sedentary activity. The exercise training consisted of $45 \mathrm{~min}$ exercise on a cycle ergometer at $75 \% \mathrm{VO}_{2 \max }$ three times a week. Each session was preceded by a 5 min warming-up and completed by a 5 min cooling down. The sessions were strictly supervised and heart rate was monitored. The work load was adjusted to maintain a constant heart rate which was between $130-160$ beats/min for each subject. Subjects took no medication and kept factors as physical activity, diet and weight as constant as possible during the study. Weight was measured weekly, body fat was calculated from the sum of 4 skinfolds (6), at the start and end of each period. Urine was collected for 24 hour at the start and end of each period, to determine urinary sodium excretion. In the non-training period subjects were seen in our laboratory, every week, to promote compliance with the sedentary lifestyle. 
Measurements were performed at the start of the study and at the end of each 6 -week period. After the training period, evaluation took place two days after the last exercise bout to avoid acute post-exercise effects (15). Measurements were performed between 9 and 12 a.m. after an overnight fast and abstinence of caffeine for at least 12 hours. Care was taken that every subject was investigated at the same time of the day for the three measurements sessions.

\section{Measurements}

Blood pressure was measured after 5 minutes in sitting position, and after 30 minutes in a supine position using a Hawksley random-zero sphygmomanometer. The mean of 3 consecutive measurements in each position was taken. All blood pressure measurements were made by the same investigator. Cardiac output at rest was measured with the subjects in left lateral recumbent position by means of echocardiography and Doppler ultrasound measurements of blood flow velocity over the aortic valve with a conventional echosystem (Ultramarkt V; ATL, Bothell, Washington, USA) after 30 minutes of supine rest.

Aortic diameter (D) was measured from a standard 2-dimensional long-axis parasternal view at the site of the aortic root with a $2.25 \mathrm{Mhz}$ transducer.

The cross-sectional area (CSA) of the aortic anulus was calculated from the aortic diameter as CSA $=0.25 \pi * D^{2}$. Maximal blood flow velocity in the ascending aorta was recorded from the cardiac apex with a $1.9 \mathrm{Mhz}$ continuous wave transducer. The RR-interval was derived from a simultaneous recorded ECG. Heart rate (HR) was calculated as $60 / \mathrm{RR}$-interval.

Evaluation of the flow velocity-time curve for each heart cycle gives an estimate of blood flow which is related to stroke volume. The area under the flow velocity curve - or the flow velocity integral (FVI) - and its corresponding RR-interval were determined off-line with built in electronic calipers. Cardiac output was computed according to the equation: $\operatorname{CO}(1 / \mathrm{min})=\operatorname{CSA}\left(\mathrm{cm}^{2}\right) *$ FVI $(\mathrm{cm}) * \mathrm{HR}$ (beats $/ \mathrm{min}) * 10^{-3}$. The mean of 6 heart beats was taken. The average stroke volume $(\mathrm{ml})$ was calculated as $\mathrm{CO} / \mathrm{HR} * 1000$. In our hands, stroke volume intra- and inter-day variability, expressed as coefficient of variation, was less than $5 \%$. Simultaneous arterial pressure was measured using a semi-automated device (Dinamap, Criticon, Tampa, USA). Mean arterial pressure (MAP) was calculated as diastolic pressure $+1 / 3$ pulse pressure. Systemic vascular resistance index was calculated as MAP/cardiac index $(\mathrm{CI})$.

Thereafter a progressive maximal cycle ergometer (Lode, Groningen, The Netherlands) test was performed. This test started with a work rate of $100 \mathrm{~W}$ for 5 minutes, which was increased by $30 \mathrm{~W}$ every 3 minutes until exhaustion. Heart rate and systolic blood pressure (sphygmomanometer) were measured at rest, and at the end of the $100 \mathrm{~W}$ and $160 \mathrm{~W}$ stage. A blood sample was obtained from an antecubital vein for determination of plasma lactate con- 
centration at exhaustion. During exercise oxygen consumption and respiratory exchange ratio were measured with a Sensor Medics Horizon metabolic measurement card. Peak oxygen uptake was defined as the mean oxygen uptake during the last minute. Plasma lactate was measured by an enzymatic auto-analyzer method, urine sodium levels by flame photometry. Ambulatory blood pressure was monitored with a non-invasive automated device, Spacelabs system model 90207 (Spacelabs Inc, Redmond, Wash, USA). With this system blood pressure is measured by oscillometry. All registrations were done on a weekday and included working periods employed outside the home. The subjects were asked to keep the same day and night rhythm throughout the three measurement periods and perform their normal daily routine. Blood pressure and heart rate were recorded every 15 minutes during the day ( 7 a.m. to 11 p.m.) and every 30 minutes during the night (11 p.m. to 7 a.m.). Subjects were instructed to stop muscular activity and keep their arms entirely still during BP measurements. Each reading was edited by computer and was rejected if the diastolic blood pressure was less than $40 \mathrm{mmHg}$ or more than $140 \mathrm{mmHg}$, systolic blood pressure less than $80 \mathrm{mmHg}$ or more than $245 \mathrm{mmHg}$, pulse pressure less than $20 \mathrm{mmHg}$ and heart rate less than $40 \mathrm{bpm}$ or more than $150 \mathrm{bpm}$. Over a 24 hour period, for each subject 70 to 80 blood pressure values could be analyzed.

\section{Statistical analysis}

Statistical analysis was performed according to the non-parametric Koch procedure for the two-way cross-over design using the Mann-Whitney U-test (16). If appropriate, the method of Willan and Pater (28) was used. Comparative data analysis with baseline data was made by Wilcoxon m.p.s.r. Ambulatory blood pressure data were compared by one-way analysis of variance (repeated measurements) and the Bonferroni post-hoc test. A p-value $<0.05$ was considered statistically significant. All data are expressed as mean \pm standard error of the mean.

\section{RESULTS}

No interactions and order effects were found, except for a slight carry-over effect for $\mathrm{VO}_{2 \max }$. Analysis according to Willan and Pater (28), however, indicated that the cross-over analysis of $\mathrm{VO}_{2 \max }$ based on the data of the two periods was a better estimate than a parallel group comparison based only on the data of the first period.

Twenty subjects entered the study, but one stopped in the training period due to lack of motivation. Due to technical failures in two subjects more than $25 \%$ of the recordings of ambulatory blood pressure after the training period were unsuccessful. The recordings of these subjects were not used in the analysis. As a consequence, data are presented for 19 subjects, except for 
ambulatory blood pressure $(n=17)$. At the start of the study, the subjects were on average $37 \pm 1$ years old, weighed $77 \pm 2 \mathrm{~kg}$, had a percentage body fat of $20 \pm 2 \%$ and were $179 \pm 1 \mathrm{~cm}$ tall. The weight and percentage body fat remained unchanged throughout the study. The 24-hour urinary excretion of sodium was $184 \pm 17 \mathrm{mmol}$ at the start of the study and was not significantly different after the sedentary $(167 \pm 17 \mathrm{mmol})$ and training period $(150 \pm 15$ mmol).

Based on casual blood pressure measurements there were 12 normotensive subjects and 7 subjects with a (borderline) elevated blood pressure. Using the recently proposed reference values for ambulatory pressure (25), only one subject was probably hypertensive (blood pressure over 24 hours $>139 / 87$ $\mathrm{mmHg}$ ) with an average blood pressure of $139 / 91 \mathrm{mmHg}$ at the start of the study. Data are presented for the whole group. In addition, subanalyses of blood pressure at rest and during exercise were made in the elevated blood pressure group $(n=7)$.

Six weeks of training increased peak oxygen uptake $\left(\mathrm{VO}_{2 \max }\right)$ by $9 \%(\mathrm{p}<$ 0.01 ) (Table 1). Heart rate after $30 \mathrm{~min}$ supine rest declined from $60 \pm 2 \mathrm{bpm}$ after sedentary activity to $57 \pm 2 \mathrm{bpm}$ after endurance training ( $<<0.05$ ) (Fig. 1). Stroke volume increased from $82 \pm 3 \mathrm{ml}$ to $89 \pm 3 \mathrm{ml}$ ( $p<0.02$ ) (Fig. 2). Calculated stroke index increased from $42.2 \pm 1.3$ to $45.6 \pm 1.4 \mathrm{ml} / \mathrm{m}^{2}$ at rest $(\mathrm{p}<0.001)$ and calculated cardiac index at rest increased significantly $(\mathrm{p}<$ 0.05 ) during training from $2.57 \pm 0.09$ to $2.71 \pm 0.091 / \mathrm{min} / \mathrm{m}^{2}$. Calculated systemic vascular resistance index fell from $2875 \pm 114$ dyn.s. $\mathrm{cm}^{-5} \cdot \mathrm{m}^{2}$ at the end of the sedentary period to $2692 \pm 90$ dyn.s. $\mathrm{cm}^{-5} \cdot \mathrm{m}^{2}$ after training $(\mathrm{p}<0.05)$ (Fig. 3).

Table 2 presents data of resting sitting and supine blood pressure measured with the Hawksley random-zero meter. As expected, values after 5 min sitting were slightly higher compared to the supine rest values. No significant changes in resting blood pressure were found at the end of 6 weeks of training. When resting blood pressure was analyzed for the subgroup with casually elevated blood pressure $(n=7)$ no significant changes occurred either (At the end of the sedentary period $130 \pm 5 / 84 \pm 4 \mathrm{mmHg}$ versus at the end of the training period, $130 \pm 3 / 83 \pm 2 \mathrm{mmHg}$ ). Heart rate in this group declined from

Table 1. Data on maximal aerobic exercise capacity $(n=19)$.

\begin{tabular}{lllll}
\hline & At start study & & Sedentary period & Training period \\
\cline { 4 - 4 } Peak heart rate $(\mathrm{bpm})$ & $181 \pm 3$ & & $180 \pm 2$ & $178 \pm 3$ \\
Peak oxygen uptake $(1 / \mathrm{min})$ & $3.15 \pm 0.08$ & $3.13 \pm 0.09$ & $3.40 \pm 0.08^{*}$ \\
Peak respiratory exchange ratio & $1.15 \pm 0.01$ & $1.16 \pm 0.02$ & $1.18 \pm 0.01$ \\
Peak lactate (mmol/1) & $11.3 \pm 0.7$ & $10.3 \pm 0.6$ & $11.8 \pm 0.7$ \\
\hline
\end{tabular}

All values are expressed as mean \pm standard error. ${ }^{*} p<0.01$ for difference between sedentary and training period. 

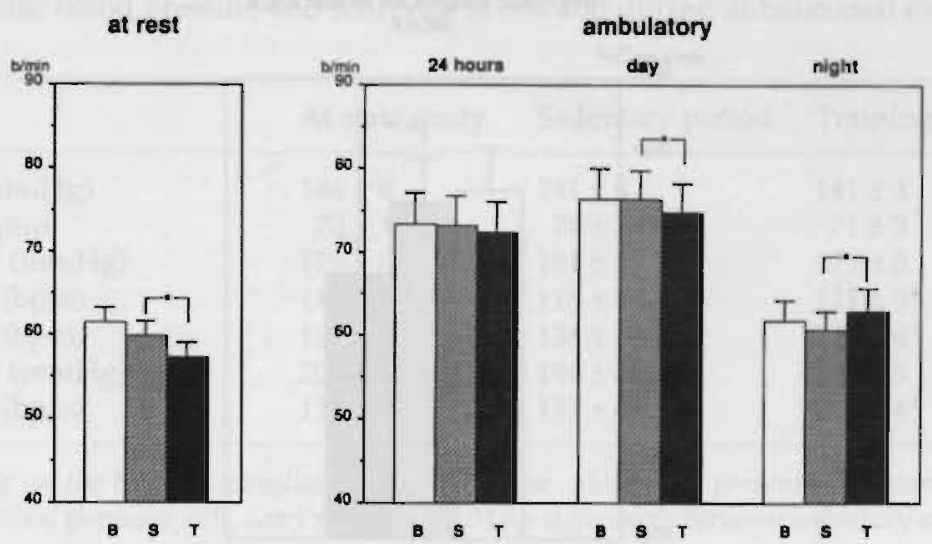

Fig. 1 Heart rate after 30 min of supine rest and during 24-hour ambulatory recording at the start of the study (B), at the end of a sedentary period of 6 weeks (S) and at the end of the training period $(T) .{ }^{*} p<0.05$ for differences from sedentary values.
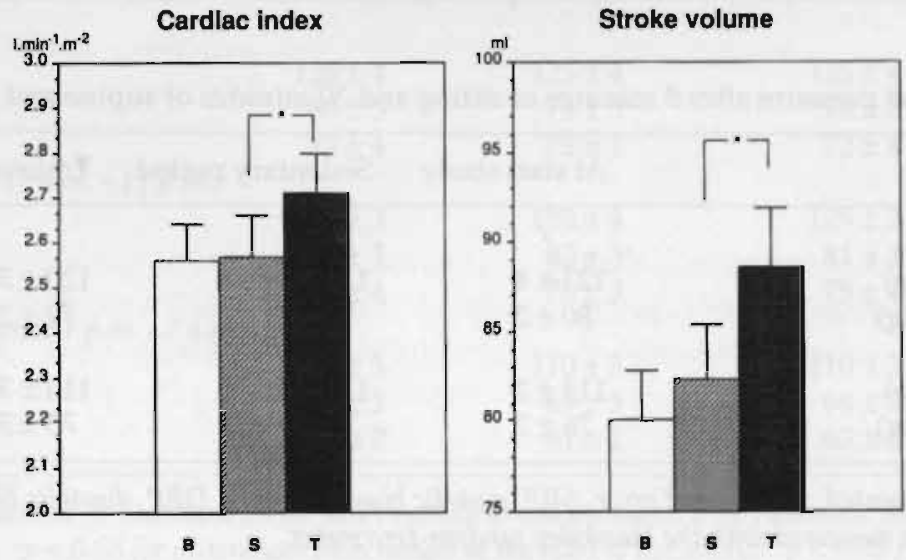

Fig. 2 Cardiac index and stroke volume at the start of the study (B), at the end of a sedentary period of 6 weeks (S) and at the end of the training period (T). ${ }^{*} p<0.05$ for differences from sedentary values.

$65 \pm 2 \mathrm{bpm}$ to $60 \pm 3 \mathrm{bpm}(\mathrm{p}<0.02)$. Blood pressure and heart rate measured at rest sitting on the bicycle and during submaximal exercise are shown in Table 3. No significant changes in blood pressure were found due to the exercise training; this in contrast to a highly significant decline $(p<0.01)$ in the submaximal exercise heart rate following training. Comparable changes were observed in the elevated blood pressure group: sitting systolic blood pressure was $157 \pm 4 \mathrm{mmHg}$ after the sedentary period and $151 \pm 6 \mathrm{mmHg}$ 


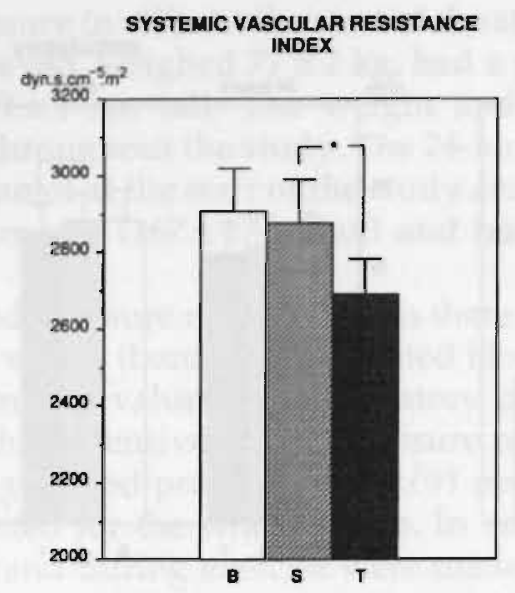

Fig. 3 Systemic vascular resistance index at the start of the study $(B)$, at the end of the sedentary $(S)$ and at the end of the training period $(T) .{ }^{*} p<0.05$ for differences from sedentary values.

Table 2. Blood pressure after 5 minutes of sitting and 30 minutes of supine rest $(n=19)$

\begin{tabular}{lccc}
\hline & At start study & Sedentary period & Training period \\
\hline Sitting & & & \\
SBP (mmHg) & $123 \pm 4$ & $117 \pm 3$ & $120 \pm 3$ \\
DBP $(\mathrm{mmHg})$ & $80 \pm 2$ & $78 \pm 2$ & $79 \pm 2$ \\
Supine & & & \\
SBP $(\mathrm{mmHg})$ & $115 \pm 2$ & $111 \pm 2$ & $113 \pm 3$ \\
DBP $(\mathrm{mmHg})$ & $76 \pm 2$ & $73 \pm 2$ & $73 \pm 3$ \\
\hline
\end{tabular}

Means are presented \pm standard error. SBP, systolic blood pressure; DBP, diastolic blood pressure. Blood pressure measured with the Hawksley random-zero meter.

after training (not significant), whereas sitting heart rate at rest was significantly decreased from $79 \pm 5 \mathrm{bpm}$ to $72 \pm 4 \mathrm{bpm}$ after training $(p<0.05)$. At a workload of $100 \mathrm{~W}$, a systolic blood pressure of $192 \pm 9 \mathrm{mmHg}$ was found after the sedentary period and $194 \pm 7 \mathrm{mmHg}$ after training (n.s.); for the heart rate, these values were $124 \pm 6$ and $113 \pm 4 \mathrm{bpm}(\mathrm{p}<0.05)$.

Table 4 presents data of the ambulatory blood pressure monitoring and Fig. 4 shows the 24 -hour blood pressure profile. Ambulatory blood pressure is not lowered by training, neither during 24 hours nor during the day- or nighttime. There is a small, but statistically significant decline in ambulatory 
Table 3. Systolic blood pressure and heart rate at rest and during submaximal exercise $(\mathrm{n}=19)$.

\begin{tabular}{lrrc}
\hline & At start study & Sedentary period & Training period \\
\hline SBP at rest $(\mathrm{mmHg})$ & $146 \pm 4$ & $141 \pm 4$ & $141 \pm 4$ \\
HR at rest $(\mathrm{bpm})$ & $70 \pm 3$ & $74 \pm 3$ & $71 \pm 3$ \\
SBP at $100 \mathrm{~W}(\mathrm{mmHg})$ & $179 \pm 6$ & $181 \pm 5$ & $177 \pm 5$ \\
HR at $100 \mathrm{~W}(\mathrm{bpm})$ & $118 \pm 4$ & $118 \pm 3$ & $111 \pm 3^{*}$ \\
$\mathrm{HR}$ at $130 \mathrm{~W}(\mathrm{bpm})$ & $137 \pm 4$ & $136 \pm 4$ & $129 \pm 4^{*}$ \\
SBP at $160 \mathrm{~W}(\mathrm{mmHg})$ & $201 \pm 6$ & $194 \pm 6$ & $198 \pm 5$ \\
HR at $160 \mathrm{~W}(\mathrm{bpm})$ & $157 \pm 4$ & $157 \pm 4$ & $145 \pm 4^{*}$ \\
\hline
\end{tabular}

At rest: sitting on the bicycle immediately before exercise. Means are presented \pm standard error. $S B P$, systolic blood pressure; $H R$, heart rate. ${ }^{*} p<0.01$ for differences between sedentary and training period.

Table 4. Ambulatory blood pressure and heart rate $(n=17)$.

\section{At start study Sedentary period Training period}

$\begin{array}{lrcc}24 \text { hr mean } & & & \\ \text { SBP } & 126 \pm 4 & 125 \pm 4 & 125 \pm 4 \\ \text { DBP } & 80 \pm 3 & 79 \pm 3^{+} & 78 \pm 3^{+} \\ \text {HR } & 73 \pm 4 & 73 \pm 3 & 72 \pm 4 \\ \text { Daytime mean (7 a.m. - } 11 \text { p.m.) } & & & \\ \text { SBP } & 130 \pm 3 & 129 \pm 4 & 129 \pm 3 \\ \text { DBP } & 83 \pm 3 & 82 \pm 3^{+} & 81 \pm 3^{+} \\ \text {HR } & 76 \pm 4 & 76 \pm 3 & 75 \pm 4^{+*} \\ \text { Night time mean (11 p.m. }-7 \text { a.m.) } & & & \\ \text { SBP } & 112 \pm 3 & 110 \pm 3 & 110 \pm 3 \\ \text { DBP } & 67 \pm 3 & 65 \pm 3 & 64 \pm 2 \\ \text { HR } & 62 \pm 2 & 61 \pm 2 & 63 \pm 3^{*}\end{array}$

Means are presented \pm standard error. SBP, systolic blood pressure; DBP, diastolic blood pressure; $H R$, heart rate. ${ }^{+} p<0.05$ for differences from values at the start of the study; ${ }^{*} p<0.05$ for differences between sedentary and training period.

diastolic blood pressure between the first (at the start of the study) recording and the recordings during the cross-over periods. Training lowered the heart rate only during the daytime $(\mathrm{p}<0.05)$. During nighttime heart rate was even somewhat higher after training $(p<0.05)$. For the elevated casual blood pressure group, only 5 subjects had complete records and the average 24-hour blood pressure was $130 \pm 3 / 84 \pm 4 \mathrm{mmHg}$ for the sedentary period, and $130 \pm$ $5 / 83 \pm 2 \mathrm{mmHg}$ after training. Day- and night-time recordings were in line 


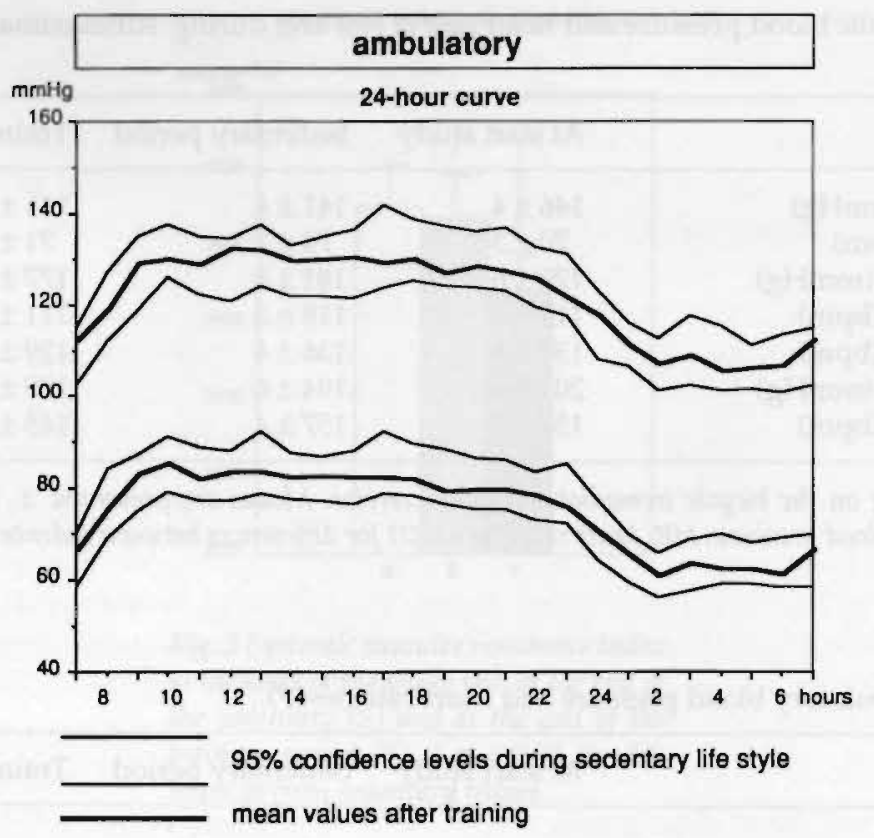

Fig. 4 Circadian rhythm of systolic and diastolic blood pressure at the end of the sedentary and training period. The ambulatory blood pressure curve after training is compared with the $95 \%$ confidence limits of the ambulatory blood pressure curve in the sedentary period.

with the whole group and showed no effect of physical exercise training, while conditioning lowered the heart rate during the day $(p<0.05)$.

\section{DISCUSSION}

The anticipated fall in resting blood pressure from exercise training in sedentary normotensive subjects is small (8). An average fall of $4 \mathrm{mmHg}$ for systolic as well as diastolic blood pressure must be viewed against the magnitude of the variability in blood pressure. Fluctuations of $40 \%$ in blood pressure can readily occur at random during the day (18). By using ambulatory recordings and thus increased numbers of readings, the variability between repeated blood pressure estimations is markedly reduced and smaller differences in blood pressure fall are more easily detected (4). In addition, evidence is growing that ambulatory blood pressure measurement is superior to traditional blood pressure measurements in providing a proper estimate of the real pressure load to the heart (19).

In this study a Spacelabs 90207 oscillometric blood pressure monitor was used, which has been successfully validated according to the British Hyper- 
tension Society protocol (23). All but one of the subjects in this study could be classified as normotensive based on recently proposed reference values for ambulatory blood pressure, although 7 subjects had elevated casual blood pressure values at the start. This points to an additional advantage of ambulatory monitoring, namely to better differentiate between true and pseudohypertensives (24). It is conceivable that part of the inability to find a significant decrease in systolic blood pressure by conditioning in 11 out of 33 studies in sedentary hypertensive men (10) can be explained by misdiagnosis. Comparing the ambulatory diastolic blood pressure averages at the start with sedentary and training (pooled) averages, there is a small but significant decline. Thus, the absence of some first measurement effect cannot be ruled out (5).

The most important finding of this study, however, is the lack of any hypotensive effect, as measured with $\mathrm{ABP}$, of conditioning in normotensive sedentary subjects. This is in agreement with other studies $(9,27)$. Gilders et al (9) studied 10 normotensive sedentary male and female subjects after a 16-week endurance exercise conditioning period ( 3 days/week, $30 \mathrm{~min}$ of exercise at $80 \%$ of maximal heart rate) and after a 12-week de-conditioning period. Although conditioning increased $\mathrm{VO}_{2 \max }$ in that study by $14 \%$, which is higher than the average $9 \%$ in the present study, blood pressure (measured with the Del Mar Pressurometer III) did not decrease, neither over 24-hours nor during the day or night. A shortcoming of the study by Gilders et al is the fixed order in which conditioning and de-conditioning periods were alternated, which cannot rule out an order effect. Using a randomized cross-over design, Van Hoof et al (27) studied 26 sedentary men who trained for 4 months ( 3 days / week, intensity not mentioned) or continued their sedentary lifestyle for 4 months. An increase in $\mathrm{VO}_{2 \max }$ by $14 \%$ did not change the ambulatory blood pressure during the day or the night (measured by a Spacelabs 5200 device), except for the day-time diastolic blood pressure which was lowered by $5 \mathrm{mmHg}$. Average 24 -hour blood pressure values were not given because measurements between 6 and 8 A.M. and 8 and 12 P.M. were excluded. The findings in the present study and afore-mentioned studies (9, 27) on ambulatory blood pressure and training are in contrast with the prevailing view that endurance training lowers blood pressure at rest in normotensive sedentary subjects (8).

We also measured casual blood pressure at rest after 5 min sitting and in a more basal state after $30 \mathrm{~min}$ of rest but did not find a reduction in blood pressure, despite of clear adaptive effects at rest of the heart rate, stroke volume and systemic vascular resistance to training. Jo et al (14) trained 14 untreated hypertensives and 14 normotensives for 12 weeks and observed a significant fall in blood pressure in the hypertensive group but not in the normotensives. Lightfoot et al (17), studying the effect of 10 weeks of aerobic training on lower body negative pressure responses, did not find a change in systolic and diastolic blood pressure at rest in normotensive subjects in spite 
of a $20 \%$ increase in $\mathrm{VO}_{2 \max }$. It is possible that the blood pressure response to training was influenced by other factors. Diet, weight and body composition were, however, not altered. It can be argued that the level of physical activity of our subjects in normal daily life was too high to see an effect of conditioning on blood pressure. Jennings et al (12) suggested that the antihypertensive effect of regular exercise is a low threshold phenomenon and the major effect occurs when sedentary subjects increase their activity level to only moderate levels. But all our subjects had white-collar jobs and did not engage in regular (endurance) sporting activities for the last 2 years. Vanhees et al (26) and Van Hoof et al (27), reporting on the same normotensive subjects, described training-induced changes varying according to the measuring conditions. They found that in the basal state (after about one hour rest in recumbent position), the effect of physical training on blood pressure in normotensive subjects is neglible (26), but becomes more important during conditions of stress. They reported a decrease in submaximal exercise blood pressure. In sharp contrast to our findings, Meredith et al (20) measured supine blood pressure after the normotensive subjects had been lying for $25 \mathrm{~min}$, and found a decrease of 8 $\mathrm{mmHg}$ for systolic blood pressure and $5 \mathrm{mmHg}$ for diastolic blood pressure after 4 weeks of training at a workload of $60-70 \% \mathrm{~W}_{\max }$. In the present study no effect of training on exercise blood pressure measured at 100 and $160 \mathrm{~W}$ was found despite a clear reduction in submaximal heart rate and this is in accordance with De Vries et al (5), who found no effect on blood pressure measured at $75 \mathrm{~W}$ in older men.

Remarkably, training induced a significant $6 \%$ increase in cardiac index. This modest rise in the resting cardiac index is in line with previous studies $(11,20)$, using the "indirect Fick" method, but conflicts with the study by Gilders et al (8), who measuring cardiac output with echo-Doppler, found an unaltered cardiac output at rest following conditioning. The increase in cardiac index was caused by an increase in stroke volume, which in turn is most likely to be the result of an increased preload and increased central blood volume associated with training (1). Because the mean arterial pressure was found to be unchanged by training and the cardiac index was increased, systemic vascular resistance index was consequently decreased. Afterload reduction is a crucial component of the integrated cardiovascular response to training. An increase in the size of the capillary bed of the skeletal muscle is a well-known training effect. This could in part account for the reduction, but it is believed that regulatory effects on arteriolar level are most important (2). A lot of research has focussed on a probable decline in sympathetic activity due to conditioning, but results lack consistency (10).

Although we discussed the subjects as one group, being normotensive based on their ambulatory recordings, we made analyses of the subjects with elevated casual blood pressure. A hypotensive effect of a physical exercise training could not be detected neither on resting, exercise or ambulatory blood pressure. Recently, Blumenthal and colleagues (3) assessed the effects 
of a moderate physical exercise program in patients classified as mild hypertensives, based on resting blood pressure. Ambulatory blood pressure monitoring was performed using an Accutracker monitor, from 8 am until bedtime. The study was designed as a randomized controlled trial. After 4 months of exercise training ( 3 times a week, aerobic exercise for 35 minutes at $70 \% \mathrm{VO}_{2 \max }$ ) subjects in the aerobic exercise group did not exhibit greater reductions in ambulatory blood pressure than subjects in the control group.

In conclusion, this study shows that in normotensive sedentary subjects six weeks of training does not lower ambulatory blood pressure, blood pressure at rest and during exercise, despite clear cardiac adaptations and a reduction in systemic vascular resistance at rest.

\section{REFERENCES}

1. Astrand P-O, Rodahl K. Textbook of Work Physiology. McGraw Hill, New York, 1986.

2. Blomquist CG, Saltin B. Cardiovascular adaptations to physical training. Ann Rev Physiol 45: 169-189, 1983.

3. Blumenthal JA, Siegel WC, Appelbaum M. Failure of exercise to reduce blood pressure in patients with mild hypertension. JAMA 266: 2098-2104, 1991.

4. Conway J, Coats A. Value of ambulatory blood pressure monitoring in clinical pharmacology. J Hypertension 7 (suppl 3): 29-32, 1989.

5. De Vries HA. Physiological effects of an exercise training regimen upon men aged 52-88. J Gerontol 25: 325-336, 1970.

6. Durnin JA, Womersley J. Body fat assessed from total body density and its estimation from skinfold thickness: measurement on 481 men and women aged from 16-72 years. Br J Nutr 32: 77-94, 1974.

7. Fagard R, Bielen E, Hespel P. Physical exercise in hypertension, in Laragh J., Brenner B. (eds.): Hypertension: pathophysiology, diagnosis and management. Raven Press, New York, 1990.

8. Fagard R, Duprez D, Clement D, Amery A. Physical exercise in the management of hypertension: a consensus statement by the World Hypertension League.J Hypertension 9: 283-287, 1991.

9. Gilders RM, Voner C, Dudley GA. Endurance training and blood pressure in normotensive and hypertensive adults. Med Sci Sports Exerc 21: 629-636, 1989.

10. Hagberg JM. Exercise, fitness, and hypertension, in Bouchard C (ed.): Exercise, fitness, and health. Human Kinetic Publishers, Champaign, 1990.

11. Jennings G, Nelson L, Nestel P, Esler M, Korner P, Burton D, Bazelmans J. The effects of changes in physical activity on major cardiovascular risk factors, hemodynamics, sympathetic function, and glucose utilization in men: a controlled study of four levels of activity. Circulation 73: 30-40, 1986.

12. Jennings GL, Deaking G, Dewar E, Laufer E, Nelson L. Exercise, cardiovascular disease and blood pressure. Clin Exp Hypertens AII: 1035-1052, 1989.

13. Jennings G, Nelson L, Dewar E, Korner P, Esler M, Laufer E. Antihypertensive and hemodynamic effects of one year's regular exercise. J Hypertension 4 (suppl 6): 659-661, 1986.

14. Jo Y, Arita M, Baba A, Nakamura H, Ueda E, Hano T, Ueno Y, Kuchii M, Noshio I, Masuyama $Y$. Blood pressure and sympathetic activity following responses to aerobic exercise in patients with essential hypertension. Clin Exp Hypertens AII: 411-417, 1989. 
15. Kaufman FL, Hughson RL, Schaman JP. Effect of exercise on recovery blood pressure in normotensive and hypertensive subjects. Med Sci Sports Exerc 19: 17-20, 1987.

16. Koch GG. The use of non-parametric methods in statistical analysis of the two-period change- over design. Biometrics 28: 577-584, 1972.

17. Lightfoot JT, Claytor RP, Torok DJ, Journell TW, Fortney SM. Ten weeks of aerobic training do not affect lower body negative pressure responses. J Appl Physiol 67: 894-901, 1989.

18. Mancia G, Parati G, Pomiodossi G, Casadei R, DiRienzo M, Zanchetti A. Arterial baroreflexes and blood pressure and heart rate variabilities in humans. Hypertension 8 : 147-153, 1985.

19. Mancia G, Zanchetti A. Value of echocardiographic and ambulatory blood pressure monitoring in hypertension. Clin Exp Hypertens AII: 869-886, 1989.

20. Meredith IT, Jennings GL, Esler MD, Dewar EM, Bruce AM, Fazio VA, Korner PI. Time course of the antihypertensive and autonomic effects of regular endurance exercise in human subjects. J Hypertension 8: 859-866, 1990.

21. Nelson L, Jennings GL, Esler MD, Korner PI. The effect of changing levels of physical activity on blood pressure and haemodynamics in patients with essential hypertension. Lancet ii: 474-478, 1986.

22. O'Brien E, Cox JP, O'Malley K. Ambulatory blood pressure measurement in the evaluation of blood pressure lowering drugs. J Hypertension 7, 243-247, 1989.

23. O'Brien E, Mee F, Atkins N, O'Malley K. Accuracy of the Spacelabs 90207 determined by the British Hypertension Society protocol. J Hypertension 9: 573-574, 1991.

24. Pickering TG, James GD, Boddie C, Harsfield GA, Blank S, Laragh J. How common is white coat hypertension? JAMA 259: 225-228, 1988.

25. Staessen JA, Fagard RH, Lijnen PJ, Thijs L, Van Hoof R, Amery AK. Mean and range of the ambulatory pressure in normotensive subjects from a meta-analysis of 23 studies. Am J Cardiol 67: 723-727, 1991.

26. Vanhees L, Hespel P, Van Hoof R, Fagard R, Amery A. Effect of physical training on systemic and brachial artery hemodynamics in normal men. Int J Sports Med 13: 145-151, 1992.

27. Van Hoof R, Hespel P, Fagard R, Lijnen P, Staessen J, Amery A. Effect of endurance training on blood pressure at rest, during exercise and during 24 hours in sedentary men. Am J Cardiol 63: 945-949, 1989.

28. Willan AR, Pater JL. Carryover and two-period cross-over design. Biometrics 42: 593-599, 1986. 


\section{CHAPTER 3}

\section{Vessel wall properties of large arteries in trained and sedentary subjects}

JAG Wijnen, H Kuipers, MJF Kool, APG Hoeks, MA van Baak, HAJ Struijker Boudier, FTJ Verstappen, and LMAB Van Bortel

Departments of Pharmacology, Physiology and Biophysics, University of Limburg, Maastricht, The Netherlands, and Institute of Sports Medicine Limburg, Maastricht, The Netherlands

Adapted from: Basic Res Cardiol 86 (suppl 1): 25-29, 1991 


\section{ABSTRACT}

Vessel wall properties (distensibility and compliance) of the elastic common carotid artery and the muscular femoral and brachial arteries were studied with a dedicated ultrasound system in 15 trained male cyclists and 15 healthy sedentary males matched for age, height and weight. Simultaneously, arm blood pressure was measured with a Dinamap and heart rate and stroke index with bioimpedance electrocardiography.

Heart rate at rest was significantly lower and stroke index significantly higher in the trained subjects. Blood pressure and pulse pressure did not differ. Vessel wall properties and diameter of the common carotid artery showed no differences between the groups. Diameter of the femoral artery was significantly larger $(p<0.05)$ in cyclists and cross-sectional compliance tended to be higher. Distensibility coefficient was not different. Diameter of the brachial artery did not differ between the two groups. Cross-sectional compliance of the brachial artery was significantly higher in the cyclists $(p<0.02)$, distensibility coefficient was $22 \%$ higher $(p=0.09)$.

These results suggest that endurance training in cyclists might cause structural adaptation of the femoral artery and a more general decrease in smooth muscle tone of muscular arteries.

\section{INTRODUCTION}

Physical conditioning, especially endurance training is accompanied by various central and peripheral cardiovascular adaptations. Striking features of the training response are an increase in left ventricular end-diastolic volume of the heart, a sinus bradycardia at rest, a decreased heart rate during submaximal exercise and an increase in the size of the capillary bed of the skeletal muscle (1).

Furthermore physical training increases the capacity for vasodilation in active limbs, probably by increasing the capacity of arteriolar vessels to accommodate blood flow during exercise (2). Large arteries have a conduit and buffering function (3). They transform the systolic flow jet from the heart into a more continuous flow for tissue perfusion. Arterial distensibility and compliance are vessel-wall properties that determine, respectively, the elastic and buffering function of large arteries. Whether physical training induces changes in these properties has not been studied yet.

Recently, ultrasound techniques have been developed (4), by which these vessel-wall properties can be measured. In the present study we compared the vessel-wall properties of three large arteries i.e. the common carotid artery, the brachial artery and the common femoral artery, between endurancetrained cyclists and sedentary subjects at rest. 


\section{MATERIALS AND METHODS}

\section{Subjects}

The study was performed on 15 well-trained male cyclists and 15 healthy sedentary male subjects matched for age $( \pm 2 \mathrm{yr})$, height $( \pm 2 \mathrm{~cm})$ and body mass $( \pm 2 \mathrm{~kg})$. The cyclists had been active in competition for at least two consecutive years and measurements were taken in the second month of the training season. The sedentary subjects did not perform endurance or competitive types of sports and were mostly recruited from a student population. All subjects were free of overt cardiovascular disease, did not smoke and used no cardiovascular medication.

After 15 min of supine rest, 3 consecutive measurements of blood pressure with a Hawksley random zero meter showed a blood pressure less than $140 / 90 \mathrm{mmHg}$ in all subjects. The protocol was approved by the institutional Ethics Committee. Informed written consent was obtained from each subject.

\section{Methods}

On the day of examination, the subjects abstained from caffeine and reported at the laboratory at least 3 hours after they had their last meal. Furthermore, no vigorous exercise was performed the day before. Body height and body mass were measured and body fat was calculated from the sum of 4 skinfolds according to Durnin and Womersley (4).

The ultrasound investigation was carried out in a quiet room $\left(22 \pm 1^{\circ} \mathrm{C}\right)$ after $15 \mathrm{~min}$ in the recumbent position. Arterial blood pressure was measured every $2 \mathrm{~min}$ at the left arm with a semi-automated oscillometric blood pressure device (Dinamap, Criticon, Tampa, USA). Systolic and diastolic pressures were recorded at least 6 times during the echo investigations and the average value was taken as the subject's reading.

\section{Vessel wall properties}

A 7.5 MHz ultrasound system (Ultramark-V, ATL, Bothell, Washington, USA) was used to locate subsequently the common carotid artery, the common femoral artery and brachial artery, all at the right side, whereafter the system was switched to the $\mathrm{M}$-mode with $\mathrm{M}$-line placed perpendicular to the axis of the vessel. For a period of 4 to 5 seconds, the radio-frequency signals received in M-mode were stored temporarily in a dedicated memory module (5), synchroneous with an ECG-derived trigger for timing reference purposes. After completion of the data collection, the signals were transferred to a personal computer ( $\mathrm{PC}$ ), where the first $\mathrm{M}$-line acquired was used to identify the positions of the vessel walls. Off-line Doppler processing of the radio-frequency signals within windows coinciding with both walls (Fig. 1A) reveals 


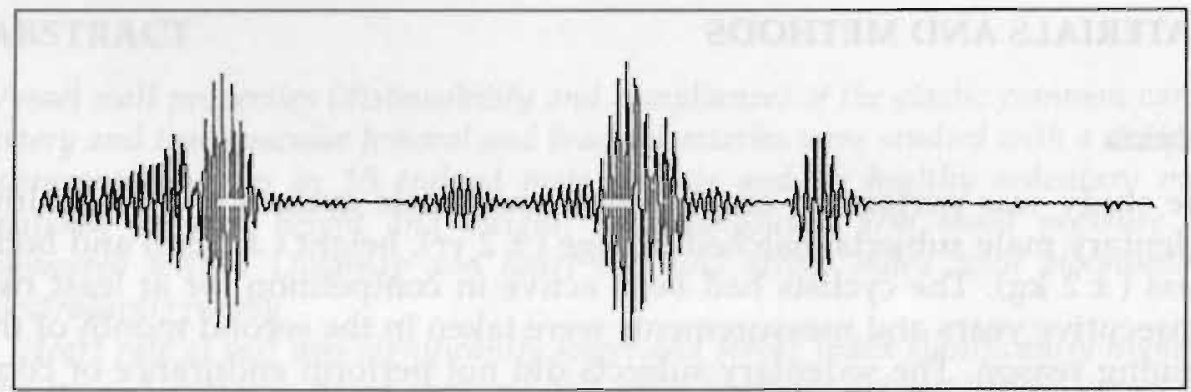

Fig. 1A Radio-frequency (RF) signal with RF-DAS (5)

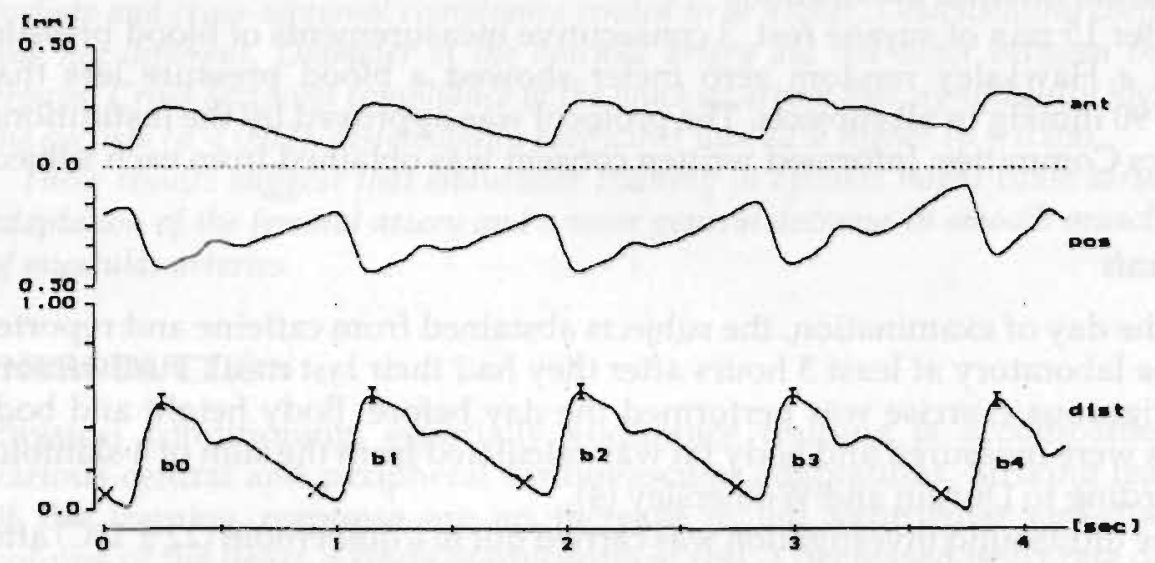

Fig. 1B Registration of the vessel wall movement of the common carotid artery during 5 heart cycles in a young healthy volunteer. ant: anterior wall movement; pos: posterior wall movement; dist: distension, change in diameter during the heart cycle

the displacement of the arterial walls was a function of time, while the difference between both represents the distension waveform (Fig. 1B). The coefficient of variation in the peak-to-peak distension varied from $8-13 \%$, depending on the artery (6). This variation can (partly) be attributed to the beat-to-beat changes in local pulse pressure.

From the diameter at the onset of the cardiac cycle (D), the relative change in diameter during the cardiac cycle (distension; $\Delta \mathrm{D}$ ) and pulse pressure $(\Delta \mathrm{P}$, systolic minus diastolic blood pressure), distensibility coefficient (DC), and cross-sectional compliance (CC.) were calculated using the following equations:

$$
D C=\frac{\Delta A / A}{\Delta P}=\frac{2(\Delta D / D)}{\Delta P}
$$




$$
C C=\frac{\Delta V / L}{\Delta P}=\frac{\pi D * \Delta D}{2 \Delta P}
$$

$\Delta A / A$ : relative change in cross-sectional area of the vessel

$\Delta V / L$ : change in volume per unit of length

Cardiac output measurement

Cardiac output and heart rate were continuously measured by electrical bioimpedance (NCCOM3-R7; BoMed Medical Manufacturing LTD, Irvine, California, USA). The monitor automatically averages stroke volume over 12 cardiac cycles. Recently, Northridge et al (7) compared this method to Doppler echocardiography and the thermodilution method in patients within 24 hours after acute myocardial infarction and found close agreement in most patients, and good reproducibility.

\section{Exercise test.}

After the ultrasound investigations, maximal working capacity $\left(\mathrm{W}_{\max }\right)$ was assessed on a bicycle ergometer (Lode, Groningen, The Netherlands) with a progressive protocol until exhaustion (start $100 \mathrm{~W}$; then $50 \mathrm{~W}$ increase every $3 \mathrm{~min}$ ). Peak heart rate was obtained from ECG and blood was sampled from a cubital vein after $3 \mathrm{~min}$ in the recovery phase for determination of plasma lactate. Plasma lactate was determined spectrophotometrically according to the LDH method with a centrifugal analyzer (type Cobas Bio).

\section{Data analysis}

Results are presented as mean \pm SEM ( $n=15$ in both groups). Comparison between the trained and sedentary subjects was made by the non-parametric Mann-Whitney U-test. A p-value less than 0.05 was considered statistically significant.

\section{RESULTS}

Subject characteristics are presented in Table 1. With regard to age, height and body mass no significant differences between the two groups existed. Trained subjects had a significantly lower percentage body fat and resting heart rate was on average 10 beats. min $^{-1}$ lower $(p<0.05)$. Stroke index was significantly higher. Maximal effort during the progressive maximal exercise test was comparable between the two groups as judged by maximal heart rate and peak plasma lactate concentration. A large significant difference was found in absolute maximal aerobic power $\left(W_{\max }\right)$ and $W_{\max }$ standardized for body mass $\left(\mathrm{W}_{\max } \cdot \mathrm{kg}^{-1}\right)$. 
Table 1. Subject characteristics

\begin{tabular}{|c|c|c|}
\hline & Sedentary & Trained \\
\hline Age (y) & $24.3 \pm 1.0$ & $24.4 \pm 1.0$ \\
\hline Body height $(\mathrm{cm})$ & $183.5 \pm 1.3$ & $182.2 \pm 1.9$ \\
\hline Body mass $(\mathrm{kg})$ & $74.7 \pm 2.5$ & $74.9 \pm 2.1$ \\
\hline Body fat (\%) & $14.3 \pm 1.0$ & $10.8 \pm 1.6^{*}$ \\
\hline Systolic blood pressure ( $\mathrm{mmHg}$ ) & $120.9 \pm 2.9$ & $117.5 \pm 2.4$ \\
\hline Diastolic blood pressure ( $\mathrm{mmHg}$ ) & $68.5 \pm 1.9$ & $63.5 \pm 1.1$ \\
\hline Pulse pressure (mmHg) & $52.3 \pm 2.6$ & $54.0 \pm 2.0$ \\
\hline Resting heart rate (bpm) & $60.2 \pm 2.1$ & $50.0 \pm 2.1^{*}$ \\
\hline Stroke index (ml.m-2) & $66.9 \pm 2.9$ & $74.8 \pm 3.4^{*}$ \\
\hline$W_{\max }(W)$ & $289.6 \pm 10.4$ & $392.2 \pm 12.8^{*}$ \\
\hline$W_{\max } \cdot \mathrm{kg}^{-1}\left(\mathrm{~W} \cdot \mathrm{kg}^{-1}\right)$ & $3.91 \pm 0.15$ & $5.24 \pm 0.12^{*}$ \\
\hline Maximal heart rate (bpm) & $189.7 \pm 2.6$ & $186.1 \pm 2.8$ \\
\hline Plasma lactate $\left(\mathrm{mmol} . \mathrm{l}^{-1}\right)$ & $10.9 \pm 0.6$ & $11.5 \pm 0.4$ \\
\hline
\end{tabular}

${ }^{*} p<0.05$. Blood pressure measured with Dinamap in supine position.

Table 2. Arterial diameter (D), diameter change $(\Delta D)$, distensibility coefficient $(D C)$ and cross-sectional compliance (CC) for the right common carotid artery, right common femoral artery and right brachial artery in sedentary and trained subjects

\begin{tabular}{lll}
\hline & Sedentary & Trained \\
\hline Carotid artery & & \\
$D(\mathrm{~mm})$ & $6.37 \pm 0.13$ & $6.41 \pm 0.11$ \\
$\Delta \mathrm{D}(\mu \mathrm{m})$ & $630 \pm 24$ & $669 \pm 33$ \\
$\mathrm{DC}\left(10^{-3} / \mathrm{kPa}\right)$ & $29.6 \pm 2.0$ & $30.3 \pm 2.9$ \\
$\mathrm{CC}\left(\mathrm{mm}^{2} / \mathrm{kPa}\right)$ & $0.93 \pm 0.05$ & $0.97 \pm 0.08$ \\
Femoral artery & & \\
$D(\mathrm{~mm})$ & $8.81 \pm 0.18$ & $9.89 \pm 0.31^{*}$ \\
$\Delta \mathrm{D}(\mu \mathrm{m})$ & $690 \pm 43$ & $819 \pm 57$ \\
$\mathrm{DC}\left(10^{-3} / \mathrm{kPa}\right)$ & $23.4 \pm 1.9$ & $25.4 \pm 3.8$ \\
$\mathrm{CC}\left(\mathrm{mm}^{2} / \mathrm{kPa}\right)$ & $1.43 \pm 0.12$ & $1.82 \pm 0.19$ \\
Brachial artery & & \\
$\mathrm{D}(\mathrm{mm})$ & $4.36 \pm 0.08$ & $4.40 \pm 0.11$ \\
$\Delta \mathrm{D}(\mu \mathrm{m})$ & $409 \pm 39$ & $523 \pm 35^{*}$ \\
$\mathrm{DC}\left(10^{-3} / \mathrm{kPa}\right)$ & $27.5 \pm 2.6$ & $33.7 \pm 2.5$ \\
$\mathrm{CC}\left(\mathrm{mm} \mathrm{m}^{2} / \mathrm{kPa}\right)$ & $0.40 \pm 0.03$ & $0.51 \pm 0.03^{*}$ \\
\hline
\end{tabular}

$* p<0.05$. 
With regard to blood pressure, systolic blood pressure was not significantly different, but diastolic blood pressure tended to be lower in the trained group $(p=0.05)$. Pulse pressure did not differ.

In Table 2, vessel wall properties of the three large arteries are shown. No significant differences for the elastic common carotid artery were found. Diameter of the muscular common femoral artery was on average $12 \%$ larger in the cyclists $(p<0.02)$. Cross-sectional compliance averaged $27 \%$ higher and distensibility coefficient $9 \%$ higher, but the level of significance was not reached ( $p=0.09$ for cross-sectional compliance). Diameter of the muscular brachial artery showed no difference between the groups. Distensibility of the brachial artery tended to be higher $(23 \% ; p=0.09)$ in the trained group. Cross-sectional compliance was $28 \%$ higher $(p<0.02)$ in the cyclists.

\section{DISCUSSION}

In this study assessment of local vessel wall properties was made by a dedicated ultrasound technique. Using this technique, it has previously been shown that distensibility and compliance of large arteries decrease with age (8), that they are lower in females than in males (9), and that arterial (borderline) hypertension is associated with a decrease in compliance and distensibility (10). Recently a diurnal pattern in vessel wall properties of large arteries has been demonstrated (11).

It has been established that in order to increase maximal cardiac output with physical training the combined effects of an improved myocardial performance and a reduced resistance to flow are needed (12). Physical training increases the capacity for vasodilation in the active muscles, probably by structural changes at the arteriolar level, and enables the trained individual to utilize a larger fraction of maximal vascular conductance than the sedentary subject (2). Literature data on the effect of physical training on large arteries are scarce.This is the first study in which vessel wall properties of large arteries were compared between endurance trained athletes and sedentary subjects.

Physical training of competitive cyclists is characterized by many hours of repeated bouts of high-intensity exercise, predominantly isotonic and performed especially with the quadriceps muscles. In addition, some work is done by the arms and upper body, mainly isometric in nature. The present study observed several differences between the vessel wall properties of the large arteries of cyclists and their sedentary counterparts, which could be the result of physical training. However, the possibility that these differences merely reflect genetic endowment cannot be ruled out. With regard to the common femoral artery, the internal diameter was found to be $12 \%$ larger in cyclists at rest. Most likely this represents a local adaptation to facilitate the large blood flow to the quadriceps muscles during strenuous exercise. It can be hypothesized that it is in part the resultant of [1] a chronic flow-dependent 
vasodilation (13), [2] caused by a reduced sympathetic stimulation during exercise, [3] by other neurohumoral regulatory mechanisms or [4] simply is the consequence of volume overload.

It is not clear whether the vasodilation seen at rest is primary functional or rather structural in origin. Recently, it has been found (14) that the radial artery of the dominant arm of hammer throwers has a significantly larger diameter and increased compliance at rest, compared to the opposite arm and the arms of sedentary controls, which probably suggests a more structural adaptation. A flow-dependent vasodilation of the femoral artery at rest seems unlikely, because leg blood flow at rest is not different in endurance-trained and sedentary subjects (2). A more systemic functional component to the dilation could be imagined, however, this is not revealed by differences in the brachial diameter between the two groups.

Surprisingly, we found no differences in vessel wall properties (cross-sectional compliance and distensibility coefficient) of the femoral artery in cyclists. Distensibility coefficient of the femoral artery was not significantly different, probably as a consequence of the structurally larger diameter. An increased cross-sectional compliance could be expected since the diameter was significantly larger with an unchanged distensibility coefficient. An obvious explanation for the absence of statistical significance could be the wide dispersion of individual data.

The most interesting finding of the present study is a better cross-sectional compliance of the brachial artery in trained subjects compared to that of sedentary subjects. As described in the method section, cross-sectional compliance is related to diameter and distensibility coefficient. Because average diameter was only $1 \%$ larger in the trained group and average distensibility coefficient was $23 \%$ higher, the better cross-sectional compliance has to be considered the resultant of a better vessel wall distensibility. The better cross-sectional compliance was only observed in the muscular brachial artery and not in the more elastic common carotid artery. Therefore, it is tentative to suggest that aerobic training can induce a decrease in muscle tone of the brachial artery and perhaps also a more general decrease in muscle tone of other muscular arteries. This could be related to a reduction in sympathetic activity. Whole-body spill-over rate of norepinephrine into the plasma, a measure of average sympathetic neural activity, is significantly reduced with training (15). Whether central, peripheral or local mechanisms are primarily or secondarily responsible for this change remains to be established. A preferential effect of endurance exercise training on renal sympathetic activity has been noticed (16) and endurance training reduced sympathetic activity of the peroneal nerve assessed by microneurography (17). Alternatively, training could decrease the response to adrenergic stimulation at the level of the smooth muscle (18). The renin-angiotensin system could also play a role since in trained subjects lower levels of plasma renin have been found $(15,19)$. In 
addition, endothelial-mediated flow-dependent changes of the arterial wall cannot be ruled out (20).

An improvement in vessel wall properties of large arteries in cyclists is in line with the observed higher regional compliance of the aorta of athletes compared to age-matched controls as measured with magnetic resonance imaging (21). A strong inverse linear relationship was found between pulse wave velocity measured over the carotid-femoral traject and physical working capacity in young men (22). This indicates a positive relation between aortic distensibility and physical working capacity. Arterial compliance is a major determinant of the afterload of the heart (23). A decrease in afterload by a decrease in vascular impedance due to an increase in arterial compliance with training could therefore improve cardiac performance (24).

Longitudinal studies are needed to find out whether training can improve vessel wall properties of large arteries in sedentary populations. If it does, it might contribute to explain why physical inactivity is associated with a higher risk of developing hypertension (25) and with a higher cardiovascular morbidity and mortality (26).

\section{REFERENCES}

1. Blomqvist CG, Saltin B. Cardiovascular adaptations to physical training. Ann Rev Physiol 45: 159-189, 1983.

2. Snell PG, Martin WD, Buckey JC, Blomqvist CG. Maximal vascular leg conductance in trained and untrained men. J Appl Physiol 62: 606-610, 1987.

3. O'Rourke M. Arterial stiffness, systolic blood pressure, and a logical treatment of arterial hypertension. Hypertension 15: 339-347, 1990.

4. Durnin JA, Womersley J. Body fat assessed from total body density and its estimation from skinfold thickness: measurement on 481 men and women aged from 16-72 years. Br J Nutr 32: 77-94, 1974.

5. Hoeks APG, Brands PJ, Smeets FM, Reneman RS. Assessment of the distensibility of superficial arteries. Ultrasound Med Biol 16: 121-128, 1990.

6. Kool MJ, Van Merode T, Reneman RS, Hoeks AP, Struijker Boudier HA, Van Bortel LM. Non-invasive evaluation of vessel wall properties of large arteries with a vessel wall movement detector system. Cardiovasc Res 28: 610-614, 1994.

7. Northridge DB, Findlay IN, Wilson J et al. Non-invasive determination of cardiac output by Doppler echocardiography and electrical bioimpedance. Br Heart J 63: 93-97, 1990.

8. Reneman RS, Van Merode T, Hick P, Muytjens AMM, Hoeks APG. Age-related changes in carotid artery wall properties in men. Ultrasound Med Biol 12: 465-471, 1986.

9. Van Merode T, Hick PJJ, Hoeks APG, Smeets FAM, Reneman RS. Diff́erences in carotid artery wall properties between presumed healthy men and women. Ultrasound Med Biol 14: 571-574, 1988.

10 Van Merode T, Hick PJJ, Hoeks APG, Rahn KH, Reneman RS. Carotid artery wall properties in normotensive and borderline hypertensive subjects of various ages. Ultrasound Med Biol 14: 563-569, 1988.

11. Kool MJ, Wijnen JA, Hoeks AP et al. Diurnal pattern of vessel wall properties of large arteries in healthy men. J Hypertens 9 (suppl 6): 108-109, 1991.

12. Clausen JP. Effect of physical training on cardiovascular adjustments to exercise in man. Phys Rev 57: 779-815, 1977. 
13. Laurent S, Lacolley $\mathrm{P}, \mathrm{Brunel} \mathrm{P}$ et al. Flow-dependent vasodilation of brachial artery in essential hypertension. Am J Physiol 258: H1004-H1011, 1990.

14. Giannattasio $C$, Cattaneo BM, Mangoni AA et al. Changes in arterial compliance induced by physical training in hammer-throwers. J Hypertens 10 (suppl 6): 53-55, 1992.

15. Jennings $G$, Nelson $L$, Nestel $P$ et al. The effects of changes in physical activity on major cardiovascular risk factors, hemodynamics, sympathetic function, and glucose utilization in man: a controlled study of four levels of activity. Circulation 73: 30-40, 1986.

16. Meredith IT, Friberg P, Jennings GL et al. Exercise training lowers resting renal but not cardiac sympathetic activity in humans. Hypertension 18: 575-582, 1991.

17. Grassi G, Seravalle G, Calhoun D et al. Physical exercise in essential hypertension. Chest 101 (suppl): 312-314, 1992.

18. Rogers PJ, Miller TD, Bauer BA et al. Exercise training and responsiveness of isolated coronary arteries. J Appl Physiol 71: 2346-2351, 1991.

19. Fagard R, Grauwels R, Groeseneken D et al. Plasma levels of renin, angiotensin II and 6-keto-prostaglandin $F_{1 \alpha}$ in endurance athletes. J Appl Physiol 59: 947-952, 1985.

20. Pehl U, Holtz J, Busse RF, Bassenge E. Crucial role of endothelium in the vasodilator response to increased flow in vivo. Hypertension 8: 37-44, 1986.

21. Mohiaddin RH, Underwood SR, Bogren HG et al. Regional aortic compliance studied by magnetic resonance imaging: the effects of age, training, and coronary artery disease. $\mathrm{Br}$ Heart J 62: 90-96, 1989.

22. Eugene $M$, Vandewalle $H$, Bertholon, JF, Teillac A. Arterial elasticity and physical working capacity in young men. J Appl Physiol 61: 1720-1723, 1986.

23. Van Bortel LM, Hoeks AP, Kool MJ, Struijker Boudier HA. Introduction to large artery properties as a target for risk reduction by antihypertensive therapy. J Hypertens 10 (suppl) 6: 123-126, 1992.

24. Yagihuma R, Wakabayashi A. Effects of aortic distensibility on the cardiac force in man. Jpn Circ J 36: 187-193, 1972.

25. Blair SN, Goodyear NN, Gibbons LW, Cooper KH. Physical fitness and incidence of hypertension in healthy normotensive men and women. JAMA 252: 487-490, 1984.

26. Blair SN, Kohl HW, Paffenbarger RS et al. Physical fitness and all-cause mortality: a prospective study of healthy men and women. JAMA 262: 2395-2401, 1989. 


\section{CHAPTER 4}

\section{Vessel wall properties of large arteries and endurance training}

JAG Wijnen, MJF Kool, JP Kooman, MA van Baak, AP Hoeks, HAJ Struijker Boudier, and LMAB Van Bortel

Departments of Pharmacology, Human Biology, Internal Medicinc, and Biophysics, University of Limburg, Maastricht, The Netherlands

Adapted from: J Hypertension 11 (suppl 5): $88-89,1993$ 


\section{ABSTRACT}

Cross-sectional studies found a positive relation between arterial elasticity and physical working capacity, higher regional compliance of the aorta in endurancetrained athletes and better vessel wall properties of the brachial and femoral artery in cyclists compared to sedentary subjects.

In this study, it has been hypothesized that physical training might induce changes in vessel wall properties of large arteries in sedentary men. Nineteen healthy men entered a randomized two-way cross-over study, consisting of either continuation of their sedentary lifestyle for 6 weeks or 6 weeks of moderate exercise training at 75\% $V_{2} \mathrm{O}_{\text {max }}, 3$ times a week for 45 minutes. Before and after these periods, vessel wall properties (distensibility and compliance) of the elastic common carotid artery and the muscular femoral and brachial arteries were studied with a dedicated ultrasound system. In addition, plasma catecholamines, plasma renin and plasma atrial natriuretic peptide concentrations were measured at rest.

Training increased $V_{2 \max }$ from $3.13 \pm 0.09$ to $3.40 \pm 0.08 \mathrm{l} / \mathrm{min}(p<0.01)$. Resting heart rate declined significantly. Resting blood pressure was $118 \pm 2 / 74 \pm 2$ $m m H g$ before and $117 \pm 3 / 74 \pm 2 \mathrm{mmHg}$ after training. Pulse pressure was unaltered. Diameter, distensibility coefficient and cross-sectional compliance of the three large arteries were not significantly different between the sedentary and training period. No significant changes in neurohumoral parameters were found following training.

In conclusion, a moderate exercise training program of 6 weeks does not change the vessel wall properties of large arteries in sedentary men.

\section{INTRODUCTION}

Recent training studies have provided supporting evidence for a blood pressure lowering effect of regular moderate isotonic exercise, both in normotensive $(1,2)$ and in hypertensive populations $(3,4)$. The underlying hemodynamic mechanisms, however, remain unclear; both changes in cardiac output and/or a decline in vascular resistance have been reported $(5,6)$.

To what extent neurohumoral changes are associated with the decrease in blood pressure also remains a matter of debate. A reduction in sympathetic nervous system activity has been a common finding $(2,3,4)$, while a role of the renin-angiotensin-aldosterone system is controversial $(2,5)$. At present, few data are available on the effect of training on atrial natriuretic peptides (ANP). In animals, an increase in resting ANP was observed after training (6), but in humans cross-sectional comparison between sedentary and endurancetrained subjects failed to show significant differences (7).

Beside a possible decline in vascular resistance, exercise training could have an effect on another component of vascular impedance, i.e. compliance. This has been suggested by cross-sectional studies finding a positive relationship between arterial elasticity and physical working capacity in young men (8), higher regional compliance of the aorta in endurance-trained athletes vs. sedentary age-matched controls (9) and in a recent study which found cyclists 
to have improved vessel wall properties of the brachial and femoral artery compared to sedentary controls (10).

Pulsatile stress in the vessel wall is substantially determined by arterial distensibility and may play a role in the onset of atherosclerosis. A decrease in compliance increases pulse pressure and left ventricular load. Distensibility and compliance are vessel wall properties properties which can now be measured non-invasively with ultrasound techniques (11). Distensibility and compliance have been found decreased with age (12) and hypertension (13).

An improvement by training of vessel wall properties may offset the age-related changes and the changes seen with high blood pressure and may help to explain why physically inactive persons have a higher risk of developing hypertension and cardiovascular disease $(14,15)$.

The primary hypothesis to be tested in this study was whether moderate exercise training would result in an improvement of vessel wall properties of large arteries in sedentary men. Furthermore, the possibility that improved vessel wall properties might be associated with changes in neurohumoral parameters (i.e. plasma catecholamines, ANP, and plasma renin) was investigated.

\section{SUBJECTS AND METHODS}

\section{Subjects}

Nineteen healthy male subjects entered the study. They were all non-smokers. None of the subjects had been engaged in regular sport activities for more than $1 \mathrm{~h} /$ week over the last 2 years and their life style and jobs were sedentary. They aged 37 years (range $22-44 \mathrm{y}$ ), weighed $77 \mathrm{~kg}$ (range $58-95 \mathrm{~kg}$ ) and were $179 \mathrm{~cm}$ tall (range $169-186 \mathrm{~cm}$ ). Casual systolic/diastolic blood pressure was up to $160 / 100 \mathrm{mmHg}$.

\section{Study design}

Each subject gave written informed consent. The protocol was approved by the Ethical Committee of the University of Limburg. Subjects entered a randomized, two-way, cross-over study, consisting of either continuation of their sedentary life style for 6 weeks or 6 weeks of exercise training on a cycle ergometer at a previously determined workload of $75 \% \mathrm{VO}_{2 \max } 3$ times per week for 45 minutes. Physical activity, diet and weight were monitored and kept constant during the study. Compliance to the sedentary life style was promoted by weekly returns to the laboratory.

Subjects were investigated at the start of the study (data not used in analysis) and after each 6-week period. Evaluation after the training period took place 2 days after the last exercise bout. Measurements were performed 
between 9 and 12 a.m. after an overnight fast and abstinence of caffeine for 12 hours, for each subject at the same time of the day.

On arrival at the laboratory, a short catheter was inserted in the v. cubitalis of the left arm, whereafter the subjects rested for at least $30 \mathrm{~min}$. Hemodynamic measurements were performed in the recumbent position after another $15 \mathrm{~min}$ of supine rest in a quiet room $\left(22 \pm 1^{\circ} \mathrm{C}\right)$. The diameter (D) and relative change in diameter (distension; $\Delta \mathrm{D}$ ) during the heart cycle of the elastic right common carotid artery, the muscular right brachial artery and the muscular right common femoral artery were measured over $5 \mathrm{~s}$ with a vessel wall movement detector system. This system, as described by Hoeks et al (11), consists of an radio-frequency-data acquisition system, a conventional echo imager (Ultramark-V, ATL, Bothell, Washington, USA) and a personal computer. Simultaneously, blood pressure was measured with a Dinamap (Criticon, Tampa, USA). Pulse pressure $(\Delta \mathrm{P})$ was defined as systolic blood pressure minus diastolic blood pressure. Vessel wall properties were calculated as:

$$
\begin{aligned}
& D C(\text { distensibility coefficient })=\frac{\Delta A / A}{\Delta P}=\frac{2(\Delta D / D)}{\Delta P} \\
& C C(\text { cross-sectional compliance })=\frac{\Delta V / L}{\Delta P}=\frac{\pi D * \Delta D}{2 \Delta P}
\end{aligned}
$$

$\triangle A / A$ : relative change in cross-sectional area of the vessel $\Delta V / L$ : change in volume per unit of length

The average value of $\Delta D$ and $D$ measured 3 times and the average value of blood pressure (BP) recorded 6 times were taken as the subject's readings. Thereafter, blood samples were obtained, with the subjects in supine position for $30 \mathrm{~min}$, for determination of plasma catecholamines, plasma renin (REN) and plasma atrial natriuretic peptide (ANP) concentrations.

Blood samples were collected in $5 \mathrm{ml}$ polystyrene tubes for ANP and REN and in $10 \mathrm{ml}$ polystyrene chilled tubes for norepinephrine (NE) and epinephrine (E), kept on ice-water. Tubes for ANP and REN contained EDTA (1 mg). Those for NE and E were heparinized and contained $12 \mathrm{mg}$ glutathione. For ANP, the peptidase inhibitor aprotinin (10,000 U/1) was added. After collection, the samples were centrifuged immediately at $4^{\circ} \mathrm{C}$ during 30 $\min$ at $1,500 \mathrm{~g}$ for NE/E and during $15 \mathrm{~min}$ at $1,500 \mathrm{~g}$ for the other hormones. Plasma was stored at $-70^{\circ} \mathrm{C}$ until assayed.

$\mathrm{NE}$ and $\mathrm{E}$ levels were measured by means of HPLC with fluorescence detection, according to Van der Hoorn et al (17). The intra-assay coefficient of 
variation was $4 \%$ for $\mathrm{NE}$ and $12.3 \%$ for $\mathrm{E}$, the interassay coefficient of variation $6.9 \%$ for NE and $16 \%$ for E. The detection limit was $20 \mathrm{pg} / \mathrm{ml}$ for NE and 3 $\mathrm{pg} / \mathrm{ml}$ for E. ANP was determined with an indirect RIA (INC-Star; Stillwater, USA) after extraction on SepPak C18 cartridges (Water Associates, Milford, Massachusetts, USA). The intra-assay coefficient of variation was $8.6 \%$ and the interassay coefficient of variation $11.6 \%$ (18). REN was quantitated with an indirect RIA as described by Derkx et al (19).

$\mathrm{VO}_{2 \max }$ was determined in a progressive maximal exercise test, measuring oxygen consumption with a Sensor Medics Horizon metabolic measurement card. Data are presented as means \pm S.E.M. and statistical analysis was performed according to the non-parametric Koch procedure for a two-way crossover design using the Mann-Whitney U-test. $\mathrm{P}<0.05$ was considered statistically significant.

\section{RESULTS}

Endurance training increased $\mathrm{VO}_{2 \max }$ from $3.13 \pm 0.09$ to $3.40 \pm 0.08 \mathrm{l} / \mathrm{min}$ ( $\mathrm{p}$ $<0.01$ ). Resting heart rate declined from $60 \pm 2$ to $57 \pm 2 \mathrm{bpm}(\mathrm{p}<0.05)$. Resting BP, measured with the Dinamap, was $118 \pm 2 / 74 \pm 2 \mathrm{mmHg}$ before and $117 \pm 3 / 74 \pm 2 \mathrm{mmHg}$ after training. $\Delta \mathrm{P}$ was unaltered (sedentary: $44 \pm 2$ $\mathrm{mmHg}$; trained: $43 \pm 2 \mathrm{mmHg}$ ). Differences in D, DC and CC of the three large arteries between the 2 periods were not statistically significant. Data are presented in Table 1. Training induced no significant changes in the various hormones measured at supine rest. Data are presented in Table 2.

Table 1. Diameter (D), distensibility coefficient (DC) and cross-sectional compliance (CC) of the right conmon carotid artery (CCA), right brachial artery (BA) and right common femoral artery (FA).

\begin{tabular}{lll}
\hline & Sedentary & Trained \\
\hline$D_{C C A}(\mathrm{~mm})$ & $6.39 \pm 0.10$ & $6.50 \pm 0.11$ \\
$D_{B A}(\mathrm{~mm})$ & $4.13 \pm 0.08$ & $4.17 \pm 0.09$ \\
$D_{F A}(\mathrm{~mm})$ & $8.34 \pm 0.17$ & $8.45 \pm 0.18$ \\
$D_{C C A}\left(10^{-3} / \mathrm{kPa}\right)$ & $27.3 \pm 1.7$ & $27.5 \pm 2.0$ \\
$D_{B A}\left(10^{-3} / \mathrm{kPa}\right)$ & $24.7 \pm 2.7$ & $22.9 \pm 2.1$ \\
$D_{\mathrm{FA}}\left(10^{-3} / \mathrm{kPa}\right)$ & $18.7 \pm 1.6$ & $19.4 \pm 1.5$ \\
$\mathrm{CCCCA}\left(\mathrm{mm}^{2} / \mathrm{kPa}\right)$ & $0.88 \pm 0.06$ & $0.91 \pm 0.06$ \\
$\mathrm{CC}_{\mathrm{BA}}\left(\mathrm{mm}^{2} / \mathrm{kPa}\right)$ & $0.32 \pm 0.03$ & $0.31 \pm 0.03$ \\
$\mathrm{CC}_{\mathrm{FA}}\left(\mathrm{mm}^{2} / \mathrm{kPa}\right)$ & $1.04 \pm 0.09$ & $1.10 \pm 0.09$ \\
\hline
\end{tabular}

Mean values \pm S.E.M.; no significant differences between sedentary and training periods. 
Table 2. Plasma catecholamine concentration, plasma ANP and plasma renin at supine rest, during sedentary lifestyle and after training.

\begin{tabular}{llll}
\hline & & Sedentary & Trained \\
\hline Norepinephrine & $(\mathrm{pg} / \mathrm{ml})$ & $229 \pm 26$ & $224 \pm 11$ \\
Epinephrine & $(\mathrm{pg} / \mathrm{ml})$ & $24 \pm 7$ & $20 \pm 4$ \\
ANP & $(\mathrm{pg} / \mathrm{ml})$ & $49 \pm 11$ & $55 \pm 12$ \\
Renin & $(\mu \mathrm{U} / \mathrm{ml})$ & $8.0 \pm 0.7$ & $7.6 \pm 0.9$ \\
\hline
\end{tabular}

Mean values $\pm S E M ;$ no significant differences between sedentary and training periods.

\section{DISCUSSION}

The present study provides no evidence for the hypothesis that 6 weeks of moderate exercise training can improve vessel wall properties in previously sedentary men, despite a clear increase in maximal exercise capacity of $9 \%$ and a significant decrease in resting heart rate following training. Changes in vessel wall properties could occur due to changes in transmural pressure, changes in the contractile state of the vascular smooth muscle, or due to structural changes of the vessel wall. Basal systemic arterial pressure was, however, unaltered.

This failure of training to lower blood pressure(BP) seems to contradict with most studies, finding a decrease in resting blood pressure (BP) in normotensive and hypertensive populations (20). As previously reported (16), 24-h blood pressure monitoring at the start of the study showed that 18 subjects could be classified as normotensive, based on recently proposed criteria (average 24-h BP: $126 \pm 4 / 80 \pm 3 \mathrm{mmHg}$ ). One subject was probably hypertensive (mean 24-h BP: 139/91 mmHg).

A BP lowering effect following training, if any, is expected to be small; on the average a decline of $4 \mathrm{mmHg}$ in both systolic and diastolic BP is found (20). On the other hand, our findings agree with some recent studies which have neither found a hypotensive effect on basal BP $(21,22)$ or on 24-hr BP (22). Furthermore, even in labile hypertensive subjects (23) or in established hypertensives (24), a failure of exercise training to lower BP has been reported (see for a detailed discussion chapter 2).

One could argue that the duration ( 6 weeks) or intensity $\left(75 \% \mathrm{VO}_{2 \max }\right.$ ) of the training program was inappropriate. However, even 4 weeks of moderate $\left(60-70 \% \mathrm{~W}_{\text {max }}\right)$ exercise has shown to reduce BP significantly in sedentary normotensive subjects. With regard to the training intensity, however, there is growing support to favor mild to moderate exercise $\left(50-60 \% \mathrm{VO}_{2 \max }\right.$ ) (25).

Our subjects could have been physically too active, a possibility we cannot rule out in Western Europe where it is more common to habitually walk or cycle. Nevertheless, all our subjects had a sedentary lifestyle, their jobs were physically not demanding, and none of the subjects had been engaged in 
regular sport activities for more than $1 \mathrm{~h} /$ week over the last 2 years. In addition, the sedentary leg of our experiment was closely supervised.

The absence of a change in vessel wall properties of large arteries in our study could be solely due to a failure to reduce blood pressure with training. This is supported by the findings of Gilders et al (26) who did not observe a reduction in blood pressure with conditioning and a change in pulse wave velocity both in normotensives and in hypertensives. In contrast, Cameron et al (27) reported an increased arterial compliance and a fall in systolic blood pressure in sedentary subjects after 4 weeks of training. In the latter study, it was stated that further modeling of the changes in arterial compliance suggested a contribution from alteration in pressure-independent factors in addition to a passive, pressure-dependent mechanism, although this was not substantiated by the limited data presented.

Intrinsic modification of vessel wall properties by training was also suggested by cross-sectional studies comparing trained athletes and sedentary individuals $(9,10)$ and a strong inverse linear relationship that was found between pulse wave velocity and physical working capacity in young men (8). In a recent study (10), we observed a higher cross-sectional compliance of the brachial artery and a tendency for a better compliance of the common femoral artery in cyclists when compared to sedentary controls, without significant differences in pulse pressure between the two groups. The better compliance of the brachial artery was due to a better arterial distensibility, probably by a decrease in muscle tone. A decrease in muscle tone could be the resultant of a decline in resting sympathetic nervous activity by endurance training or be mediated via changes in circulating hormones, e.g., the renin-angiotensin system or ANP. Alternatively, animal studies $(28,29)$ have provided some evidence for the fact that training is associated with a decrease in response to adrenergic stimulation at the level of the smooth muscle.

In the present study, however, no changes in resting plasma catecholamines, plasma renin or plasma ANP were detected following training. The absence of a reduction in supine basal norepinephrine levels is contradictory to most training studies, although no significant changes in resting norepinephrine concentrations have been noted by other authors in both normotensives (30) and patients with labile (23) or established hypertension (30, 31 ), following training. No reduction in plasma renin activity was found after 4 weeks of training in sedentary normotensive subjects (2) and in hypertensives (32), which is in agreement with the present study. In accordance with a cross-sectional study, which did not find a difference in resting plasma ANP between controls and distance runners (7), no change in plasma ANP at rest was found.

At present, the effect of training on vessel wall properties of large arteries has not been studied in hypertensives who are likely to have a reduced arterial compliance and distensibility and are possibly more likely to show an improvement after training. Oppliger and colleagues (33) trained hypertensive 
rats and found lower vessel wall/lumen ratios of several large arteries in the trained compared to the untrained, resulting from similar wall thickness values but significantly larger lumen diameters.

In conclusion, a moderate exercise training program of 6 weeks does not lead to an improvement in vessel wall properties in previously sedentary subjects, despite a clear training effect on $\mathrm{VO}_{2 \max }$ and a decrease in resting heart rate.

\section{REFERENCES}

1. DeVries HA. Physiological effects of an exercise training regimen upon men aged 52-88. J Gerontol 25: 325-336, 1970.

2. Jennings G, Nelson L, Nestel P et al. The effects of changes in physical activity on major cardiovascular risk factors, hemodynamics, sympathetic function, and glucose utilization in man: a controlled study of four levels of activity. Circulation 73: 30-40, 1986.

3. Nelson L, Esler MD, Jennings JL, Korner PI. Effect of changing levels of physical activity on blood pressure and hemodynamics in essential hypertension. Lancet ii: 473-476, 1986.

4. Martin JE, Dubbert PJ, Cushman WC. Controlled trial of aerobic exercise in hypertension. Circulation 81: 1560-1567, 1990.

5. Kiyonaga A, Arakawa K, Tanaka $\mathrm{H}$, Shindo $\mathrm{M}$. Blood pressure and humoral response to aerobic exercise. Hypertension 7: 125-131, 1985.

6. Ibanez J, Gauquelin G, Desplanches D et al. Atrial natriuretic peptide response to endurance physical training in the rat. Eur J Appl Physiol 60: 265-270, 1990.

7. Freund BJ, Claybaugh JR, Dice MS, Hashiro GM. Hormonal and vascular fluid responses to maximal exercise in trained and untrained males. J Appl Physiol 63: 669-675, 1987.

8. Eugene $\mathrm{M}$, Vandewalle $\mathrm{H}$, Bertholon JF, Taillac A. Arterial elasticity and physical working capacity in young men. J Appl Physiol 61: 1720-1723, 1986.

9. Mohiaddin RH, Underwood SR, Bogren HG et al. Regional aortic compliance studied by magnetic resonance imaging: the effects of age, training, and coronary artery disease. $\mathrm{Br}$ Heart J 62: 90-96, 1989.

10. Wijnen JAG, Kuipers H, Kool MJF et al. Vessel wall properties of large arteries in trained and sedentary subjects. Basic Res Cardiol 86 (suppl 1): 25-29, 1991.

11. Hoeks AP, Brands PJ, Smeets FA, Reneman RS. Assessment of the distensibility of large arteries. Ultrasound Med Biol 16:121-128, 1990.

12. Reneman RS, Van Merode T, Hick P, Hoeks APG. Flow velocity patterns in and distensibility of the carotid artery bulb in subjects of various ages. Circulation 71:500-509, 1985.

13. Van Merode T, Hick PJJ, Hoeks APG et al. Carotid artery wall properties in normotensive and borderline hypertensive male subjects of various ages. Ultrasound Med Biol 14:563$569,1988$.

14. Blair SN, Goodyear NN, Gibbons LW, Cooper KH. Physical fitness and incidence of hypertension in healthy normotensive men and women. JAMA 252: 487-490, 1984.

15. Blair SN, Kohl HW, Paffenbarger RS, et al. Physical fitness and all-cause mortality: a prospective study of healthy men and women. JAMA 262: 2395-2401, 1989.

16. Wijnen JAG, Kool MJF, Van Baak MA et al. Effect of exercise training on ambulatory blood pressure. Int J Sports Med 15: 10-15, 1994.

17. Van der Hoorn FA, Boomsma F, Man in 't Veld AJ, Schalekamp MA. Determination of catecholamines in human plasma by high-performance liquid chromatography: comparison between a new method with fluorescence detection and an established method with electrochemical detection. J Chromatogr 487: 17-28, 1989. 
18. Van Bortel LM, Schiffers PM, Böhm RO et al. The influence of chronic treatment with verapamil on plasma atrial natriuretic peptide levels in young and elderly hypertensive patients. Eur J Clin Pharmacol 39 (suppl 1): 39-40, 1990.

19. Derkx FH, Stuenkel C, Schalekamp MP et al. Immunoreactive renin, prorenin, and enzymatically active renin in plasma during pregnancy and in women taking oral contraceptives. J Clin Endocrinol Metab 63: 1008-1015, 1986.

20. Fagard R, Duprez D, Clement D, Amery A. Physical exercise in the management of hypertension: a consensus statement by the World Hypertension League. J Hypertens 9: 283-287, 1991.

21. Vanhees L, Hespel P, Van Hoof R et al. Effect of physical training on systemic and brachial artery hemodynamics in normal men. Int J Sports Med 13: 145-151, 1992.

22. Gilders RM, Voner C, Dudley GA. Endurance training and blood pressure in normotensive and hypertensive adults. Med Sci Sports Exerc 21: 629-636, 1989.

23. Cléroux J, Péronnet F, De Champlain J. Effects of exercise training on plasma catecholamines and blood pressure in labile hypertensive subjects. Eur J Appl Physiol 56: 550-554, 1987.

24. Blumenthal JA, Siegel WC, Appelbaum M. Failure of exercise to reduce blood pressure in patients with mild hypertension: results of a randomized controlled trial. JAMA 266: 2098-2104, 1991.

25. Hagberg JM. Exercise, fitness and hypertension. In: Bouchard $C$ et al (eds). Exercise, fitness and health, Human Kinetics, Champaign, ILL, USA, 1990.

26. Gilders RM, Dudley GA. Endurance training and treatment of hypertension: the controversy. Sports Med 13: 71-77, 1992.

27. Cameron JD, Dart AM, Topham S. Effects of 4 weeks of exercise training on arterial compliance in man. Circulation 86 (suppl 1): 276, 1992.

28. Rogers PJ, Miller TD, Bauer BA et al. Exercise training and responsiveness of isolated coronary arteries. J Appl Physiol 71: 2346-2351, 1991.

29. Wiegman DL, Harris PD, Joshua IG, Miller FN. Decreased vascular sensitivity to norepinephrine following exercise training. J Appl Physiol 51: 282-287, 1981.

30. Jo Y, Arita M, Baba A et al. Blood pressure and sympathetic activity following responses to aerobic exercise in patients with essential hypertension. Clin Exp Theory Pract A11 (suppl 1): 411-417, 1989.

31. Duncan JJ, Farr JE, Upton J et al. The effects of aerobic exercise on plasma catecholamines and blood pressure in patients with mild essential hypertension. JAMA 254: 2609-2613, 1985.

32. Urata $H$, Tanabe $Y$, Kiyonaga A et al. Antihypertensive and volume-depleting effects of mild exercise on essential hypertension. Hypertension 9: 245-252, 1987.

33. Oppliger RA, Hodgins T, Tipton CM et al. The influence of training on wall/humen ratio of WKY and SHR populations. Med Sci Sports Exercise 12 (suppl): 130, 1980. 


\section{CHAPTER 5.1}

\section{Variations in exercise systolic blood pressure in physically active middle-aged men with normal and elevated blood pressure}

JAG Wijnen, MA van Baak, ES Tan, AMP Bovens, JGP Vrencken, and FTJ Verstappen

Departments of Occupational Health, Pharmacology, Movement Sciences, and Medical Informatics and Statistics, University of Limburg and Institute of Sports Medicine Limburg, Maastricht, The Netherlands

Int J Sports Med 9: 412-416, 1988 


\section{ABSTRACT}

Considerable interindividual variation in the response of blood pressure to exercise has been found. In this study the response of systolic blood pressure during a progressive maximal bicycle ergometer test was investigated in 747 physically active male subjects over age of 40 years with normal, borderline elevated, and elevated resting blood pressure. The influence of several subject characteristics on this response was studied: $53 \%$ of variation in exercise systolic blood pressure (eSBP) could be explained by work load, pre-eSBP, and maximal working capacity $\left(W_{\text {max }}\right)$. No difference in the slope of eSBP during the exercise test was seen between the three groups. Subjects with higher $W_{\max }$ had lower systolic blood pressure at the same work load compared with subjects with a lower $W_{\text {max }}$. Subjects in the elevated blood pressure group had significantly lower $W_{\max }$, although maximal heart rate and lactate were similar. Other variables were not significantly associated with eSBP.

\section{INTRODUCTION}

Exercise stress testing usually includes measurements of blood pressure before, during, and for several minutes after exercise. Routine measurements during exercise are mainly performed to detect an inadequate blood pressure rise as can be due to aortic valve disease or left ventricular impairment. However, in the last decade it has also been indicated that the blood pressure response during exercise may be of diagnostic and prognostic value in various study populations. In subjects with coronary heart disease, maximal systolic blood pressure showed to be significantly related to the severity of coronary artery disease (12). Also, ratios of early recovery systolic pressure to peak systolic blood pressure have been found to be a sensitive tool for identification of patients with severe coronary artery disease (1). The blood pressure response during exercise testing has been used in the assessment of hypertension $(8,18,21)$ or to detect persons at risk for future hypertension $(5,13,26)$. A common finding in most of these studies is a considerable amount of intersubject variation in the response of blood pressure to exercise $(8,12,23$, 27). Factors independently contributing to this variation are insufficiently evaluated. In men, higher age, obesity index, and cigarette smoking have been shown to be associated with a more pronounced systolic blood pressure response to treadmill exercise. Regular exercise (judged by questionnaire) was not associated independently (4). On the other hand, cross-sectional studies actually measuring physical working capacity suggest that physical fitness is independently and inversely related to resting blood pressure (10). The risk of developing hypertension was found to be substantially increased with low levels of physical fitness (3). Recently, training studies have shown that regular exercise significantly lowered resting systolic and diastolic blood pressure and exercise systolic blood pressure in normotensive and untreated hypertensive sedentary subjects $(14,15,22)$. It is not clear whether the reduction of exercise systolic blood pressure is merely related to a decrease in 
resting blood pressure or is independently associated with an increase in physical fitness.

In this study the response of systolic blood pressure during a progressive maximal bicycle ergometer test was investigated in three different resting blood pressure groups to further evaluate the influence of several subject characteristics on this response, i.e., age, body height, body weight, body fat, supine resting $\mathrm{DBP}$, supine resting $\mathrm{SBP}$, supine resting heart rate, pre-exercise DBP, pre-exercise SBP, pre-exercise heart rate, smoking, alcohol consumption, exercise heart rate, and maximal working capacity.

\section{METHODS}

At three different centers for community health in the south of The Netherlands, 1840 male subjects over the age of 40 years and actively participating in sports at least $1 \mathrm{~h} /$ week volunteered to participate in an experimental sportsmedical examination. At the three centers the same protocol and equipment were used by three especially trained physicians throughout the study. A detailed medical and family history was taken. Subjects were asked about their age, alcohol use, smoking habits, and about medication they were taking. Alcohol consumption was converted into g ethanol/week, the number of cigarettes was recorded. Anthropometric measurements taken included body height, body weight, and body fat (\%), estimated from the sum of four skinfolds (6). Supine blood pressure was measured from the right upper arm by standard sphygmomanometry; if it was elevated, it was remeasured after at least another $5 \mathrm{~min}$ supine rest. The lowest value was taken. Fifth-phase diastolic pressures were used. Based on these casual blood pressure measurements, the participants were classified into a group with normal supine blood pressure (diastolic $<90 \mathrm{mmHg}$ and systolic $<140 \mathrm{mmHg}$ ), borderline-elevated supine blood pressure ( $90 \leq$ diastolic $<95 \mathrm{mmHg}$ and/or $140 \leq$ systolic $<160 \mathrm{mmHg}$ ), or elevated supine blood pressure (diastolic $\geq 95 \mathrm{mmHg}$ and/ or systolic $\geq 160 \mathrm{mmHg}$ ), according to WHO criteria, excluding 65 subjects using cardiovascular drugs. Prior to the exercise test, a thorough physical examination was performed to judge whether the subjects could safely perform the test, supine heart rate was measured, and a 12-lead ECG in supine position made. Ten subjects were excluded (three for signs of recent infarction, four because of severe hypertension (diastolic $>120 \mathrm{~mm} \mathrm{Hg}$ ), two were poorly regulated diabetics, one had a left bundle-branch block with heart murmur).

\section{Exercise test}

The subjects were seated upright on a Lode bicycle ergometer with the 3-lead (II, V1, V5) ECG electrodes in place. The test was performed with a pedal frequency between 60 and $80 \mathrm{rpm}$, starting $5 \mathrm{~min}$ at a work load of $100 \mathrm{~W}$. 
Thereafter, the work load was increased by $50 \mathrm{~W}$ every $2.5 \mathrm{~min}$ until a heart rate between 140 and $150 \mathrm{~b} / \mathrm{min}$ was reached. Then the increment was $25 \mathrm{~W}$ every 2.5 min until exhaustion. Maximal work load $\left(W_{\max }\right)$ was the highest work load that could be maintained for $2.5 \mathrm{~min}$. If the final work load was not completed, $\mathrm{W}_{\max }$ was calculated out of the completed time. Between the 3rd and 5 th min of recovery, a blood sample was drawn form a cubital vein for measurement of plasma lactate concentration (LA 640 Roche)(9). This exercise test design was chosen because it allowed to evaluate the maximal working capacity $\left(\mathrm{W}_{\text {max }}\right)$ in a relatively short time (approximately $15 \mathrm{~min}$ ) and yet to make reliable blood pressure measurements. It has been shown that at higher work loads, a plateau in blood pressure is reached after $2 \mathrm{~min}$ (21). Systolic and diastolic blood pressures were recorded with standard sphygmomanometry at rest just before testing, sitting on the bicycle (pre-exercise blood pressure), and during the last $30 \mathrm{~s}$ of each work load. The point of muffling of Korotkoff sounds (phase IV) was taken as exercise diastolic blood pressure. During measurements, the arm was extended over the handle bars of the bicycle ergometer and supported by the physician. Heart rate was determined from the ECG at the end of each work load.

\section{Statistical analysis}

Data records of 1765 male subjects not using cardiovascular medication and having performed the exercise test were available. The measurement of exercise systolic blood pressure (esBP) at the final work load was judged to be unreliable and not included. To compare between the three blood pressure groups with respect to the means of baseline characteristics, analysis of variance (ANOVA) and two sample t-tests were performed. Differences between frequencies were evaluated by the chi square test. Significance tests were performed at the 0.05 and 0.01 levels. Inspection of individual data on eSBP at different work loads suggested that a linear relationship between eSBP and work load would be appropriate. At higher work loads the observed lines leveled off. Hence, a multiple regression analysis was performed with eSBP as the dependent variable and work load (WL) as the independent variable and 14 prognostic factors to control for intersubject variation: age, body height, body weight, body fat, supine DBP, supine SBP, supine heart rate, pre-exercise $\mathrm{DBP}$, pre-exercise $\mathrm{SBP}$, pre-exercise heart rate, smoking, alcohol consumption, exercise heart rate, and $\mathrm{W}_{\max }$. Only subjects with at least two values of eSBP (i.e., exercise test with two or more submaximal work loads) were included because no linear relation can be assumed with only one measurement. As a consequence, subjects included in the analysis had a $W_{\max }$ of $150 \mathrm{~W}$ or more $(n=1726)$. Moreover, only subjects who fulfilled strict criteria for a maximal exercise performance (i.e., maximal heart rate $\geq$ (220age) and plasma lactate after exercise $\geq 8 \mathrm{mmol} / \mathrm{l}$ ) were included so that with greatest possible certainty true $W_{\max }$ was reached. This limited analyses to 
747 subjects. To test whether the relationships between ESBP and WL were different for the three blood pressure groups, two dummy variables were introduced in the multiple regression analysis. The first dummy variable BORD (value 0 or 1 ) identified the borderline-elevated blood pressure group, the second dummy variable ELEV (value 0 or 1 ) identified the elevated blood pressure group. The decision on how many prognostic factors to retain in the final form of the regression model was made by using the all-possible subset method. That subset with the largest number of prognostic factors plus WL and the two dummy variables with regression coefficients significantly different from zero was selected and considered to be the best-fitted model. The assessment of significance was done by comparing the estimated regression coefficients relative to their standard errors with the usual 0.975 percentile of the $t$-distribution. As a by-product, the coefficient of determination $R^{2}$ was assessed. $R^{2}$ represents the proportion of total variability of the dependent variable that is accounted for by the regression model. In the multiple regression analysis, the dependence of eSBP between successive work loads within individuals was ignored. This resulted in an overestimation of the standard errors of the regression coefficient estimators. For this reason the best-fitted model according to the all-subset method might be only suboptimal. However, only the relation between WL and ESBP for the three blood pressure groups was of particular interest. The other variables were considered in the analysis only to adjust for these factors. As a consequence, the regression coefficient for WL of the best-fitted model was compared with that of the regression model containing all possible prognostic factors at hand. If the two coefficients were not substantially different than for reasons of parsimony the condensed model was considered to be a more convenient summary of data.

\section{RESULTS}

Subject characteristics for the three blood pressure groups are presented in Table 1. The subjects in the highest blood pressure group were slightly older than in the other groups. Body weight did not differ across the blood pressure groups, but the subjects with borderline elevated or elevated blood pressure had a significantly higher \% body fat than the normal blood pressure group. Compared with the other groups the borderline-elevated group was slightly taller. Smoking habits and alcohol consumption did not significantly differ between the groups. Supine heart rate was lower in the normal blood pressure group. $W_{\max }$ was significantly lower in the highest blood pressure group despite the fact that maximal heart rate and plasma lactate were similar in all three groups. Average eSBP for the three groups at 100, 150, 200 and $250 \mathrm{~W}$ are presented in Table 2 . Results from the multiple regression analysis on eSBP are shown in Table 3. The variable explaining most of the variance was work load $(W L)\left(R^{2}=0.386\right)$. An additional $14.2 \%$ could be explained by pre-exercise SBP (pre-eSBP) $\left(R^{2}=0.099\right)$ and $W_{\max }\left(R^{2}=0.043\right) ; 6.6 \%$ of 
Table 1. Comparison between normal, borderline-elevated, and elevated blood pressure groups.

\begin{tabular}{|c|c|c|c|}
\hline \multirow[b]{2}{*}{ Variables (means $\pm \mathrm{SD}$ ) } & \multicolumn{3}{|l|}{ blood pressure } \\
\hline & $\begin{array}{l}\text { Normal } \\
(n=322)\end{array}$ & $\begin{array}{l}\text { Borderline-elevated } \\
(n=278)\end{array}$ & $\begin{array}{l}\text { Elevated } \\
(n=147)\end{array}$ \\
\hline Age (y) & $46.4 \pm 4.8$ & $47.2 \pm 6.4$ & $48.4 \pm 6.4^{* *}$ \\
\hline Body height $(\mathrm{cm})$ & $175.2 \pm 6.2$ & $175.5 \pm 6.1 *$ & $174.2 \pm 6.3$ \\
\hline Body weight (kg) & $77.1 \pm 8.0$ & $78.1 \pm 8.2$ & $78.1 \pm 7.8$ \\
\hline Body fat $(\%)$ & $22.5 \pm 5.0^{* *}$ & $23.8 \pm 4.7$ & $24.7 \pm 4.9 * *$ \\
\hline Smokers (\%) & 24.8 & 21.7 & 27.2 \\
\hline Alcohol consumers (\%) & 89.1 & 90.1 & 85.7 \\
\hline Alcohol consumption $(\mathrm{g} / \mathrm{w})$ & $139 \pm 112$ & $136 \pm 114$ & $154 \pm 132$ \\
\hline Supine SBP (mmHg) & $126.0 \pm 7.5^{* *}$ & $138.9 \pm 7.5^{* *}$ & $149.2 \pm 12.0^{* *}$ \\
\hline Supine DBP (mmHg) & $80.8 \pm 4.4^{* *}$ & $88.0 \pm 3.4^{* *}$ & $96.8 \pm 4.5^{* *}$ \\
\hline Supine HR (bpm) & $62.6 \pm 7.8^{* *}$ & $64.6 \pm 8.6^{* *}$ & $68.0 \pm 9.5^{* *}$ \\
\hline Pre-exercise SBP (mmHg) & $127.5 \pm 10.4^{* *}$ & $134.3 \pm 10.9^{* *}$ & $144.8 \pm 12.5^{* *}$ \\
\hline Pre-exercise DBP (mmHg) & $84.6 \pm 6.1^{* *}$ & $89.3 \pm 5.2 * *$ & $96.3 \pm 5.6^{* *}$ \\
\hline Pre-exercise HR (bpm) & $68.0 \pm 10.6^{* *}$ & $69.7 \pm 10.7^{* *}$ & $73.5 \pm 11.1^{* *}$ \\
\hline$W_{\max }(W)$ & $258.5 \pm 43.9$ & $258.6 \pm 45.6^{* *}$ & $243.2 \pm 46.2 * *$ \\
\hline$H R_{\max }(\mathrm{bpm})$ & $181.9 \pm 7.7$ & $181.8 \pm 10.1$ & $181.2 \pm 7.9$ \\
\hline Plasma lactate (mmol/1) & $12.0 \pm 2.5$ & $11.9 \pm 2.6$ & $11.7 \pm 2.2$ \\
\hline
\end{tabular}

${ }^{*} p<0.05 ;{ }^{* *} p<0.01$ (for two-sample t-test, based on between-group significance in ANOVA test). Asterisks after the third column refer to differences between the first and third columns. Asterisks between columns refer to differences between adjacent columns. SBP, systolic blood pressure; DBP, diastolic blood pressure; HR, heart rate.

Table 2. Exercise systolic blood pressure (mean $\pm \mathrm{SD}, \mathrm{mmHg}$ ) at different work loads for the normal, borderline-elevated, and elevated blood pressure groups.

\begin{tabular}{llll}
\hline & \multicolumn{3}{l}{ blood pressure } \\
\cline { 2 - 4 } Work load $(W)$ & Normal & Borderline-elevated & Elevated \\
\hline 100 & $163 \pm 15$ & $169 \pm 16$ & $180 \pm 17$ \\
$\mathbf{n}$ & 322 & 278 & 147 \\
150 & $179 \pm 17$ & $185 \pm 16$ & $197 \pm 19$ \\
$\mathbf{n}$ & 322 & 277 & 146 \\
200 & $192 \pm 16$ & $198 \pm 17$ & $208 \pm 18$ \\
$\mathbf{n}$ & 291 & 249 & 115 \\
250 & $201 \pm 17$ & $203 \pm 16$ & $216 \pm 14$ \\
$\mathbf{n}$ & 166 & 129 & 48 \\
\hline
\end{tabular}

$n=$ number of subjects 
Table 3. Summary of multiple regression results on exercise systolic blood pressure.

\begin{tabular}{llll}
\hline Variable & Regression coefficient & Standard deviation & t-ratio \\
\hline Constant & 103 & 3 & 32.27 \\
Pre-exercise SBP & 0.64 & 0.02 & 25.65 \\
Work load & 0.274 & 0.005 & 55.25 \\
cWork load $^{2}$ & -0.00059 & 0.00007 & -8.07 \\
cW $_{\max }$ & -0.115 & 0.007 & -17.48 \\
cW $_{\max }{ }^{2}$ & 0.00034 & 0.00009 & 3.68 \\
BORD & 1.4 & 0.6 & 2.30 \\
ELEV & 4.8 & 0.8 & 5.7 \\
\hline
\end{tabular}

$R^{2}=.594 ; s=14.34 ; R^{2}=$ proportion variance explained by the model; $s=$ standard deviation of the error; $a=$ all $t$-ratios are significant at 0.05 level; $c$ Work load $=$ work load - mean work load (172.59); $c W_{\max }=W_{\max }-$ mean $W_{\max }(264.33) ; B O R D=$ dummy variable $(0-1)$ of borderline-elevated blood pressure group; $E L E V=$ dummy variable (0-1) of elevated blood pressure group. Regression equation is $e S B P=92.3+.64$ pre-exercise $S B P+.474$ work load $-59 \times 10^{-5}$ work load ${ }^{2}-.295 W_{\max }+34 x$ $10^{-5} \mathrm{~W}_{\text {max }^{2}}+1.42 B O R D+4.83 E L E V$

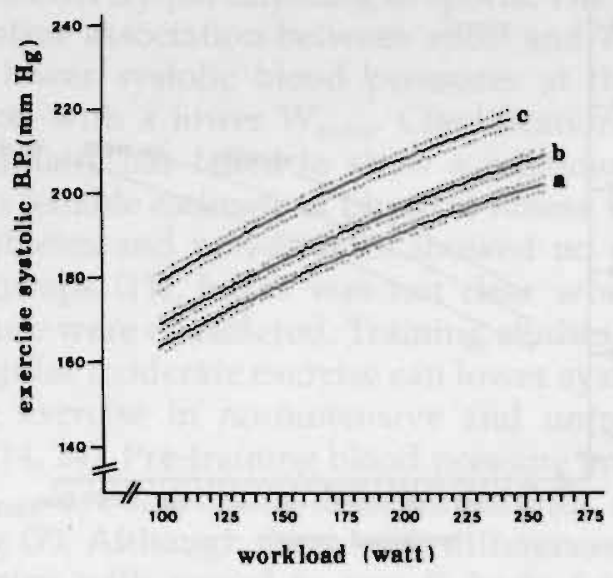

Fig. 1 Regression lines with $95 \%$ confidence bands for the relation between $E S B P$ and work load for the normal $(a)$, borderline-eleonted $(b)$, and eleonted $(c)$ blood pressure group.

variation was accounted for by the division of supine blood pressure in the three blood pressure groups. In addition, other prognostic variables did not independently contribute to the variation of eSBP. Fig. 1 shows regression lines with $95 \%$ confidence bands of ESBP and WL for the three blood pressure groups. Note that at high work loads the increase in eSBP becomes less. Analysis reveals it is not caused by a selection of subjects at higher work loads 


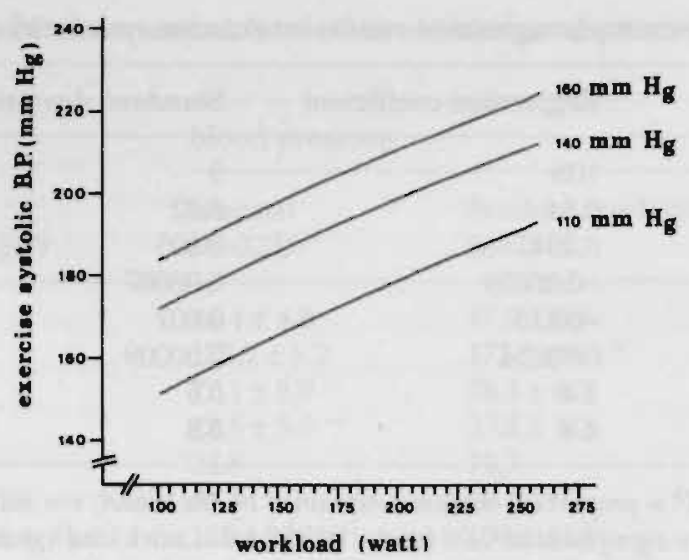

Fig. 2 Regression lines of $\mathrm{SBP}$ in relation to work load for three different levels of pre-exercise systolic blood pressure $(110,140$, and $160 \mathrm{mmHg})$ when adjustments are made for $W_{\max }$.

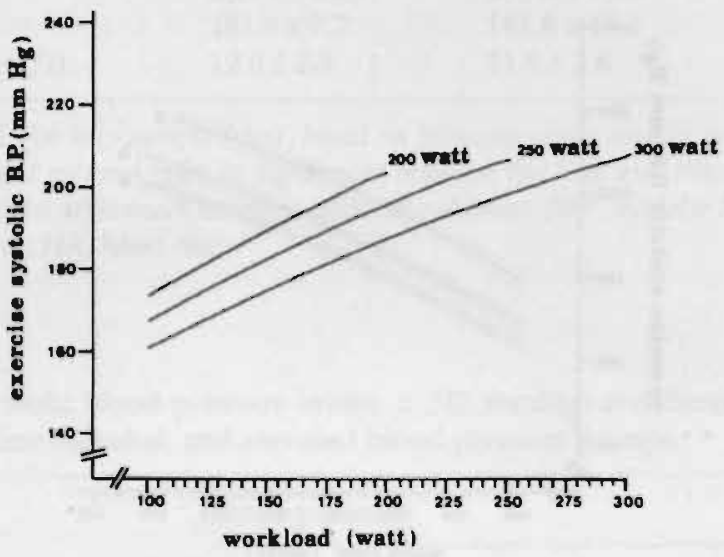

Fig. 3 Regression lines of $\mathrm{SSBP}$ in relation to work load for three different levels of $W_{\max }(200,250$, and $300 \mathrm{~W})$ when adjustments are made for pre-exercise systolic blood pressure.

with a high $W_{\max }$ and low pre-eSBP. Mean increase above pre-eSBP at a work load of $100 \mathrm{~W}$ was $35 \mathrm{mmHg}$ in the normal, borderline-elevated, and elevated blood pressure group. Figures 2 and 3 show regression lines of eSBP in relation to work load when adjustments are made for $W_{\max }$ or pre-eSBP, respectively. When $W_{\max }$ is controlled initial differences in pre-eSBP are maintained during exercise. Analysis (by introducing interaction between the dummy and other variables) showed no difference in pressure rise for dif- 
ferent levels in pre-eSBP. In case pre-eSBP is controlled differences in physical working capacity are reflected. For example, a subject with a pre-eSBP of 125 $\mathrm{mmHg}$ and a $\mathrm{W}_{\max }$ of $200 \mathrm{~W}$ has an eSBP of $168 \mathrm{mmHg}$ at $100 \mathrm{~W}$ compared with $161 \mathrm{mmHg}$ for a subject with the same pre-eSBP but a $\mathrm{W}_{\max }$ of $250 \mathrm{~W}$.

\section{DISCUSSION}

The study shows that $53 \%$ of variation in eSBP during cycle ergometry could be explained by work load, pre-eSBP and $W_{\max }$. No differences in the slope of eSBP between groups of subjects with normal, borderline-elevated, and elevated supine blood pressure were seen although absolute values were clearly different. In accordance with other studies using either treadmill testing or bicycle ergometry $(4,8,12,27)$, our study showed a wide variability of eSBP. This is reflected by the fact that work load alone explains only $39 \%$ of total variance in eSBP. Our values of eSBP during submaximal exercise are comparable with those found in a physically active population of the same age by Heck et al (11), but somewhat lower than in a study on sedentary subjects by Nordenfeldt et al (23), which could be explained by the fact that our subjects were all actively participating in sports. The main finding in our study was the negative association between eSBP and $W_{\max }$. Subjects with higher $W_{\max }$ had lower systolic blood pressures at the same work load compared to subjects with a lower $W_{\max }$. Classification of physical fitness based on a questionnaire has failed to show a relationship with eSBP (4), possibly because no reliable estimate of physical fitness was obtained. Comparison between athletes and non-athletes showed no differences in eSBP between the two groups (11), but it was not clear whether differences in resting blood pressure were considered. Training studies, on the other hand, have shown that regular moderate exercise can lower systolic blood pressure at rest and during exercise in normotensive and untreated hypertensive sedentary subjects $(14,24)$. Pre-training blood pressure and the magnitude of the increase in $W_{\max }$ are important determinants for the blood pressure response to training (7). Although there were differences between the three blood pressure groups with regard to age, \% body fat, body height, and resting heart rate, we could not find an independent association with $\mathrm{SSBP}$ for these variables. Subjects in the elevated blood pressure group had significantly lower $W_{\max }$ than those in the two other groups, although maximal heart rates were similar, suggesting differences in stroke volume between the groups $(2,19)$. No differences in eSBP were found between the three blood pressure groups. This confirms studies by other authors $(4,12,16,20,21)$. On the other hand, one study showed an exaggerated systolic blood pressure response during exercise in a subgroup of borderline hypertensives (8). Others have pointed to the fact that an excessive rise in SBP during exercise is mainly seen in hypertensives with advanced stages of disease (25). Subjects with severe hypertension and those using antihypertensive medication were 
excluded from our study (see Methods section). Although some studies show positive associations between age and $\operatorname{eSBP}(4,17,19)$, we could not confirm an independent relationship. A possible explanation is the relatively small ag range (40-63 y) in our study compared to other studies. In another study with a comparable range in age, no relationship was found between changes in nificantly correlated with SBP In treadmill testing a strong were not sigtion was found between Quetelet index and $\mathrm{CSBP}$, with the association was found between Quetelet index and eSBP, with the regression coeffict able that an independentl found during treadmill exercise, where the intensity at a certain speed For treadmill testing only positive associations with $\mathrm{SBP}$ at higher work For treadmill testing only positive associations with eSBP at higher work loads were found (4). Assocition of smoking with ESBP could be masked by There was no association between ESBP and alcohol consumption (yes which is in agrement with wa in wupine heart rate, and exercise heart rate were not independently associated with SBP. wroups. There was a mean increase of $5 \mathrm{~b} / \mathrm{min}$ in resting hlood pressure gupine to sitting position incssibly also due to some anticipation to the supine to sitting positio The variables determin

determined in our study explained $59 \%$ of variation in eSBP It is reasonable to assume there are some variables we did not include in our study which influen SBP additionally (for intance, bioch monal factors). The variability of the indirect method for blood presure monal factors. The variability of the indirect method for blood pressure

\section{REFERENCES}

1. Amon KW, Richards KL, Crawford MH. Usefulness of the post-exercise response of systolic blood pressure in the diagnosis of coronary artery disense. Circulation 70 : 951-956, 1984

2. Van Baak MA, Koene FM, Verstappen FT. Exercise hemodynamics and maximal exercise capacity during beta-adrenoceptor blockade in normotensive and hypertensive subjects. Br J Clin Pharmacol 25: 169-178, 1988

3. Blair SN, Goodyear NN, Gibson LW, Cooper KH. Physical fitness and incidence of 4. Criqui MH. Haskell WL Heiss G, Tyroler HA Green P. Rubenstein CI. Predictors systolic blood pressure response to treadmill exercise: the lipoid research clinic program

Dlin RA, Hant

, Silverberg DS, Bar-Or $\mathrm{O}$. Follow-up of normotensive men with

Durnin JV, Womersley J. Body fat assessed form total body density and its est

from skinfold thickness: measurements on 481 men and women aged 16 to 72 years. $\mathrm{Br}$ I Nutr 32: 77-97, 1974 .
7. Fagard R. Habitual physical activity, training, and blood pressure in normo- and hyperFranz IW. Ergometry in the assesment of arterial hypertension. Cardiology 72: 147-159,

Geyssaut A, Dormois D, Barthelemy JC, Lacour [R. Lactate determination with the lactate analyser LA 640: a critical study. Scand I Clin Lab Invest 45: 145-149, 19 ing and alcohol consumption in Copenhagen males aged 40-59. Acta Med Scand 195: (3) 380,1974

11. Heck H, Rost R, Hollmann W. Standard blood pressure values during ergometric bicycle tests. Disch Z Sportmed 7: 243-249, 1984

2. Irving JB, Bruce RA, De Rouen TA. Variations in and significance of systolic pressur

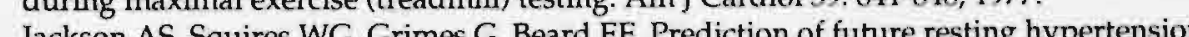
13. Jackson AS, Squires WG, Grimes G, Beard EF. Prediction of furture rest

Jennings $G$, Nelson $L$ Nestel P, Esler M, Korner P, Burton D, Bazelmans J. The effects of unction and glucose utilization in man: a controlled study of four levels of activity. Circulation 73: 30-40, 1986

15. Jennings G, Nelson L, Dewar E, Korner P, Esler M, Laufer E. Antihypertensive and hemodynamic effects of one year's regular exercise. J Hypertension $4.5659-5661,1986$.

17. Karlefors $T$, Nilsen $R$, Westling $H$. On the accuracy of indirect auscultatory blood

pressure measurements during exercise. Acta Med Scand (suppl) 449: 81-87, 1966.

18. Leibel B, Kobrin I, Ben-Ishay D. Exercise testing in the assessment of hypertension. Br Med J 285: 1535-1536, 1982.

19. Lund-Johansen A. Hemodynamics in essential hypertension. Acta Med Scand 482 (suppl): 8-102, 1967

20. Lund-Larsen $P G$, Helgeland $A$, Leren $P$. Systolic blood pressure and heart rate changes 680: $31-33,1982$

1. Millar-Craig MW, Balasubramanian V, Mann S, Raftery EB. Use of graded exercise

testing in assessing the hypertensive patient. Clin Cardiol 3: 236-240, 1980.

22. Nelson $L$, Jennings $G$, Esler $M$, Komer PI. Effect of changing levels of physical activity on blood pressure and hemodynamics in essential hypertension. Lancet ii: $474-476,1986$

23. Nordenfelt 1, Adolfson L, Nilsson JE, Olsson $\mathrm{S}$. Reference values for exercise tests with

.

.

25. Sannerstedt $R$. Hemodynamic response to exercise in patients with arterial hypertension.

Acta Med Scand (suppl) 458: 7-83, 1966 .

26. Wilson NV, Meyer BM. Early prediction of hypertension using exercise blood pressure. Prev Med 10: 62-68, 1981

A Fischer J, Triebwasser HH. The response of healthy men to Wre 
7. Fagard R. Habitual physical activity, training, and blood pressure in normo- and hypertension. Int J Sports Med 6: 57-67, 1985.

8. Franz IW. Ergometry in the assessment of arterial hypertension. Cardiology 72: 147-159, 1985.

9. Geyssaut A, Dormois D, Barthelemy JC, Lacour JR. Lactate determination with the lactate analyser LA 640: a critical study. Scand J Clin Lab Invest 45: 145-149, 1985.

10. Gyntelberg F, Meyer J. Relationship between blood pressure and physical fitness, smoking and alcohol consumption in Copenhagen males aged 40-59. Acta Med Scand 195: 375-380, 1974.

11. Heck $\mathrm{H}$, Rost $\mathrm{R}$, Hollmann $W$. Standard blood pressure values during ergometric bicycle tests. Dtsch Z Sportmed 7: 243-249, 1984.

12. Irving JB, Bruce RA, De Rouen TA. Variations in and significance of systolic pressure during maximal exercise (treadmill) testing. Am J Cardiol 39: 841-848, 1977.

13. Jackson AS, Squires WG, Grimes G, Beard EF. Prediction of future resting hypertension from exercise blood pressure. J Cardiac Rehab 3: 263-268, 1983.

14. Jennings G, Nelson L, Nestel P, Esler M, Korner P, Burton D, Bazelmans J. The effects of changes in physical activity cardiovascular risk factors, hemodynamics, sympathetic function and glucose utilization in man: a controlled study of four levels of activity. Circulation 73: 30-40, 1986.

15. Jennings G, Nelson L, Dewar E, Korner P, Esler M, Laufer E. Antihypertensive and hemodynamic effects of one year's regular exercise. J Hypertension 4: 5659-5661, 1986.

16. Julius S, Pascual AV, Sannerstedt R, Mitchell C. Relationship between cardiac output and peripheral resistance in borderline hypertension. Circulation 43: 3832-390, 1971.

17. Karlefors T, Nilsen R, Westling $\mathrm{H}$. On the accuracy of indirect auscultatory blood pressure measurements during exercise. Acta Med Scand (suppl) 449: 81-87, 1966.

18. Leibel B, Kobrin I, Ben-Ishay D. Exercise testing in the assessment of hypertension. Br Med J 285: 1535-1536, 1982.

19. Lund-Johansen A. Hemodynamics in essential hypertension. Acta Med Scand 482 (suppl): 8-102, 1967.

20. Lund-Larsen PG, Helgeland A, Leren P. Systolic blood pressure and heart rate changes during exercise in three groups of $40-49$ year old men in Oslo. Acta Med Scand (suppl) 680: 31-33, 1982.

21. Millar-Craig MW, Balasubramanian V, Mann S, Raftery EB. Use of graded exercise testing in assessing the hypertensive patient. Clin Cardiol 3: 236-240, 1980.

22. Nelson L, Jennings G, Esler M, Korner PI. Effect of changing levels of physical activity on blood pressure and hemodynamics in essential hypertension. Lancet ii: 474-476, 1986.

23. Nordenfelt I, Adolfson L, Nilsson JE, Olsson S. Reference values for exercise tests with continuous increase in load. Clin Phys 5: 161-172, 1985.

24. Roman O, Camuzzi AL, Villalon E, Klenner C. Physical training program in arterial hypertension. A long-term prospective follow-up. Cardiology 67: 230-243, 1981.

25. Sannerstedt $R$. Hemodynamic response to exercise in patients with arterial hypertension. Acta Med Scand (suppl) 458: 7-83, 1966.

26. Wilson NV, Meyer BM. Early prediction of hypertension using exercise blood pressure. Prev Med 10: 62-68, 1981.

27. Wolthuis RA, Froelicher VF, Fischer J, Triebwasser HH. The response of healthy men to treadmill exercise. Circulation 55: 153-157, 1977. 


\section{CHAPTER 5.2}

\section{Exercise systolic blood pressure in middle-aged women with normal and elevated blood pressure}

JAG Wijnen, ES Tan, MA van Baak, AMP Bovens, JGP Vrencken, FTJ Verstappen, and M Schim van der Loeff

Departments of Pharmacology, Medical Informatics and Statistics, Human Biology and Movement Sciences, University of Limburg and Institute of Movement Sciences, Maastricht, The Netherlands

Int J Sports Med 1995, 16, in press 


\section{ABSTRACT}

Considerable interindividual variation in the response of blood pressure to exercise has been found. Factors independently contributing to this variation are insufficiently evaluated. This especially true for women and older age groups. Reference values of progressive maximal exercise testing in middle-aged, active subjects, especially in women, are scarce. In this study, the response of systolic arterial blood pressure during a progressive maximal cycle ergometer test was investigated in 871 physically active female subjects aged 40 years or older with normal, borderline elevated and elevated blood pressure. The influence of 14 different subject characteristics on this response was studied: $63 \%$ of variation in exercise systolic blood pressure (eSBP) could be explained by work load, pre-eSBP, age and exercise heart rate. No difference in eSBP with increasing work load was found between the three groups. Subjects with higher exercise heart rates had higher systolic blood pressures at the same work load compared to subjects with lower exercise heart rates. Maximal working capacity $\left(W_{\max }\right)$ was significantly lower in the elevated blood pressure group although maximal heart rate and lactate were similar. $W_{\max }$ was age-dependent. Other subject variables were not significantly associated with eSBP. Values of eSBP for reference purposes are presented.

\section{INTRODUCTION}

Nowadays, the blood pressure response during exercise testing is often used for diagnostic and prognostic purposes. In patients with coronary heart disease, maximal systolic blood pressure was shown to be significantly related to the severity of coronary artery disease (10). The blood pressure response to exercise has been used in the assessment of hypertension $(7,14)$ or to detect persons at risk for future hypertension $(4,21)$. Considerable amount of variation in blood pressure has been reported (2).

Factors independently contributing to this variation are insufficiently evaluated. This is especially true for women and older age groups. In women, systolic blood pressure (SBP) increased more during bicycle exercise in subjects aged 50 years or older than in younger subjects (15). During submaximal treadmill exercise, a positive association was found between SBP response and age in 20 to 49 year old women but not in women of 50 years or older (3). In 20 to 49 year old women, Quetelet index and alcohol consumption were all positively associated with the SBP response to treadmill exercise, but smoking and regular exercise were not (3).

In this study the response of SBP during a progressive maximal cycle ergometer test was investigated in a large, middle-aged female population. The influence of several subject characteristics (i.e. age, body weight, body height, body fat, supine resting diastolic blood pressure (DBP), supine resting $S B P$, supine resting heart rate (HR), pre-exercise DBP, pre-exercise SBP, preexercise HR, smoking, alcohol consumption, exercise heart rate and maximal 
work capacity) on SBP response to maximal exercise was studied in women with normal, borderline elevated and elevated resting blood pressure.

\section{SUBJECTS AND METHODS}

At three different centers for community health in the south of the Netherlands, 1257 female subjects over the age of 40 years and actively participating in sports at least $1 \mathrm{~h} /$ week volunteered to participate in an experimental sports-medical examination. Most popular types of sport were calisthenics $(37 \%)$, tennis (35\%), jogging ( $22 \%)$, and swimming (20\%). On the average, the study population participated $3.5 \pm 2.8 \mathrm{~h} /$ week in sport activities in the year preceding this examination. At the three centers the same protocol and equipment were used by three specially trained physicians throughout the study. A detailed medical and family history was taken. Subjects were asked about their age, alcohol use, smoking habits, and about any medication they were taking. Alcohol consumption was converted into g ethanol/week, the number of cigarettes per day was recorded. Anthropometric measurements taken included body weight, body height, and body fat (\%), estimated from the sum of four skinfolds (6). Casual supine blood pressure was measured after $10 \mathrm{~min}$ rest from the right upperarm by standard mercury sphygmomanometry; if it was elevated ( $\geq 140 / 90 \mathrm{mmHg}$ ), it was remeasured after at least another $5 \mathrm{~min}$ supine rest. The lowest values were taken. Fifth phase diastolic pressures were used. Based on these casual blood pressure measurements, the participants were classified into a group with normal supine arterial blood pressure (diastolic $<90 \mathrm{mmHg}$ and systolic $<140 \mathrm{mmHg}$ ), borderline elevated supine arterial blood pressure $(90 \leq$ diastolic $<95 \mathrm{mmHg}$ and/or $140 \leq$ systolic $<160 \mathrm{mmHg}$ ), or elevated supine arterial blood pressure (diastolic $\geq 95$ $\mathrm{mmHg}$ and/or systolic $\geq 160 \mathrm{mmHg}$ ), excluding 85 subjects using cardiovascular drugs. Prior to the exercise test, a thorough examination was performed to judge if the subjects could safely perform the test, supine heart rate measured, and a 12-lead ECG in supine position made. Sixteen subjects were excluded (five severe anemia, six severe hypertension (diastolic pressure > $120 \mathrm{mmHg}$ ), one orthopedic disability, one instable angina, three poorly regulated diabetes mellitus).

\section{Exercise test}

The subjects were seated upright on a Lode cycle ergometer with the 3-lead (II, V1, V5) ECG electrodes in place. The test was performed with a pedal frequency between 60 and $80 \mathrm{rpm}$, starting $5 \mathrm{~min}$ at a work load of $50 \mathrm{~W}$. Thereafter, with the pedal rate fixed, the work load was increased by $50 \mathrm{~W}$ every $2.5 \mathrm{~min}$ until a heart rate between 140 and 150 beats/min was reached. Then the increment was $25 \mathrm{~W}$ every 2.5 min until exhaustion. Maximal work load $\left(W_{\max }\right)$ was the highest work load that could be maintained for $2.5 \mathrm{~min}$. If the final increment of power output could not be maintained for $2.5 \mathrm{~min}$, 
$\mathrm{W}_{\max }$ was calculated with a correction for the completed time of that increment ( $5 \mathrm{~W}$ per $30 \mathrm{~s}$ ). Between the $3 \mathrm{rd}$ and 5 th min of recovery, a blood sample was drawn from a cubital vein for measurement of plasma lactate concentration (LA640 Roche) (8). This exercise test design was chosen because it made it possible to evaluate the maximal working capacity in a relatively short time (approx. $15 \mathrm{~min}$ ) and yet to make reliable blood pressure measurements. It has been shown that at higher work loads a plateau in blood pressure is reached after $2 \mathrm{~min}$ (16). Systolic and diastolic blood pressures were recorded with standard mercury sphygmomanometry at rest just before testing, sitting on the cycle ergometer (pre-exercise blood pressure) and during the last $30 \mathrm{~s}$ of each work load. The point of muffling of Korotkoff sounds (phase IV) was taken as exercise diastolic blood pressure. During measurements, the arm was extended over the handle bars of the bicycle ergometer and supported by the physician. Heart rate was determined from the ECG before exercise and at the end of each work load.

\section{Statistical analysis}

Data records of 1156 female subjects not using cardiovascular medication and having performed the test were available. To compare between the three blood pressure groups with respect to baseline characteristics, analyses of variance (ANOVA) and two sample t-tests were performed. Differences between frequencies were evaluated by chi square test. Significance tests were performed at the 0.05 and 0.01 levels. Inspection of individual data on exercise systolic blood pressure (eSBP) at different work loads suggested that a linear relationship between $\mathrm{SBP}$ and work load was appropriate. Hence, a multiple regression analysis was performed with $\mathrm{ESBP}$ at the dependent variable and work load $(W L)$ as the independent variable and with 14 prognostic factors to control for intersubject variation: age, body height, body weight, body fat, supine DBP, supine SBP, supine heart rate, pre-exercise DBP, pre-exercise SBP, pre-exercise heart rate, smoking, alcohol consumption, exercise heart rate, and $W_{\max }$. Only subjects with at least two values of eSBP (i.e. exercise test with two or more submaximal work loads) were included because no linear relation can be assumed with only one measurement. As a consequence, subjects included in the analysis had a $W_{\max }$ of $100 \mathrm{~W}$ or more $(n=1149)$. Moreover, only subjects who fulfilled strict criteria for a maximal exercise performance (i.e. maximal heart rate ( $\geq$ (200-age) and/or plasma lactate after exercise $\geq 6 \mathrm{mmol} / \mathrm{l}$ ) were included, so that with greatest possible certainty true $W_{\max }$ was reached. This limited analysis to 817 subjects. To test whether the relationships between $\mathrm{SBBP}$ and WL were different for the three blood pressure groups, two dummy variables were introduced in the multiple regression analysis. The first variable BORD (value 0 or 1 ) identified the borderline elevated blood pressure group, the second dummy variable ELEV (value 0 or 1 ) identified the elevated blood pressure group. The decision on 
how many prognostic factors to retain in the final form of the regression model was made by using the all-possible subset method. That subset with the largest number of prognostic factors plus WL and the two dummy variables with the regression coefficients significantly different from zero was selected and considered to be the best-fitted model. The assessment of significance was done by comparing the estimated regression coefficients relative to their standard errors with the usual 0.975 percentile of the $t$-distribution. As a by-product the coefficient of determination $R^{2}$ was assessed. $R^{2}$ represents the proportion of total variability of the dependent variable that is accounted for by the regression model. In the multiple regression analysis, the dependence of eSBP between successive work loads within individuals was ignored. This resulted in an overestimation of the standard errors of the regression coefficient estimators. For this reason the best-fitted model according to the all-subset method might be only suboptimal. However, only the relation between WL and eSBP for the three blood pressure groups was of particular interest. The other variables were considered in the analysis only to adjust for these factors. As a consequence, the regression coefficient for WL of the best fitted model was compared with that of the regression model containing all possible prognostic factors at hand. If the two coefficients were not substantially different than for reasons of parsimony the condensed model was considered to be a more convenient summary of data.

\section{RESULTS}

In Table 1, subject characteristics for the three blood pressure groups are shown. Subjects with borderline elevated and elevated blood pressure were significantly older, had a higher total body weight, and \% body fat than subjects in the normal blood pressure group (all; $p<0.01$ ). Compared with the other groups, the elevated blood pressure group had a lesser height $(p<0.01)$. Smoking habits and alcohol consumption did not differ across the groups. Supine heart rate was lower in the normal blood pressure group $(p<0.01)$. Only slight differences in maximal heart rate and similar plasma lactate in all three groups were found. $W_{\max }$ was significantly higher in the normal blood pressure group $(\mathrm{p}<0.05)$. Analysis of covariance with $\mathrm{W}_{\max }$ as dependent and age as independent variable showed $W_{\max }$ to be age-related. Average eSBP for the three groups at $50 \mathrm{~W}, 100 \mathrm{~W}, 150 \mathrm{~W}$, and $175 \mathrm{~W}$ are given in Table 2 . Results from the multiple regression analysis on eSBP are presented in Table 3. Most of the variance was explained by the variable work load (WL) $\left(\mathrm{R}^{2}=0.414\right)$. Pre-exercise systolic blood pressure explained $9.8 \%$ of the variation. Age $\left(R^{2}=0.019\right)$ and exercise heart rate $(e H R)\left(R^{2}=0.032\right)$ had a relatively small, although significant influence; $6.7 \%$ of variation was accounted for by the division of supine blood pressure in the three blood pressure groups. None of the other prognostic variables did additionally contribute to the variation of eSBP. 
Table 1. Comparison between normal, borderline-elevated, and elevated blood pressure groups

\begin{tabular}{|c|c|c|c|}
\hline \multirow[b]{2}{*}{ Variables (means $\pm \mathrm{SD}$ ) } & \multicolumn{3}{|l|}{ blood pressure } \\
\hline & $\begin{array}{l}\text { Normal } \\
(n=497)\end{array}$ & $\begin{array}{l}\text { Borderline elevated } \\
(n=212)\end{array}$ & $\begin{array}{l}\text { Elevated } \\
(n=108)\end{array}$ \\
\hline Age (y) & $45.8 \pm 5.4^{* *}$ & $48.5 \pm 7.0^{*}$ & $50.3 \pm 7.3^{*}$ \\
\hline Body height $(\mathrm{cm})$ & $164.1 \pm 5.8$ & $163.7 \pm 6.3$ & $162.3 \pm 5.8^{* *}$ \\
\hline Body weight $(\mathrm{kg})$ & $62.3 \pm 7.0^{* *}$ & $64.4 \pm 7.8$ & $65.2 \pm 8.2 * *$ \\
\hline Body fat $(\%)$ & $32.0 \pm 5.1^{* *}$ & $33.8 \pm 3.9^{*}$ & $34.9 \pm 5.3^{* *}$ \\
\hline Smokers (\%) & 20.3 & 17.0 & 17.8 \\
\hline Alcohol consumers (\%) & 71.7 & 75.5 & 70.1 \\
\hline Alcohol consumption $(\mathrm{g} / \mathrm{w})$ & $78 \pm 75$ & $86 \pm 81$ & $81 \pm 80$ \\
\hline Supine SBP (mmHg) & $123.3 \pm 8.4$ ** & $141.2 \pm 7.9^{* *}$ & $153.2 \pm 13.1$ ** \\
\hline Supine DBP (mmHg) & $79.1 \pm 5.4^{* *}$ & $86.6 \pm 4.7^{* *}$ & $95.8 \pm 6.0^{* *}$ \\
\hline Supine HR (b/min) & $65.3 \pm 8.0^{* *}$ & $69.1 \pm 9.9$ & $69.3 \pm 10.8^{* *}$ \\
\hline Pre-exercise SBP (mmHg) & $122.8 \pm 10.2^{* *}$ & $135.9 \pm 11.2^{* *}$ & $146.9 \pm 16.0 * *$ \\
\hline Pre-exercise DBP (mmHg) & $80.7 \pm 6.7^{* *}$ & $87.3 \pm 7.7^{* *}$ & $93.7 \pm 8.2^{* *}$ \\
\hline Pre-exercise HR (b/min) & $72.2 \pm 10.7 * *$ & $76.0 \pm 12.5$ & $74.1 \pm 11.6$ \\
\hline$W_{\max }(W)$ & $166.2 \pm 27.1 *$ & $161.3 \pm 27.5$ & $157.6 \pm 25.7 * *$ \\
\hline $\mathrm{HR}_{\max }(\mathrm{b} / \mathrm{min})$ & $173.2 \pm 10.9 *$ & $171.2 \pm 11.2$ & $172.1 \pm 10.6$ \\
\hline Plasma lactate (mmol/l) & $8.4 \pm 2.3$ & $8.6 \pm 2.7$ & $8.9 \pm 2.6$ \\
\hline
\end{tabular}

${ }^{*}=P<0.05 ;{ }^{* *}=P<0.01$ (for two sample $t$-test, based on between-group significance in ANOVA test). Asterisks after the third column refer to differences between the first and third columins. Asterisks between columns refer to differences between adjacent columns. SBP $=$ systolic blood pressure $; D B P=$ diastolic blood pressure; $H R=$ heart rate.

Table 2. Exercise systolic blood pressure (mean $\pm \mathrm{SD}$, $\mathrm{mmHg}$ ) at different work loads for the normal, borderline-elevated, and elevated blood pressure groups

blood pressure

\begin{tabular}{llll}
\cline { 2 - 3 } Work load $(\mathrm{W})$ & Normal & Borderline elevated & Elevated \\
\hline $50 \mathrm{~W}$ & $145 \pm 14$ & $159 \pm 15$ & $171 \pm 21$ \\
$\mathrm{n}$ & 497 & 212 & 108 \\
$100 \mathrm{~W}$ & $163 \pm 16$ & $177 \pm 15$ & $187 \pm 16$ \\
$\mathrm{n}$ & 497 & 212 & 108 \\
$150 \mathrm{~W}$ & $175 \pm 15$ & $189 \pm 18$ & $200 \pm 17$ \\
$\mathrm{n}$ & 322 & 126 & 60 \\
$175 \mathrm{~W}$ & $183 \pm 16$ & $192 \pm 16$ & $202 \pm 22$ \\
$\mathrm{n}$ & 39 & 12 & 9 \\
\hline
\end{tabular}

$n=n u m b e r$ of subjects 
Table 3. Summary of multiple regression results on exercise systolic blood pressure

\begin{tabular}{lclr}
\hline Variable & Regression coefficient & Standard deviation & t-ration $^{\text {in }}$ \\
\hline Constant & 17.20 & 3.94 & 4.37 \\
Pre-exercise SBP & 0.53 & 0.02 & 21.99 \\
Work load & 0.17 & 0.01 & 15.61 \\
Exercise heart rate & 0.28 & 0.02 & 14.81 \\
Age & 0.53 & 0.05 & 11.04 \\
BORD & 5.32 & 0.73 & 7.30 \\
ELEV & 8.93 & 1.03 & 8.69 \\
\hline
\end{tabular}

$R^{2}=0.630 ; s \pm 13.34 ; R^{2}=$ proportion of variance explained by the model; $s=$ standard deviation of the error; $a=$ all $t$-ratios are significant at 0.001 level; $B O R D=d u m m y$ zariable $(0-1)$ of borderline elevated blood pressure group. ELEV = dummy variable (0-1) of elevated blood pressure group. Regression equation is $e S B P=17.2+0.53$ pre-exercise $S B P+0.17$ zork load +0.28 exercise heart rate + 0.53 age $+5.32 B O R D+8.93 E L E V$.

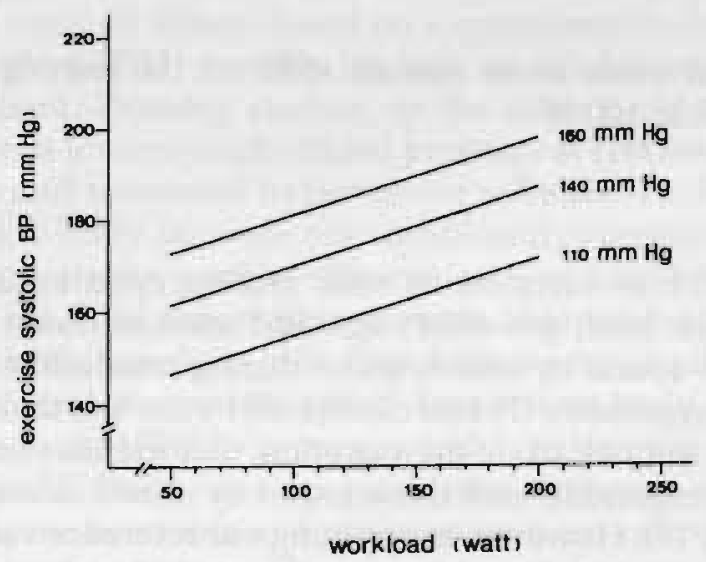

Fig. 1 Regression lines of eSBP in relation to work load for three different levels of pre-exercise systolic blood pressure $(110,140$, and $160 \mathrm{mmHg}$ ) when adjustments are made for age and exercise heart rate.

Figures 1 and 2 show regression lines of eSBP in relation to work load when adjustments are made for age and eHR or pre-eSBP and eHR, respectively. When age and eHR are controlled initial differences in pre-eSBP are maintained during exercise. Analysis (by introducing interaction between dummy and other variables) revealed no difference in pressure rise for different levels in pre-eSBP. In case pre-eSBP and eHR are controlled differences in age are reflected. For example, a subject, 40 years of age, with a pre-eSBP of 125 $\mathrm{mmHg}$ has an eSBP of $155 \mathrm{mmHg}$ at $100 \mathrm{~W}$ when eHR is 120 beats/min. A 


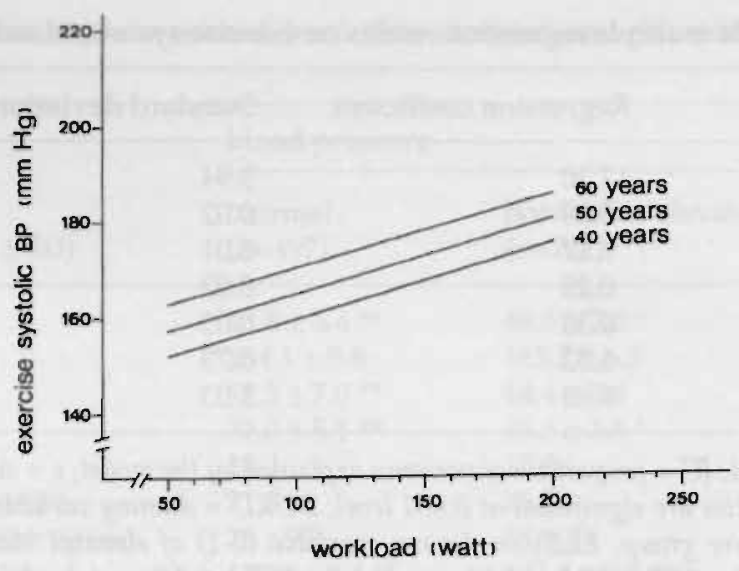

Fig. 2 Regression lines of eSBP in relation to work load for 40,50 , and 60 years old females when adjustments are made for pre-exercise systolic blood pressure and exercise heart rate.

female subject ten years older has an eSBP of $160 \mathrm{mmHg}$ with the same pre-eSBP and eHR at $100 \mathrm{~W}$.

\section{DISCUSSION}

We found that $63 \%$ of variation in eSBP during cycle ergometry could be explained by work load, pre-eSBP, age and exercise heart rate. The wide variability in $\operatorname{eSBP}$ found by others, either during treadmill exercise $(3,10)$ or testing on a cycle ergometer (7) was confirmed by the fact that work load itself could account for only $41.4 \%$ of the variation. Our values of eSBP at different work loads are comparable with those found by others in studies with much smaller groups $(9,17)$. However, in applying our reference values it should be stressed that all our female subjects were regularly physically active. No differences in ESBP behavior were found between the three blood pressure groups. Mean increase above pre-eSBP at $100 \mathrm{~W}$ was $40 \mathrm{mmHg}$ in all groups. In a recent study (5) no differences in SSBP-rise between normotensive and borderline hypertensive young women were found, either. Some authors point to the fact than an excessive rise in SBP during exercise is mainly seen in hypertensives with advances stages of disease (19). These subjects were, however, excluded from our study. Age was positively and significantly related to $\mathrm{ESBP}$ in middle-aged women, so that an increase of 10 years of age was associated with an $5 \mathrm{mmHg}$ eSBP increase for the same resting systolic blood pressure. A significant correlation between age and maximal systolic blood pressure during cycle ergometry was recently observed by Michelsen et al (15), too. It was not clear however if differences in resting SBP were considered. It has been reported that the age-related increase in SBP can be 
possibly attributed to a decrease in distensibility of large arteries with age (18). We found a clear and positive association of exercise heart rate with eSBP. For every 10 beats/min difference in eHR between individuals with same age and pre-eSBP a difference of $2-3 \mathrm{mmHg}$ in eSBP was found. Differences between individuals in eHR at the same work load may reflect differences in physical fitness-level (1). In middle-aged men a significant negative association between $W_{\max }$ and $\mathrm{ESBP}$ was found (22), but no association with eHR. The fact that in our study $W_{\max }$ was not associated with eSBP, may be because only a relative small range in $W_{\max }$ was found for women in this study (100-263 W) compared to men (150-400 W) (22) or $W_{\text {max }}$ was mainly a reflection of genetic endowment than of physical fitness. Alternatively, one could argue that maximal oxygen consumption $\left(\mathrm{VO}_{2 \max }\right)$ is a better estimate of physical fitness than $W_{\text {max }}$. In our experience, however, the feasibility of the direct measurement of $\mathrm{VO}_{2 \max }$ is poor in large scale studies because of unfamiliarity of the subjects with the proceedings. Furthermore, in cycle ergometry $\mathrm{VO}_{2 \max }$ and $\mathrm{W}_{\max }$ are closely related (20) and the intra-individual variation of $\mathrm{W}_{\max }$ is lower than the intra-individual variation of $\mathrm{VO}_{2 \max }$ (13). Classification of physical fitness based on a questionnaire has failed to show a relationship with ESBP (3) possibly because no reliable estimate of physical fitness was obtained. Training studies, on the other hand, have shown that regular exercise can lower systolic blood pressure at rest and during exercise in normotensive and untreated hypertensive subjects $(11,12)$. Body weight, body height and \% body fat were not significantly correlated with eSBP. In treadmill testing, a strong positive association was found between Quetelet index and eSBP (3). It is conceivable than an independent relationship between $\mathrm{ESBP}$ and body weight is only found during treadmill exercise, where the physiological load at a certain speed depends on body weight. Smoking was not associated with $\mathrm{SBP}$ in women, which is in keeping with results from treadmill testing (3). There was no association between $\mathrm{SSBP}$ and alcohol consumption. Supine heart rate and pre-exercise heart rate were higher in the elevated blood pressure groups. There was a mean increase of 5-7 beats/min in resting heart rate from supine to sitting position in women, possibly also due to some anticipation to the beginning of exercise. We were not able to explain the remaining $37 \%$ of variation in eSBP in this study. Some authors show that education and use of gonadal hormones (especially postmenopausal estrogens) can contribute to total variation in eSBP (3). We believe that the variability of the indirect method for blood pressure measurement and biological variability in eSBP itself also explains at least part of the remaining variation.

\section{REFERENCES}

1. Astrand P-O, Rodahl K. Textbook of work physiology. McGraw Hill, New York, 1986.

2. Benbassat J, Froom P. Blood pressure response to exercise as a predictor of hypertension. Arch Intern Med 146: 2053-2055, 1986. 
3. Criqui MH, Haskell WL, Heiss G, Tyroler HA, Green P, Rubenstein CJ. Predictors of systolic blood pressure response to treadmill exercise: the lipid research clinic prevalence study. Circulation 68 (2): 225-233, 1983.

4. Dlin RA, Hanne N, Silverberg DS, Bar-Or O. Follow-up of normotensive men with exaggerated blood pressure response to exercise. Am Heart J 106: 316-320, 1983.

5. Drory Y, Pines A, Fisman EZ, Kellermann JJ. Exercise response in young women with borderline hypertension. Chest 97: 298-301, 1990.

6. Durnin J, Womersley J. Body fat assessed from total body density and its estimation from skinfold thickness: measurements on 481 men and women aged 16 to 72 years. $\mathrm{Br}$ J Nutr 32: 77-97, 1974.

7. Franz IW. Ergometry in the assessment of arterial hypertension. Cardiology 72: 147-159, 1985.

8. Geyssant A, Dormois D, Barthelemy JC, Lacour JR. Lactate determination with the lactate analyzer LA 640: a critical study. Scand J Clin Lab Invest 45: 145-149, 1985.

9. Heck H, Rost R, Hollmann W. Standard blood pressure values during ergometric bicycle tests. Dtsch Z Sportmed 7: 243-249, 1984.

10. Irving JB, Bruce RA, De Rouen TA. Variations in and significance of systolic pressure during maximal exercise (treadmill) testing. Am J Cardiol 39: 841-848, 1977.

11. Jennings G, Nelson L, Dewar E, Kornen P, Esler M, Laufer E. Antihypertensive and hemodynamic effects of one year's regular exercise. J Hypertension 4: 5659-5661, 1986.

12. Kiyonaga A, Arakawa K, Tanaka h, Shindo M. Blood pressure and hormonal responses to aerobic exercise. Hypertension 7: 125-131, 1985.

13. Kuipers H, Verstappen FT, Keizer HA, Geruten P, Van Kranenbrug G. Variability of aerobic performances in the laboratory and its physiological correlates. Int J Sports Med 6: 179-201, 1985.

14. Leibel B, Kobrin I, Ben-Ishay D. Exercise testing in the assessment of hypertension. $\mathrm{Br}$ Med J 285: 1535-1536, 1982.

15. Michelsen S, Hurlen M, Stugaard M, Otterstad JE. Influence of age on physical performance, heart rate and systolic blood pressure response in apparently healthy women. Scand J Clin Lab Invest 49: 97-102, 1989.

16. Millar-Graig MW, Balasubramanian V, Mann S, Rafferty EB. Use of graded exercise testing in assessing the hypertensive patient. Clin Cardiol 3: 236-240, 1980.

17. Nordenfelt I, Adolfson L, Nilsson JE, Olsson S. Reference values for exercise tests with continuous increase in load. Clin Physiol 5: 161-172, 1985.

18. Reneman RS, van Merode T, Hick PJ. Age-related changes in carotid artery wall properties in man. Ultrasound Med Biol 12: 465-471, 1986.

19. Sannerstedt $R$. Hemodynamic response to exercise in patients with arterial hypertension. Acta Med Scand 458: 7-83, 1966.

20. Storer TW, Davis JA, Caiozzo VJ. Accurate prediction of $\mathrm{VO}_{2 \max }$ in cycle ergometry. Med Sci Sports Exerc 22: 704-201, 1990.

21. Wilson NV, Meyer BM. Early prediction of hypertension using exercise blood pressure. Prev Med 10: 62-68, 1981.

22. Wijnen JA, van Baak MA, Tan ES, Bovens AM, Vrencken JG, Verstappen FT. Variations in exercise systolic blood pressure in physically active middle-aged men with normal and elevated blood pressure. Int J Sports med 9: 412-416, 1988. 


\section{CHAPTER 6}

\section{Beta-blockade and lipolysis during endurance exercise}

JAG Wijnen, MA van Baak, C de Haan, HAJ Struijker Boudier, FS Tan, and LMAB Van Bortel

Departments of Pharmacology, Human Biology, and Medical Informatics and Statistics, University of Limburg, Maastricht, The Netherlands

Eur J Clin Pharmacol 45: 101-105, 1993 


\section{ABSTRACT}

Inhibition of adipose tissue lipolysis may be involved in the impairment of endurance capacity after administration of a $\beta$-blocker. During endurance exercise, no significant decrease in plasma glycerol and free fatty acid (NEFA) concentrations after $\beta$-blockade is found. However, the levels during recovery from exhaustion are lower after $\beta$-blockade. This study was designed to investigate whether these lower levels after exercise are due to $\beta$-blockade or to the shorter time to exhaustion after $\beta$-blocker administration. In a single-blind study, 11 well-trained male subjects (age $23 \pm 0.9$ yr) performed a cycle ergometer test at $70 \% W_{\max }$ until exhaustion, $2 \mathrm{hr}$ after intake of $80 \mathrm{mg}$ propranolol. One week later, the test was repeated after intake of placebo and was stopped at the time of exhaustion of the previous test. Average exercise time was $24 \pm 2 \mathrm{~min}$. During exercise plasma glucose was lower, whereas plasma lactate and respiratory exchange ratio were higher on propranolol (all $p<0.05$ ). Glycerol and NEFA concentrations during exercise were not significantly different comparing both conditions. Despite an identical exercise time, during recovery glycerol and NEFA concentrations were lower after propranol treatment $(p<0.05)$. In conclusion, lipolysis is inhibited during exercise after propranolol, probably causing a shift from fat to carbohydrate combustion.

\section{INTRODUCTION}

Beta-adrenoceptor antagonists are commonly used in various cardiovascular disorders such as hypertension, coronary artery disease and cardiac arrhythmias. For many patients with these disorders dynamic physical exercise is considered to be beneficial (18). Since a large number of the physically active patients are treated with $\beta$-blocking drugs, the side-effects of blockade of $\beta_{1}$ and $\beta_{2}$-adrenoceptors during exercise has become the scope of numerous studies. It has been shown that $\beta$-blockade interferes with hemodynamics, energy metabolism, thermoregulation and potassium homeostasis during exercise $(4,21)$. Maximal aerobic exercise capacity is significantly reduced in most studies in normotensive and hypertensive subjects (21). More important from a therapeutic point of view, however, is the effect of $\beta$-blockade during endurance exercise. Endurance exercise is the performance of work at a constant submaximal intensity. Both in normotensive and hypertensive subjects, reductions in exercise time ranging from 16 to $50 \%$ were found, compared to placebo (21). The negative effect is more pronounced during non-selective blockade than during $\beta_{1}$-selective blockade. The exact mechanism behind this reduced endurance performance is not yet clear. It has been suggested that a reduced exercise cardiac output is responsible or possibly a reduced rate of lipolysis or changes in potassium homeostasis (21). With regard to an inhibition of adipose tissue lipolysis, plasma glycerol and nonesterified fatty acid (NEFA) reductions ranging from 0 to $50 \%$ were found (21). In one study NEFA levels at the end of a one hour run were even higher when subjects were given $\beta$-blockers than when given placebo (13). However, 
the levels during recovery from exhaustive endurance exercise are consistently found to be lower during $\beta$-blockade $(14,15)$. This study was designed to differentiate whether these lower NEFA levels after exercise are due to $\beta$ blockade or to a shorter time to exhaustion after $\beta$-blocker administration.

\section{SUBJECTS AND METHODS}

Eleven trained healthy males volunteered in this study. All subjects were cyclists involved in a consistent cardiorespiratory training regime. They were normotensive (blood pressure $<140 / 90 \mathrm{mmHg}$ ) and used no medication. Each subject gave written informed consent. The protocol of the study was approved by the Ethical Committee of the University of Limburg. The physical characteristics are described in table 1. Each subject completed an initial progressive maximal cycle ergometer (Lode, Groningen, The Netherlands) test without medication to determine maximal aerobic power $\left(\mathrm{W}_{\max }\right)$. This test started with a work rate of $100 \mathrm{~W}$ for 5 minutes, which was increased by $50 \mathrm{~W}$ every 3 minutes until a heart rate of 160 beats $/ \mathrm{min}$, whereafter the increment was $25 \mathrm{~W}$ every 3 minutes until exhaustion. Two days later, the subjects returned to the laboratory to perform their first endurance test, followed by a second endurance test one week later. A light standardized breakfast was taken two hours before arrival in the lab. In combination with the meal, one tablet of propranolol $80 \mathrm{mg}$ was taken before the first test and one placebo tablet before the second test (single blind). Systolic and diastolic blood pressure (Hawksley random-zero, Korotkoff V) and heart rate were measured after 5 minutes of quiet sitting. The first endurance test started with a 5 minutes warming-up at $100 \mathrm{~W}$; thereafter, subjects cycled at $70 \% \mathrm{~W}_{\max }$ until exhaustion, which was defined as the moment the subjects were no longer able to maintain a pedalling frequency above 50 revolutions per minute. The exercise time to exhaustion was recorded. The second endurance test was performed at the same intensity until the exercise time to exhaustion of the first test, so that the same amount of work was delivered. The subjects

Table 1. Characteristics of the subjects (mean \pm SEM)

\begin{tabular}{|c|c|}
\hline Age (y) & $23 \pm 1$ \\
\hline Height $(\mathrm{cm})$ & $182 \pm 3$ \\
\hline Weight (kg) & $74 \pm 4$ \\
\hline $\mathrm{VO}_{2 \max }\left(\mathrm{ml} \cdot \mathrm{min}^{-1}\right)$ & $4701 \pm 171$ \\
\hline $\mathrm{VO}_{2 \max } \cdot \mathrm{kg}^{-1}\left(\mathrm{ml} \cdot \mathrm{min}^{-1} \cdot \mathrm{kg}^{-1}\right)$ & $64 \pm 2$ \\
\hline$W_{\max }$ (watt) & $340 \pm 12$ \\
\hline $\mathrm{R}_{\max }$ & $1.15 \pm 0.02$ \\
\hline $\mathrm{HR}_{\max }$ (beats. $\min ^{-1}$ ) & $192 \pm 2$ \\
\hline
\end{tabular}

$n=11 ; V_{2 \max }=$ maximal oxygen uptake; $W_{\max }=$ maximal aerobic power $; R_{\max }=$ maximal respiratory exchange ratio; $H R_{\max }=$ maximal heart rate 
were unaware of the purpose of this procedure and were told they had to cycle to exhaustion in the second test as well. After exhaustion, the subjects cycled for 10 minutes at $75 \mathrm{~W}$ (recovery). Blood samples were obtained from a cubital vein for determination of plasma glycerol, non-esterified fatty acids (NEFA), lactate, glucose, and potassium concentrations. To detect changes in plasma volume, hemoglobin and hematocrit were measured (6). Heart rate, systolic and diastolic blood pressures (sphygmomanometry, Korotkoff IV during exercise) were measured. All these measurements were performed at rest, every 10 minutes during exercise, just before exhaustion and 3,6 and 10 minutes in the recovery phase, in a sitting position. At rest and during exercise oxygen consumption and respiratory exchange ratio $(R)$ were also measured (SensorMedics Horizon metabolic measurement cart). Subjective feelings of exertion were rated with the Borg scale every 10 minutes during exercise and at exhaustion (3). Plasma lactate and glucose levels and plasma glycerol and NEFA concentrations were measured by enzymatic autoanalyzer methods, and potassium levels by flame photometry (Instrumentation Laboratory 243).

Results are presented as mean values \pm SEM. Statistical analysis was performed by Zerbe's test for response curves (23). The Wilcoxon-test was used for two-point pairwise comparison. Statistical significance was established at $\mathrm{p}<0.05$.

\section{RESULTS}

At rest, sitting systolic blood pressure was reduced from $128 \pm 5 \mathrm{mmHg}$ after placebo to $115 \pm 4 \mathrm{mmHg}$ during beta-blockade ( $<<0.01$ ), while sitting diastolic pressure was unaffected $(73 \pm 3 \mathrm{mmHg}$ and $77 \pm 3 \mathrm{mmHg}$ respectively). Heart rate was significantly reduced from $67 \pm 3$ beats. $\mathrm{min}^{-1}$ on placebo to 51 \pm 2 beats. $\mathrm{min}^{-1}$ during beta-blockade $(\mathrm{p}<0.01$ ). Exercise time was $24 \pm 2$ minutes in the first endurance test (propranolol) and as a consequence of the design of the study the same in the second (placebo) test. Rating of perceived exertion at the end of exercise was significantly higher during propranolol (18.2 \pm 0.3 vs. $12.5 \pm 0.7 ; p<0.05$ ). Exercise systolic blood pressure was significantly lower during propranolol than during placebo treatment (figure 1). After 20 minutes of exercise blood pressure during placebo was $189 \pm 4 / 71 \pm$ $6 \mathrm{mmHg}$ and $166 \pm 3 / 65 \pm 5 \mathrm{mmHg}$ during propranolol ( $\mathrm{p}<0.01$ for systolic blood pressure). Diastolic exercise blood pressure was not different. During exercise, heart rate (figure 2) was significantly reduced after propranolol (167 \pm 3 vs. $124 \pm 2$ beats. min $^{-1} ; p<0.01$ ). There was no statistically significant difference in plasma NEFA concentration during exercise between placebo and propranolol (figure 3 ). However, during recovery a clear and strong increase in plasma NEFA concentration was seen after placebo, which differed significantly from an only modest increase after propranolol $(p<0.05)$. At 10 minutes recovery, the mean plasma NEFA concentration was $0.91 \pm 0.14$ $\mathrm{mmol} / \mathrm{l}$ after placebo and $0.45 \pm 0.08 \mathrm{mmol} / \mathrm{l}$ during propranolol treatment 


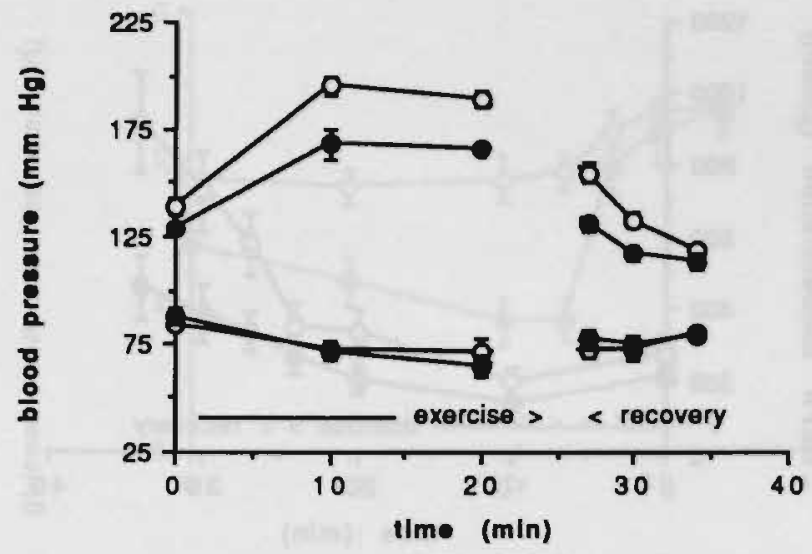

Fig. 1 Systolic and diastolic blood pressure during placebo and propranolol. Means and SEM are shown. For figure 1-7: all points, $n=11$ except at 20 min exercise, $n=8$. ० Placebo SBP; $\bullet$ Propanolol SBP; O Placebo DBP; • Propanolol DBP

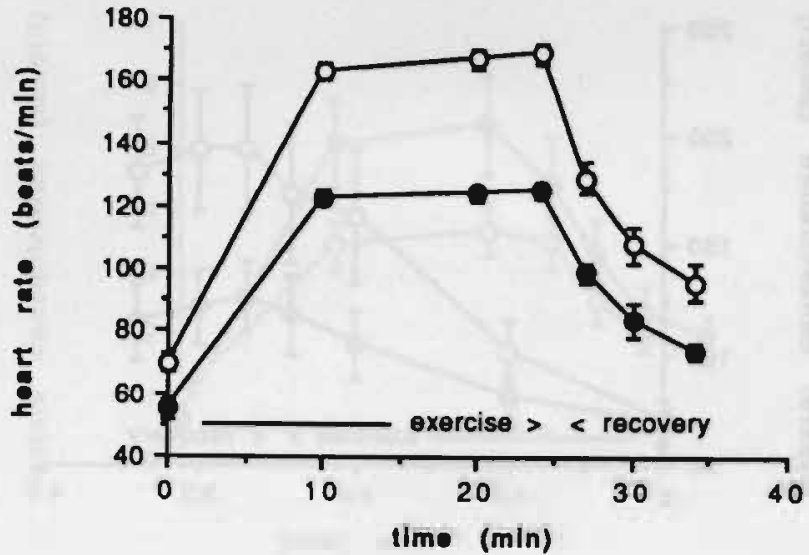

Fig. 2 Heart rate during placebo and propranolol. Means and SEM are shown. For figure. 2-7: the last point during extrcise is the value at exhaustion, which is shown at the appropriate average extercise time. o Placebo; $\bullet$ Propanolol

$(p<0.05)$. Although lower after $\beta$-blockade during exercise, plasma glycerol concentrations did not differ significantly between placebo and propranolol (figure 4). During recovery the plasma glycerol concentrations were significantly higher after placebo $(p<0.05)$. In contrast to NEFA, no clear postexercise peak was seen and glycerol concentrations gradually declined. The plasma glucose concentration decreased during the first 20 minutes after 


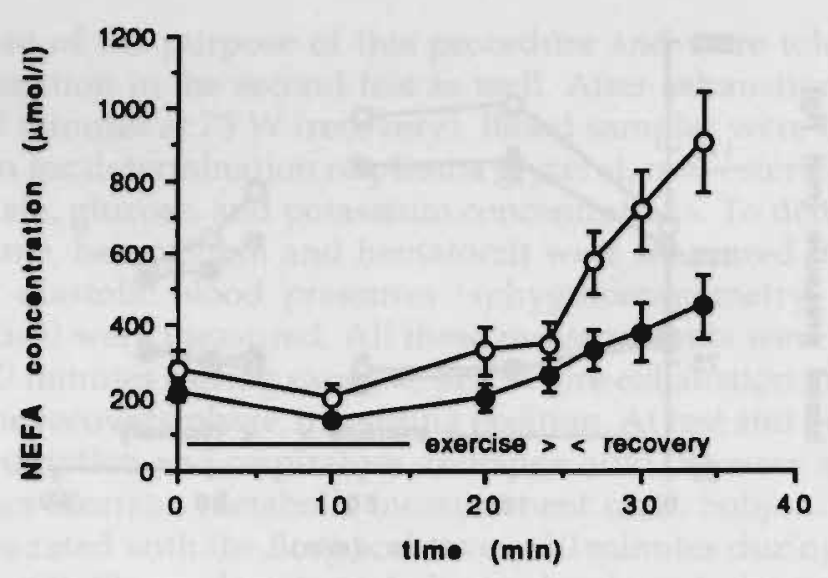

Fig. 3 Plasma non-esterifired fatty acid (NEFA) concentration during placebo and propranolol. Means and SEM are shown. - Placebo; - Propanolol

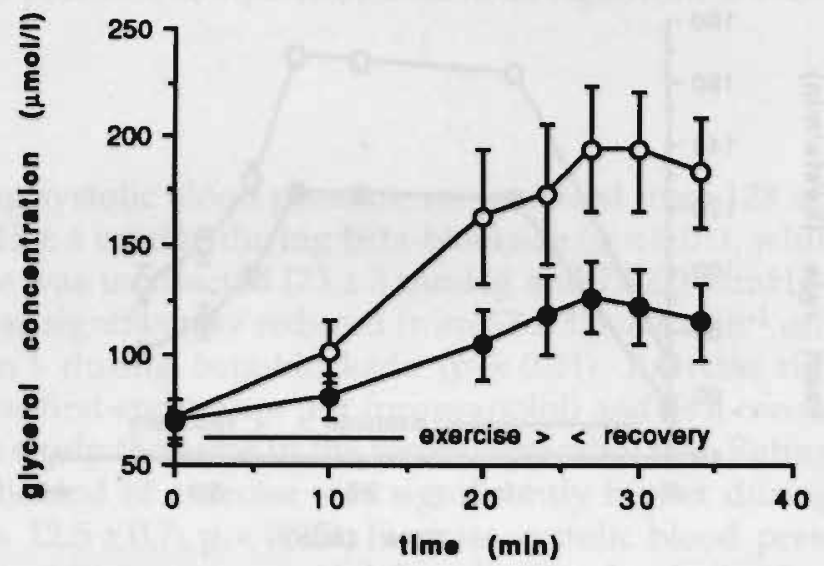

Fig. 4 Plasma glycerol concentration during placebo and propranolol. Means and SEM are shown. O Placebo; $\bullet$ Propanolol

propranolol but not on placebo (significant difference between placebo and propranolol; $\mathrm{p}<0.01$; figure 5). At exhaustion the plasma glucose concentration after propranolol was $3.87 \pm 0.14 \mathrm{mmol} / 1 \mathrm{compared}$ to $4.40 \pm 0.20 \mathrm{mmol} / \mathrm{l}$ at rest $(\mathrm{p}<0.05)$. During exercise there was a higher plasma glucose concentration after placebo $(p<0.05)$. Because the average resting value for plasma glucose also differed between propranolol and placebo $(4.40 \pm 0.20 \mathrm{vs}$. $4.86 \pm 0.15 \mathrm{mmol} / \mathrm{l}, \mathrm{p}<0.05)$ we compared the change in plasma glucose during and after excercise from resting values in the two conditions. No 


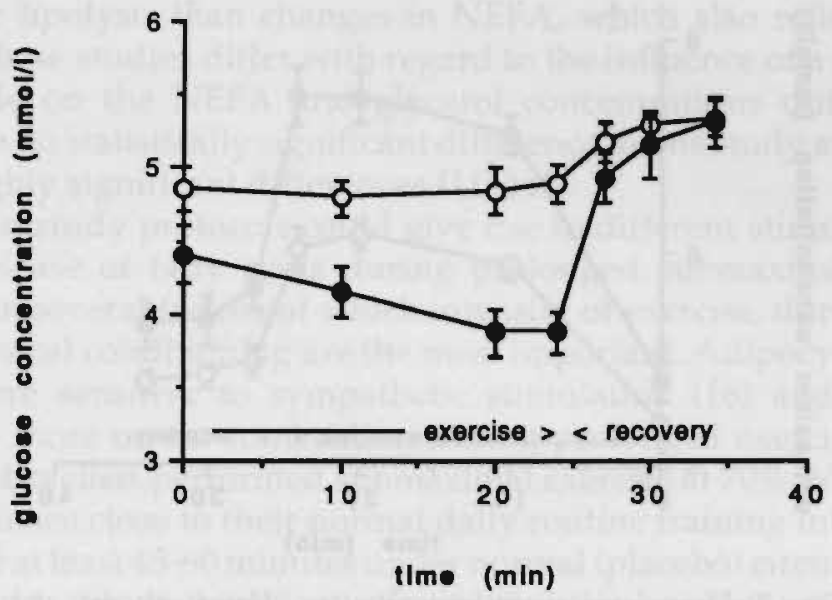

Fig. 5 Plasma glucose concentration during placebo and propranolol. Means and SEM are shown. o Placebo; $\bullet$ Propanolol

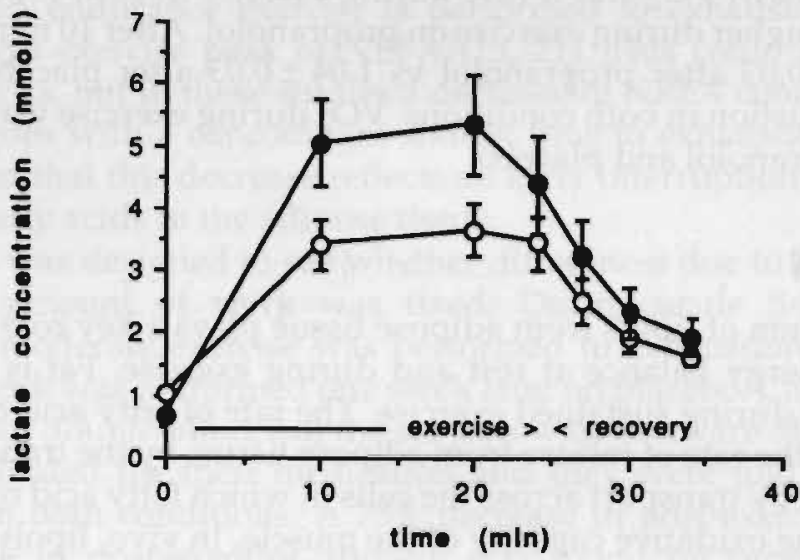

Fig. 6 Plasma lactate concentration during placebo and propranolol. Means and SEM are shown. O Placebo; • Propanolol

significant differences were found. After exhaustion, the plasma glucose levels quickly rose above pre-exercise levels. Compared to placebo, differences from the resting values were higher during recovery after propranolol ( $p$ $<0.05)$. During and after exercise plasma lactate was higher after propranolol ( $p<0.05$; figure 6). After 20 minutes of exercise, plasma lactate was $5.25 \pm 0.80$ $\mathrm{mmol} / 1$ after propranolol and $3.65 \pm 0.43 \mathrm{mmol} / \mathrm{l}$ after placebo $(\mathrm{p}<0.05)$. Significant differences in plasma potassium were seen during and after exercise ( $p<0.01$; figure 7 ). At exhaustion, the mean plasma potassium concentra- 


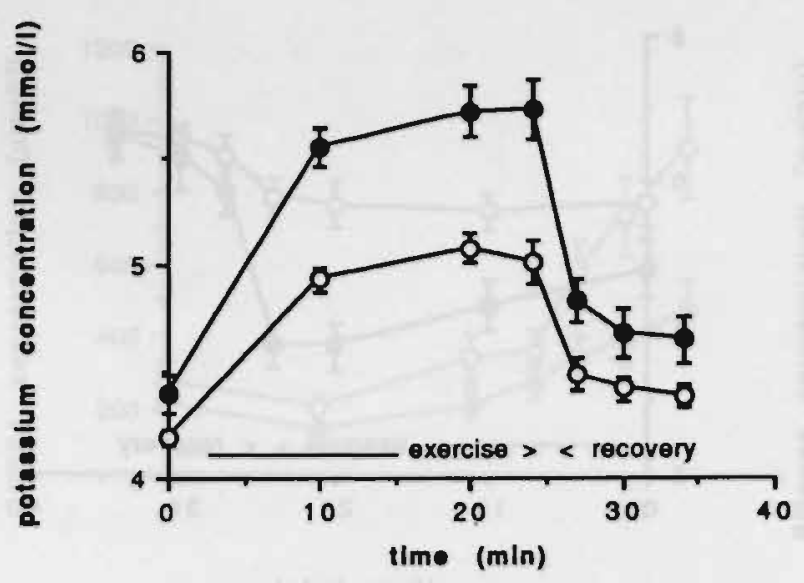

Fig. 7 Plasma potassium concentration during placebo and propranolol. Means and SEM are shown. o Placebo; $\bullet$ Propanolol

tion was $5.73 \pm 0.14 \mathrm{mmol} / \mathrm{l}$ after propranolol and $5.01 \pm 0.10 \mathrm{mmol} / \mathrm{l}$ after placebo $\left(\mathrm{p}<0.01\right.$ ). $\mathrm{VO}_{2}$ and $\mathrm{R}$ rose during exercise in both conditions. $\mathrm{R}$ was significantly higher during exercise on propranolol. After 10 minutes exercise, $R$ was $1.09 \pm 0.03$ after propranolol vs $1.04 \pm 0.03$ after placebo. $R$ declined towards exhaustion in both conditions. $\mathrm{VO}_{2}$ during exercise was not different between propranolol and placebo.

\section{DISCUSSION}

The mobilization of lipids from adipose tissue plays a key role in the regulation of the energy balance at rest and during exercise. Fat is an important oxidative fuel during sustained exercise. The rate of fatty acid oxidation may be limited by the rate of release from adipose tissue, by the transport capacity of the plasma, by transport across the cells in which fatty acid oxidation takes place, or by the oxidative capacity of the muscle. In vivo, lipolysis in adipose tissue is regulated by adrenergic mechanisms at rest and during exercise. Alpha-adrenergic inhibitory effects modulate lipolysis at rest, whereas $\beta$ adrenergic stimulatory effects modulate lipolysis during exercise (1). Furthermore, human lipolysis seems to be continuously inhibited by the action of hormones and parahormones (insulin, growth hormone, prostaglandins, adenosine, nicotinic acid) (12).

Submaximal endurance performance is seriously impaired by $\beta$-blockade (21) and one of the mechanisms might be a reduction in fat supply to working muscles which causes an increased carbohydrate utilization. (11). A reduced fat supply may be caused by an inhibited lipolysis. Several studies have tried to monitor lipolysis during exercise by plasma NEFA and glycerol concentrations. It is assumed that during exercise changes in glycerol levels are a better 
indicator for lipolysis than changes in NEFA, which also reflect their consumption. These studies differ with regard to the influence of a non-selective beta-blockade on the NEFA and glycerol concentrations during exercise, ranging from no statistically significant difference in this study and others (10, $13,15)$ to highly significant differences $(11,14)$.

Variation in study protocols could give rise to different stimuli to increase lipolysis. Release of fatty acids during prolonged submaximal exercise is dependent on several factors of which intensity of exercise, duration of exercise and physical conditioning are the most important. Adipocytes in trained men are more sensitive to sympathetic stimulation (16) and conditioned subjects rely more on fat combustion during prolonged exercise (9). In our study trained cyclists performed submaximal exercise at $70 \% \mathrm{~W}_{\max }$, which is in our experience close to their normal daily routine training intensity and is sustained for at least 45-60 minutes under normal (placebo) circumstances. On the other hand, the methodology of studying lipolysis by measurement of plasma NEFA and glycerol concentration during exercise can be erroneous and may also (in part) explain the variation of results in different studies.

Plasma NEFA concentration reflects the balance between a continuing release of NEFA from adipose tissue and uptake of NEFA by the working muscle. When endurance exercise is performed to exhaustion $\beta$-blockade blunts the post-exercise peak of NEFA $(15,21)$. This could indicate an inhibited lipolysis, but in these studies a decrease in NEFA concentration with $\beta$-blockade goes with a concomitant shorter time to exhaustion. It therefore can be argued that this decrease reflects an early interruption of the production of free fatty acids in the adipose tissue.

This study was designed to see whether differences due to $\beta$-blockade still exist if the amount of work was fixed. During acute $\beta$-blockade with propranolol moderate exercise was performed to exhaustion and the same amount of work was performed one week later on placebo. Consequently the design was not double-blind, but the subjects were unaware of the purpose of the study, blinded for their medication and they were told to perform to exhaustion in both conditions. A 75\% decrease in post-exercise NEFA and $50 \%$ decrease in post-exercise glycerol was found on propranolol, while during exercise differences never reached statistical significance. So it seems that adipose tissue lipolysis is inhibited during exercise by $\beta$-blockade, which becomes more apparent during recovery from exercise.

The reason for a rapid increase in plasma concentration of NEFA after exercise is not clear, but it is a common finding in studies on fat metabolism $(2,7,22)$. After exercise there may be a continuing high rate of production of NEFA when utilization is suddenly decreased. In this way a decreased rate of production of NEFA during $\beta$-blockade can be unmasked during early recovery. An alternative hypothesis is suggested by Hodgetts et al (8). They studied fat mobilization during exercise by sampling venous blood that drains from subcutaneous tissue of the anterior abdominal wall. From that 
study there is strong evidence that free fatty acids accumulate within the adipose tissue during exercise because of a limitation of transport into the systemic plasma, whereas glycerol because of its smaller size and water solubility is able to escape into the general circulation. The last could also explain the fact that in studies on fat metabolism no pronounced post-exercise peak for plasma glycerol is found.

When lipolysis is attenuated, a lower availability of NEFA for energy production in the active skeletal muscles would cause a shift from fat to carbohydrate combustion. An increased use of carbohydrates may lead to a more rapid depletion of the limited carbohydrate stores in the body and thus to early fatigue. A shift from fat to carbohydrate combustion is in line with a higher lactate production, leading to the higher plasma lactate concentration that was found during propranolol treatment. Since during endurance exercise the rate of muscle glycogen utilization has been found to be unaffected by non-selective as well as $\beta_{1}$-selective blockade (5), mainly plasma glucose will be used as source for carbohydrate conbustion. A small, but insignificant drop in plasma glucose was seen after propranolol treatment in this study. It could indicate that the liver is unable to produce sufficient amounts of glucose. Theoretically, one could argue that the lower levels of NEFA after exercise are due to the fact that the consumption of NEFA was higher during exercise after $\beta$-blocker treatment. This is, however, not in keeping with the higher respiratory exchange ratio found during exercise. Cleroux et al (5) by actually measuring muscle triglyceride levels suggest that the decreased exercise capacity found by non-selective beta-blockade may at least in part be due to inhibition of triglyceride hydrolysis in slow-twitch fiber by blockade of $\beta_{2^{-}}$ adrenoceptors. In the same study non-selective beta-blockade, but not $\beta_{1^{-}}$selective blockade induced a significant decrease in muscle potassium with a simultaneous rise in serum potassium during exhaustive exercise. In our study a significant increase in serum potassium during submaximal exercise on propranolol was found. The mentioned effects on potassium homeostasis may induce significant changes in muscle membrane potential resulting in impaired excitability and thus contractibility of the muscle fibers, thereby contributing to the decreased exercise capacity observed with non-selective B-blockade (19).

In conclusion, the results of the present study suggest that the reduction of plasma non-esterified fatty acid concentration during recovery from exhaustive endurance exercise during non-selective $\beta$-blockade reflects attenuation of adipose tissue lipolysis during exercise.

\section{Acknowledgements}

The authors thank Monique Fuss, Annemie Gijssen and Jet Bost for excellent technical assistance, and Els Geurts and Mia Hogenboom for secretarial assistance. 


\section{REFERENCES}

1. Arner P, Kriegholm E, Engfeldt P, Bolinder J. Adrenergic regulation of lipolysis in situ at rest and during exercise. J Clin Invest 85: 893-898, 1990.

2. Bloom SR, Johnson RH, Park DM, Rennie MJ, Sulaiman WR. Differences in the metabolic and hormonal response to exercise between racing cyclists and untrained individuals. J Physiol London 258: 1-18, 1976.

3. Borg G. Perceived exertion as an indicator of somatic stress. Scand J Rehab Med 2: 92-98, 1970.

4. Chick TW, Halperin AK, Gacek EM. The effects of antihypertensive medications on exercise performance, a review. Med Sci Sports Exerc 20: 447-454, 1988.

5. Cléroux J, Nguyen van $P$, Taylor AW, Leenen FH. Effects of $\beta_{1}$ vs. $\beta_{1}+\beta_{2}$-blockade on exercise endurance and muscle metabolism in humans. J Appl Physiol 66: 548-554, 1989.

6. Dill DB, Costill DL. Calculations of percentages changes in the volume of blood, red cells and plasma in dehydration. J Appl Physiol 37: 247-248, 1974.

7. Havel RJ, Naimark A, Borchgrevink CF. Turnover rate and oxidation of free fatty acids of blood plasma in man during exercise, studies during continuous infusion of palmitate1-C ${ }^{14}$. J Clin Invest 42: 1054-1063, 1963.

8. Hodgetts V, Coppack SW, Frayn KN, Hockaday TD. Factors controlling fat mobilization from human subcutaneous adipose tissue during exercise. J Appl Physiol 71: 445-451, 1991.

9. Holloszy JO, Rennie MJ, Hickson RC, Conlee RK, Hagberg JM. Physiological consequences of the biochemical adaptations to endurance exercise. Ann NY Acad Sci 301: 440-450, 1977.

10. Jesek JK, Martin NB, Broeder CE, Thomas EL. Changes in plasma free fatty acids and glycerols during prolonged exercise in trained and hypertensive persons taking propranolol and pindolol. Am J Cardiol 66: 1336-1341, 1990.

11. Juhlin-Dannfelt A. Beta-adrenoceptor blockade and exercise, effects on endurance and physical training. Acta Med Scand (suppl) 672: 49-54, 1983.

12. Kather H, Bieger W, Michel G, Aktories K, Jakobs KH. Human fat cell lipolysis is primarily regulated by inhibitory modulators acting through distinct mechanisms. J Clin Invest 76: 1559-1565, 1985.

13. Lehtonen A, Huupponen R, Himanen P. Effect of the short-term beta-adrenoceptor blockade on exercise metabolism in cold weather. Int J Clin Pharmacol Ther Toxicol 22: 86-90, 1984.

14. Lundborg $\mathrm{P}$, Aström $\mathrm{H}$, Bengtsson $\mathrm{C}$, Fellenius E. Effect of beta-adrenoceptor blockade on exercise performance and metabolism. Clin Sci 61: 299-305, 1981.

15. MacDonald A, Bennett T, Brown AM, Wilcox RG, Skene AM. The effects of acute or chronic ingestion of propranolol or metoprolol on the metabolic and hormonal response to prolonged submaximal exercise in hypertensive men. Brit J Clin Pharmacol 17: 283-293, 1984.

16. Martin III WH, Coyle EF, Joyner M, Santensanio D, Ehsani AA, Holloszy JO. Effects of stopping exercise training on epinephrine-induced lipolysis in humans. J Appl Physiol 56: 845-848, 1984.

17. McLeod AA, Brown JE, Kitchell BB, Sedor FA, Kuhn C, Shand DG, Williams RS. Hemodynamic and metabolic responses to exercise after adrenoceptor blockade in humans. J Appl Physiol 56: 716-722, 1984.

18. Siscovick DS, Laporte RE, Newman JH. The disease-specific benefits and risks of physical activity and exercise. Public Health Reports 100: 180-185, 1985.

19. Sjøgaard G, Adams RP, Saltin B. Water and ion shifts in skeletal muscle of humans with intense dynamic knee extension. Am J Physiol 248: R190-R196, 1985. 
20. Van Baak MA, Böhm ROB, Petri J, Rahn KH. Metabolic effects of verapamil and propranolol during submaximal endurance exercise in patients with essential hypertension. Int J Sports Med 8: 270-274, 1987.

21. Van Baak MA. Beta-adrenoceptor blockade and exercise: an update. Sports Med 5: 209-225, 1988.

22. Wolfe RR, Klein S, Carraro F, Weher JM. Role of triglyceride-fatty acid cycle in controlling fat metabolism in humans during and after exercise. Am J Physiol 258: E382-E389, 1990.

23. Zerbe GD. Randomization analysis of randomized blocks design extended to growth and response curves. Commun Stat Theor Meth 8A: 191-205, 1979. 


\section{CHAPTER 7}

\section{Effect of antihypertensive treatment with carvedilol on submaximal endurance performance in patients with essential hypertension}

JAG Wijnen, MA van Baak, F Hartgens, FHM Derkx, H Kuipers, HAJ Struijker Boudier, and LMAB Van Bortel

Departments of Pharmacology, Human Biology, and Physiology, University of Limburg, Maastricht, and Department of Internal Medicine, Dijkzigt Hospital, Rotterdam, The Netherlands 


\section{ABSTRACT}

In a randomized cross-over study of 16 patients with mild to moderate essential hypertension, the influence of antihypertensive treatment with carvedilol, a nonselective beta-blocker with vasodilating effect on submaximal exercise performance was studied. Resting blood pressure, and systolic blood pressure and heart rate during exercise were significantly reduced during carvedilol treatment. Submaximal endurance exercise performance was reduced by $36 \%(p<0.001)$. Plasma lactate and glucose levels were not influenced during exercise, but plasma non-esterified fatty acid and glycerol concentrations were significantly reduced by carvedilol treatment. Significantly higher plasma potassium concentrations were found during exercise on carvedilol. Compared to placebo conditions, plasma catecholamines and atrial natriuretic peptide concentrations were significantly higher during exercise, whereas plasma renin was reduced (-20\%) although not significantly. Our results indicate that carvedilol $25 \mathrm{mg}$ once daily is an effective antihypertensive drug. The hemodynamic, metabolic, and humoral effects during exercise and the effects on endurance performance of carvedilol resemble those of non-selective beta-blockers.

\section{INTRODUCTION}

Maintenance of good quality of life is a key factor in a successful and optimal treatment strategy for patients with hypertension. When treating physically active patients with hypertension, physicians should choose an antihypertensive drug that does not interfere with exercise performance. Especially, betablocker therapy is often accompanied by a reduced exercise tolerance and a feeling of increased exertion during exercise (1). The impairment becomes even more marked during submaximal endurance performance, which more closely mirrors leisure time sporting activity, and is more pronounced during non-selective than during beta-1 selective blockade (2).

At present, the precise mechanism underlying this impairment is incompletely understood. The hemodynamic effects of beta-blockers may play a role, because a reduction of skeletal muscle blood flow during submaximal exercise has been observed $(3,4)$. Alternatively, it has been suggested that inhibition of adipose tissue lipolysis or changes in potassium homeostasis may be involved (2). Currently, beta-blockers with vasodilating activity become more widely available and may prove to be an attractive alternative to classical beta-blockers in the treatment of the physically active patient by lowering blood pressure in a more physiological way: by lowering the elevated peripheral resistance usually seen in hypertension, in addition to a minor decrease in cardiac output. Studies on the effect of these drugs on endurance performance and metabolism during exercise are, however, limited.

Carvedilol is a new antihypertensive agent with both non-selective betablocking and vasodilating properties. Vasodilation is mainly due to alpha-1 adrenoceptor blockade (8). Carvedilol has been shown to effectively reduce blood pressure at rest and during exercise in hypertensive patients, by lower- 
ing both total peripheral resistance and cardiac output $(9,10)$. Alpha-1 blockers have little potential for adverse effects on exercise performance and metabolism $(5,6)$, while they may increase exercise blood flow (7). Therefore, reduction in exercise tolerance by non-selective beta-blockade might be attenuated by alpha-1 blocker mediated increase in exercise blood flow.

The present study investigates the effects of carvedilol on exercise tolerance, perceived exertion and metabolic parameters during submaximal exercise in physically active patients with mild to moderate hypertension. Furthermore, the effect of carvedilol on some blood pressure regulatory hormones (catecholamines, atrial natriuretic peptides and renin) during exercise is studied.

\section{PATIENTS AND METHODS}

Initially, 31 patients were recruited for this study from the outpatients' clinic of the department of Internal Medicine or by newspaper advertisement. Fourteen patients did not enter the study: 10 because of normotension after the placebo wash-out period, 3 had a systolic blood pressure $>170 \mathrm{mmHg}$ at rest, and one was suspected of coronary heart disease. Seventeen patients entered the study. One patient dropped out because of poor compliance and 16 subjects, all men with a mean age of $42 \pm 2$ years, mean body mass $78 \pm 3$ $\mathrm{kg}$, and mean height of $175 \pm 3 \mathrm{~cm}$, completed the study. All had mild to moderate hypertension (mean sitting diastolic blood pressure: 91-115 $\mathrm{mmHg}$ ). They were physically active on a recreational level. The protocol of the study was approved by the Ethics Committee of the University of Limburg (Maastricht, The Netherlands). Each subject gave written informed consent.

\section{Design of the study}

All patients underwent an extensive, preliminary examination, consisting of a complete medical history, physical examination, laboratory analyses, chest $X$-ray, 12-lead resting ECG, and eye-mirroring. All hypertensive patients were in WHO stage I and none had overt cardiovascular disease, or other obvious disease. The study started with a 3-week placebo wash-out period. After 2 weeks in the wash-out period, blood pressure (BP) was measured 3 times with a Hawksley random zero meter and maximal exercise capacity $\left(W_{\max }\right)$ was determined on a cycle ergometer. Three days later, the subjects returned to the laboratory and performed a submaximal endurance test at $70 \%$ of their maximal exercise capacity $\left(W_{\max }\right)$ for familiarization purposes.

Subjects were then treated orally in a single-blind, randomized cross-over manner with carvedilol for 2 weeks or placebo (double-dummy method) for 3 weeks. $12.5 \mathrm{mg}$ Carvedilol was given for 2 days, followed by 12 days of 25 $\mathrm{mg}$ carvedilol once daily.

At the end of each period, sitting (after $10 \mathrm{~min}$ of rest) and standing blood pressure (after $2 \mathrm{~min}$ ) (Hawksley random zero meter) and heart rate were 
measured $2 \mathrm{hr}$ after the last intake of medication, followed by a submaximal endurance test.

\section{Protocol of the submaximal endurance test}

The subjects were asked to avoid intensive physical exercise for $48 \mathrm{~h}$ preceding the examination and not to consume alcohol, coffee or nicotine on the day of the test. Exercise tests were performed at least $2 \mathrm{hr}$ after the last light meal.

After insertion of a short catheter in the v. cubitalis, the subjects rested for $20 \mathrm{~min}$. Subsequently, the exercise test was started. After a warming-up period at 100 Watt on a cycle ergometer (Lode, Groningen, The Netherlands), subjects exercised at the predetermined workload of $70 \% \mathrm{~W}_{\max }$ until exhaustion. The test was terminated when the subject was unable to maintain a pedalling rate $>50$ revolutions per min.

Just prior to the start of the test, every 10 min during exercise, at exhaustion, and after 3, 6, and $10 \mathrm{~min}$ of recovery, heart rate (from the electrocardiogram) and systolic and diastolic blood pressure (mercury sphygmomanometry, Korotkoff I and IV during exercise) and blood samples were obtained. The latter for determination of hemoglobin, oxygen saturation, hematocrit, plasma glycerol, non-esterified fatty acid (NEFA), lactate, glucose, and potassium concentrations. At $30 \mathrm{~min}$ of exercise, blood samples were obtained for determination of plasma ANP, renin (REN), prorenin (PRO), norepinephrine (NE) and epinephrine (E). Every 10 min during exercise and at exhaustion, ratings of perceived exertion were recorded using the Borg scale (11).

\section{Methods}

Plasma glycerol, NEFA, glucose, and lactate were measured by enzymatic methods and plasma potassium levels by flame photometry (Instrumentation Laboratory 243). Venous blood hematocrit (microcentrifugation) and hemoglobin and oxygen saturation (Hemoximeter OSM2, Radiometer, Copenhagen, Denmark) were determined immediately.

Blood samples were collected in $5 \mathrm{ml}$ polystyrene tubes for ANP and PRA and in $10 \mathrm{ml}$ polystyrene chilled tubes for $\mathrm{NE}$ and $\mathrm{E}$, kept on ice-water. Tubes for ANP and PRA contained EDTA (1 mg). Those for NE and E were heparinized and contained $12 \mathrm{mg}$ of glutathione. For ANP, the peptidase inhibitor aprotinin $(10,000 \mathrm{U} / \mathrm{l})$ was added. After collection, the samples were centrifuged immediately at $4^{\circ} \mathrm{C}$ for $30 \mathrm{~min}$ at $1,500 \mathrm{~g}$ for $\mathrm{NE} / \mathrm{E}$ and for $15 \mathrm{~min}$ at $1,500 \mathrm{~g}$ for the other hormones. Plasma was stored at $-70^{\circ} \mathrm{C}$ until assayed.

ANP was determined with an indirect RIA (INC-star; Stillwater, USA) after extraction on SepPak C18 cartridges (Waters Associates, Milford, Massachusetts, USA). The intra-assay coefficient of variation was $8.6 \%$ and the inter-assay coefficient of variation $11.6 \%$ (12). 
REN and PRO were quantitated with an indirect RIA as described by Derkx et al (13). REN and PRO concentrations as measured by this method have shown to be a valid estimate of the real renin and prorenin content in human plasma. NE and E levels were measured by means of HPLC with fluorescence detection, according to Van der Hoorn et al (14). The intra-assay coefficient of variation was $4 \%$ for $\mathrm{NE}$ and $12.3 \%$ for $\mathrm{E}$, and the inter-assay coefficient of variation $6.9 \%$ for $\mathrm{NE}$ and $16 \%$ for $\mathrm{E}$. The detection limit was $20 \mathrm{pg} / \mathrm{ml}$ for NE and $3 \mathrm{pg} / \mathrm{ml}$ for $\mathrm{E}$.

\section{Data analysis}

Results are presented as mean \pm S.E.M. Changes in plasma volume were calculated from hemoglobin and hematocrit (15). T-test or Mann-Whitney test (for humoral data) were performed to test for period effects or treatmentperiod interaction. Paired-t-test or Wilcoxon matched pairs test (for humoral data) were used to test for treatment effects. Zerbe's randomization test (16) was used to compare response curves. Post-hoc pairwise comparisons between groups were performed with Scheffe's F-test; $\mathrm{P}<0.05$ was regarded as statistically significant.

\section{RESULTS}

\section{Blood pressure and heart rate}

During carvedilol treatment, measurement of standing blood pressure immediately after a 10-minute sitting period did not show a drop of systolic blood pressure $>30 \mathrm{mmHg}$ in any of the patients; in 5 patients a drop of diastolic blood pressure between 20 and $30 \mathrm{mmHg}$ was measured.

No period effects or interactions occurred between the two cross-over periods. Sitting blood pressure was reduced from $136 \pm 3 / 95 \pm 3 \mathrm{mmHg}$ during placebo to $125 \pm 4 / 86 \pm 3 \mathrm{mmHg}$ during carvedilol treatment $(\mathrm{p}<$ 0.0001 ). Sitting heart rate did not differ significantly between placebo $(66 \pm 2$

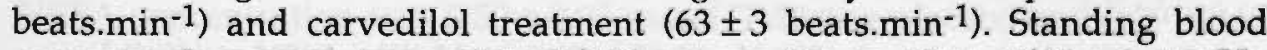
pressure decreased from $139 \pm 3 / 101 \pm 2 \mathrm{mmHg}$ to $123 \pm 4 / 91 \pm 3 \mathrm{mmHg}$ during carvedilol $(p<0.0001)$. Standing heart rate decreased from $72 \pm 3$ to 67 \pm 3 beats. min $^{-1}$ ( $\left.\mathrm{p}<0.05\right)$.

During exercise, systolic blood pressure was significantly lower during carvedilol treatment than during placebo treatment (Fig. 1). After $30 \mathrm{~min}$ of exercise, the average blood pressure during placebo was $207 \pm 5 / 96 \pm 3$ $\mathrm{mmHg}$ and was $191 \pm 7 / 99 \pm 4 \mathrm{mmHg}$ during carvedilol $(\mathrm{p}<0.01$ for systolic blood pressure). Exercise diastolic blood pressure was unaffected by carvedilol. Exercise heart rate was significantly lowered by carvedilol (Fig. 2). After $30 \mathrm{~min}$ of exercise, average heart rate was $160 \pm 4$ beats. min $^{-1}$ during placebo and $127 \pm 4$ beats. min $^{-1}$ during carvedilol ( $p<0.01$ ). 


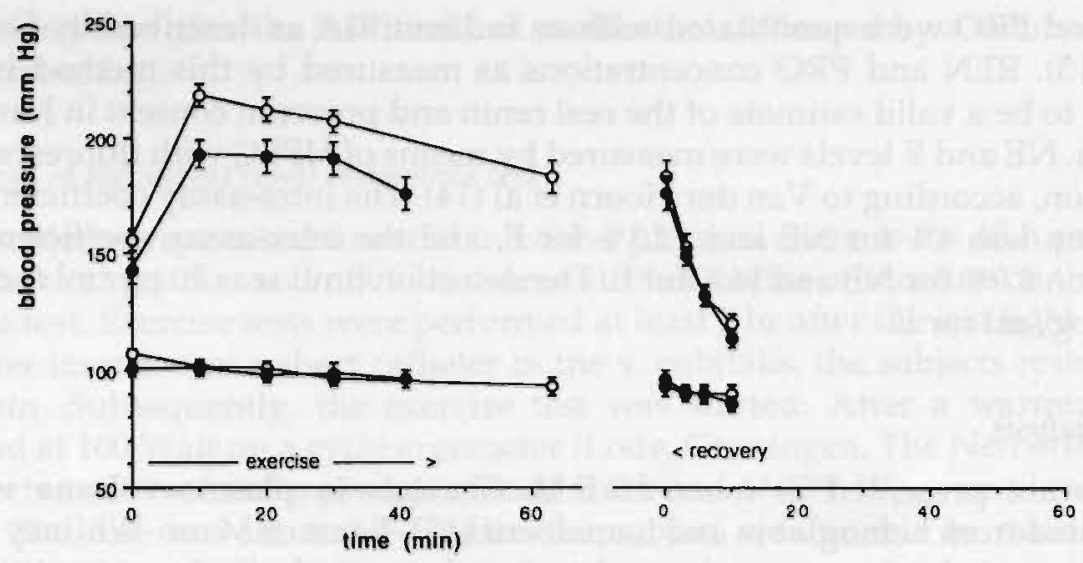

Fig. 1 Systolic and diastolic blood pressure during placebo and caroedilol treatment. Means and SEM are shown. For figures 1-7, the last point during exercise is the value at exhaustion, which is shown at the appropriate average exercise time. o Placebo; $\bullet$ Carvedilol; o Placebo; $\bullet$ Carvedilol
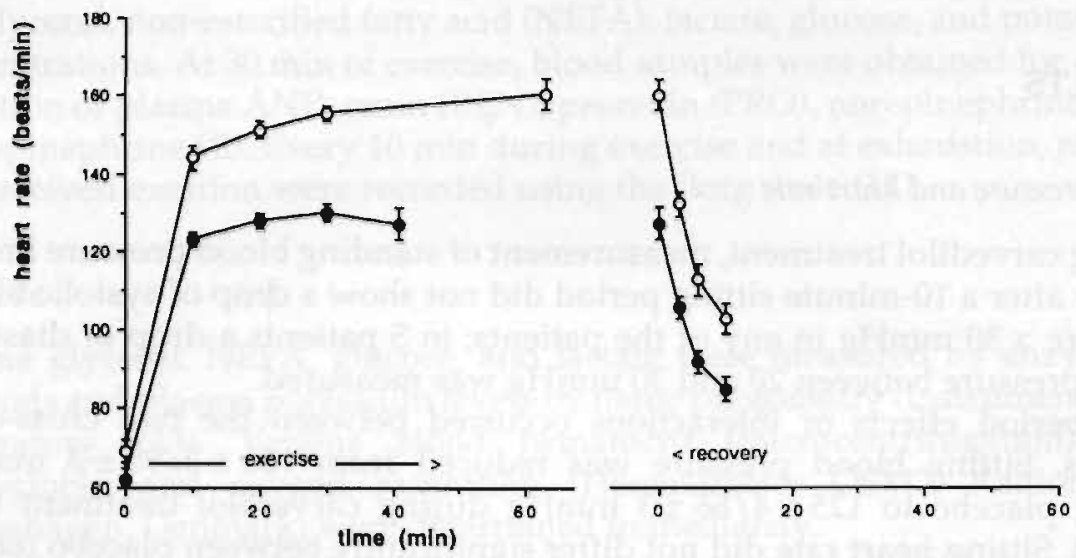

Fig. 2 Heart rate during placebo and caroedilol treatment. Means and SEM are shown. o Placebo; $\bullet$ Carvedilol

\section{Endurance time}

Endurance time was $64 \pm 4 \mathrm{~min}$ in the placebo exercise test and decreased during carvedilol treatment to $41 \pm 4 \mathrm{~min}$. This decrease of $36 \%$ was statistically significant $(\mathrm{p}<0.001)$. 


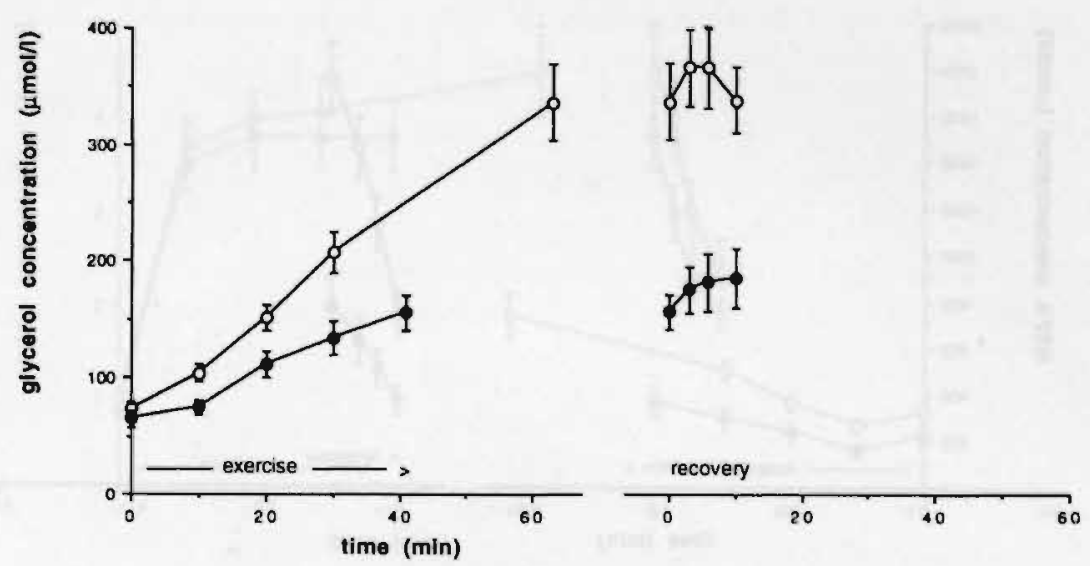

Fig. 3 Plasma glycerol concentration during placebo and carvedilol treatment. Means and SEM are shown. O Placebo; $\bullet$ Carvedilol

\section{Metabolic parameters}

During the placebo treatment oxygen saturation of the forearm venous blood increased from $39 \pm 5 \%$ at rest to $89 \pm 2 \%$ at $30 \mathrm{~min}$ of exercise, and did not differ significantly from the carvedilol treatment. The changes in plasma volume were small $(<7 \%)$ and did also not differ between the treatments.

The plasma glycerol concentration was not significantly different between the two treatment conditions at rest, but in contrast to placebo carvedilol lowered plasma glycerol both during and after exercise ( $<<0.001$; Fig. 3 ). At $30 \mathrm{~min}$ of exercise, the mean plasma glycerol concentration was $0.21 \pm 0.02$ $\mathrm{mmol} / \mathrm{l}$ during placebo and $0.13 \pm 0.02 \mathrm{mmol} / \mathrm{l}$ during carvedilol treatment $(p<0.001)$. The plasma NEFA concentrations were not statistically different at rest. During exercise, the plasma NEFA concentrations were reduced on carvedilol compared to placebo and this reduction was even more marked after exercise ( $p<0.001$; Fig. 4). At $30 \mathrm{~min}$ of exercise, the average plasma NEFA concentration was $0.50 \pm 0.05 \mathrm{mmol} / \mathrm{l}$ during placebo and $0.29 \pm 0.05$ $\mathrm{mmol} / 1$ during carvedilol $(\mathrm{p}<0.02)$. At $10 \mathrm{~min}$ into recovery, the mean plasma NEFA concentration was $1.75 \pm 0.16 \mathrm{mmol} / \mathrm{l}$ during placebo and $0.77 \pm$ $0.13 \mathrm{mmol} / 1$ during carvedilol $(\mathrm{p}<0.001)$.

Plasma glucose concentrations were not different at rest, during or after exercise between both conditions (Fig. 5).

Plasma lactate levels tended to be lower after carvedilol treatment at rest and during exercise, but the differences became only significant during recovery ( $\mathrm{p}<0.01 ;$ Fig. 6 ).

No statistically significant difference in plasma potassium concentration at rest was found between the treatment periods. During and after exercise, plasma potassium was increased during carvedilol treatment $(\mathrm{p}<0.001$; Fig. 

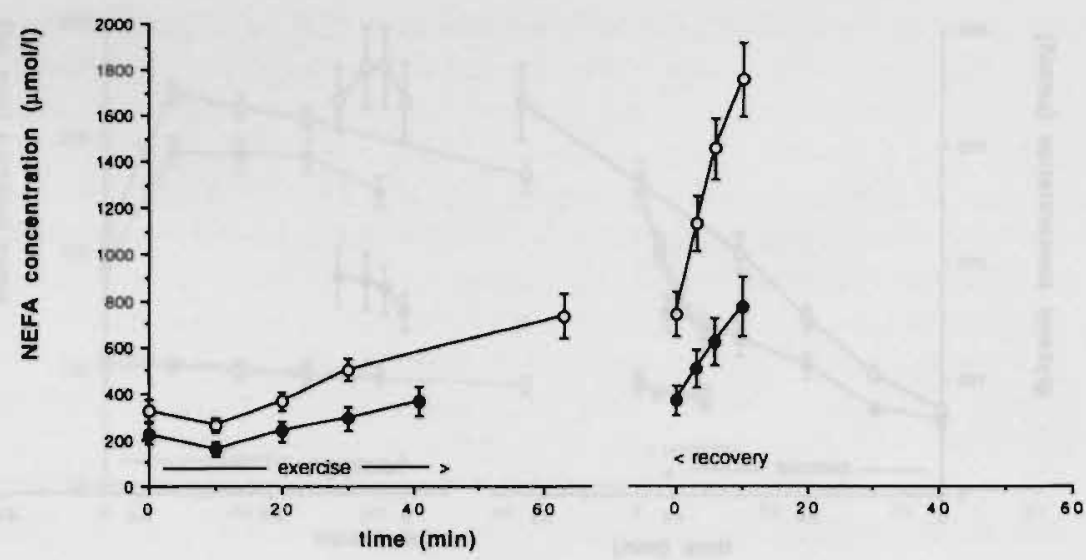

Fig. 4 Plasma non-esterified fatty acid (NEFA) concentration during placebo and carvedilol treatment. Means and SEM are shown. O Placebo; $\bullet$ Carvedilol
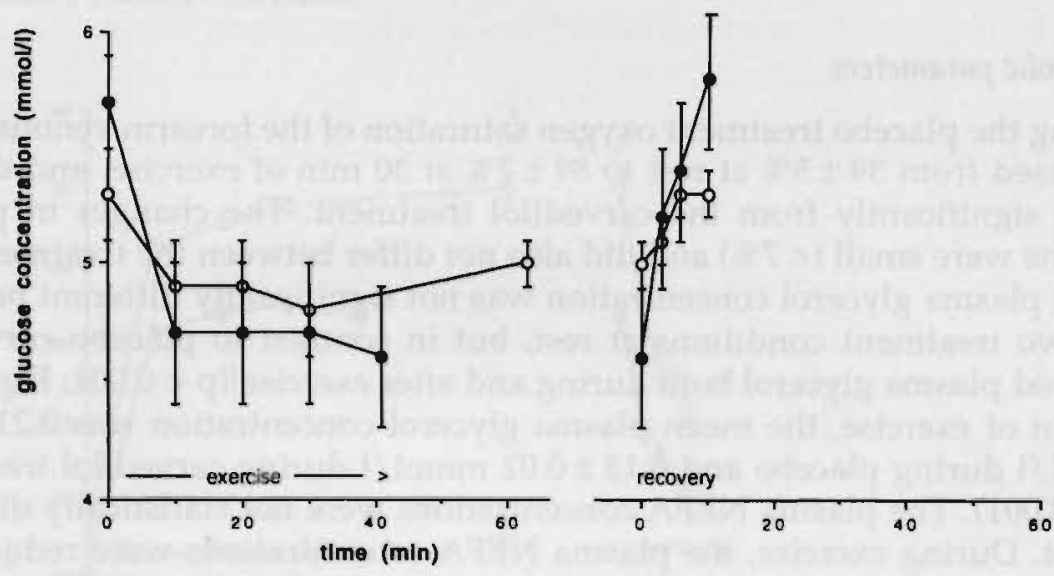

Fig. 5 Plasma glucose concentration during placebo and caroedilol treatment. Means and SEM are shown. O Placebo; - Carvedilol

7). At $30 \mathrm{~min}$ of exercise, average plasma potassium concentration was $4.98 \pm$ $0.09 \mathrm{mmol} / \mathrm{l}$ during placebo and $5.43 \pm 0.09 \mathrm{mmol} / 1$ during carvedilol treatment $(\mathrm{p}<0.001)$.

\section{Hormones}

Average ANP levels at $30 \mathrm{~min}$ of exercise were significantly increased from $212 \pm 14 \mathrm{pg} / \mathrm{ml}$ during placebo to $391 \pm 31 \mathrm{pg} / \mathrm{ml}$ during carvedilol treatment $(p<0.001)$. Both NE and $E$ mean concentrations were significantly higher ( $p$ 

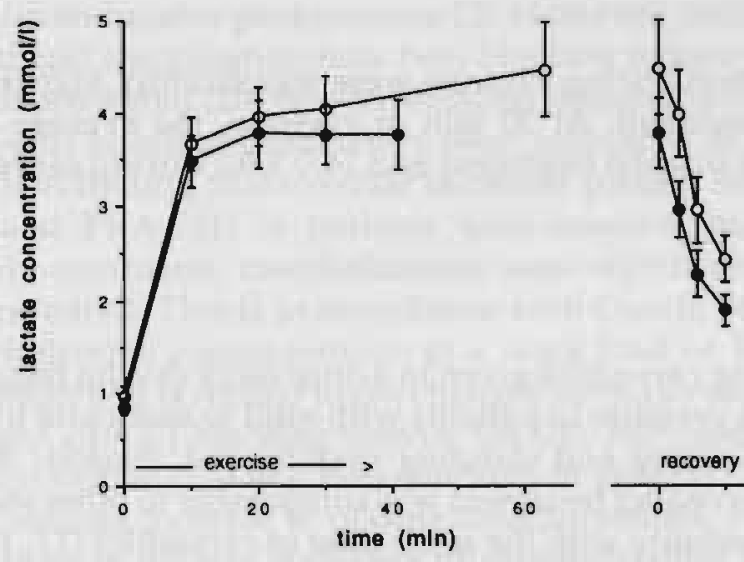

Fig. 6 Plasma lactate concentration during placebo and carvedilol treatment. Means and SEM are shown. O Placebo; $\bullet$ Carvedilol
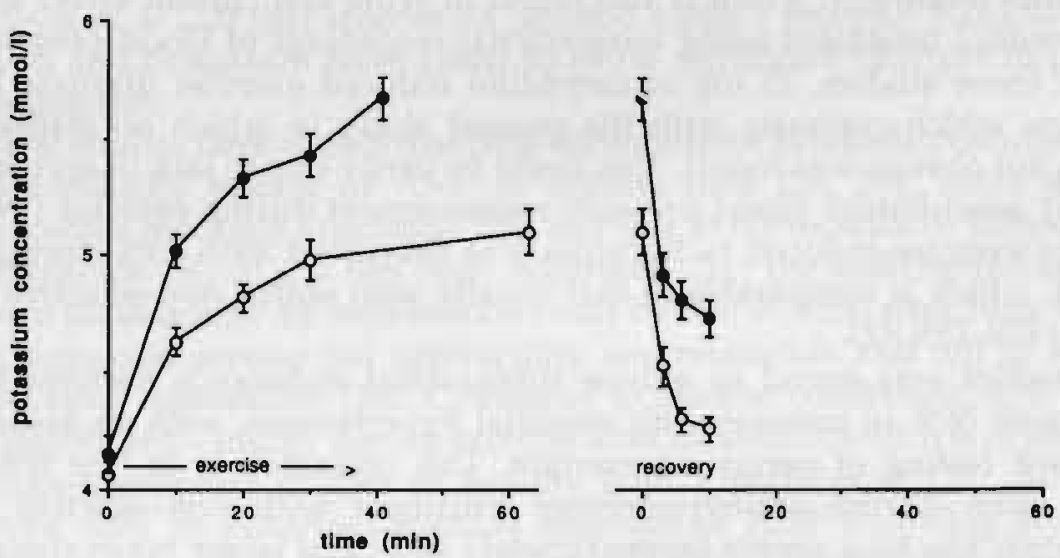

Fig. 7 Plasma potassium concentration during placebo and carvedilol treatment. Means and SEM are shown. O Placebo; $\bullet$ Carzedilol

$<0.001$ ) at $30 \mathrm{~min}$ of exercise during carvedilol treatment (NE: $3235 \pm 302$ $\mathrm{pg} / \mathrm{ml}$; E: $631 \pm 128 \mathrm{pg} / \mathrm{ml}$ ) compared to placebo (NE: $1811 \pm 169 \mathrm{pg} / \mathrm{ml}$; E: $156 \pm 15 \mathrm{pg} / \mathrm{ml}$ ).

No statistically significant differences in plasma REN and PRO concentrations were found between the two treatments, although REN averaged 20\% lower during carvedilol. At $30 \mathrm{~min}$ of exercise, average REN concentration was $35 \pm 7 \mu \mathrm{U} / \mathrm{ml}$ during placebo and $28 \pm 6 \mu \mathrm{U} / \mathrm{ml}$ during carvedilol treatment (n.s.). Average PRO concentrations were at $30 \mathrm{~min}$ of exercise $144 \pm 12$ $\mu \mathrm{U} / \mathrm{ml}$ during placebo treatment and $165 \pm 17 \mu \mathrm{U} / \mathrm{ml}$ during carvedilol (n.s.). 
Ratings of perceived exertion during exercise were significantly higher ( $\mathrm{p}<$ 0.05 ) during carvedilol treatment. At $30 \mathrm{~min}$ of exercise, the average Borg score was $13.1 \pm 0.4$ during placebo treatment and $14.0 \pm 0.7$ during carvedilol treatment $(p<0.05)$.

\section{DISCUSSION}

This study shows that $25 \mathrm{mg}$ carvedilol given in a once daily dosing regime is effective in reducing blood pressure in patients with mild to moderate hypertension. The reduction of sitting and standing systolic and diastolic blood pressure (8-11\%) during carvedilol treatment was comparable to other studies measuring supine blood pressure with the same dose of carvedilol $(17,18)$. A slight though significant reduction in standing, but not in sitting heart rate, was found which is in agreement with the afore-mentioned studies $(17,18)$. During exercise, the systolic blood pressure was significantly reduced during carvedilol treatment, which is also found in acute and chronic effect studies of carvedilol treatment using intra-arterial recordings of blood pressure (9, 10). In those studies, $25 \mathrm{mg}$ of carvedilol reduced exercise diastolic blood pressure which contrasts with the present study in which no statistically significant change was found. This could be partly due to lack of accuracy of indirect auscultatory blood pressure measurement during exercise (19). On average exercise-induced tachycardia was decreased with $19 \%$ during carvedilol, which is comparable to that usually seen with a non-selective betablocker $(20-25 \%)(2)$.

Carvedilol was found to reduce submaximal endurance exercise by an average of $36 \%$ in patients with essential hypertension, with an associated increased feeling of perceived exertion. This reduction is in line with the effects seen during antihypertensive treatment with non-selective betaadrenergic blocking agents (approximately $40 \%$ ) and larger when compared to beta-1 selective blockers (approximately 25\%) (20). The metabolic effects of carvedilol during submaximal steady-state exercise found in this study were [1] a significant reduction of plasma glycerol and NEFA concentrations by $25-40 \%$; [2] unchanged levels of plasma glucose and a tendency of lower lactate levels; [3] increased potassium levels by $5-10 \%$. Administration of beta-1 selective or non-selective beta-blockers have found to reduce plasma glycerol and NEFA concentrations during exercise by approximately $30 \%$ (range $0-50 \%$ ), slightly reduce plasma lactate and not to change plasma glucose in normally fed subjects (2). Increased plasma potassium concentrations $(5-10 \%)$ during exercise after beta-blockade have usually been found (2). So the metabolic effects of carvedilol closely resemble those seen with classical beta-blocker therapy.

Both an inhibition of adipose tissue lipolysis or changes in potassium homeostasis have been postulated as mechanisms by which beta-blockade 
impairs endurance performance (2). However, definite prove has yet not been found and the question how beta-blockers reduce endurance performance is still unanswered (20) (see for detailed discussion Chapter 1).

Several humoral parameters were measured at $30 \mathrm{~min}$ of exercise. It is a common finding that exercise increases plasma NE and E (21), plasma ANP (22) and PRA (21) in patients with essential hypertension. Compared to placebo treatment, catecholamines were significantly higher during exercise on carvedilol. This is in accordance with Omvik et al (23), who found higher catecholamine concentrations at a work load of 100 watt during carvedilol treatment and is similar to the changes normally seen with other beta-blockers without alpha-1 blocking activity $(24,25)$. Furthermore, these studies indicate that carvedilol $(23)$ and beta-blockers in general $(24,25)$ potentiate the exercise-induced increase in plasma catecholamines. Possibly this is caused by a reduction in plasma clearance of catecholamines (26) as a consequence of a lower splanchnic-hepatic blood flow during exercise seen after beta-blocker administration (27). A possible effect of the alpha-1 blocking activity of carvedilol on plasma catecholamines cannot be ruled out, although it is reported by Omvik et al (23) that studies on isolated alpha-1 receptor blockade with prazosin and doxazosin have failed to show significant changes in plasma catecholamines.

Several studies have shown that beta-adrenoceptor blockade potentiates the exercise-induced release of ANP in healthy men $(28,29)$, while alpha-1 adrenoceptor blockade attenuates this increase in normotensive subjects and hypertensives $(30,31)$. It has been suggested that the exercise-induced increase in plasma ANP by beta-blockers may be due to atrial stretching following a decreased myocardial contractility and relaxation and not to alpha-1 adrenoceptor stimulation (30). Compared to placebo conditions, ANP levels were significantly higher during exercise after carvedilol which is in line with the afore-mentioned studies in healthy men. Omvik et al (23), however, observed only an enhanced exercise response of ANP following acute administration of a single dose of $25 \mathrm{mg}$ carvedilol in a hypertensive population, but not after chronic treatment for 9 months, suggesting an adaptation in time. The exact physiological role of an induced release of ANP during exercise and its potentiation during beta-blockade is not known.

REN levels at $30 \mathrm{~min}$ of exercise were not significantly altered by carvedilol treatment compared to placebo. There was, however, a tendency for lower levels $(-20 \%)$. It has been shown that the release of renin is at least partially mediated by beta- 1 adrenergic receptors at rest and during exercise, whereas the beta- 2 adrenergic receptors play only a minor or no role in the control of renin secretion, especially during exercise $(32,33)$. Although our data failed to show significant differences, lower levels would be in agreement with most studies finding a reduction in REN at rest and during exercise with beta-1 selective or non-selective beta-blockers (33-35). Whether the increase in REN during exercise is suppressed by beta-blockade remains controversial (33-35). 
Lower levels of REN at rest and during exercise have also been observed with labetalol $(36,37)$, a non-selective beta-blocker with alpha-1 antagonistic activity, but not with the alpha-1 blocker prazosin (31). Chronic treatment with carvedilol reduced REN at rest in hypertensive subjects (38). PRO, a precursor of active renin, was not significantly different between the 2 treatments, although on average slightly higher levels after carvedilol treatment were seen $(+15 \%)$. This could point to the possibility of reduction in negative feedback regulation of REN by angiotensin II, which, in turn, augments PRO from renal or extrarenal sources (39).

In conclusion, the study shows that carvedilol is an effective, antihypertensive drug in patients with mild to moderate essential hypertension. During exercise, metabolic and humoral effects of carvedilol resemble those seen with non-selective beta-blockers. It reduces endurance exercise capacity comparable to non-selective beta-blockers, which suggests that in physically active patients, it might not be a first line drug.

\section{Acknowledgements}

The authors thank Smith Kline Beecham Pharma BV for funding this research and J. Couvée for his valuable help in statistical analysis. The practical assistance of J. Mooij, F. Koene, C. de Haan, M. Fuss, A. Gijssen and J. Bost was greatly appreciated, as was the secretarial assistance of E. Geurts and M. Hogenboom.

\section{REFERENCES.}

1. Editorial. Fatigue as an unwanted effect of drugs. Lancet i, 1285-1286, 1980.

2. Van Baak MA. Beta-adrenoceptor blockade and exercise: an update. Sports Med 4: 209-225, 1988.

3. Smith RS, Warren DJ. Effect of acute oral beta-adrenergic blockade on muscle blood flow in man. Cardiovasc Res 16: 205-208, 1982.

4. Frisk-Holmberg $M$, Juhlin-Dannfelt A, Aström. Hemodynamic and metabolic responses to prolonged exercise after chronic beta-1 adrenoceptor blockade in hypertensive man. Clin Physiol 5: 231-242, 1985.

5. Chick TW, Halpern AK, Gacek EM. The effect of antihypertensive medications on exercise performance: a review. Med Sci Sports Exerc 20: 447-454, 1988.

6. Gillin AG. Fletcher PJ, Horvath IS et al. Comparison of doxazosin and atenolol in mild hypertension, and effects on exercise capacity, hemodynamics and left ventricular function. Am J Cardiol 63: 950-954, 1989.

7. Lund-Johansen P, Omvik P, Haugland $H$. Acute and chronic hemodynamic effects of doxazosin in hypertension at rest and during exercise. Br J Clin Pharmacol 21: 45-54, 1986.

8. Van Zwieten PA. Pharmacology of antihypertensive agents with multiple actions. Eur J Clin Pharmacol 38 (suppl): 77-81, 1990.

9. Onvik P, Lund-Johansen P. Acute hemodynamic effects of carvedilol in essential hypertension at rest and during exercise. Eur Heart J 12: 736-748, 1991.

10. Lund-Johansen P, Omvik P. Chronic hemodynamic effects of carvedilol in essential hypertension at rest and during exercise. Eur Heart J 13: 281-286, 1992. 
11. Borg G. Perceived exertion as an indicator of somatic stress. Scand J Rehab Med 2: 92-98, 1970.

12. Van Bortel LM, Schiffers PM, Böhm RO et al. The influence of chronic treatment with verapamil on plasma atrial natriuretic peptides levels in young and elderly hypertensive patients. Eur J Clin Pharmacol 39 (suppl 1): 39-40, 1990.

13. Derkx FH, Stuenkel C, Schalekamp MP et al. Immunoreactive renin, prorenin, and enzymatically active renin in plasma during pregnancy and in women taking oral contraceptives. J Clin Endocrinol Metab 63: 1008-1015, 1986.

14. Van der Hoorn FA, Boomsma F, Man in 't Veld AJ, Schalekamp MA. Determination of catecholamines in human plasma by high-performance liquid chromatography: comparison between a new method with fluorescence detection and an established method with electrochemical detection. J Chromatogr 487: 17-28, 1989.

15. Dill DB, Costill DL. Calculation of percentage changes in volumes of blood, plasma, and red cells in dehydration. J Appl Physiol 37: 247-248, 1974.

16. Tan ES, Roos JM, Volovics A, Van Baak MA, Does RJ. An interactive computer program for analysis of response curves with facilities for multiple comparisons. Comp Biomed 25: 101-116, 1992.

17. Ollivier JP, Durier P, Bussiere JL, Gayet JL. Safety and efficacy of one-daily carvedilol vs. twice-daily labetalol in mild to moderate hypertension. Eur J Clin Pharmacol 38 (suppl): 164-166, 1990.

18. Widman L, Van der Does R, Hörrmann M, Machwirth M. Safety and antihypertensive efficacy of carvedilol and atenolol alone and in combination with hydrochlorothiazide. Eur J Clin Pharmacol 38 (suppl 1): 143-146, 1990.

19. Kayser L. The indirect method of recording blood pressure during exercise - can the diastolic pressure be measured? Clin Physiol 7: 175-179, 1987.

20. Van Baak MA. Hypertension, $\beta$-adrenoceptor blocking agents and exercise. Int J Sports Med 15: 112-115, 1994.

21. Jindra A, Savlikova J, Bultas J. Relationship between plasma catecholamines and the renin-aldosterone system during exercise in normal and essential hypertensive subjects. Clin Exp Hypertension A12: 415-435, 1990.

22. Nishikimi T, Kohno M, Matsuura T et al. Circulating atrial natriuretic polypeptide during exercise in patients with essential hypertension. J Hypertension 4 (suppl 6): 546-549, 1986.

23. Omvik P, Lund-Johansen $P$, Myking $O$. Effects of carvedilol on atrial natriuretic peptide, catecholamines, and hemodynamics in hypertension at rest an during exercise. J Cardiovasc Pharmacol 18 (suppl 1): 90-96, 1992.

24. Irving MH, Britton BJ, Wood WG et al. Effects of beta-adrenergic blockade on plasma catecholamines in exercise. Nature 248: 531-533, 1974.

25. Gullestad L, Dolva LO, Kjeldsen SE et al. Effect of beta-adrenergic blockade on hormonal responses during continuous and intermittent exercise. Cardiovasc Drugs Ther 3: 63-71, 1989.

26. Cryer PE, Rizza RA, Haymond MW, Gerich JE. Epinephrine and norepinephrine are cleared through beta-adrenergic, but not alpha-adrenergic mechanisms in man. Metab Clin Exp 29 (suppl 1): 1114-1118, 1980.

27. Trap-Jensen J, Clausen JP, Noer I et al. The effects of beta-adrenoceptor blockers on cardiac output, liver blood flow and skeletal muscle flow in hypertensive patients. Acta Phys Scand 98 (suppl 440): 30, 1976.

28. Donckier JE, De Coster PM, Buysschaert $M$ et al. Effect of beta-adrenergic blockade on plasma atrial natriuretic factor and cardiac volumes during exercise in normal men. Am J Cardiol 63: 1000-1002, 1989.

29. Deray G, Berlin I, Maistre $G$ et al. Beta-adrenoceptor blockade potentiates exercise induced release of atrial natriuretic peptide. Eur J Clin Pharmacol 38: 363-366, 1990. 
30. Berlin I, Lechat $\mathrm{Ph}$, Deray G et al. Beta-adrenoceptor blockade potentiates acute exerciseinduced release of atrial natriuretic peptide by increasing atrial diameter in normotensive healthy subjects. Eur J Clin Pharmacol 44: 127-133, 1993.

31. Kohno M, Yokokawa K, Yasunari K et al. Acute effects of alpha- and beta-adrenoceptor blockade on plasma atrial natriuretic peptides during exercise in elderly patients with mild hypertension. Chest 99: 847-854, 1991.

32. Zambraski EJ, Tucker MS, Lakos CS et al. Mechanism of renin release in exercising dogs. Am J Physiol 246: E71-E76, 1984.

33. Hespel P, Lijnen P, Van Hees L et al. Beta-adrenoceptors and the regulation of blood pressure and plasma renin during exercise. J Appl Physiol 60: 108-113, 1986.

34. McLeod A, Brown J, Kuhn C et al. Differentiation of hemodynamic, humoral and metabolic responses to beta- 1 and beta- 2 adrenergic stimulation in man using atenolol and propranolol. Circulation 87: 1076-1084, 1983.

35. Winer N, Mason WD, Carter CH et al. Effects of atenolol on blood pressure, heart rate, renin and norepinephrine during exercise. Clin Pharmacol Ther 26: 315-325, 1979.

36. Fagard R, Lijnen P, Amery A. Response of the systemic pulmonary circulation to labetalol at rest and during exercise. Br J Clin Pharmacol 13 (suppl 1): 13-17, 1982.

37. Koch $\mathrm{G}$. Hemodynamic adaptation at rest and during exercise to long-term antihypertensive treatment with combined alpha- and beta-adrenoceptor blockade by labetalol. $\mathrm{Br}$ Heart J 41: 192-198, 1979.

38. Dupont AG. Effects of carvedilol on renal function. Eur J Clin Pharmacol 38 (suppl 1): 96-100, 1990.

39. Ioanno $\mathrm{P}$, Ismail R, Loh AY, Osmond DH. Does angiotensin regulate systemic conversion of prorenin to renin? Clin Exp Hypertension A11: 1273-1300, 1989. 


\section{CHAPTER 8}

\section{General discussion}

\section{INTRODUCTION}

Regular physical exercise has become an integral part of lifestyle modification programs for the general population because there is increasing agreement that it benefits health and promotes quality of life.

Epidemiological studies have provided evidence that individuals with low levels of physical activity and poor fitness are at greater risk to develop hypertension and cardiovascular disease $(1,2)$. This greater risk depends partly on a more unfavorable profile of established cardiovascular risk factors, such as blood pressure or serum cholesterol, found with a sedentary lifestyle, but even exists after taking these factors into consideration. Possibly the independence of physical inactivity as a risk factor is linked to direct changes at the level of the heart and/or vasculature.

In patients with hypertension, diabetes, $\mathrm{CHD}$ or osteoporosis, regular physical activity is more often considered as the first step in the prevention of further deterioration of the disease, as non-pharmacological treatment or as adjuvant to medication. When starting drug therapy, it is preferable to choose a drug that does not interfere with exercise performance.

Exercise testing has become an important tool to promote adherence to exercise programs, to screen participants to these programs and is widely used as a prognosticum and diagnosticum in various diseases (CARA, CHD, hypertension).

In the present thesis, seven studies related and relevant to the above-mentioned topics have been described.

\section{ENDURANCE TRAINING AND BLOOD PRESSURE}

There is strong evidence from training studies that regular isotonic exercise can lower resting casual blood pressure in sedentary untreated hypertensive 
subjects. Studies meeting the highest scientific standards with regard to design have found an average reduction of $7 \mathrm{mmHg}$ for systolic blood pressure and $5 \mathrm{mmHg}$ for diastolic blood pressure (3). This modest reduction may be sufficient to normalize blood pressure in a large group of patients with borderline or mild hypertension and compares favorably with that of other non-pharmacological interventions (4).

However, one should bear in mind that the majority of studies has evaluated the effect of regular exercise on blood pressure only for weeks or months. Whether regular exercise will result in sustained and equally effective lowering of blood pressure over years remains to be established. It has been reported that some hypertensive patients were not able to maintain normotension with training beyond one year, despite an initial fall in blood pressure and good compliance to the exercise program (5). Adherence to exercise may be critical because it is likely that blood pressure will gradually return to pre-training levels on cessation of regular exercise. For most hypertensive patients, it is easier to comply to a low-intensity exercise program than to a more strenuous regimen. In this respect, there is growing support to assume that low-intensity training (approximately $50 \% \mathrm{VO}_{2 \mathrm{max}}$ ) is almost equally effective in lowering blood pressure as moderate-intensity training (approximately $70 \% \mathrm{VO}_{2 \max }$ ) (6).

Although blood pressure is lowered in many hypertensive patients by exercise training, the magnitude of the decrease is often not sufficient to normalize blood pressure whereas some patients do not respond at all (7). Future research should determine subsets of patients with hypertension who are not responsive to the blood pressure lowering effect of exercise training.

In normotensive sedentary subjects, a possible hypotensive action of regular endurance training still remains a matter of debate although in recent reviews $(3,8)$ a small average decline of 2 to $4 \mathrm{mmHg}$ for systolic as well as for diastolic blood pressure at rest is assumed. Even such a small change in BP could produce a substantial reduction in cardiovascular risk in the general population. It has been estimated that a $2 \mathrm{mmHg}$ downward shift in the entire distribution of systolic blood pressure in the general population might reduce the annual mortality from stroke by $6 \%$ and coronary heart disease by $4 \%$ (9). A lowering of diastolic blood pressure by 1 to $3 \mathrm{mmHg}$ in subjects with high normal blood pressure may reduce the incidence of hypertension by as much as $20-50 \%$ (9).

The reason why some controlled studies failed to show any blood pressure lowering effect by endurance training is not clear. Some investigators suggested that in the basal state the effect of endurance training on blood pressure is very small if any, becoming more important, however, during conditions of stress (10). Furthermore, a small anticipated fall in blood pressure of 2-4 $\mathrm{mmHg}$ by training, representing a change of $2-5 \%$ from sedentary levels, could be difficult to detect, when viewed against the magnitude of a $40 \%$ fluctuation in blood pressure that can occur at random during the day (11). 
Using ambulatory monitors, it is possible to achieve a 24-hour profile of blood pressure during normal daily stress and to detect smaller differences more easily by reducing within-subject variability due to a greater number of measurements. In addition, although not conclusive, evidence is growing that ambulatory blood pressure measurements are superior to traditional blood pressure measurements in providing a proper estimate of the real pressure load to the heart (12).

In chapter 2, the effect of a 6-week moderate-intensity endurance training program on ambulatory blood pressure in 19 sedentary male subjects with normal or slightly elevated resting casual blood pressure was described. Based on baseline 24-hour blood pressure, all but one of the 7 subjects with elevated casual blood pressure were judged to be normotensive. The latter pointing to an additional advantage of ambulatory monitoring, namely to better differentiate between true and pseudo-hypertensives. Endurance training resulted in a significant increase in $\mathrm{VO}_{2 \max }$, clear cardiac adaptations and a decrease in total systemic vascular resistance. Despite these hemodynamic changes, blood pressure measured either at rest, during exercise or ambulatory during 24 hours was not affected by training.

To date, three other studies (13-15) have used the technique of ambulatory monitoring to evaluate the effect of endurance training on blood pressure in normotensive subjects. Like the present study none of these studies seem to indicate that endurance training lowers blood pressure at night. With regard to the effect of training on blood pressure during daily activities, studies are inconclusive. No effect on day-time blood pressure was found (13) in keeping with the present study, a significantly lowering of only diastolic day-time blood pressure was observed (14) and a significant reduction of both systolic and diastolic day-time blood pressure with endurance training has been reported (15).

The reason of the discrepancy in results between the studies is not clear. Blood pressure evaluation using the ambulatory technique could be biased by deviation in extent and intensity of daily activities between measurement days since the blood pressure profile during the day is mainly determined by physical activity (16). Further studies should therefore better document levels of physical activity during measurement days. The same holds for documentation of baseline levels of sedentary activity before enrollment in a training study. As suggested by Jennings et al (15), the antihypertensive effect of regular exercise could be a low threshold phenomenon and the major effect occurs when strictly sedentary subjects increase their activity level to only very moderate levels. Although in some studies, including the present study, subjects were judged to be sedentary because they had white-collar jobs and did not engage in regular sporting activities, their baseline levels of normal daily activities could have been already too high to show a blood pressure lowering effect by endurance training. 


\section{ENDURANCE TRAINING AND VESSEL WALL PROPERTIES OF LARGE ARTERIES}

Large arteries have a conduit and buffering function and they transform the systolic flow jet from the heart into a more continuous flow for tissue perfusion. Vessel wall distensibility and arterial compliance are important vessel wall properties. Distensibility reflects the elasticity of the artery and is a determinant of the stress on the vessel wall. Compliance reflects the buffering capacity of large arteries and is an important determinant of the afterload on the heart. In aging subjects and in (borderline) hypertensive subjects, arteries become less elastic leading to a decrease in distensibility and compliance (17, 18). A decrease in arterial distensibility and compliance increases pulse pressure and left ventricular load and may play a role in the onset of atherosclerotic disease and cardiac hypertrophy $(19,20)$.

As described in chapter 1, physically inactive and unfit persons have a higher likelihood to develop future hypertension and are at higher risk of death from coronary heart disease and other cardiovascular diseases. Since these findings seem not to be due to confounding by conventional cardiovascular risk factors, other possible mechanisms should be considered.The objective of the studies described in chapter 3 and 4 was to investigate possible changes in vessel wall properties of large arteries at rest in relation to regular physical exercise.

In chapter 3, a cross-sectional comparison of vessel wall properties (distensibility and compliance) of the elastic common carotid artery and the muscular femoral and brachial arteries was described between cyclists and sedentary controls. The main findings of this study were a significantly higher cross-sectional compliance of the brachial artery and a tendency for a better compliance of the common femoral artery in cyclists compared to the sedentary controls, without significant differences in pulse pressure between the two groups.

Because the diameter of the brachial artery was not different between the sedentary and the trained group, whereas the distensibility coefficient was $23 \%$ higher in the trained the better compliance must be considered to be the resultant of a better vessel wall distensibility of this artery. With regard to the common femoral artery, the internal diameter was found to be $12 \%$ larger in cyclists. Most likely, this represents a local adaptation to facilitate the large blood flow to the quadriceps muscles during strenuous exercise and is structural in origin, comparable to the larger diameter of the radial artery observed in hammer-throwers (21). Distensibility coefficient of the femoral artery was not significantly different in cyclists, probably as a consequence of the structurally larger diameter. Since the diameter of the femoral artery was significantly larger in cyclists and vessel wall distensibility unchanged, an increased cross-sectional compliance of this artery could be expected. An obvious explanation for the absence of statistical significance in compliance could be the wide dispersion of individual data. 
The observed findings, especially of the brachial artery, suggest that aerobic training can induce a decrease in muscle tone of predominantly muscular arteries. This is further supported by studies which found a higher regional compliance of the aorta in athletes compared to age-matched controls (22) and a strong positive relationship between aortic distensibility and physical working capacity in young men (23).

Therefore, we trained sedentary men for 6 weeks at a moderate intensity level (chapter 4). It was hypothesized that endurance training would result in an improvement of vessel wall properties of large arteries and that these changes could be dependent on or independent of a blood pressure lowering effect of training. Despite a clear training effect, judged by an increase in $\mathrm{VO}_{2 \max }$ and a decrease in resting heart rate, vessel wall properties were unchanged. Because blood pressure in the basal state (after 45 min of rest) was not lowered by conditioning, it was concluded that no intrinsic modification of vessel wall properties occurred, which is in line with findings of Gilders et al (24), who did neither observe a reduction in blood pressure with training nor a change in pulse wave velocity both in normotensive and hypertensive subjects. Furthermore, in the present study basal levels of plasma catecholamines, plasma ANP and plasma renin were not changed following endurance training. On the other hand, in a recent study by Cameron et al (25) a fall in systolic blood pressure with concomitantly increased arterial compliance was found following training, which suggests a dependency of a better compliance on a reduction in transmural pressure. The combined results of chapter 3 and 4 could implicate that modification of vessel wall properties of large arteries with regular exercise is a long-term adaptation which takes months or even years to develop. Alternatively, it is possible that the observed differences between cyclists and sedentary subjects merely reflect genetic endowment. Further research should determine whether endurance training of longer duration (at least 6 months) can improve vessel wall properties of large arteries and should include subjects with (borderline) hypertension who are likely to have a decreased arterial compliance and distensibility (20).

\section{VARIATIONS IN EXERCISE SYSTOLIC BLOOD PRESSURE}

Exercise stress testing usually includes measurements of blood pressure before, during and for several minutes after exercise. In the last decades, it has been indicated that the blood pressure response during exercise may be of diagnostic and prognostic value in various populations (see chapter 1). A common finding in most of these studies is a considerable amount of intersubject variation in the response of blood pressure to exercise. Factors independently contributing to this variation are insufficiently evaluated and reference values for exercise blood pressure are rather scarce, especially in older and female populations. In chapter 5.1 (males) and chapter 5.2 (females), 
the response of systolic blood pressure (eSBP) to a progressive maximal bicycle ergometer test was investigated in three large population samples of subjects 40 years or older with either normal, borderline elevated or elevated resting blood pressure. The influence of several variables on the blood pressure response was studied, including age, weight, blood pressure at rest, heart rate at rest and during exercise, smoking, alcohol consumption, and maximal work capacity. Reference values at different work loads were established for eSBP. In males, $53 \%$ of the variation in eSBP during cycle ergometry could be explained by work load, SBP at the start of the exercise test and maximal working capacity. In females, $63 \%$ of the variation in eSBP was explained by work load, SBP at the start of the exercise test, age, and exercise heart rate. In both males and females, no differences in the slope of eSBP between groups of subjects with normal, borderline elevated and elevated supine blood pressure were seen, although absolute values were clearly different, which confirms studies by other authors. It has been suggested that an excessive rise in SBP during exercise is mainly seen in hypertensives with advanced stages of disease (26); they were excluded in our studies. Subjects in the elevated blood pressure groups had a significantly lower maximal working capacity compared to the two other groups, although maximal heart rates were similar, suggesting differences in stroke volume between the groups (27).

The main finding in the male study was the negative association between eSBP and $W_{\text {max }}$. Classification of physical fitness based on a questionnaire has failed to show a relationship with $\operatorname{eSBP}$ (28), possibly because no reliable estimate of physical fitness was obtained. In the female study, $W_{\max }$ was not associated with eSBP, possibly because of the relative small range in $W_{\text {max }}$. On the other hand, eSBP was positively associated with exercise heart rate which could be an indicator of physical fitness (29).

A fairly large proportion of the variation in eSBP could not be explained, neither in males nor in females. We believe that at least part of the remaining variation could be accounted for by the variability of the indirect method of blood pressure measurement itself.

\section{ENDURANCE EXERCISE AND BETA-BLOCKADE}

Beta-adrenoceptor antagonists are commonly used in the treatment of various cardiovascular disorders, such as hypertension, coronary artery disease, and cardiac arrhythmias. For many patients with these disorders, dynamic physical exercise is thought to be beneficial. Since a large number of the physically active patients are treated with beta-blocking drugs, the side-effects of blockade of beta- 1 and beta- 2 adrenoceptors during exercise has become the scope of numerous studies. It has been shown that beta-blockade interferes with hemodynamics, energy metabolism, thermoregulation and potassium homeostasis during exercise. Maximal aerobic exercise capacity is significantly reduced in most studies in normotensive and hypertensive subjects (30). 
More important from a therapeutic point of view, however, is the effect of beta-blockade during endurance exercise, i.e., the performance of work at a constant submaximal intensity. Both in normotensive and hypertensive subjects reductions in exercise time ranging from $11-55 \%$ were found compared to placebo (30).

The exact mechanism behind this reduced endurance performance is not yet clear. Both reduced exercise cardiac output and reduced rate of lipolysis or changes in potassium homeostasis have been held responsible. With regard to an inhibition of adipose tissue lipolysis, plasma glycerol and NEFA reductions ranging from 0 to $50 \%$ were found during exercise (31). During recovery from exhaustive endurance exercise however, consistently lower levels were found. These lower NEFA and glycerol levels could be the consequence rather than the cause of a shorter exercise time. Therefore, a study was designed (chapter 6) in which the amount of work performed was the same after acute administration of propranolol and placebo. While during exercise no significant differences were found in serum NEFA and glycerol concentrations between propranolol and placebo, a decrease of $75 \%$ in post-exercise NEFA and $50 \%$ in post-exercise glycerol on propranolol was found, compared to placebo. Although this study is supportive for the hypothesis that reduced availability of NEFA during exercise may be involved in the impairment of endurance exercise performance after beta-blocker administration, this was questioned by a recent study of our group (32). In this study, we increased the availability of NEFA during exercise by Intralipid (triglyceride) infusions, when healthy volunteers were treated with placebo, atenolol and propranolol. Endurance time was significantly reduced by $40 \%$ by propranolol compared to placebo and by $49 \%$ by propranolol plus Intralipid compared to placebo plus Intralipid. The results of this study do not support the lack of NEFA for energy consumption during exercise with beta-blockade. However, an effect of beta-blockade on NEFA membrane transport can not be ruled out.

In chapter 7 the effect of antihypertensive treatment with carvedilol on endurance performance was studied in patients with essential hypertension. Carvedilol is a non-selective beta-blocker with vasodilating activity. It was speculated that carvedilol would impair endurance performance to a lesser extent than classical beta-blockers because of its vasodilating properties. Furthermore, to date only limited data are available on the metabolic effects of vasodilating beta-blockers during exercise (20). Compared to placebo treatment, endurance time was reduced by $36 \%$ by carvedilol, a reduction comparable to that seen with non-selective beta-blockade (30). The hemodynamic and metabolic effects during exercise resembled those seen during non-selective beta-blockade (31). In line with other studies (31), both propranolol (chapter 5) and carvedilol (chapter 7) increased potassium levels significantly during exercise. Increased plasma potassium levels could induce significant changes in muscle membrane potential, resulting in impaired excitability and thus contractibility of muscle fibers (33), which could explain (in part) the 
impairment of endurance performance by beta-blockade. The role of changes in potassium homeostasis in the impaired endurance performance by betablockade needs further research.

As described in chapter 1, thus far all antihypertensive agents studied have been found to reduce endurance performance, although the largest impairment in endurance performance is clearly found with beta-blockers and diuretic agents. From the viewpoint of the patient with uncomplicated hypertension who wants to engage in sporting activities, treatment with ACE-inhibitors or calcium antagonists is preferable. Based on current knowledge, these agents will only lead to a minor impairment in endurance performance and complaints about fatigue in relation to physical exercise have usually not been reported $(34,35)$. The therapeutic dilemma facing the physician however, is the absence at present of studies showing ACE-inhibitors and calciumantagonists to reduce cardiovascular morbidity and mortality in contrast to beta-blockers and diuretics (36).

\section{REFERENCES}

1. Blair SN, Goodyear NN, Gibbons LW, Cooper KH. Physical fitness and incidence of hypertension in healthy normotensive men and women. JAMA 252: 487-490, 1984.

2. Powell KE, Thompson PD, Caspersen CJ, Kendrick JS. Physical activity and the incidence of coronary heart disease. Ann Rev Publ Health 8: 253-287, 1987.

3. Fagard RH. Physical fitnes and blood pressure. J Hypertens 11 (suppl 5): 47-52, 1993.

4. Gordon NF, Scott CB, Wilkinson WJ et al. Exercise and mild essential hypertension. Sports Med 10: 390-404, 1990.

5. Jennings G, Nelson L, Dewar E et al. Antihypertensive and hemodynamic effects of one year's regular exercise. J Hypertens 4 (suppl 6): 659-661, 1986.

6. Tashiro E, Miura S, Koga M et al. Cross-over comparison between the depressor effects of low and high work-rate exercise in mild hypertension. Clin Exp Pharmacol Physiol 20: 689-696, 1993.

7. Tipton CM. Exercise, training and hypertension: an update. Exerc Sports Sci Revs 19: 447-505, 1991.

8. Fagard R. Physical exercise in the management of hypertension: a consensus statement by the World Hypertension League. J Hypertens 9: 283-287, 1991.

9. National High Blood Pressure Education Program Working Group Report on Primary Prevention of Hypertension. Arch Intern Med 153: 186-208, 1993.

10. Vanhees L, Hespel P, Van Hoof R et al. Effect of physical training on systemic and brachial artery hemodynamics in normal men. Int J Sports Med 13: 145-151, 1992.

11 Mancia G, Parati G, Pomiodossi G et al. Arterial baroreflexes and blood pressure and heart rate variabilities in humans. Hypertension 8: 147-153, 1985.

12. Mancia G, Zanchetti A. Value of echocardiographic and ambulatory blood pressure monitoring in hypertension. Clin Exp Hypertens A11: 869-886, 1989.

13. Gilders RM, Voner C, Dudley GA. Endurance training and blood pressure in normotensive and hypertensive adults. Med Sci Sports Exer 21: 629-636, 1989.

14. Van Hoof R, Hespel P, Fagard R et al. Effect of endurance training on blood pressure at rest, during exercise and during 24 hours in sedentary men. Am J Cardiol 63: 945-949, 1989.

15. Jennings GL, Deaking G, Dewar E et al. Exercise, cardiovascular disease and blood pressure. Clin Exp Hypertens A11: 1035-1052, 1989. 
16. Baumgart $P$, Walger $P$, Fuchs $G$ et al. Twenty-four hour blood pressure is not dependent of endogenous circadian rhythm. J Hypertens 7: 331-334, 1989.

17. Reneman RS, Van Merode T, Hick P, Hoeks APG. Flow velocity patterns in and distensibility of the carotid artery bulb in subjects of various ages. Circulation 71: 500-509, 1985.

18. Van Merode T, Hick PJJ, Hoeks APG et al. Carotid artery wall properties in normotensive and borderline hypertensive subjects of various ages. Ultrasound Med Biol 14: 563-569, 1988.

19. O'Rourke M. Arterial stiffness, systolic blood pressure, and a logical treatment of arterial hypertension. Hypertension 15: 339-347, 1990.

20. Van Bortel LM. Beyond the tension of hypertension. Ph.D. Thesis, Rijksuniversiteit Limburg, Maastricht, 1993.

21. Giannattasio C, Cattaneo BM, Mangoni AA et al. Changes in arterial compliance induced by physical training in hammer-thowers. J Hypertens 10 (suppl 6): 53-55, 1992.

22. Mohiaddin R, Underwood SR, Bogren HG et al. Regional aortic compliance studied by magnetic resonance imaging: the effects of age, training, and coronary artery disease. $\mathrm{Br}$ Heart J 62: 90-96, 1989.

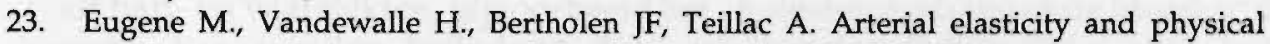
working capacity in young men. J Appl Physiol 61: 1720-1723, 1986.

24. Gilders RM, Dudley GA. Endurance training and treatment of hypertension: the controversy. Sports Med 13: 71-77, 1992.

25. Cameron JD, Dart AM, Topham S. Effects of 4 weeks of exercise training on arterial compliance in men. Circulation 86 (suppl 1): 276, 1992.

26. Sannerstedt $R$. Hemodynamic response to exercise in patients with arterial hypertension. Acta Med Scand suppl 458: 7-83, 1966.

27. Fagard R, Staessen J, Amery A. Maximal aerobic power in essential hypertension. J Hypertens 6: 859-865, 1988.

28. Criqui MH, Haskell WL, Heiss G et al. Predictors of systolic blood pressure response to exercise: the lipid research clinic program prevalence study. Circulation 68: 225-233, 1983.

29. Astrand P-O, Rodahl K. Textbook of work physiology. McGraw Hill, New York, 1986.

30. Van Baak MA. Hypertension, beta-adrenoceptor blocking agents and exercise. Int J Sports Med 15: 112-115, 1994.

31. Van Baak MA. Beta-adrenoceptor blockade and exercise: an update. Sports Med 5: 209-225, 1988.

32. Van Baak MA, Mooij JM, Wijnen JA. Effect of increased plasma non-esterified fatty acid concentrations on endurance performance during beta-adrenoceptor blockade. Int J Sports Med 14: 2-8, 1993.

33. Sjegaard G. Adams RP, Saltin B. Water and ion shifts in skeletal muscle of humans with intense dynamic knee extension. Am J Physiol 248: R190-R192, 1985.

34. Van Baak MA, Mooij JM, Wijnen JA, Tan FS. Submaximal endurance exercise performance during enalapril treatment in patients with essential hypertension. Clin Pharmacol Ther 50: 221-227, 1991.

35. MooijJ, Van Baak MA, Böhm R et al. The effects of verapamil and propranolol on exercise tolerance in hypertensive patients. Clin Pharmacol Ther 41: 490-495, 1987.

36. The fifth report of the Joint National Committee on Detection, Evaluation, and Treatment of High Blood Pressure (JNC V). Arch Intern Med 153: 154-183, 1993. 



\section{Samenvatting}

Uit epidemiologisch onderzoek blijkt dat lichamelijke inaktiviteit en een gering lichamelijk prestatievermogen belangrijke en onafhankelijke risikofaktoren zijn voor hart- en vaatziekten net zoals onder meer roken en een verhoogde bloeddruk. Tevens blijkt dat bij fysieke inaktiviteit het risiko op een hoge bloeddruk duidelijk toeneemt.

Verschillende studies hebben aangetoond dat een aantal risikofaktoren voor hart- en vaatziekten, bijvoorbeeld het cholesterolgehalte of de bloeddruk gunstig kan worden beïnloed door regelmatige lichamelijke aktiviteit. Meestal worden in deze studies vrijwilligers die een zittend bestaan leiden, getraind; dat wil zeggen, de konditie wordt verbeterd, maar of konditieverbetering per se een voorwaarde is voor een verbetering van risikofaktoren staat momenteel ter diskussie.

Van met name duurinspanning (fietsen, joggen) is overtuigend aangetoond dat het de bloeddruk in rust kan verlagen bij mensen met hypertensie, gemiddeld met ongeveer $7 \mathrm{mmHg}$ voor de bovendruk (systolische bloeddruk) en met gemiddeld $5 \mathrm{mmHg}$ voor de onderdruk (diastolische bloeddruk). Een voorwaarde is wel dat de inspanning van voldoende duur is (minstens 30 minuten) en voldoende zwaar (circa $50-70 \%$ van iemands maximaal prestatievermogen). De effekten van regelmatige duurinspanning op de bloeddruk bij gezonde mensen met een normale rust-bloeddruk zijn geringer, ongeveer 2-4 $\mathrm{mmHg}$ voor zowel de systolische als de diastolische bloeddruk. Door sommige onderzoekers wordt overigens betwijfeld of regelmatige inspanning de bloeddruk in rust kan verlagen, omdat zij dit in hun training-studies niet konden bevestigen. Een mogelijke verklaring hiervoor zou kunnen zijn dat het moeilijk is een klein verschil van $2-4 \mathrm{mmHg}$ in bloeddruk aan te tonen bij de grote schommelingen in rust bloeddruk (tot $\pm 40 \%$ ), gedurende de dag. Een andere verklaring veronderstelt dat een bloeddruk verlagend effekt vooral wordt gezien onder meer stressvolle omstandigheden, zoals die gedurende het dagelijks leven of tijdens inspanning. In hoofdstuk 2 worden de resultaten beschreven van een studie waarbij ongetrainde vrijwilligers met een normale of licht verhoogde bloeddruk gedurende 6 weken werden getraind. De bloeddruk werd gemeten in rust (basaal nivo), tijdens inspanning en gedurende 24 uur tijdens het normale dagelijkse leven met behulp van een ambulante monitor. Ondanks een duidelijke verbetering in konditie en een daling van de hartfrekwentie in rust en tijdens inspanning, was er geen effekt van de training op de bloeddruk. 
De efficiëntie van het hart- en vaatstelsel wordt verbeterd door regelmatige duurinspanning. Mortaliteit en morbiditeit ten gevolge van hypertensie toont een beter verband met de systolische bloeddruk dan met de diastolische bloeddruk, wat een pulsatiel stress-effekt suggereert. Vaatwandeigenschappen (kompliantie en distensibiliteit) van grote arteriën bepalen voor een belangrijk deel dit pulsatiel stress-effekt. Of deze vaatwandeigenschappen verbeteren door training is onbekend.

In hoofdstuk 3 vergeleken wij de vaatwandeigenschappen van drie grote arteriën (de a. carotis, de a. femoralis en de a. brachialis) van zeer goed getrainde wielrenners met die van ongetrainden van gelijke leeftijd, gewicht en lengte. Er bleek geen verschil in vaatwandeigenschappen van de a. carotis tussen de getrainden en ongetrainden. De diameter van de a. femoralis van de wielrenners was signifikant groter en de kompliantie beter, hoewel statistisch juist niet signifikant. De kompliantie van de a. brachialis van de wielrenners was signifikant beter door een grotere distensibiliteit (rekbaarheid) van de vaatwand. Deze bevindingen suggereren een mogelijke daling van spiertonus van de muskulaire arteriën door duurtraining.

In hoofdstuk 4 toetsten wij deze hypothese door ongetrainde vrijwilligers 6 weken te trainen. Wij veronderstelden hierbij dat de vaatwandeigenschappen een verbetering konden laten zien ten gevolge van een eventuele bloeddrukdaling of onafhankelijk hiervan door intrinsieke veranderingen. Ondanks een duidelijke verbetering van de $\mathrm{VO}_{2 \max }$ (konditieverbetering) na 6 weken training werden er geen verschillen gezien in de vaatwandeigenschappen. Een mogelijke verklaring hiervoor zou kunnen zijn dat het langer duurt, voordat door training vaatwandeigenschappen worden veranderd of dat de verschillen die wij zagen tussen wielrenners en ongetrainden, eerder een uitdrukking zijn van verschillen in genetische aanleg.

De laatste jaren staat de bloeddrukreaktie tijdens gestandaardiseerd inspanningsonderzoek in de belangstelling. Een abnormaal sterke bloeddrukstijging bij mensen met een normale rust-bloeddruk zou een belangrijke voorspeller zijn voor het ontwikkelen van een latere hypertensie. Verder zou de bloeddrukstijging tijdens inspanningsonderzoek een betere differentiatie mogelijk maken tussen individuen met een echte hypertensie in rust en een verhoogde bloeddruk in rust ten gevolge van bijvoorbeeld spanning. Tegelijkertijd wordt echter gekonstateerd dat referentiewaarden voor bloeddruk tijdens belasting grotendeels ontbreken, vooral voor ouderen en vrouwen. Tevens blijkt er een aanzienlijke variatie tussen personen te bestaan in inspanningsbloeddruk. Het doel van de studies in hoofdstuk 5.1 (mannen) en hoofdstuk 5.2 (vrouwen) was een evaluatie van die faktoren die een onafhankelijke bijdrage leveren aan de interindividuele variatie in systolische bloeddruk tijdens inspanning. Dit werd gedaan door 747 mannen en 871 vrouwen die 40 jaar of ouder waren, op een gestandaardiseerde manier op een fietsergometer te belasten en een groot aantal mogelijk prognostische faktoren te onderzoeken (zoals: bloeddruk in rust, gewicht, vetpercentage, leeftijd, alkoholkonsump- 
tie, rookgewoonten, prestatievermogen). Bij de mannen blijkt $53 \%$ van de interindividuele variatie in systolische bloeddruk te verklaren uit fysiek belastingsnivo, de systolische bloeddruk vlak voor de start van de inspanningstest en het maximaal prestatievermogen. Bij vrouwen is $63 \%$ van de interindividuele variatie te verklaren uit fysiek belastingsnivo, systolische bloeddruk vlak voor de start van de inspanningstest, leeftijd en de hartfrekwentie tijdens inspanning. Voor zowel mannen als vrouwen werden er geen verschillen gevonden in bloeddrukreaktie tijdens inspanning tussen groepen met in rust een normale, borderline verhoogde of verhoogde bloeddruk. Mannen en vrouwen met een hoge bloeddruk hebben gemiddeld een lager prestatievermogen en hogere hartfrekwentie in rust. Referentiewaarden voor systolische bloeddruk tijdens inspanning werden voor mannen en vrouwen voorgesteld.

Bij de behandeling van patiënten met een lichte tot matige hypertensie wordt allereerst getracht de bloeddruk te normaliseren met behulp van een aantal niet-medicamenteuze maatregelen: gewichtsreduktie, beperking van zoutkonsumptie en regelmatige lichamelijke inspanning. Bij een groot aantal van deze patiënten wordt echter geen adekwate bloeddrukregulatie bereikt, zodat medicamenteuze behandeling noodzakelijk wordt. Beta-blokkers zijn hierbij medicijnen van eerste keuze, omdat hiervan overtuigend is aangetoond dat zij de lange-termijn komplikaties van een te hoge bloeddruk beperken. Beta-blokkade vermindert echter het maximaal lichamelijk prestatievermogen aanzienlijk. Van grotere praktische betekenis is het feit dat het duurprestatievermogen belangrijk wordt beperkt. Het duurprestatievermogen wordt hierbij gedefinieerd als de volhoudtijd van een submaximale belasting, meestal ongeveer $70 \%$ van het maximaal prestatievermogen. Beta-blokkade vermindert deze volhoudtijd met gemiddeld $11-55 \%$ zowel bij normotensieve proefpersonen als bij patiënten met hypertensie. Het mechanisme waardoor het duurprestatievermogen wordt beperkt, is niet bekend. Een aantal mogelijke verklaringen is gesuggereerd: [1] een verminderd hartminuutvolume tijdens inspanning vermindert de bloedstroom naar de spieren, [2] de lipolysis in het vetweefsel wordt geremd, waardoor vrije vetzuren als energiebron minder beschikbaar zijn, of [3] de kaliumhomeostasis verandert, waardoor de prikkelbaarheid en dus het kontraktievermogen van de spiervezels afneemt. Met betrekking tot de geremde lipolysis van het vetweefsel werden er tijdens duurtesten met beta-blokkers zowel lagere, onveranderde en zelfs hogere plasma glycerol- en vrije vetzuurspiegels gevonden. Een konsistente bevinding was echter dat in de herstelfase na een uitputtende duurinspanning lagere plasma glycerol- en vrije vetzuurspiegels werden gezien. Deze laatste bevinding kan echter het gevolg in plaats van de oorzaak zijn van een beperkte duurprestatie. In hoofdstuk 6 werd getracht oorzaak en gevolg te scheiden door gezonde vrijwilligers zowel tijdens beta-blokkade als tijdens placebokondities een gelijke duurprestatie te laten verrichten. Tijdens duurinspanning waren er geen signifikante verschillen in plasma glycerol- en vrije 
vetzuurkoncentraties tussen beide kondities. In de herstelfase echter waren de vrije vetzuurkoncentraties $75 \%$ en de glycerolkoncentraties $50 \%$ lager tijdens beta-blokkade. Deze studie bevestigt de hypothese dat beta-blokkade de lipolysis in het vetweefsel tijdens inspanning remt.

In hoofdstuk 7 werd het effekt van een nieuwe niet-selektieve beta-blokker met vaatverwijdende eigenschappen (carvedilol) op het duurprestatievermogen en metabolisme tijdens inspanning onderzocht in patiënten met essentiële hypertensie. Wij veronderstelden dat carvedilol, omdat het de bloeddruk op een meer fysiologische manier verlaagt (door een verlaging van de perifere weerstand), het prestatievermogen minder zou beperken. Uit de resultaten van deze studie blijkt echter dat carvedilol tijdens inspanning dezelfde metabole effekten laat zien als een niet-selektieve beta-blokker en dat het duurprestatievermogen met $39 \%$ wordt beperkt, vergelijkbaar met niet-selektieve beta-blokkers zonder vaatverwijdende eigenschappen.

Zoals beschreven in hoofdstuk 1 , verminderen alle bloeddrukverlagende medicijnen, die tot nu toe zijn onderzocht, in meer of mindere mate het duurprestatievermogen. De grootste vermindering in duurprestatievermogen wordt echter gezien bij behandeling met beta-blokkers en diuretica. Vanuit het perspektief van de hypertensiepatiënt die lichamelijk aktief wil zijn, is behandeling met ACE-remmers of calciumantagonisten te prefereren. Deze middelen verminderen het duurprestatievermogen in geringe mate en geven meestal geen vermoeidheidsklachten tijdens lichamelijke inspanning. Het therapeutische dilemma voor de behandeld arts is echter, dat van deze antihypertensiva nog niet is aangetoond dat zij een gunstig effekt hebben op kardiovaskulaire morbiditeit en mortaliteit. 


\section{List of abbreviations}

$\begin{array}{ll}\text { ANP } & \text { atrial natriuretic peptide } \\ \text { BA } & \text { brachial artery } \\ \text { BP } & \text { blood pressure } \\ \text { bpm } & \text { beats per minute } \\ \text { BORD } & \text { borderline elevated blood pressure group } \\ \text { CC } & \text { cross-sectional compliance } \\ \text { CCA } & \text { common carotid artery } \\ \text { CO } & \text { cardiac output } \\ \text { CHD } & \text { coronary heart disease } \\ \text { CVD } & \text { cardiovascular disease } \\ \text { D } & \text { diameter } \\ \triangle D & \text { change in diameter } \\ \text { DBP } & \text { diastolic blood pressure } \\ \text { DC } & \text { distensibility coefficient } \\ \text { E } & \text { epinephrine } \\ \text { ECG } & \text { electrocardiogram } \\ \text { eHR } & \text { exercise heart rate } \\ \text { ELEV } & \text { elevated blood pressure group } \\ \text { eSBP } & \text { exercise systolic blood pressure } \\ \text { FA } & \text { femoral artery } \\ \text { FFA } & \text { free fatty acids } \\ \text { HDL } & \text { high-density lipoprotein } \\ \text { HR } & \text { heart rate } \\ \text { LDL } & \text { low-density lipoprotein } \\ \text { LV } & \text { left ventricle } \\ \text { LVH } & \text { left ventricular hypertrophy } \\ \text { LVM } & \text { left ventricular mass } \\ \text { LVMI } & \text { left ventricular mass index } \\ \text { NE } & \text { norepinephrine } \\ \text { NEFA } & \text { non-esterified fatty acids } \\ \triangle P & \text { pulse pressure } \\ \text { PRA } & \text { plasma renin activity } \\ \text { PRO } & \text { prorenin } \\ & \\ \text { HE } & \end{array}$


R

$\mathrm{R}^{2}$

RAAS

REN

SBP

SEM

SD

SNS

SV

SVR

TPR

W

WL

$\mathrm{W}_{\max }$

$\mathrm{VO}_{2 \max }$ respiratory exchange ratio coefficient of determination renin-angiotensin-aldosterone system renin

systolic blood pressure standard error of the mean standard deviation sympathetic nervous system stroke volume systemic vascular resistance total peripheral resistance watt work load maximal work capacity maximal oxygen uptake 


\section{Dankwoord}

"Vele wegen leiden naar Rome" luidt een toepasselijk gezegde. De weg naar "Rome" die ik de afgelopen drie jaar aflegde, leek soms moeilijk begaanbaar, vol hobbels, files en tal van omleggingen. Dat "Rome" toch werd bereikt, dank ik aan velen die, ieder op hun persoonlijke manier, mij steunden en stimuleerden en belangstelling bleven tonen.

Precies acht jaar heb ik gewerkt als wetenschappelijk medewerker aan een jonge, enthousiaste universiteit waaraan ik ook het genoegen had tot basisarts te mogen worden opgeleid.

Het was een vruchtbare periode waarin ik energieke en talentrijke kollega's heb ontmoet, in het begin bij de vakgroep Arbeidsgeneeskunde en het Instituut Sportgeneeskunde Limburg (ISL) en later bij de vakgroep Farmakologie. Het ISL vormde de basis voor mijn onderzoekscarrière, waarbij Marleen van Baak vanaf het begin tot einde een waarachtig voorbeeld was. Op velerlei momenten en verschillende hoedanigheden heb ik haar leren kennen en waarderen: als leider van het ISL/DGD-projekt, als vertegenwoordiger van de medewerkers in het ISL-bestuur, als lid van de begeleidingskommissie bij de reorganisatie van het ISL en tenslotte als co-promotor bij mijn promotieonderzoek, waarvoor zijn de beslissende impulsen gaf.

Frans Verstappen dank ik voor het inzetten van zijn organisatietalent, waarbij met blijvend optimisme goede voorwaarden voor onderzoek werden geboden. Fons Bovens en Sjef Vrencken, de kollega-artsen van het ISL, dank ik voor hun altijd plezierige en konstruktieve samenwerking in de projekten die wij uitvoerden. Alle medewerkers van het ISL, in het bijzonder Jolanda, Marion, Gerrit, Jean, Wim en Gène, ben ik erkentelijk voor een zeer fijne samenwerking. Medewerkers van de GG en GD te Heerlen dank ik voor de jaren die ik daar gedetacheerd ben geweest, in het bijzonder mijn assistente Cécile en de heer W. Balvert.

De vakgroep Farmakologie was een tweetal jaren een hoogstaande wetenschappelijke thuisbasis voor mij. Luc Van Bortel ben ik bijzonder dankbaar voor de voortreffelijke wijze waarop hij in een korte tijd een uiterst produktieve klinisch-farmakologische sektie vormde en hieraan leiding gaf. Naast zijn uitgebreid eigen onderzoekprogramma bleek hij in staat mij altijd op een kritische manier te stimuleren tot letterlijk "good clinical practice". Hij stelde mij tevens in staat gebruik te maken van geavanceerde onderzoektechnieken en methodieken en nam mijn financiële zorgen weg. Als co-promotor was hij immer bereid de manuskripten 's avonds te bespreken. 
Mijn naaste kollega Mirian Kool is een toonbeeld van ongebreidelde kreativiteit en vitaliteit. Dankzij Mirian's onuitputtelijke energie en aanstekelijkheid was het mogelijk vele proefpersonen vele malen rustig en zorgvuldig te meten. Ik ben haar zeer dankbaar. Monique Fuss dank ik voor de steun, gezelligheid en goede organisatie bij mijn studies. Altijd vroeg aanwezig, stelde zij de proefpersonen op hun gemak en zorgde voor een feilloze verwerking van de talloze monsters. Claudia de Haan, begonnen als student bij de trainingsstudies, ontwikkelde zich tot een serieuze, onmisbare schakel en onderzoeker, ook bij mijn afwezigheid. Fred Hartgens was bereid een belangrijke studie af te ronden op zijn bijzondere en aimabele manier.

Jeroen Kooman haalde mij op alle fronten in met zijn onverzettelijke "drive" en vond toch altijd de rust op een boeiende wijze mijn onderzoek te ondersteunen. Jet Bost dank ik voor de zeer sekuur uitgevoerde analyses en bovendien voor de vele goede raadgevingen.

Mia Hogenboom en Els Geurts waren de reddende engelen in nood. Niet alleen hun sekretariële ondersteuning heb ik gewaardeerd, maar bovenal hun support bij het halen van de door hen vooraf gestelde deadlines.

Harry Struijker Boudier, voorzitter van de vakgroep Farmakologie en promotor, ben ik bijzonder erkentelijk voor het vertrouwen dat hij in mij stelde, het uitzicht op struktuur die hij het proefschrift bood, en de vele goede adviezen die hij mij gaf bij de afronding van mijn proefschrift. Ondanks zijn drukke agenda was hij altijd tot steun.

De leden van de beoordelingskommissie dank ik voor hun kritische beoordeling. In het bijzonder Harm Kuipers, niet in de laatste plaats, omdat hij mij ook leerde hoe snel je gedachten en goede ideeën omzet in een onderzoeksvoorstel.

Bijzondere dank aan alle medewerkers van vakgroepen en diensten die mijn onderzoek mede mogelijk hebben gemaakt: Harry Wetzelaar, Frans Tan, Alex Volovics, Arnold Hoeks, Frans Smeets, Jacques Lambregts, Jaap Mooij, Fred Koene, Peter Geurten, Annemiek Gijssen, Jacques Debets en vele anderen.

Ik dank medewerkers van SmithKline Beecham BV en de Janssen Research Foundation voor hun verschillende bijdragen.

Het onderzoek zou niet mogelijk zijn geweest als de honderden proefpersonen in Limburg niet bereid waren geweest tijd, geduld en veel energie te doneren. Mijn grote dank.

Karin, jouw voortdurende steun en liefde waren onmisbaar. 


\section{Curriculum vitae}

$1958 \quad$ Geboren 8 juni te Maastricht

1970-1976 Atheneum B, St. Maartenscollege te Maastricht

1976-1982 Studie Geneeskunde, Rijksuniversiteit Limburg, Maastricht

1981 Doctoraal examen, Rijksuniversiteit Limburg, Maastricht

1982 Artsexamen, Rijksuniversiteit Limburg, Maastricht

1983-1991 Wetenschappelijk medewerker Instituut Sportgeneeskunde Limburg

1983-1989 Wetenschappelijk medewerker vakgroep Arbeidsgeneeskunde (voorzitter: prof. dr. Tj. de Boorder), Rijksuniversiteit Limburg, Maastricht

1984-1987 Detachering bij GGD Zuid-Oost Limburg, Heerlen

1989-1991 Wetenschappelijk medewerker vakgroep Farmacologie (voorzitter: prof. dr. H.A.J. Struijker Boudier), Rijksuniversiteit Limburg, Maastricht

1991-heden Adviserend geneeskundige, bedrijfseenheid AOV, Algemeen Burgerlijk Pensioenfonds, Heerlen en Maastricht

1992-1993 Projectcoördinator, afdeling Professionele Ondersteuning, bedrijfseenheid AOV, Algemeen Burgerlijke Pensioenfonds, Heerlen

1993-heden Opleiding tot sociaal-geneeskundig specialist, tak verzekeringsgeneeskunde, Utrecht 


\section{List of publications}

\section{Papers}

1. Wijnen JAG, Verstappen $F$, Kuipers $\mathrm{H}$. The influence of intravenous $\mathrm{NaHCO}_{3}$ administration on interval exercise: acid-base balance and endurance. Int J Sports Med 5 (suppl): 130-132, 1984

2. Wijnen JAG, Van Baak MA, Tan ES, Bovens AMP, Vrencken JGP, Verstappen FTJ. Variations in exercise systolic blood pressure in physically active middle-aged men with normal and elevated blood pressure. Int J Sports Med 9: 412-416, 1988

3. Vrencken JGP, Bovens AMP, Wijnen JAG, Braeken JJH, Van Baak MA, Bouter LM, Verstappen FTJ. Sportbeoefening en sportblessures bij 40-plussers. Geneeskd Sport 21: $12-18,1988$

4. Janssen GME, Bovens AMP, Vrencken JGPM, Wijnen JAG. Een mogelijke testmethode ter preventie van overtraindheid bij duursporters. Geneeskd Sport 21: 76-79, 1988

5. Verstappen FTJ, Vrencken J, Bovens F, Wijnen J, Van Baak M. Injuries related to sport activities in a middle-aged population. Proceedings 3rd meeting Council of Europe "Sports injuries and their prevention", Arnhem, 1989

6. Wijnen JAG, Bovens AMP, Vrencken JGP, Van Baak MA, Verstappen FTJ. Verwijzing naar huisarts voor nader cardiologisch onderzoek op basis van een sportkeuring bij 40-plussers. Resultaten na een jaar follow-up. Geneeskd Sport 22: 85-89, 1989

7. Kuipers $\mathrm{H}$, Wijnen JAG, Hartgens F, Willems SMM. Welke informatie geeft aminozuurbepaling in het plasma bij gezonde sporters? Sportgericht 11: 113-116, 1989

8. Bovens AMPM, Van Baak MA, Vrencken JGPM, Wijnen JAG, Verstappen FTJ. Variability and reliability of joint measurements. Am J Sports Med 18: 58-63, 1990

9. Wijnen JAG, Kuipers H, Kool MJF, Hoeks APG, Van Baak MA, Struyker Boudier HAJ, Verstappen FTJ, LMAB Van Bortel. Vessel wall properties of large arteries in trained and sedentary subjects. Basic Res Cardiol 86 (suppl 1): 25-29, 1991

10. Kuipers H, Wijnen JAG, Hartgens F, Willems SMM. Influence of anabolic steroids on body composition, blood pressure, lipid profile, and liver functions in body builders. Int J Sports Med 12: 413-418, 1991

11. Willems SMM, Kuipers $H$, Wijnen JAG, Hartgens F. Body building: een inventariserende studie naar training, voeding en spierversterkende middelen. Geneeskd Sport 24:51-55, 1991

12. Van Baak MA, Mooij JM, Wijnen JA, Tan FS. Submaximal endurance exercise performance during enalapril treatment in patients with essential hypertension. Clin Pharmacol Ther 50: 221-227, 1991

13. Kool MJ, Wijnen JA, Hoeks AP, Struijker Boudier HA, Van Bortel LM. Diumal pattern of vessel wall properties of large arteries in healthy men. J Hypertens 9 (suppl 6): 108-109, 1991

14. Kooman JP, Wijnen JAG, Draaijer P, Van Bortel L, Gladziwa U, Peltenburg H, Struijker Boudier HAJ, Van Hooff JP, Leunissen KML. Compliance and reactivity of the peripheral venous system in patients with chronic intermittent dialysis. Kidney Int 41: 1041-1048, 1992 
15. Kool MJ, Struijker Boudier HA, Wijnen JA, Hoeks AP, Van Bortel LM. Effects of diurnal variability and exercise training on properties of large arteries. J Hypertens 10 (suppl 6): 49-52, 1992

16. Kooman JP, Gladziwa U, Böcker G, Wijnen JAG, Van Bortel LMAB, Luik AJ, De Leeuw PW, Van Hooff JP, Leunissen KML. Blood pressure during the interdialytic period in hemodialysis patients: estimation of representative blood pressure values. Nephrol Dial Transplant 7: 917-923, 1992

17. Kooman JP, Gladziwa U, Böcker G, Wijnen JAG, Van Bortel LMAB, Luik AJ, De Leeuw PW, Van Hooff JP, Leunissen KML. The role of the venous system in hemodynamics during ultrafiltration and bicarbonate dialysis. Nephrol Dial Transplant 42: 718-726, 1992

18. Hartgens F, Kuipers H, Wijnen JAG, Willems SMM. Androgene-anabole steroiden en sport; een literatuuroverzicht. Geneesk Sport 25: 8-20, 1992

19. Hartgens F, Wijnen JAG, Willems SMM, Kuipers H. De effekten van androgene-anabole steroiden tijdens gebruik en na stoppen bij ervaren bodybuilders. Geneeskd Sport 25: 64-71, 1992

20. Verstappen FTJ, Bovens AMP, Vrencken JGP, Wijnen JAG, Van Baak MA. Sportmedische screening en advisering van sportende 40 -plussers. Inst voor Bewegingswetenschappen, Maastricht, 1992

21. Wijnen JAG, Van Baak MA, De Haan C, Struijker Boudier HAJ, Tan FS, Van Bortel LMAB. Beta-blockade and lipolysis during exercise. Eur J Clin Pharmacol 45: 101-105, 1993

22. Van Baak MA, Mooij JM, Wijnen JA. Effect of increased plasma non-esterified fatty acid concentrations on endurance performance during beta-adrenoceptor blockade. Int J Sports Med 14: 2-8, 1993

23. Wijnen JA, Kool MJ, Kooman JP, Van Baak MA, Struijker Boudier HA, Van Bortel LM. Vessel wall properties of large arteries and endurance training. J Hypertens 11 (suppl 5): 88-89, 1993

24. Verstappen FTJ, Diederiks JPP, Wijnen JAG. Gezondheidsbeleving en -effekten van een "zwemprogramma" door hart-vaat patienten. Ned Tijdschr Fysiother 8: 100-108, 1993

25. Kuipers H, Peeze Binkhorst FM, Hartgens F, Wijnen JAG, Keizer HA. Muscle ultrastructure after strength training with placebo or anabolic steroid. Can J Appl Physiol 18: 189-196, 1993

26. Bovens AM, Van Baak MA, Vrencken JG, Wijnen JA, Saris WH, Verstappen FT. Physical activity, fitness, and selected risk factors for CHD in active men and women. Med Sci Sports Exerc 25: 572-576, 1993

27. Bovens AMP, Van Baak MA, Vrencken JG, Wijnen JAG, Verstappen FTJ. Maximal heart rates and plasma lactate concentrations observed in middle-aged men and women during a maximal cycle ergometer test. Eur J Appl Physiol 66: 281-284, 1993

28. Bovens AM, Van Baak MA, Vrencken JGP, Wijnen JAG, Saris WHM, Verstappen FTJ. Maximal aerobic power in cycle ergometry in middle-aged men and women, active in sports, in relation to age and physical activity. Int J Sports Med 14: 66-71, 1993

29. Wijnen JAG, Kool MJF, Van Baak MA, Kuipers H, De Haan CHA, Verstappen FT], Struijker Boudier HAJ, Van Bortel LMAB. Effect of exercise training on ambulatory blood pressure. Int J Sports Med 15: 10-15, 1994

30. Kool MJ, Wijnen JA, Derkx FH, Struijker Boudier HA, Van Bortel LM. Diurnal variation in prorenin in relation to other humoral factors and hemodynamics. Am J Hypertens 7: 723-730, 1994

31. Wijnen JAG, Tan ES, Van Baak MA, Bovens AMP, Vrencken JGP, Verstappen FTJ, Schim van der Loeff $M$. Exercise systolic blood pressure in middle-aged women with normal and elevated blood pressure. Int J Sports Med 1995, in press 


\section{List of publications}

\section{Abstracts}

1. Verstappen F, Wijnen J, Kuipers H. Induced alkalosis and physical performance. Experientia 40: 1299, 1984

2. Wijnen J, Van Baak M, Volovics A, Vrencken J, Bovens A, Braeken J, Verstappen F. Exercise systolic blood pressure as a function of work load in relation to some subject characteristics. Proceedings 28th Dutch Federation Meeting 546, 1987

3. Vrencken J, Wijnen J, Bovens A, Van Baak M, Braeken J, Verstappen F. Sports participation and injuries in a middle-aged population, active in sports. Int J Sports Med 9: 389, 1988

4. Wijnen JA, Van Baak MA, Tan ES, Bovens AM, Vrencken JG, Verstappen FT. Exercise systolic blood pressure and maximal work capacity in middle-aged men with normal and elevated blood pressure. Int J Sports Med 9: 364, 1988

5. Wijnen JA, Tan ES, Verstappen FT, Van Baak MA, Bovens AM, Vrencken JG, Schim van der Loeff M. Variations in exercise systolic blood pressure (eSBP) in middle-aged women with normal and elevated blood pressure. PAAVo Nurmi Congress Book, Turku, Finland 345, 1989

6. Koene FMM, Van Baak MA, Wijnen JAG, Adam JJME, Van Bortel L. The influence of clonidine on exercise performance in healthy volunteers. Proceedings 12 th PUIJO Symposium on "Physical activity and hypertension", 1989

7. Hartgens F, Kuipers H, Wijnen JAG, Willems SMM. Influence of nandrolone decanoate on body composition in experienced body builders. Pflügers Arch 414: S197, 1989

8. Hartgens F, Kuipers H, Wijnen JAG, Willems SMM. Influence of anabolic steroids on body composition in experienced body builders. Med Sci Sport Exercise 21 (suppl): 26, 1989

9. Kool MJF, Van Bortel LMAB, Wijnen JAG, Hoeks APG, Struijker Boudier HAJ. Circadian rhythm and vessel wall properties of large arteries. The Netherl J Med 37, A38, 1990

10. Noordzij T, Wijnen J, Van Bortel L, Leunissen K. Venous compliance is normal in normotensive dialysis patients. Nephrol Dial Transplant 5: 708, 1990

11. Van Bortel LMAB, Van Baak MA, Kool MJF, Wijnen JAG, Struijker Boudier HAJ. Beta-adrenoceptor blockade, antihypertensive effect and exercise tolerance with nebivolol and atenolol. Pharmaceut Wkbl Sci Ed 12 (suppl 6): J4, 1990

12. Kool MJF, Wijnen JAG, Hoeks APG, Struijker Boudier HAJ, Van Bortel LMAB. Vessel wall properties and circadian rhythm in large arteries. Eur J Pharmacol 183: 825, 1990

13. Van Bortel L, Kool M, Wijnen J, Struijker Boudier H. Beta-adrenoceptor blockade and beta-1 selectivity of nebivolol and atenolol. Abstracts 1st Int Nebivolol Investigators' Meeting, Antwerp, September 13-16, C11, 1990

14. Van Baak MA, Mooij JMV, Wijnen JAG. Effects of enalapril during submaximal exercise in hypertensive patients. Pharmaceut Wkbl Sci Ed 12 (suppl C): C3, 1990 
15. Wijnen JAG, Kool MJF, Kuipers H, Van Baak MA, Struijker Boudier HAJ, Verstappen FTJ, Van Bortel LMAB. Vessel wall properties of large arteries in trained and sedentary subjects. Abstract book symposium on "Pharmacology of vascular and cardiac remodelling", Maastricht, 1990

16. Bovens AMPM, Tan ES, Van Baak MA, Wijnen JAG, Vrencken JGP, Verstappen FTJ. Variability in maximal workload in middle-aged men and women, active in sport. Abstract book FIMS World Congress, Amsterdam, May 27 - June 1, 1990

17. Vrencken JGPM, Bovens AMPM, Wijnen JAG, Van Baak MA, Verstappen FTJ. Flexibility: a movement specific characteristic. Med Sci Sports Exercise 22 (suppl): 9, 1990

18. Bovens AMPM, Van Baak MA, Vrencken JGPM, Wijnen JAG, Verstappen FTJ. Gender difference in peak plasma lactate concentration. Med Sci Sports Exercise 22 (suppl): 15, 1990

19. Kooman JP, Wijnen JAG, Noordzij TC, Van Bortel L, van Hooff JP, Leunissen KML. Hypertension and not chronic renal failure is reducing peripheral venous compliance in hemodialysis patients. Kidney Int 40: 347, 1991

20. Van Bortel LMAB, Kool MJF, Wijnen JAG, Struijker Boudier HAJ. Beta-adrenoceptor blocking properties and antihypertensive effect differ between nebivolol and atenolol. Proceedings Internistendagen 91: P174, 1991

21. Kooman JP, Wijnen JAG, Draaijer P, Van Bortel LMAB, Struijker Boudier HAJ, Van Hooff JP, Leunissen KML. The peripheral venous system in normotensive and hypertensive patients on hemodialysis (HD). J Hypertens 9 (suppl 6): 547, 1991

22. Wijnen JAG, Kool MJF, Kuipers H, Van Baak MA, Struijker Boudier HAJ, Van Bortel LMAB. Differences in vessel wall properties of superficial arteries in cyclists and sedentary subjects. Ric Sci Educ Perman suppl 90: abstr nr 773, 1991

23. Wijnen JAG, Kool MJF, Van Bortel LMAB, Van Baak MA, Struijker Boudier HAJ. Exercise training and ambulatory blood pressure in sedentary male subjects. Ric Sci Educ Perman suppl 90: abstr nr 774, 1991

24. Van Bortel LMAB, Kool MJF, Wijnen JAG, Struijker Boudier HAJ. Beta-adrenoceptor blockade and beta-1 selectivity of nebivolol and atenolol. Drug Invest 3 (suppl 1): 173, 1991

25. Kool MJF, Wijnen JAG, Kuipers H, Van Baak MA, Struijker Boudier HAJ, Van Bortel LMAB. Do vessel wall properties of superficial arteries differ between endurance trained and sedentary subjects? Proceedings Internistendagen 91: P188, 1991

26. Kool MFJ, Derkx FHM, Wijnen JAG, Struijker Boudier HAJ, Van Bortel LMAB. Different diurnal variation in prorenin and renin. Ric Sci Educ Perman suppl 90: abstr nr 346, 1991

27. Wijnen JAG, Kool MFJ, Van Baak MA, Struijker Boudier HAJ, Van Bortel LMAB. Exercise training does not lower ambulatory blood pressure in sedentary male subjects. Eur Heart J 12 (suppl): 29, 1991

28. Kool MJF, Derkx FHM, Wijnen JAG, Struijker Boudier HAJ, Van Bortel LMAB. Prorenin and renin do not have the same diurnal variation. Eur Heart J 12 (suppl): 151, 1991

29. Van Bortel LMAB, Kool MJF, Derkx FHM, Wijnen JAG, Struijker Boudier HAJ. Diurnal variation in humoral factors. Pharmaceut Wkbld Sci Ed 13 (suppl L): L5, 1991

30. Kool MJF, Wijnen JAG, Van Bortel LMAB, Struijker Boudier HAJ. Circadian pattern of vessel wall properties of large arteries in healthy men. Ric Sci Educ Perman suppl 90, abstr nr 345, 1991

31. Kool MJF, Wijnen JAG, Struijker Boudier HAJ, Van Bortel LMAB. Vessel wall properties of large arteries show a diurnal variation. Pharmaceut Wkbld Sci Ed 13 (suppl L): L5, 1991

32. Houben AJHM, Wijnen JAG, Van Bortel LMAB, Nieuwenhuijzen Kruseman AC. Local hyperglycemia increases regional blood flow directly in man. Diabetes 4 (suppl 1): $212 \mathrm{~A}$, 1991 
33. Houben AJHM, Jungbauer FHW, Wijnen JAG, Van Bortel LMAB, Slaaf DW, Nieuwenhuijzen Kruseman AC, Schaper NC. Effects of local hyperglycemia on forearm blood flow. Int J Microcirc 10: 379, 1991

34. Kooman JP, Draaijer P, Wijnen JAG, Van Bortel LMAB, Struijker Boudier HAJ, Van Hooff $\mathrm{JP}$, Leunissen KML. Functional reactivity of the peripheral venous system in patients on hemodialysis. Blood Purif 9: 35, 1991

35. Kooman JP, Gladziwa U, Böcker G, Wijnen JAG, Van Bortel L, Van Hooff JP, Leunissen KML. Non-invasive blood pressure measurements during the interdialytic period in hemodialysis in patients. JASN 2: 334, 1991

36. Kooman JP, Gladziwa U, Wijnen JAG, Böcker G, Van Bortel L, Peltenburg HG, Van Hooff JP, Leunissen KML. Representative blood pressure in hemodialysis patients by 48-hour ambulatory BP monitoring. Nephrol Dial Transplant 6: 803, 1991

37. Van Bortel LMAB, Van Baak MA, Kool MJF, Wijnen JAG, Struijker Boudier HAJ. Beta-adrenoceptor blockade and exercise tolerance. Arch Int Pharmacodyn Ther 311: 191-192, 1991

38. Van Baak MA, MooijJMV, Wijnen JAG. Intralipid administration and endurance performance during beta-adrenoreceptor blockade. Pflügers Arch 420 (suppl 1): R138, 1992

39. Van Bortel LMAB, Wijnen JA, Kool MJ, Van Baak MA, Struijker Boudier HAJ. Effect of exercise training on ambulatory blood pressure. J Hypertens 10 (suppl 4): 106, 1992

40. Struijker Boudier HAJ, Kool MJF, Wijnen JAG, Van Bortel LMAB. Circadian changes and effect of exercise training. Abstract book workshop on "Functional and structural properties of large arteries", Paris, 1992

41. Van Baak MA, Wijnen JAG, De Haan C, Struijker Boudier H, Van Bortel L. Beta-blockade and lipolysis during endurance exercise. Med Sci Sports Exerc 24 (suppl 5): 187, 1992

42. Van Bortel LMAB, Kool MJF, Wijnen JAG, Struijker Boudier HAJ. Nebivolol: not only a beta-1 selective adrenoceptor antagonist. Abstracts Vth World Conference on "Clinical pharmacology and therapeutics", P-404-03, 1992

43. Van Bortel LMAB, Kool MJF, Derkx FHM, Wijnen JAG, Struijker Boudier HAJ. Diurnal variation in hemodynamics and humoral factors. Arch Int Pharmacodyn Ther 315: 127, 1992

44. Van Bortel LM, Wijnen JA, Kool MJ, Kooman JP, Van Baak MA, Struijker Boudier HA. Vessel wall properties of large arteries and endurance training. Ric Sci Educ Perman 95 (suppl): 784, 1993 

